\author{
Carla Maria Figueiredo Martins \\ Master in Chemical and Biochemical Engineering
}

\title{
$\mathrm{CO}_{2}$ removal from anaesthesia circuits using gas-ionic liquid membrane contactors
}

\author{
Dissertation for obtaining the degree of \\ Doctor of Philosophy in \\ Chemical and Biochemical Engineering \\ Advisers: João Paulo Serejo Goulão Crespo, Full Professor, \\ NOVA University of Lisbon \\ Co-advisers: Isabel Maria Rôla Coelhoso, Associate Professor with \\ Habilitation, NOVA University of Lisbon \\ Luísa Alexandra Graça Neves, Assistant Researcher, \\ LAQV/Requimte, NOVA University of Lisbon

\section{Evaluation committee:} \\ Chair: Maria da Ascensão Carvalho Fernandes Miranda Reis, Full \\ Professor, NOVA University of Lisbon

\section{Examiner(s): Marius Sandru, Senior Researcher, Sintef Industri} \\ Adélio Miguel Magalhães Mendes, Full Professor, University \\ of Porto \\ Members: João Paulo Serejo Goulão Crespo, Full Professor, NOVA \\ University of Lisbon \\ Liliana Sofia Carvalho Tomé, Junior researcher, NOVA \\ University of Lisbon
}

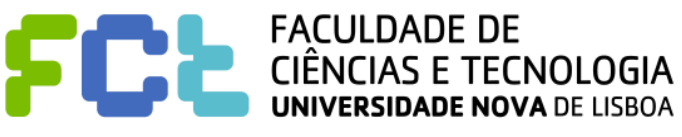

Dezembro, 2020 

Carla Maria Figueiredo Martins

Master in Chemical and Bioechemical Engineering

\section{$\mathrm{CO}_{2}$ removal from anaesthesia circuits using gas-ionic liquid membrane contactors}

Dissertation for obtaining the degree of Doctor of Philosophy in

Chemical and Biochemical Engineering 

$\mathrm{CO}_{2}$ removal from anaesthesia circuits using gas-ionic liquid membrane contactors

Copyright (c) Carla Maria Figueiredo Martins, Faculdade de Ciências e Tecnologia, Universidade Nova de Lisboa.

A Faculdade de Ciências e Tecnologia e a Universidade Nova de Lisboa têm o direito, perpétuo e sem limites geográficos, de arquivar e publicar esta dissertação através de exemplares impressos reproduzidos em papel ou de forma digital, ou por qualquer outro meio conhecido ou que venha a ser inventado, e de a divulgar através de repositórios científicos e de admitir a sua cópia e distribuição com objectivos educacionais ou de investigação, não comerciais, desde que seja dado crédito ao autor e editor. 

To my daughter. 


\section{Acknowledgements}

The accomplishment of this work was only possible due to the contribution of many people and, for them, I express my deepest gratitude.

To my supervisors, Professor João Crespo, Professor Isabel Coelhoso and Doctor Luísa Neves, for having proposed this highly interesting project, for having allowed me to develop it at the Laboratory of Membrane Processes (LMP) and for all the guidance and dedication, to bring it to a successful conclusion. Their demand and rigor, scientific support through their critical and creative sense, were decisive for the development of this work. For all the opportunities I had to share the work developed along these years, in national and international conferences, which contributed remarkably for my formation. I also want to express my gratitude for the opportunity to carry out an internship at the SINTEF institute, in Norway. All of this allowed that my personal development and fulfilment could be achieved. I am so much grateful.

To Fundação para a Ciência e Tecnologia (FCT) for the financial support through the fellowship SFRH/BD/111128/2015.

To Professor José Mota for all the contribution on the modelling and simulation of this complex $\mathrm{CO}_{2}$ absorption process. But above all for accepting the challenge and having believed in it from the very beginning.

To Professor Luísa Ferreira and Doctor Ricardo Chagas, for their dedication, sharing, affection, friendship and the scientific contribution that greatly enriched the present work, especially on the understanding of the chemical mechanisms between $\mathrm{CO}_{2}$ and the liquid phase.

To Doctor Marius Sandru, for kindly accepting me at Sintef Industri, in Trondheim (Norway). It was a great opportunity to work in a very interesting project aiming the $\mathrm{CO}_{2}$ removal in recirculating aquaculture systems. Moreover, 
during the internship period I had the opportunity to meet extraordinary people, including, Lars, Anne and Maria, which treated me always as one of the group members. I hold all the people of the Biotechnology and Nanomedicine department in great esteem.

To my colleagues from LMP and BioEng groups for the mutual aid, sharing and social events which contributed for the relaxing and good moments along the years. I would like to acknowledge particularly (but without excluding anyone) to Sergio Santoro, Ana Rute, Rita Valério, Rita Ferreira, Inês Meireles, Maria João, Mafalda Cadima, Jorge Bernardo, Joana Monte, Usman Seyed and Suchintan Mondal, for all their friendship and comprehension. To Mariella Polino for being my great companion, both in the laboratory and abroad in most of the international conferences that we have attended. And finally, to Paloma Ortiz for the most special and genuine bond that I have made inside the group. All these people contributed remarkably for my scientific and personal enrichment. Thank you all!

To all the people of the organic chemistry group on the $2^{\text {nd }}$ floor, for the good moments and for the help, especially to Rafael Rippel.

To Ricardo Chagas, for everything! THANK YOU!

Finally, to Francisco for being supportive and cheering when I had confidence crises, and for our lovely baby girl. Both are what motivated me most to complete this work. 
You cannot hope to build a better world without improving the individuals. To that end, each of us must work for our own improvement.

- Marie Curie - 


\section{Abstract}

Inhalational anaesthesia is delivered through assisted ventilation and is typically composed by $65-70 \%$ of anaesthetic gas (nitrous oxide or xenon), $30 \%$ of oxygen and $1-3 \%$ of halogenated hydrocarbons (HHCs). Due to the elevated costs of the anaesthesia agents, the remaining anaesthetics present in exhalation are recycled and reused, to minimize the amount of fresh anaesthesia and thus reduce the costs. An alkali hydroxide mixture, commonly called by soda lime, is used to remove $\mathrm{CO}_{2}$ from the exhalation, to allow the rebreathing of the anaesthetics. However, some controversy is associated to the use of soda lime, due to the toxic compounds that can be formed in contact with HHCs.

The present dissertation concerns the development of a membrane device to replace soda lime, based on two membrane contactors and a biocompatible ionic liquid as a safer strategy for the $\mathrm{CO}_{2}$ removal in anaesthesia circuits. The work is divided in three main topics. The first topic focuses on the study of different cholinium-based ionic liquids affinity towards $\mathrm{CO}_{2}$, enhanced by the addition of carbonic anhydrase enzyme. The ionic liquids were tested with different water activities to assess the optimum water amount for the enzyme activity. The results showed an increased affinity towards $\mathrm{CO}_{2}$, when compared with most used ILs. The presence of a very low amount of carbonic anhydrase (0.1 mgCA/gIL) enhanced the $\mathrm{CO}_{2}$ transport with a maximum increase of $63 \%$.

The second topic involved the understanding of the equilibrium and kinetics of $\mathrm{CO}_{2}$ absorption in a cholinium lysinate ionic liquid solution. $\mathrm{CO}_{2}$ absorption was monitored through $\mathrm{pH}$ measurements and attenuated total reflectance Fourier transform infrared spectroscopy (ATR-FTIR). A comprehensive model based on chemisorption thermodynamics and absorption kinetics is proposed and validated experimentally. Also, it is demonstrated the 
potential of using ATR-FTIR as a monitoring tool for absorption of $\mathrm{CO}_{2}$ in aqueous solutions of cholinium lysinate.

Finally, the third topic focuses on the evaluation of the performance of two distinct membrane contactors with cholinium-based ionic liquids: a microfluidic contactor with a dense polydimethylsiloxane membrane and a porous polytetrafluoroethylene capillary membrane contactor. The characterisation of the systems involved the determination of the mass transfer parameters, i.e. $\mathrm{CO}_{2}$ flux across the membrane, overall mass transfer coefficients, selectivity and $\mathrm{CO}_{2}$ loadings. Both configurations showed high performance for the capture of $\mathrm{CO}_{2}$, considering either nitrous oxide or xenon as inhalation anaesthetic agents. Aiming an extended shelf-life, a regenerating unit for the ionic liquid solution was considered. The results showed that the use of ion-exchange resins is suitable to revert the chemisorption of $\mathrm{CO}_{2}$ in these ionic liquids, avoiding the use of thermal regeneration.

The major outcome from the work developed in this Ph.D. is that membrane contactors combined with cholinium-based ionic liquids are suitable for $\mathrm{CO}_{2}$ removal from anaesthesia circuits and the recycling of anaesthetics with reuse of ionic liquid significantly reduces the cost per operation, leaving space for a widespread use of better performing, although more expensive, gases like xenon.

Keywords: $\mathrm{CO}_{2}$ removal; Anaesthesia recovery; Membrane contactors; cholinium-based ionic liquids. 
A anestesia é administrada por ventilação assistida e é tipicamente constituída por $65-70 \%$ de gás anestésico (óxido nitroso ou xénon), 30\% de oxigénio e 1-3\% de hidrocarbonetos halogenados. Devido ao seu elevado preço, os agentes anestésicos remanescentes presentes na expiração são reciclados, de modo a reduzir a quantidade de gases de anestesia necessários e, desta forma, reduzir os custos. Actualmente, para a remoção de $\mathrm{CO}_{2}$ da corrente de expiração, é utilizada uma mistura alcalina, denominada cal sodada. No entanto, existe alguma controvérsia associada à utilização da cal sodada, devido à possibilidade de formação de compostos tóxicos através do contacto com os hidrocarbonetos halogenados.

A presente dissertação centra-se no desenvolvimento de um processo de membranas para a substituição da cal sodada, baseado em dois contactores de membranas e um líquido iónico biocompatível, como alternativa mais segura para a remoção de $\mathrm{CO}_{2}$ de circuitos de anestesia. $\mathrm{O}$ trabalho está dividido em três tópicos principais. O primeiro tópico foca-se no estudo da afinidade para o $\mathrm{CO}_{2}$ de diferentes líquidos iónicos à base do catião colina, aumentada pela adição da enzima anidrase carbónica. Os líquidos iónicos foram testados com diferentes atividades de água para avaliar a quantidade de água ideal para assegurar a atividade enzimática. Os resultados obtidos mostram que o sistema proposto tem uma afinidade superior para o $\mathrm{CO}_{2}$, quando comparado com os líquidos iónicos mais utilizados. A presença de uma quantidade reduzida de enzima (cerca de 0.1 mgCA/gIL) conduz a um aumento de cerca de $63 \%$ no transporte de $\mathrm{CO}_{2}$.

O segundo tópico centra-se na compreensão do equilíbrio e da cinética da absorção de $\mathrm{CO}_{2}$ numa solução de líquido iónico de lisinato de colina. A absorção de $\mathrm{CO}_{2}$ foi monitorizada através de medidas de $\mathrm{pH}$ e de espectroscopia de 
infravermelho por transformada de Fourier com reflectância total atenuada (ATR-FTIR). Foi proposto e validado experimentalmente um modelo termodinâmico e cinético de quimissorção. Foi ainda demonstrado o potencial da utilização de ATR-FTIR como ferramenta de monitorização da absorção de $\mathrm{CO}_{2}$ em soluções aquosas de lisinato de colina.

Finalmente, o terceiro tópico implica a avaliação do desempenho de dois contactores de membrana distintos com líquidos iónicos que integram o catião colina: um contactor microfluídico com uma membrana densa de polidimetilsiloxano, e um contactor de membrana capilar de politetrafluoroetileno poroso. Para estas configurações, foram determinados os parâmetros de transferência de massa, ou seja, o fluxo de $\mathrm{CO}_{2}$ através da membrana, coeficientes globais de transferência de massa, selectividade e capacidade máxima de absorção de $\mathrm{CO}_{2}$. Ambas as configurações demonstraram um elevado desempenho para a captura de $\mathrm{CO}_{2}$, considerando tanto o óxido nitroso como o xénon como agentes de anestesia. Visando uma vida útil prolongada, foi ainda considerada uma unidade de regeneração para a solução de líquido iónico. Os resultados mostraram que a utilização de resinas de permuta iónica é adequada para reverter a quimissorção do $\mathrm{CO}_{2}$ nestes líquidos iónicos.

O principal resultado do trabalho desenvolvido neste doutoramento é a demonstração da eficiência de contactores de membranas, com utilização de líquidos iónicos integrando o catião colina, na remoção de $\mathrm{CO}_{2}$ em circuitos de anestesia. Igualmente relevante o facto de a recirculação dos compostos anestésicos e a regeneração do líquido iónico usado, reduzir significativamente os custos por operação, deixando espaço para o uso generalizado de gases mais seguros e eficientes, como o xénon apesar de mais dispendiosos.

Palavras-chave: Remoção de $\mathrm{CO}_{2}$; Recuperação de anaestesia; Contactores de membranas; Líquidos iónicos à base de colina. 


\section{Contents}

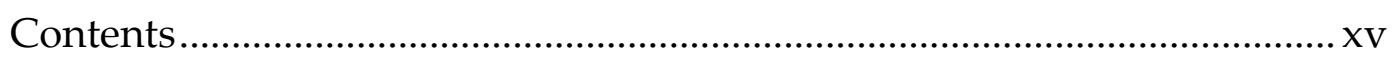

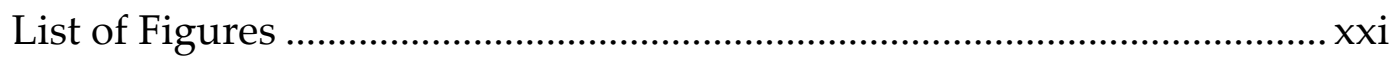

List of Tables ................................................................................. XXV

List of Acronyms ...............................................................................xvii

1 Introduction: Background, Motivation and Dissertation outline........ 1

1.1 Background and motivation....................................................... 1

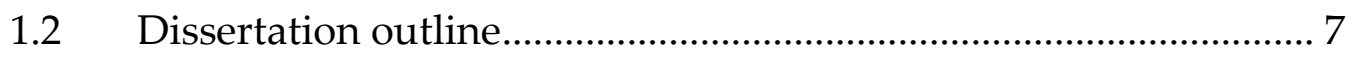

2 Effect of water activity on carbon dioxide transport in cholinium-based

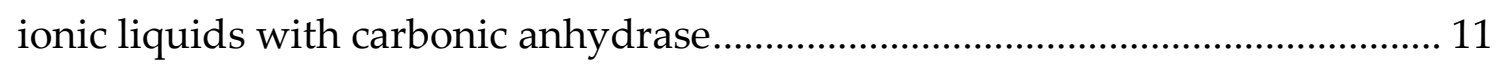

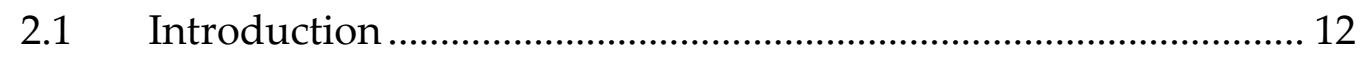

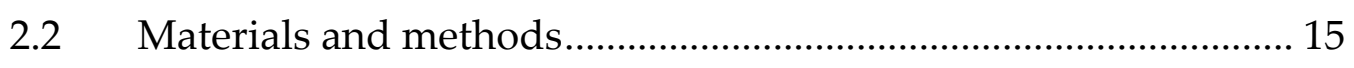

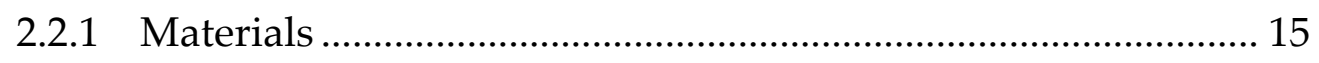

2.2.1.1 Cholinium-based ionic liquids ............................................ 15

2.2.1.2 Carbonic anhydrase enzyme............................................. 17

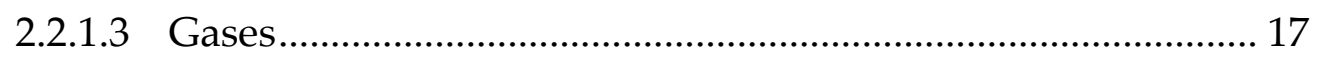


2.2.2.1 Water activity and water content ...................................... 17

2.2.2.2 Viscosity measurements ............................................... 17

2.2.2.3 Density measurements ..................................................... 18

2.2.2.4 Gas solubility and diffusion coefficient experimental measurements 18

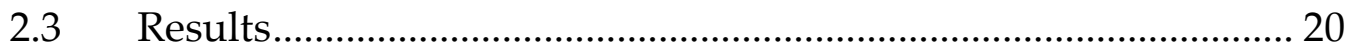

2.3.1 Characterization of cholinium-based ionic liquids with defined water activities 20

2.3.2 Gas solubility and diffusion coefficients. 23

2.3.3 $\mathrm{CO}_{2}$ Diffusion coefficient correlation for cholinium-based ionic liquids 26

2.3.4 Carbonic anhydrase: effect on carbon dioxide solubility and diffusion coefficient 29

2.4 Conclusions 33

3 Microfluidic Devices as Gas - Ionic Liquid Membrane Contactors for $\mathrm{CO}_{2}$ Removal from Anaesthesia Gases 35

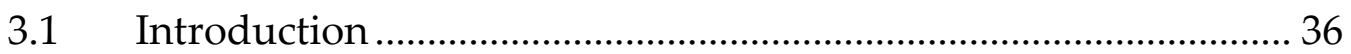

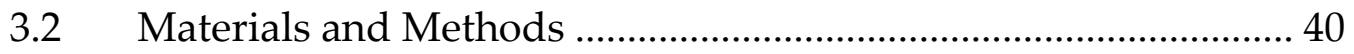

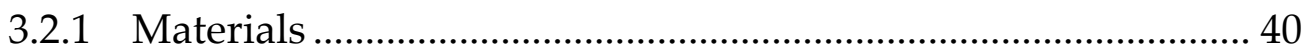

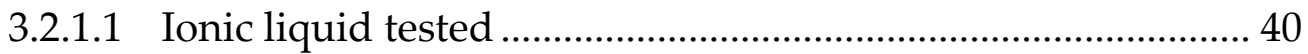

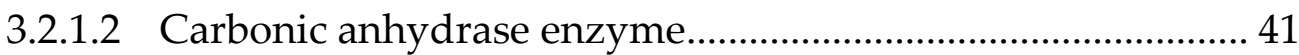

3.2.1.3 Ionic liquid and enzyme preparation ..................................... 41

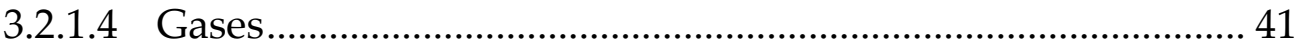

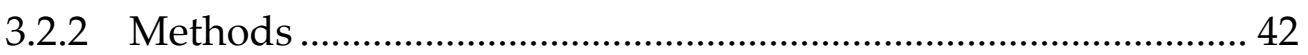

3.2.2.1 Design and fabrication of the PDMS chip............................. 42 
3.2.2.2 Characterisation of the microfluidic device

3.2.2.3 Single gas permeation experiments on PDMS membranes .. 46

3.2.2.4 Single gas permeation experiments on microfluidic devices containing ionic liquids and enzyme..... 47

3.2.3 Calculations. 48

3.2.3.1 Gas permeability calculation of a free-standing membrane . 48

3.2.3.2 Calculation of global mass transfer coefficient, individual resistances and enhancement factor 49

3.3 Results and Discussion.............................................................. 51

3.3.1 Permeability of a free-standing membrane .......................... 51

3.3.2 Gas transport in the microfluidic device ................................ 53

3.3.1 $\mathrm{CO}_{2}$ transport enhancement due to cholinium propionate ionic liquid and carbonic anhydrase enzyme 55

3.4 Conclusions 59

$4 \quad \mathrm{CO}_{2}$ removal from anaesthesia circuits using gas-ionic liquid membrane contactors. 61

$4.1 \quad$ Introduction 62

4.2 Theory 65

4.2.1 $\mathrm{CO}_{2}$ absorption with chemical reaction. 65

4.2.2 $\mathrm{CO}_{2}$ mass transfer models. 66

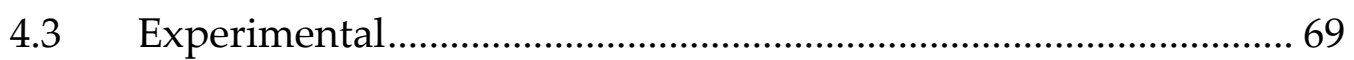

4.3.1 Materials 69

4.3.2 [Cho][Lys] synthesis and characterisation. 70

4.3.3 $\mathrm{CO}_{2}$ absorption and IL solution regeneration experimental procedures.. 70

4.3.4 Evaluation of experimental mass transfer coefficients 73 


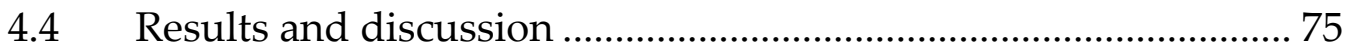

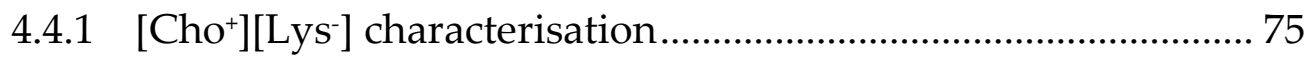

4.4.2 $\mathrm{CO}_{2}$ capture maximum absorption capacity …..................... 77

4.4.3 $\mathrm{CO}_{2}$ maximum absorption capacity and IL solution regeneration

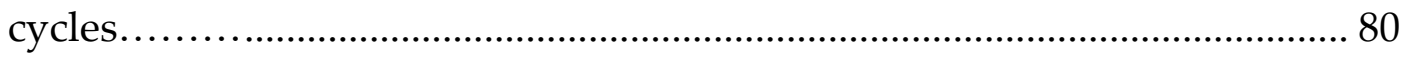

4.4.4 $\mathrm{CO}_{2}$ removal from anaesthetic gas mixtures ........................... 81

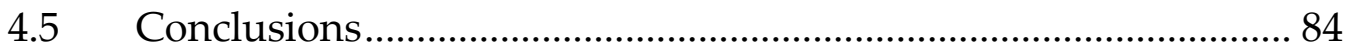

5 Modelling $\mathrm{CO}_{2}$ absorption in aqueous solutions of cholinium lysinate

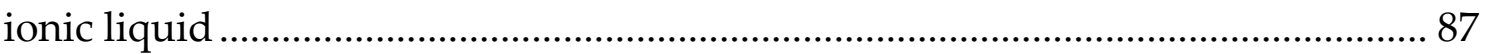

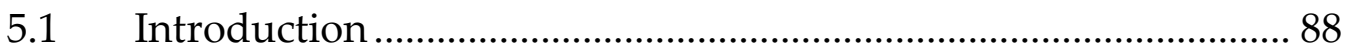

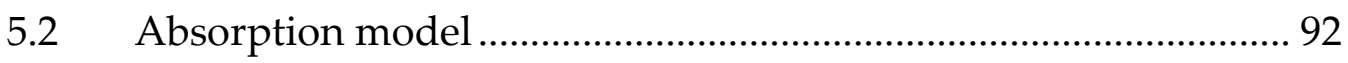

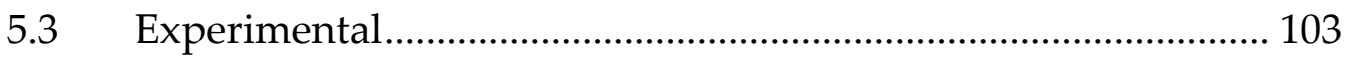

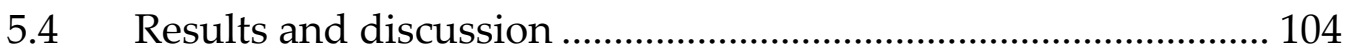

5.4.1 Infrared characterisation of aqueous [Cho+][Lys] solution ... 104

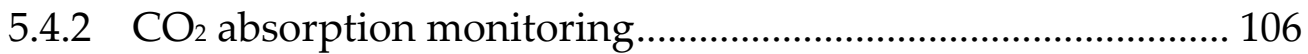

5.4.3 Model fitting and validation .................................................... 109

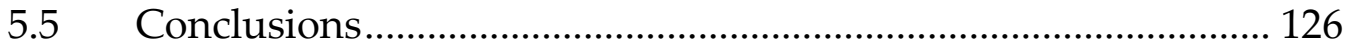

6 Removal of $\mathrm{CO}_{2}$ from Xenon anaesthesia circuits using an amino acid ionic liquid solution in a membrane contactor................................................. 129

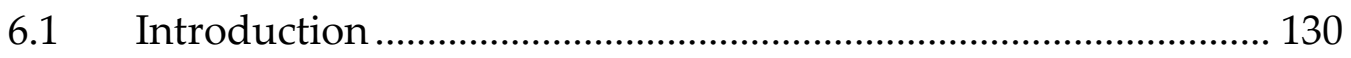

6.2 Materials and methods........................................................... 134

6.2.1 Preparation of the IL solution................................................ 134

6.2.2 Removal of $\mathrm{CO}_{2}$ from anaesthetic mixtures .......................... 135

6.2.3 Regeneration of the $\left[\mathrm{Cho}^{+}\right]\left[\mathrm{Lys}^{-}\right]$ionic liquid solution............ 136

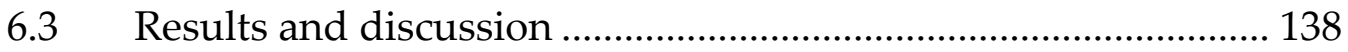

6.3.1 $\mathrm{CO}_{2}$ removal from anaesthetic gas mixtures .......................... 138 
6.3.2 Comparison of constant and pulsed flow ............................... 140

6.3.3 Comparison of different anaesthetic mixtures...................... 144

6.3.4 Ionic liquid regeneration ................................................ 145

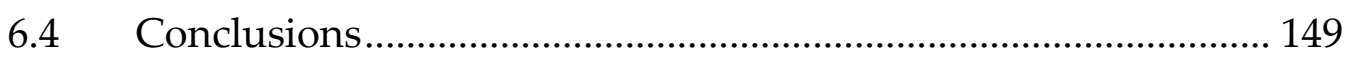

$7 \quad$ General conclusions and Future work .......................................... 151

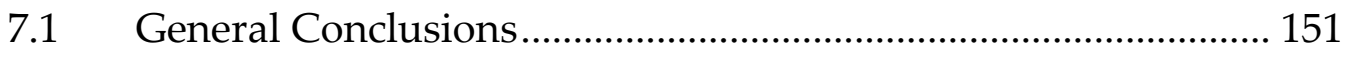

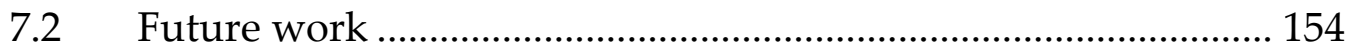

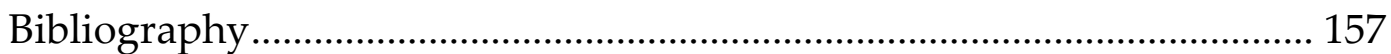

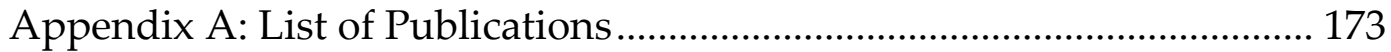

Appendix B: Supplementary material................................................. 179 


\section{List of Figures}

Figure 2.1 Water equilibrated cholinium-based ionic liquids viscosity as function

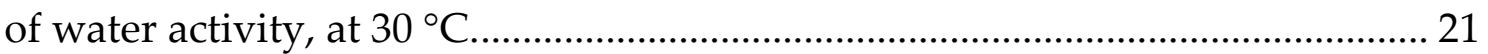

Figure 2.2 Water equilibrated cholinium-based ionic liquids density as a function of water activity, at $30^{\circ} \mathrm{C}$

Figure 2.3 (a) Carbon dioxide solubility in cholinium-based ionic liquids as a function of water activity, at $30{ }^{\circ} \mathrm{C}$; (b) Carbon dioxide diffusion coefficient in cholinium-based ionic liquids as a function of water activity, at $30^{\circ} \mathrm{C}$.

Figure 2.4 Log-log plot of carbon dioxide diffusion coefficient as function of cholinium-based ionic liquids viscosity. The coefficient of determination $\left(\mathrm{R}^{2}\right)$ is 0.94 .

Figure 2.5 Comparison of carbon dioxide diffusion coefficient measured in cholinium-based ionic liquids, at $30{ }^{\circ} \mathrm{C}$, with predictive values from the correlation proposed in this work

Figure 2.6 (a) Carbon dioxide solubility in cholinium-based ionic liquids with $0.1 \mathrm{mgCA} / \mathrm{gIL}$ and without CA as a function of water activity, at $30^{\circ} \mathrm{C}$; (b) Carbon dioxide diffusion coefficient in cholinium-based ionic liquids with $0.1 \mathrm{mgCA} / \mathrm{gIL}$ as a function of water activity, at $30^{\circ} \mathrm{C}$ 30

Figure 2.7 Carbon dioxide permeability in the cholinium-based ionic liquids, without and with $0.1 \mathrm{mgCA} / \mathrm{gIL}$ as function of water activity, at $30{ }^{\circ} \mathrm{C}$. (a) Cholinium Hexanoate, (b) Cholinium Propionate and (c) Cholinium Acetate.. 32 Figure 3.1 Process outline of the microfluidic chip fabrication. 44 
Figure 3.2 PDMS microfluidic device (A) with food dye for better visualisation of liquid and gas chamber and (B) SEM image of a microchip cross section. 46 Figure 3.3 Experimental system for measuring the transport rate of $\mathrm{CO}_{2}$ and $\mathrm{Xe}$ in the presence of ionic liquid and ionic liquid containing carbonic anhydrase.47 Figure 3.4 Normalized pressure drop in the experiments with three different gases $\left(\mathrm{O}_{2}\right.$, Xe and $\left.\mathrm{CO}_{2}\right)$ for two distinctive free-standing membranes $(60 \mu \mathrm{m}$ thickness and $126 \mu \mathrm{m}$ thickness). 52

Figure 3.5 Normalized pressure drop of $\mathrm{CO}_{2}$ in the four different chips..... 53

Figure 3.6 Normalized pressure decay in the feed side over time in the empty chip 1 (no IL), the chip 1 with cholinium propionate and the chip 1 filled with cholinium propionate and carbonic anhydrase for $\mathrm{CO}_{2}(\mathrm{~A})$ and $\mathrm{Xe}(\mathrm{B})$. 56

Figure 3.7 Enhanced $\mathrm{CO}_{2}$ transport due to the presence of ionic liquid and the enzyme in the liquid chamber: results for the 4 different chips prepared in this work 56

Figure 3.8 Simplified scheme for $\mathrm{CO}_{2}$ removal and $\mathrm{Xe}$ recycling in a closed anaesthetic circuit. 59

Figure 4.1 Structure of the most important species in water and in the presence of $\mathrm{CO}_{2}$. 65

Figure $4.2 \mathrm{CO}_{2}$ mass transfer in a non-wetted pore mode. 67

Figure 4.3. Schematic representation of the experimental set-up. 72

Figure 4.4 (a) Screening of $\mathrm{CO}_{2}$ absorption in different [Cho $\left.{ }^{+}\right]\left[\mathrm{Lys}^{-}\right]$aqueous solutions; (b) Dynamic viscosity of different $\left[\mathrm{Cho}^{+}\right]\left[\mathrm{Lys}^{-}\right]$aqueous solutions as a function of temperature. 76

Figure 4.5 Thermogravimetric curve for $\left[\mathrm{Cho}^{+}\right]\left[\mathrm{Lys}^{-}\right]$as a function of temperature. 76

Figure 4.6. Experimental $\mathrm{CO}_{2}$ absorption curves: (a) inlet and outlet $\left[\mathrm{CO}_{2}\right]$ in the gas phase as a function of time per IL solution volume; (b) Accumulated $\left[\mathrm{CO}_{2}\right]$ in gas and liquid phases as a function of time per IL solution volume. 77 
Figure $4.7 \mathrm{CO}_{2}$ absorption in $\left[\mathrm{Cho}^{+}\right]\left[\mathrm{Lys}^{-}\right]$IL solution, monitored by $\mathrm{pH}$ measurement and ATR-FTIR analysis: (a) pH variation as a function of time per IL solution volume; (b) IR absorbance as a function of the wavenumber. 79

Figure $4.8 \mathrm{CO}_{2}$ absorption and IL regeneration cycles: (a) $\mathrm{pH}$ as a function of time per IL solution volume; (b) $\mathrm{CO}_{2}$ loading as a function of time per IL solution volume.

Figure 5.1 Molecular structures of (a) cholinium cation and (b) generic amino acid anion. 89

Figure 5.2 Dissociation states of lysine in aqueous solution. 93

Figure 5.3 Structure of $\left[\mathrm{Cho}^{+}\right]\left[\mathrm{Lys}^{-}\right]$in water and in the presence of dissolved $\mathrm{CO}_{2}$. 94

Figure 5.4 Proposed reaction pathways. 95

Figure 5.5 Schematic of the experimental set-up. 104

Figure 5.6 FTIR spectra of four [Cho $\left.{ }^{+}\right]\left[\mathrm{Lys}^{-}\right]$IL solutions equilibrated at different values of water activity. 105

Figure $5.7 \mathrm{pH}$ and total $\mathrm{CO}_{2}$ solubility in the aqueous solution of $50 \mathrm{wt} \%$ [Cho+][Lys- $]$ as function of process time at $22^{\circ} \mathrm{C}$. 107

Figure 5.8 ATR-FTIR spectra. (a) Before and after $\mathrm{CO}_{2}$ absorption into aqueous solution of $50 \mathrm{wt} \%$ [Cho $\left.{ }^{+}\right]\left[\mathrm{Lys}^{-}\right]$IL. (b) Aqueous solution of $50 \mathrm{wt} \%$ [Cho $\left.{ }^{+}\right]\left[\mathrm{Lys}^{-}\right]$ IL with different $\mathrm{CO}_{2}$ loadings. 108

Figure 5.9 Summary of the workflow required for interfacing gPROMS and an Aspen Plus Property Package (interface direction: Aspen Plus $\rightarrow$ gPROMS) that complies with version 1.1 of the CAPE-OPEN Thermodynamic and Physical Properties specification. 113

Figure 5.10 Experimental (symbols) and fitted (line) curves of $\mathrm{pH}$ as a function of $\mathrm{CO}_{2}$ loading, $\mathrm{C}_{\text {tot }}(\mathrm{M})$. 115

Figure 5.11 Experimental (symbols) and fitted (line) curves of $\mathrm{CO}_{2}$ loading, $\mathrm{C}_{\text {tot }}$ $(\mathrm{M})$, as a function of process time. 117 
Figure 5.12 Simulated curves of $\mathrm{R} \equiv\left[\mathrm{Cho}^{+}\right]\left[\mathrm{Lys}^{-}\right] \mathrm{IL}$ and its two positively charged forms, $\left[\mathrm{R}^{+}\right] \equiv\left[\mathrm{Cho}^{+}\right]\left[\mathrm{Lys}^{-+}\right]$and $\left[\mathrm{R}^{2+}\right] \equiv\left[\mathrm{Cho}^{+}\right]\left[\mathrm{Lys}^{-++}\right]$, as a function of total $\mathrm{CO}_{2}$ loading, $\left[\mathrm{C}_{\text {tot }}\right]$.

Figure 5.13 Simulated curves of $\left[\mathrm{CO}_{2}(\mathrm{aq})\right], \mathrm{HCO}_{3}^{-}$, and $\mathrm{CO}_{3}^{2-}$ as a function of total $\mathrm{CO}_{2}$ loading, $\left[\mathrm{C}_{\text {tot }}\right]$. 119

Figure 5.14 Simulated concentration curves of the final products, $\mathrm{P}_{1} \equiv$ $\left[\mathrm{Cho}^{+}\right]\left[\mathrm{Lys}^{-+}\right] \mathrm{HCO}_{3}^{-}$and $\mathrm{P}_{2} \equiv\left[\mathrm{Cho}^{+}\right]\left[\mathrm{Lys}^{-++}\right] 2 \mathrm{HCO}_{3}^{-}$, and intermediate species $\mathrm{P}_{1}^{+} \equiv\left[\mathrm{Cho}^{+}\right]\left[\right.$Lys $\left.^{-++}\right] \mathrm{HCO}_{3}^{-}$as a function of total $\mathrm{CO}_{2}$ loading, $\left[\mathrm{C}_{\mathrm{tot}}\right]$.

Figure 5.15 Experimental and simulated IR absorbances as function of CO2 loading, $\left[\mathrm{C}_{\mathrm{tot}}\right]$, at $1647 \mathrm{~cm}^{-1}, 1478 \mathrm{~cm}^{-1}$, and $1358 \mathrm{~cm}^{-1}$. 122

Figure 5.16 Comparison of the experimental and fitted ATR-FTIR absorbance spectra, $\Delta \mathrm{A} \lambda(\exp )$ and $\Delta \mathrm{A} \lambda$ (fit), and their difference, $\Delta \mathrm{A} \lambda($ fit) $-\Delta \mathrm{A} \lambda(\exp )$, as a function $\mathrm{CO}_{2}$ loading over the wavelength range $1200 \leq \lambda \leq 1700 \mathrm{~cm}^{-1}$ 124

Figure 5.17 Plots of the five fitting parameters $a \lambda, i$, $i \in R, R^{+}, P_{1}, P_{1}^{+}, P_{2}$, as a function of the wavelength over the range $1200 \leq \lambda \leq 1700 \mathrm{~cm}^{-1}$ 125

Figure 6.1 Proposed process scheme.

Figure 6.2 Synthesis of [Cho $\left.{ }^{+}\right]\left[\mathrm{Lys}^{-}\right]$ionic liquid.

Figure 6.3 Schematic representation of the experimental set-up for the pulsed feed gas mixture experiments 136

Figure 6.4 Experimental $\mathrm{pH}$ as function of time. 141

Figure 6.5 Experimental IR absorbances as function of $\mathrm{CO}_{2}$ captured by the ionic liquid solution under pulsed feed flow, at $1358 \mathrm{~cm}^{-1}, 1478 \mathrm{~cm}^{-1}$ and $1647 \mathrm{~cm}^{-1}$ wavenumbers, which bands correspond respectively to bicarbonate, carbonate ions and protonated amine. 142

Figure 6.6 IR spectra of the [Cho $\left.{ }^{+}\right]\left[\mathrm{Lys}^{-}\right]$ionic liquid solution before and after being submitted to heating regeneration under controlled temperature/pressure conditions.

Figure 6.7 IR spectra of the ionic liquid, before and after regeneration with ionexchange resins. 149 


\section{List of Tables}

Table 2.1 Cholinium-based ionic liquids molecular structure, chemical formula

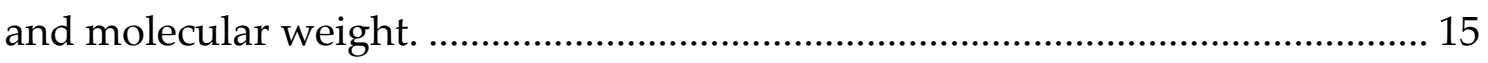

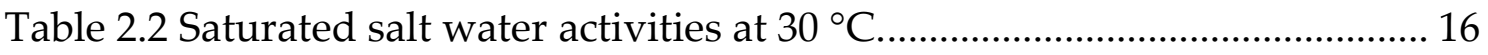

Table 2.3 Viscosity, density, molar volumes and water content for the water equilibrated cholinium-based ionic liquids, at $30^{\circ} \mathrm{C}$.

Table 2.4 Carbon dioxide Henry's constant in the water equilibrated choliniumbased ionic liquids, at $30^{\circ} \mathrm{C}$.

Table 2.5 Viscosity correlation power of commercially available RTILs 27

Table 2.6 Carbon dioxide Henry's constant for the cholinium-based ionic liquids with $0.1 \mathrm{mgCA} / \mathrm{gIL}$, at $30^{\circ} \mathrm{C}$.

Table 3.1 Parameters of the liquid phase used for $\mathrm{CO}_{2}$ capturing experiments. 42 Table $3.2 \mathrm{O}_{2}, \mathrm{CO}_{2}$ and Xe permeability values calculated for the prepared freestanding membranes. 52

Table 3.3 Mass transfer coefficients, resistances and enhancement factor for $\mathrm{CO}_{2}$ transport in cholinium propionate and cholinium propionate combined with carbonic anhydrase. $R_{C P}$ is the resistance in the ionic liquid, $R_{C P+C A}$ is the resistance in the ionic liquid combined with the enzyme, $\mathrm{E}$ is the enhancement factor due to the chemical reaction. 58

Table 4.1 Eclipse ${ }^{\mathrm{TM}}$ membrane modules specifications. 69

Table 4.2 Experimental conditions in the absorption and regeneration modules. 
Table 4.3 Experimental and calculated mass transfer parameters. 82

Table 4.4 Lennard-Jones and kinetic diameters.

Table 5.1 Equilibrium constants for the absorption reactions of $\mathrm{CO}_{2}$ in water. . 97 Table 5.2 Equilibrium constants obtained from data fitting. For completeness, the values of all constants are listed, although only the ratio $K_{5} / K_{4}$ and $K_{6}$ were adjusted. 114

Table 5.3 Values of the absorptivities for each component in the aqueous IL solution that best fit the experimental FTIR spectra. The $95 \%$ confidence interval of each estimated absorptivity is equal to $2 \sigma$.

Table 6.1 Comparison of the mass transfer parameters for constant and pulsed feed flow conditions. 141

Table 6.2 Experimental mass transfer parameters in the presence of different anaesthetic mixtures. 144

Table 6.3 Cost comparison between $\mathrm{Xe}$ and $\mathrm{N}_{2} \mathrm{O}$ anaesthesia, per hour of operation using the proposed system. 


\section{List of Acronyms}

${ }^{1} \mathbf{H}-\mathrm{NMR}$ Proton nuclear magnetic ressonance

AA Amino acids

ATR Attenuated total reflectance

Aw Water activity

BMIMTf $_{2} \mathbf{N}$ 1-Butyl-3-methylimidazolium Bis(trifluoromethylsulfonyl)imide

CA Carbonic anhydrase

[Cho] Cholinium cation

[Cho][Acetate] Cholinium Acetate

[Cho][Hexanoate] Cholinium Hexanoate

[Cho][OH] Choline hydroxide

[Cho][Lys] Cholinium Lysinate

CMSM Carbon molecular sieve membranes

[Cho][Propionate] Cholinium Propionate

CP Cholinium Propionate

Compound A Fluoromethyl-2,2-difluoro-1-(trifluoromethyl)vinyl ether

FTIR Fourier-transform infrared

G-L Gas-liquid

HHCs Halogenated hydrocarbons

IL Ionic liquid 
[Lys] Lysinate anion

LbL Layer-by-Layer

MW Molecular Weight

PDMS Polydimethylsiloxane

PEI Polyethylenimine

pH Potential or power of hydrogen

PP Polypropylene

PS Polystyrene

PTFE Polytetrafluoroethylene

PVDF Polyvinylidene fluoride

MAC Minimum alveolar concentration

MEA Monoethanolamine

RTIL Room temperature ionic liquid

SEM Scanning electron microscopy

SF Separation Factor 


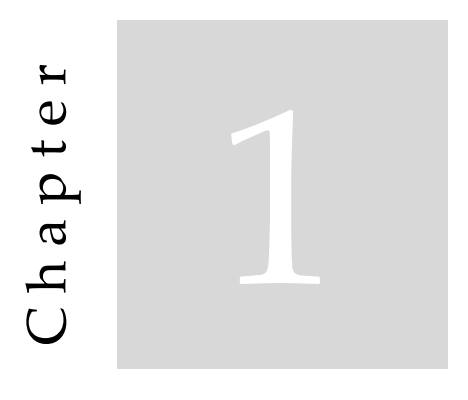

\section{Introduction: Background, Motivation and Dissertation outline}

In the present dissertation the use of membrane separation processes for carbon dioxide $\left(\mathrm{CO}_{2}\right)$ removal from anaesthesia rebreathing circuits is considered. For many years the use of xenon $(\mathrm{Xe})$ as an inhalational anaesthesia has been set aside due to its high cost. Nevertheless, several works have been published proposing alternative methodologies to allow the widespread use of $\mathrm{Xe}$, which have sustained the enduring interest in this anaesthetic gas. Hereupon, this dissertation brings out membrane contactors, using biocompatible ionic liquids and enzymes, aiming their use in anaesthesia closed circuits. An in-depth analysis is described here, both on the $\mathrm{CO}_{2}$ liquid absorbent selection and on the performance of the combined system of membrane contactors and ionic liquids, in the context of inhalation anaesthesia recycling.

\subsection{Background and motivation}

Anaesthesia is usually provided as a combination of intravenous and inhalational agents to create an unconscious state and to relief the pain during surgical interventions. The administration of specific drugs enables muscle relaxation and supress spontaneous respiration, which is granted by assisted 
mechanical ventilation ensuring the pulmonary gas exchange. In most cases, the assisted ventilation is used simultaneously for the delivery of inhalational anaesthetic agents. Typically, the inhalational mixture combines inorganic gases (e.g. nitrous oxide) with volatile halogenated hydrocarbons (isoflurane, desflurane, halothane, enflurane or sevoflurane) [1,2], in a composition of $70 \%$ of an inorganic gas, $30 \%$ of oxygen $\left(\mathrm{O}_{2}\right)$ and $1-8 \%$ of halogenated hydrocarbons (HHCs) [3]. For economic purposes, the anaesthetic gas mixture is delivered to the patient in a closed breathing circuit mode, allowing the rebreathing of the exhaled anaesthetics. As the closed breathing circuits require low fresh gas flows, to a minimum of $250 \mathrm{~mL} / \mathrm{min}$ [4], the cost-effectiveness relation of the anaesthesia delivery is favoured. The reuse of the remaining inhalational anaesthetics is possible using a solid $\mathrm{CO}_{2}$ absorbent mixture of calcium hydroxide, water, sodium hydroxide and potassium hydroxide, commonly called by soda lime [5]. The exhaled air of the patient anaesthetised contains around $65 \%$ of the anaesthetic, $27 \%$ of $\mathrm{O}_{2}, 5 \%$ of $\mathrm{CO}_{2}$ and $3 \%$ of nitrogen $\left(\mathrm{N}_{2}\right)$. The concentrations of $\mathrm{N}_{2}$ and $\mathrm{CO}_{2}$ in the recycled mixture must be lower than 3 and $0.5 \%$, in volume, respectively [6]. After the exhaled $\mathrm{CO}_{2}$ is removed, the necessary $\mathrm{O}_{2}$ is replenished and the mixture is reintroduced in the system.

Although soda lime is widely used for the removal of $\mathrm{CO}_{2}$ in anaesthesia circuits, due to its high efficiency, several drawbacks have been identified. Toxic compounds, such as carbon monoxide (CO), fluoromethyl-2,2-difluoro-1(trifluoromethyl)vinyl ether (denominated as "Compound $\mathrm{A}^{\prime}$ ) and formaldehyde, can be generated from the action of soda lime on desflurane and sevoflurane, especially in desiccated conditions under low and minimal flow anaesthesia [7]. It was demonstrated that the concentration of these products increases significantly with temperature, where the temperature of soda lime can reach $50{ }^{\circ} \mathrm{C}$ under $8 \mathrm{~h}$ of operation, due to the exothermic reaction with $\mathrm{CO}_{2}[8,9]$. The existence of fires has been reported in cases where sevoflurane was exposed to desiccated Baralyme ${ }^{\circledR}[10]$. Moreover, due to its high corrosion hazard, soda lime canister is disposed as health care waste instead of domestic waste, increasing the hospitals costs. To minimize these drawbacks, several alternatives 
have been proposed. Luttropp and Johansson [9], demonstrated that using head space volumes it is possible to reduce the temperature of soda lime under low and minimal flow anaesthesia. However, significantly increased pressures are needed in the ventilator machine to maintain the flows, which can lead to lung injury due to the risk of baro- and volotrauma, in addition to increased costs per operation. Several alternative absorbents with the ability to produce less to negligible concentrations of toxic by-products, have been proposed. Amsorb Plus ${ }^{\circledR}$ is emerging as a safer option since it does not cause anaesthetics degradation, does not possess handling risks and can be disposed as domestic waste. Despite its cost per weight is higher than soda lime, the overall costs are lower because it enables low flows of sevoflurane. Nevertheless, the side effects as post-operative nausea and vomiting, associated with the production of the toxic by-products, continued to be registered [11]. Therefore, the scientific community is kept on pursuing for an absorbent or anaesthetic purification system completely safe.

Nitrous oxide $\left(\mathrm{N}_{2} \mathrm{O}\right)$ is the most used inorganic inhalational anaesthetic due to its proven pharmacokinetic properties and low cost $(0.80 € / \mathrm{L})$. The use of an inorganic gas with anaesthetic properties as $\mathrm{N}_{2} \mathrm{O}$, allows to reduce the costs per operation, by reducing the amount of volatile halogenated hydrocarbons necessary to induce the anaesthetic state, which are significantly more expensive (Isoflurane - $126 € / \mathrm{L}$, sevoflurane - 756€/L, Desflurane - 806€/L) [12-15]. However, its use has generated some controversy due to the potential toxic effects that may occur, risks of occupational exposure and environmental impact [16]. Many efforts have been made to find a substitute; nevertheless, the excellent anaesthetic properties of $\mathrm{N}_{2} \mathrm{O}$ combined with its low cost has hindered its replacement.

The search for the ideal anaesthetic agent has been ongoing since the beginning of anaesthesia, on the $16^{\text {th }}$ of October of 1846, known as "Ether day", when the first successful demonstration of an inhalational anaesthetic took place. Diethyl ether was the first inhalational drug to be used as anaesthetic, followed by $\mathrm{N}_{2} \mathrm{O}$ and chloroform. Later, diethyl ether and chloroform were made obsolete 
due to the their many health and occupational risks [17]. It was in 1951, that Cullen et al. [18] reported for the first time the use of Xe as an anaesthetic for an operative procedure in a human being. In this study, the obtained effects in humans through mixtures of $\mathrm{Xe}: \mathrm{O}_{2}$ and $\mathrm{N}_{2} \mathrm{O}: \mathrm{O}_{2}$, administered using a closed system with soda lime to permit recirculation of the gases, were compared. It was found that Xe causes minimal effects on the cardiovascular system, producing less haemodynamic depression, which enables its use in patients with cardiac pathologies $[16,19]$. Xenon minimum alveolar concentration (MAC), that defines the minimal level of anaesthesia to allow surgery, is 71 while the MAC value for $\mathrm{N}_{2} \mathrm{O}$ is 104. Additionally, the blood-gas partition coefficient, that indicates the onset time and recovery speed of xenon is 0.115 , which is the lowest of all known anaesthetics [19-22]. In this way, a faster induction of the anaesthetic effect is achieved with less amount of gas. Moreover, the analgesic potency of xenon allows omission of further volatile inhalation agents [23]. Due to a recovery rate higher than the other anaesthetics, the use of xenon reduces the time patients spend in the hospital, which benefits the health care costs [24]. In terms of environmental impact, the anaesthetics are vented to atmosphere, which can be prejudicial when using $\mathrm{N}_{2} \mathrm{O}$, because it is related to the destruction of the ozone layer and also leads to greenhouse effects, while xenon is not associated with either [25]. Despite all the advantages mentioned, xenon does not have a widespread use due to its high cost $(11 € / L)$. A significant advance in the field of anaesthesiology can be made if xenon becomes economically viable. Therefore, efforts should be directed towards obtaining reduced costs of xenon, both in the manufacture process (cryogenic distillation of air) and in the process of anaesthesia delivery.

Due to the identified drawbacks, both in the utilisation of soda lime and $\mathrm{N}_{2} \mathrm{O}$, several alternative solutions have been studied and proposed for the continuous removal of $\mathrm{CO}_{2}$ from the conventional closed circuits. Membranebased technology has been addressed as an alternative methodology for the recycling of the inhalational anaesthetics. The investigated alternatives included the use of membrane contactors for $\mathrm{CO}_{2}$ absorption with a reactive liquid phase 
[26], hollow fibre contactors [5,27], carbon molecular sieve membranes [6,28], immobilized liquid membranes [3] and zeolite membranes [29]. Membrane contactors provide a non-dispersive, fixed and well-determined interface for gasliquid mass transfer, where instead of selectivity, the membrane offers a barrier to separate the two phases, while the selectivity is given by the liquid phase (although it is possible to use selective membranes). Typically, membrane contactors have high membrane area per unit volume resulting in higher overall throughput, high self-mechanical support, good flexibility and easy system operation, which make them highly interesting for gas separation processes, both in industrial and in small scales. [30,31]. The membrane configurations developed so far, were compromised due to different factors, such as difficulties of liquid absorbent regeneration, membrane selectivity and cost of the materials.

Aqueous amine solutions have been extensively used in industrial applications, for the capture of $\mathrm{CO}_{2}$ produced from diverse gas streams sources [32]. These liquid absorbents are submitted to temperature swing to be regenerated, enabling $\mathrm{CO}_{2}$ desorption, during the capturing process [33]. Due to their corrosive nature, degradation in the presence of $\mathrm{O}_{2}$ and high volatility, the amine aqueous solutions are not suitable for anaesthetic circuits, as alternatives to soda lime. Ideally, the absorbent solution must be biocompatible, with negligible vapour pressure to avoid the contamination of the circuit, must be chemically and thermally stable and possess high $\mathrm{CO}_{2}$ absorption capacity and selectivity in the presence of anaesthetic gases. In a perspective of an alternative system with self-regeneration, the liquid solution should also allow $\mathrm{CO}_{2}$ desorption. Studies on $\mathrm{CO}_{2}$ capture using different absorption systems increased progressively over the last three decades, where ionic liquids (ILs) have emerged as a potential alternative [34]. ILs are liquid salts with negligible volatility and their potential to capture $\mathrm{CO}_{2}$ is recognized due to their unique properties, such as the ability to be designed for $\mathrm{CO}_{2}$ absorption, excellent thermal stability, nonflammability and easy operation at liquid state [35-37].

In the present dissertation, a safer and sustainable approach for the $\mathrm{CO}_{2}$ removal in anaesthesia circuits is proposed. The proposal includes the use of 
membrane contactors and regenerable cholinium-based ionic liquids for the capture of $\mathrm{CO}_{2}$. The cholinium cation was selected as a benign cation, due to its recognized biocompatibility and high affinity towards $\mathrm{CO}_{2}$, when combined with alkanoates or amino acids [38,39]. This class of ionic liquids possesses a strong hydrophilic character allowing to accommodate high water contents, an important feature that allow the decrease of the ILs viscosity and enables the solubilization of enzymes, in particular carbonic anhydrase, able to reversibly convert $\mathrm{CO}_{2}$ into bicarbonate. The combination of biocatalysis and $\mathrm{CO}_{2}$ absorption in ionic liquids, is proved to allow for an efficient capture of $\mathrm{CO}_{2}$ [40]. Additionally, the ionic liquids studied in the present dissertation were selected aiming their use in a configuration with a $\mathrm{CO}_{2}$ desorption unit for regeneration of the liquid solution.

Two different membrane contactors were considered, along with the use of cholinium-based ionic liquids, and their performance was analysed aiming their application in closed anaesthesia circuits. There are several types of membrane modules that can be used in gas-liquid separation processes, where the module configuration plays a vital role in governing the overall mass transfer process, determining the separation performance. The modules should provide high flow rates of both the feed and the permeate, high packing density, low pressure drop and high thermal and chemical stabilities. Depending on the application, membranes can be non-porous or porous. The use of porous membranes is preferable, as long as the pores are filled with the gas phase, leading to a negligible resistance offered by the presence of the membrane. In the present work, both membrane configurations were considered. A polydimethylsiloxane (PDMS) non-porous flat membrane, assembled in a microdevice with two independent chambers, was evaluated as a proof of concept for the selective removal of $\mathrm{CO}_{2}$ in anaesthesia circuits. In this case, miniaturization of the module, that requires a reduced amount of the choliniumbased ionic liquids, and the high $\mathrm{CO}_{2}$ permeability of PDMS membrane, were exploited. Regarding the second configuration, a hydrophobic microporous polytetrafluoroethylene (PTFE) membrane was considered as a highly 
chemically resistant material, since PTFE membranes are capable to retain their non-wetting behaviour [27]. The commercially available Eclipse ${ }^{\mathrm{TM}}$ membranes were selected for the present study. The membrane was assembled as parallel capillaries in cylindrical modules, where the anaesthetic mixture with $\mathrm{CO}_{2}$ circulated in the shell side and the cholinium-based ionic liquid circulated in the lumen of the capillaries, in counter current mode. Due to an operation with low pressure in both sides of the membrane, the hydrophobic character of the membrane material excluded the penetration of the aqueous cholinium-based ionic liquids into the pores.

Aiming a prolonged use as a route to attain an economically viable alternative system for the current technology, a regeneration unit is included. Several conditions were explored for the regeneration of the ionic liquid solutions, namely the use of a sweep gas, increase of temperature and vacuum, and use of ion-exchange resins. This later approach is rather innovative methodology, since the use of ion exchange resins to enable the $\mathrm{CO}_{2}$ desorption in ionic liquid solutions, is addressed for the first time.

\subsection{Dissertation outline}

The present dissertation presents the work developed during the PhD period and is organized in seven chapters and two appendices. The work described in this dissertation includes the study of membrane separation processes using ionic liquids for the removal of $\mathrm{CO}_{2}$ from anaesthesia rebreathing circuits. Each chapter includes a summary of the work, an introduction with a short review of the state of the art, describes the materials and methods used and discusses the results and main conclusions. The methodology used in each individual chapter is detailed in the context of the respective subject and, when applicable, is related to that used in previous chapters. The work performed during this $\mathrm{PhD}$ resulted in four scientific articles, presented in Chapters 2 to 5. The work described in Chapter 6 is prepared to be submitted for publication. All the scientific papers, which have 
been published in international peer-reviewed scientific journals, are listed in Appendix A.

A brief description of the contents of each chapter is described below.

Chapter 1 - Introduction - Describes the state of the art, motivation, aim of the work and the PhD thesis outline.

Chapter 2 - Effect of water activity on carbon dioxide transport in cholinium-based ionic liquids with carbonic anhydrase - Describes the study of the affinity of biocompatible cholinium-based ionic liquids towards carbon dioxide. The $\mathrm{CO}_{2}$ diffusion and solubility in each ionic liquid were evaluated against different water activity conditions. Moreover, the enhancement on $\mathrm{CO}_{2}$ transport by the addition of carbonic anhydrase was also evaluated. The content of this chapter was published in Separation and Purification Technology, 2016, vol. 168, pp. 74-82.

Chapter 3 - Microfluidic devices as gas-ionic liquid membrane contactors for $\mathrm{CO}_{2}$ removal from anaesthesia gases - Describes the concept of an alveolar microfluidic device as gas-ionic liquid micro-contactor for removal of $\mathrm{CO}_{2}$ from an anaesthesia gas containing Xe. The working principle of the microcontactor involved the transport of $\mathrm{CO}_{2}$ through a flat PDMS membrane followed by the capture and enzymatic bioconversion in a cholinium-based ionic liquid solvent. The ionic liquid used as $\mathrm{CO}_{2}$ absorbent was selected from the work described in the previous chapter, which revealed the highest affinity to capture $\mathrm{CO}_{2}$. The content of this chapter was published in Journal of Membrane Science, 2018, vol. 545, pp. 107-115.

Chapter $4-\mathrm{CO}_{2}$ removal from anaesthesia circuits using gas-ionic liquid membrane contactors - Describes the proof of concept of using a capillary membrane contactor with a cholinium lysinate ionic liquid solution, as an alternative process to remove carbon dioxide from anaesthesia gas mixtures. The $\mathrm{CO}_{2}$ removal rate was assessed varying the feed gas conditions, i.e. composition and relative humidity, and under different ionic liquid flowrates. The $\mathrm{CO}_{2}$ absorption was accompanied by the ionic liquid solution regeneration, using a 
second membrane contactor by stripping the $\mathrm{CO}_{2}$ with a sweep gas. The content of this chapter was published in Separation and Purification Technology, 2020, vol. 250, 116983.

Chapter 5 - Modelling $\mathrm{CO}_{2}$ absorption in aqueous solutions of cholinium lysinate ionic liquid - Describes the process of $\mathrm{CO}_{2}$ absorption in an aqueous solution of cholinium lysinate ionic liquid, via mechanistic modelling supported in an experimental study performed in a membrane contactor operated in closed loop. Online $\mathrm{pH}$ measurements and attenuated total reflectance Fourier transform infrared spectroscopy (ATR-FTIR) analysis of discrete sampling of the circulating aqueous IL solution, were used for monitoring $\mathrm{CO}_{2}$ in the ionic liquid solution. A comprehensive model of chemisorption thermodynamics and absorption dynamics was proposed and validated experimentally. The content of this chapter was published in Chemical Engineering Journal, 2020, 127875.

Chapter 6 - Removing $\mathrm{CO}_{2}$ from Xenon anaesthesia circuits using an amino-acid ionic liquid solution in a membrane contactor - Describes the use of a gas-ionic liquid membrane contactor system in anaesthesia closed-circuits, for the removal of carbon dioxide, to enable the widespread utilisation of xenon as an anaesthetic agent. The proposed system was evaluated under constant and dynamic feed flow conditions. The performance of the system was also evaluated using different anaesthesia gases, either xenon or nitrous oxide. Additionally, the regeneration of the ionic liquid solution was studied using thermal and ionexchange approaches. As an innovative methodology, the use of ion-exchange resins is proposed as a chemical regeneration method. The content of this chapter is prepared to be submitted in Separation and Purification Technology.

Chapter 7 - Outlook and future work - The main results obtained in this PhD project are summarised, the general conclusions are discussed in an integrated way and suggestions for future research are presented.

Appendix A - Provides a list of the author's publications, articles in peerreviewed journals accepted and oral/poster communications. 
Appendix B - Provides supplementary results that give support to the information described in the main body of the present dissertation. 


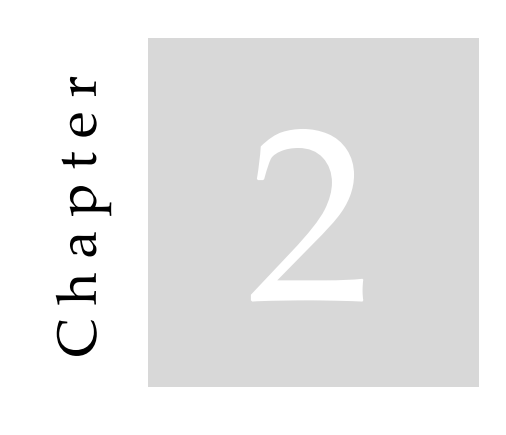

\section{Effect of water activity on carbon dioxide transport in cholinium-based ionic liquids with carbonic anhydrase}

Published as: C. F. Martins, L. A. Neves, M. Estevão, A. Rosatella, V. D. Alves, C. A. M. Afonso, J. G. Crespo and I. M. Coelhoso, "Effect of water activity on carbon dioxide transport in cholinium-based ionic liquids with carbonic anhydrase", Separation and Purification Technology, 2016,vol. 168, pp. 74-82.

\section{Summary}

The present work reports a study of the affinity of carbon dioxide towards biocompatible cholinium-based ionic liquids, aiming the development of a sustainable process for carbon dioxide removal. Moreover, the enhancement on carbon dioxide transport by the addition of carbonic anhydrase, able to catalyse the reversible reaction of carbon dioxide with water, is also evaluated.

Cholinium acetate, cholinium propionate and cholinium hexanoate were the selected ionic liquids for this study. Carbon dioxide solubility and diffusion coefficients were determined in the three cholinium ionic liquids, at different water activities, in order to identify optimal conditions for the enzyme activity and stability. A carbon dioxide diffusion coefficient correlation for the cholinium- 
based ionic liquids with different water activities is proposed, allowing for estimation of carbon dioxide diffusion coefficients.

The results obtained show that the selected cholinium-based ionic liquids possess high affinity towards carbon dioxide, when compared with most used room temperature ionic liquids. Also, it was demonstrated that a small amount of the carbonic anhydrase $(0.1 \mathrm{mgCA} / \mathrm{gIL})$ promotes an enhancement of $63 \%$ on the carbon dioxide transport rate, for cholinium propionate with a water activity of 0.753 .

\subsection{Introduction}

Conventional technologies for carbon dioxide capture from flue gas streams are based on absorption in amine solutions. Although amines are widely used due to their high affinity towards carbon dioxide, they present several limitations, such as high volatility, which is an extremely difficult issue to handle in high temperature processes, corrosive nature, high operational cost and environmental impact. In order to overcome these drawbacks, ionic liquids have been proposed as very promising substitutes of traditional organic absorbents [41]. Their unique properties, such as high thermal stability, non-volatility, solvation capability, no flammability and easy operation at liquid state, confer them the possibility to be used in a wide range of processes [36,37]. Furthermore, in the last decade, a new class of ionic liquids has emerged, the biocompatible and environmental-friendly ionic liquids. They are synthesized using naturallyderived materials, such as sugars and amino acids, are economically attractive and environmental-friendly [42-44]. This new class of ionic liquids may provide an optimum media to stabilize proteins (e.g. enzymes), allowing replacement of traditional hazardous solvents used for stabilization and purification processes, possess potential to be used in biomedical devices [45]. As an example of biocompatible ionic liquids are those based on the cholinium cation. Studies on cholinium-based ionic liquids toxicity $[38,46]$ have shown that the cholinium cation, which is a quaternary ammonium cation $([\mathrm{N}, \mathrm{N}, \mathrm{N}-$ 
trimethylethanolammonium $]^{+}$), recognized as an essential nutrient totally derived from natural products [47], combined with a range of alkanoate anions or amino acids, may provide a media where living cells can actively grow. This demonstrates that, these ionic liquids are biocompatible, which is a feature required for biomedical applications $[38,48]$.

The present work focuses on the study of carbon dioxide transport using cholinium-based ionic liquids combined with carboxylate anions derived from weak carboxylic acids which, according to the literature, can provide high carbon dioxide solubility [49-52]. It has been reported that carbon dioxide absorption is strongly dependent on the nature of the anion, while the nature of the cation has a decisive role in toxicity $[38,53,54]$. The present work reports a study about the affinity of cholinium-based ionic liquids towards carbon dioxide, using different anions, selected according to their chain length. It is also proposed the use of an enzyme, the carbonic anhydrase (CA), which is able to catalyse the reversible reaction of carbon dioxide with water to produce bicarbonate. The addition of this enzyme to the cholinium ionic liquids will enhance the carbon dioxide transport rate, due to the simultaneous absorption and reaction mechanisms. Furthermore, the hydrophilic character of these ionic liquids plays an important role in the catalytic reaction $[40,55]$. Biocatalysis in ionic liquids has attracted much attention in the last two decades. Up to the present, catalytic processes with lipases have benefited most from the use of ionic liquids as green solvents [5658]. Nevertheless, there are several publications describing the use of CA with aqueous solutions of amines [59-65]. Despite of the carbon dioxide capture enhancement in the aqueous amine solutions due to the presence of the CA, this strategy does not overcome the drawbacks associated to the use of amine solutions.

As this work involves a completely biocompatible system, studies of pure gases absorption in the different cholinium-based ionic liquids in the absence of CA and with a low quantity of CA $(0.1 \mathrm{mgCA} / \mathrm{gIL})$, were also performed with xenon, oxygen and nitrogen, aiming the evaluation of this system for removal of 
carbon dioxide from anaesthetic circuits, when anaesthesia with assisted ventilation is involved.

In a previous work [40] the removal of carbon dioxide from flue gas streams was achieved, using the ionic liquid 1-Butyl-3-methylimidazolium bis(trifluoromethylsulfonyl)imide ([BMIMTf $2 \mathrm{~N}]$ ) combined with $\mathrm{CA}$ for the enhancement of the selective transport of carbon dioxide. The results showed that it was possible to increase the carbon dioxide solubility coefficient up to $30 \%$, even when using a low enzyme concentration $(0.1 \mathrm{mgCA} / \mathrm{gIL})$. The present work follows the concept described in the previous work, using biocompatible ionic liquids.

Aiming the optimal conditions for the enzyme activity and stability in these biocompatible ionic liquids, water activity studies were performed. The impact of water activity on the viscosity of cholinium-based ionic liquids is evaluated as well as its impact on the transport of carbon dioxide. Several works report diffusion coefficient correlations for gas compounds in room temperature ionic liquids based on imidazolium, phosphonium and ammonium cations [6673]. Correlations to predict gas diffusion are required, in order to minimize time and resources usually spent on measuring the solubility and diffusion for every new system. Consequently, predictive models are an extremely powerful tool when attempting to develop new processes and applications. The present work proposes a carbon dioxide diffusion coefficient correlation for cholinium-based ionic liquids at different water activities.

To validate the concept proposed in the present work, the following aspects were investigated: 1 - determination of the carbon dioxide solubility and diffusion coefficient in cholinium-based ionic liquids; 2 - evaluation of xenon, oxygen and nitrogen transport through cholinium-based ionic liquids; 3 evaluation of the effect of the enzyme in the absorption of carbon dioxide, xenon, oxygen and nitrogen; 4 - the effect of water activity on the enzyme activity/stability and on the carbon dioxide solubility and diffusion coefficient; 
and 5 - determination of a predictive correlation of gas diffusion in the cholinium-based ionic liquids.

\subsection{Materials and methods}

\subsubsection{Materials}

\subsubsection{Cholinium-based ionic liquids}

Cholinium-based ionic liquids possess a quaternary ammonium cation $(\mathrm{N}, \mathrm{N}, \mathrm{N}-$ trimethylethanolammonium), which is a substituted tetra-alkylammonium containing one primary hydroxyl group. These ILs were selected according to the cation and anion properties. Ammonium cations possess good affinity towards carbon dioxide, as reported in the literature [67]. The anions used in this study possess high affinity towards carbon dioxide $\left(\mathrm{CO}_{2}\right)$, because they derived from week carboxylic acids [49]. In Table 2.1 are represented the ionic liquids studied.

Table 2.1 Cholinium-based ionic liquids molecular structure, chemical formula and molecular weight.

\begin{tabular}{|c|c|c|c|}
\hline Ionic Liquid & $\begin{array}{l}\text { Molecular } \\
\text { Structure }\end{array}$ & $\begin{array}{l}\text { Chemical } \\
\text { Formula }\end{array}$ & $\begin{array}{l}\text { Molecular weight } \\
\text { (g.mol-1) }\end{array}$ \\
\hline [Cho][Acetate] & & $\mathrm{C}_{7} \mathrm{H}_{17} \mathrm{NO}_{3}$ & 163.21 \\
\hline [Cho][Propionate] & & $\mathrm{C}_{8} \mathrm{H}_{19} \mathrm{NO}_{3}$ & 177.24 \\
\hline [Cho][Hexanoate] & & $\mathrm{C}_{11} \mathrm{H}_{25} \mathrm{NO}_{3}$ & 219.32 \\
\hline
\end{tabular}


Cholinium hexanoate ([Cho][Hexanoate]), cholinium propionate ([Cho][Propionate]) and cholinium acetate ([Cho][Acetate]) ionic liquids were prepared by neutralization of the respective carboxylic acids dissolved in methanol with choline hydroxide $([\mathrm{Cho}][\mathrm{OH}])$, as reported elsewhere [38], with the following modifications: to a solution of acid (1 equiv.) in methanol was slowly added to [Cho][OH] (1 equiv.). The solution was stirred overnight at room temperature, followed by solvent evaporation on a rotary evaporator. The salt obtained was stirred under vacuum $(<1 \mathrm{mmHg})$ at $60^{\circ} \mathrm{C}$ overnight. The structure and purity of the prepared ILs were confirmed by ${ }^{1} \mathrm{H}-\mathrm{NMR}$ and ${ }^{13} \mathrm{C}-\mathrm{NMR}$, where no impurities peaks were observed. Choline hydroxide, hexanoic acid, propionic acid and acetic acid were purchased from Sigma-Aldrich (USA) and were used without further purification or drying.

The cholinium-based ionic liquids were equilibrated using four different salt solutions to provide the water activities listed in Table 2.2. Potassium acetate (Merck ${ }^{\circledR}$, Germany), sodium bromide (Applichem, Panreac ${ }^{\circledR}$, Germany), sodium chloride (Applichem, Panreac ${ }^{\circledR}$, Germany) and potassium chloride (Panreac ${ }^{\circledR}$, Germany) were used for that purpose.

Table 2.2 Saturated salt water activities at $30^{\circ} \mathrm{C}$ [74].

\begin{tabular}{cc}
\hline Salt & Water activity $\left(\mathbf{a}_{\mathbf{w}}\right)$ \\
\hline Potassium Acetate & 0.216 \\
Sodium Bromide & 0.576 \\
Sodium Chloride & 0.753 \\
& \\
Potassium Chloride & 0.836 \\
\hline
\end{tabular}




\subsubsection{Carbonic anhydrase enzyme}

Carbonic anhydrase lyophilized from bovine erythrocytes from Sigma-Aldrich (USA) (reference C3934) was used in this work, without any additional purification.

\subsubsection{Gases}

The gases used in the experiments were carbon dioxide, $\mathrm{CO}_{2}$ (high-purity grade 99.998\%, Praxair, USA), xenon, Xe (purity grade 99.999\%, Praxair, USA), oxygen, $\mathrm{O}_{2}$ (purity grade $99.999 \%$, Praxair, USA) and nitrogen, $\mathrm{N}_{2}$ (purity grade $99.998 \%$, Praxair, USA).

\subsubsection{Methods}

\subsubsection{Water activity and water content}

As mentioned previously, saturated salt solutions were used to equilibrate the cholinium-based ionic liquids at a well-defined water activity through vapour phase. Saturated salt solutions were prepared by mixing inorganic salts with distilled water. Specific amounts of the cholinium-based ionic liquids were placed in four desiccators, each one with a well-defined water activity [74], as it is listed in Table 2.2, in order to promote their contact with the vapour phase. A thermohygrometer (HMI41 indicator, Vaisala ${ }^{\circledR}$, Finland) was used in order to confirm the value of the relative humidity. The equilibrium was performed at 30 ${ }^{\circ} \mathrm{C}$ and the water content of the ionic liquid samples was measured, using a KarlFischer coulometer with diaphragm $\left(\right.$ Metrohm ${ }^{\circledR}$, model 831 KF coulometer).

\subsubsection{Viscosity measurements}

The viscosities of the different cholinium-based ionic liquids equilibrated at different water activity values were determined using a stress-controlled rheometer (Thermo Scientific HAAKE MARSIII., Germany) with a Peltier heating system, equipped with a cone and plate geometry (diameter $3.5 \mathrm{~cm}$, angle $2^{\circ}$ ). Flow curves were determined using a steady state flow ramp in the range of 
shear rate from 0 to $1000 \mathrm{~s}$, at $30{ }^{\circ} \mathrm{C}$. The sample area exposed to air was covered with paraffin oil in order to prevent water evaporation. The different samples have shown a Newtonian behaviour and their viscosity was evaluated as the slope of the line obtained representing the shear stress as a function of the shear rate.

\subsubsection{Density measurements}

The density of the cholinium-based ionic liquids at different water activities was measured using a 5-mL Gay-Lussac pycnometer, pear shape, with perforated stopper, at $30^{\circ} \mathrm{C}$. The precise volume of the pycnometer was determined using deionized water at the same temperature. The density of the cholinium-based ionic liquids was determined according the Equation 2.1, where $\rho_{I L}$ and $\rho_{\mathrm{H}_{2} \mathrm{O}}$ are the ionic liquid and water densities $\left(\mathrm{g} \cdot \mathrm{cm}^{-3}\right)$ at $30{ }^{\circ} \mathrm{C}$ and $m_{I L}$ and $m_{\mathrm{H}_{2} \mathrm{O}}$ are respectively the ionic liquid and water samples weights $(g)$.

$$
\rho_{I L}=\frac{m_{I L}}{m_{H_{2} \mathrm{O}}} \rho_{\mathrm{H}_{2} \mathrm{O}}
$$

\subsubsection{Gas solubility and diffusion coefficient experimental measurements}

Gas solubility and diffusion coefficient measurements were performed for the three cholinium-based ionic liquids, equilibrated at different water activities. The experiments were carried out by monitoring the evolution of the pressure decay with time, which was related with the absorption of the gas by the ionic liquids' thin film $[40,68]$.

Both gas solubility, characterised by the Henry's law constant, and diffusion coefficient in the cholinium-based ionic liquids were estimated by fitting the pressure decay over time to a one-dimensional diffusion model using a non-linear least-squares method. Several assumptions were considered: (i) only 
diffusive transport occurs in the system; (ii) equilibrium is established at the gas/liquid interface; (iii) gas concentration in the liquid phase boundary is described by Henry's Law and (iv) gas diffusion coefficients are independent of their concentration for the partial pressures tested $(0.7 \mathrm{bar})$. It was also considered that the ionic liquid properties such as viscosity and density are constant at given temperature $\left(30^{\circ} \mathrm{C}\right)$.

Combining the Fick's second law for the diffusion over the cholinium-based ionic liquids thin-liquid film, with a mass balance on the gas phase above the liquid, the pressure decay is related to the system parameters and gas properties according to the following equation $[68,69,75]$ :

$$
\ln \frac{P}{P_{0}}=\frac{k}{H_{\text {gas }}} \sum_{n=0}^{\infty} \frac{1}{(2 n+1)^{2}}\left\{\exp \left[-\frac{(2 n+1)^{2} \pi^{2} D_{\text {gas }} t}{4 L^{2}}\right]-1\right\}
$$

with $k=\frac{8 R T V_{I L} \rho_{I L}}{\pi^{2} V_{g a s} M W_{I L}}$, where $H_{\text {gas }}$ (bar) is the Henry's constant for the gas in the ionic liquid, $D_{\text {gas }}\left(\mathrm{cm}^{2} \cdot \mathrm{s}^{-1}\right)$ the gas diffusion coefficient, $L(\mathrm{~cm})$ is the ionic liquid film thickness, $V_{I L}\left(\mathrm{~cm}^{3}\right)$ and $V_{g a s}\left(\mathrm{~cm}^{3}\right)$ are the volumes of the ionic liquid and pure gas in the absorption compartment and in the gas compartment, respectively, $M W_{I L}\left(\mathrm{~g} \cdot \mathrm{mol}^{-1}\right)$ and $\rho_{I L}\left(\mathrm{~g} . \mathrm{cm}^{-3}\right)$ are the molecular weight and density of the ionic liquid, respectively.

Equation 2.2 was fitted to the experimental transient pressure results, by adjusting $H_{\text {gas }}$ and $D_{\text {gas }}$ using a nonlinear regression method with Matlab®. It is important to mention that Equation 2.2 describes extremely well the carbon dioxide transport in the cholinium-based ionic liquids. For this reason, the errors obtained through the fitting which are reported in this paper are quite low. The Henry's law constant is related with the solubility according to the Equation 2.3, where $S(\mathrm{~mol} / \mathrm{mol})$ is the gas solubility, $R\left(\mathrm{~cm}^{3} \cdot\right.$ bar. $\left.\mathrm{K}^{-1} \cdot \mathrm{mol}^{-1}\right)$ the gas constant and $T(\mathrm{~K})$ the temperature. 


$$
S=\frac{\rho}{M W \times H} \times R \times T
$$

These measurements were also performed for the cholinium-based ionic liquids containing carbonic anhydrase (concentration of $0.1 \mathrm{mgCA} / \mathrm{gIL}$ ).

\subsection{Results}

\subsubsection{Characterization of cholinium-based ionic liquids with defined water activities}

Experimental measurements to determine viscosity and density of the cholinium-based ionic liquids were performed, at $30{ }^{\circ} \mathrm{C}$. Figures 2.1 and 2.2 illustrate the viscosity and density values as a function of water activity for all ionic liquids, respectively. In Table 2.3, all results obtained for viscosity, density, molar volumes and water content for the different ionic liquid samples are listed. Molar volumes, obtained from the density values, were calculated according to Equation 2.4, where 1 and 2 correspond to the cholinium-based ionic liquid and water respectively, $x$ is the molar fraction, $M W\left(\mathrm{~g} \cdot \mathrm{mol}^{-1}\right)$ the molecular weight and $\rho\left(\mathrm{g} . \mathrm{cm}^{-3}\right)$ the cholinium-based ionic liquid density.

As expected, the viscosity of the cholinium-based ionic liquids decreases with the increase of water activity. This behaviour can be explained by the molecular interactions that water promotes in the ionic liquids. Generally, the viscosity of the cholinium-based ionic liquids with carboxylate anions is essentially defined by the hydrogen bonding that occurs between ion-pairs and water [76]. When comparing the viscosity of the ionic liquid samples with similar water content (see Table 2.3), hydrogen bonding is stronger established in [Cho][Hexanoate] because it possesses a higher viscosity value. The carboxylate anions chain size also appears to play a role in viscosity. According to the results obtained, a dependency with the size of the anions alkyl chain is clear. The viscosity of the cholinium-based ionic liquids follows the order: $[$ Cho $][$ Hexanoate $]>[$ Cho $][$ Propionate $]>[$ Cho $][$ Acetate $]$ which corresponds to 
the trend of the molar volume values.

$$
V_{m}\left(\mathrm{~cm}^{3} \cdot \mathrm{mol}^{-1}\right)=\frac{x_{1} M W_{1}+x_{2} M W_{2}}{\rho_{12}}
$$

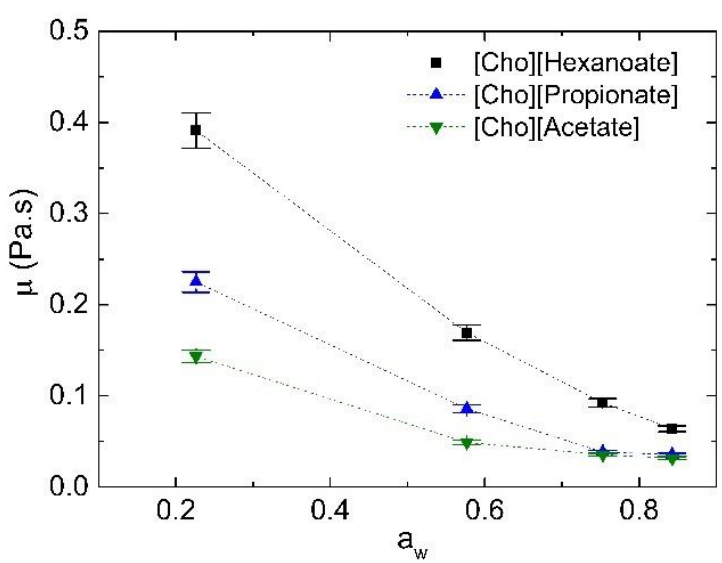

Figure 2.1 Water equilibrated cholinium-based ionic liquids viscosity as function of water activity, at $30^{\circ} \mathrm{C}$.

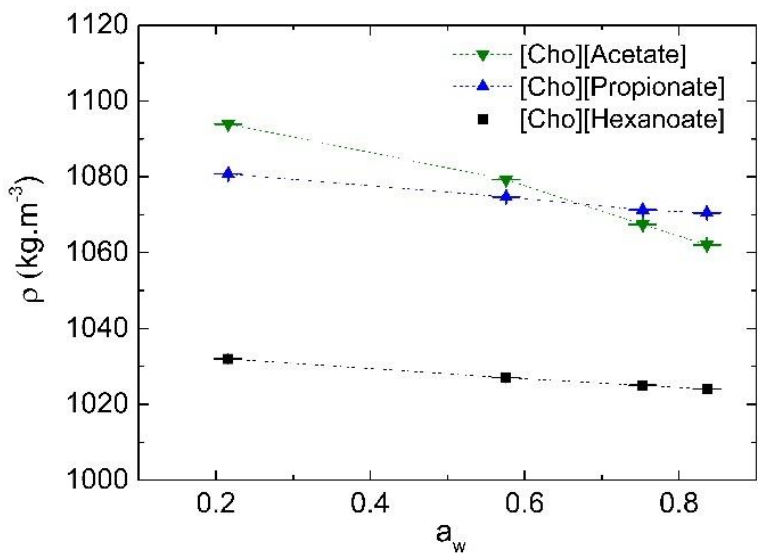

Figure 2.2 Water equilibrated cholinium-based ionic liquids density as a function of water activity, at $30^{\circ} \mathrm{C}$.

The densities of the cholinium-based ionic liquids, at $30^{\circ} \mathrm{C}$, are closer to that of water (Qwater $\left.=996 \mathrm{~kg} \cdot \mathrm{m}^{-3}\right)$ [77], when comparing with typical room-temperature ionic liquids (RTILs) [71,78,79]. From Figure 2.2 it is clear that [Cho][Hexanoate] is less dense than the other two ionic liquids. [Cho][Acetate] presents a higher density than [Cho][Propionate], until a certain water activity (aw $=0.753$ ). In general, the density values of the cholinium-based ionic liquids follow the trend 
described by other authors, where the increase of the alkyl chain length results in a decrease of the density [50,76,80]. The sharpest decrease, observed in Figure 2.2 at 0.753 water activity, for [Cho][Acetate] can be explained considering the hypothesis that the addition of water promotes, at a certain water content, different structural organizations of the alkyl chains [76].

Table 2.3 Viscosity, density, molar volumes and water content for the water equilibrated cholinium-based ionic liquids, at $30^{\circ} \mathrm{C}$.

\begin{tabular}{|c|c|c|c|c|c|}
\hline Ionic liquid & aw & $\begin{array}{c}\mu \\
\text { (Pa.s) }\end{array}$ & $\begin{array}{c}Q \\
\left(k^{-} \cdot m^{-3}\right)\end{array}$ & $\begin{array}{c}\mathrm{Vm} \\
\left(\mathrm{cm}^{3} \cdot \mathrm{mol}^{-1}\right)\end{array}$ & $\begin{array}{l}\text { Water } \\
\text { content } \\
(\% \mathrm{w} / w)\end{array}$ \\
\hline \multirow{4}{*}{ [Cho][Hexanoate] } & 0.216 & $0.390 \pm 0.020$ & $1032.23 \pm 0.02$ & 181.66 & $15.77 \pm 0.14$ \\
\hline & 0.576 & $0.169 \pm 0.008$ & $1026.92 \pm 0.01$ & 158.87 & $27.91 \pm 0.44$ \\
\hline & 0.753 & $0.092 \pm 0.005$ & $1024.97 \pm 0.03$ & 125.98 & $44.80 \pm 0.28$ \\
\hline & 0.836 & $0.064 \pm 0.003$ & $1023.72 \pm 0.01$ & 121.58 & $47.14 \pm 0.06$ \\
\hline \multirow{4}{*}{ [Cho][Propionate] } & 0.216 & $0.225 \pm 0.011$ & $1080.79 \pm 0.02$ & 141.45 & $15.31 \pm 0.45$ \\
\hline & 0.576 & $0.086 \pm 0.004$ & $1075.14 \pm 0.03$ & 118.99 & $31.02 \pm 0.54$ \\
\hline & 0.753 & $0.039 \pm 0.002$ & $1071.31 \pm 0.01$ & 112.53 & $35.63 \pm 0.69$ \\
\hline & 0.836 & $0.036 \pm 0.002$ & $1070.52 \pm 0.01$ & 97.89 & $45.51 \pm 0.93$ \\
\hline \multirow{4}{*}{ [Cho][Acetate] } & 0.216 & $0.143 \pm 0.007$ & $1093.96 \pm 0.01$ & 118.14 & $23.39 \pm 0.37$ \\
\hline & 0.576 & $0.049 \pm 0.002$ & $1079.29 \pm 0.02$ & 106.56 & $33.16 \pm 0.33$ \\
\hline & 0.753 & $0.035 \pm 0.002$ & $1067.45 \pm 0.01$ & 86.38 & $48.94 \pm 0.64$ \\
\hline & 0.836 & $0.032 \pm 0.002$ & $1062.10 \pm 0.02$ & 83.94 & $51.03 \pm 0.65$ \\
\hline
\end{tabular}

Molar volumes, obtained from the density values, decrease with the increase of water activity. For the values obtained, the variation between each 
sample is due to the change of water content and the presence of different anions, thus dictating different molar volumes for each cholinium-based ionic liquid. The hydrophilic character of these ionic liquids differs between each other. Because of that, for the same water activity, different water contents were obtained for each sample.

\subsubsection{Gas solubility and diffusion coefficients}

Both carbon dioxide solubility and diffusion coefficients in the cholinium-based ionic liquids were determined according to Equation 2.2 and 2.3. The experimental measurements were performed at $30{ }^{\circ} \mathrm{C}$ measuring the pressure decay over time. The ionic liquid samples were pre-equilibrated at a controlled water activity, at $30^{\circ} \mathrm{C}$, in order to evaluate the effect of water in $\mathrm{CO}_{2}$ solubility and diffusion. The results obtained are represented in Figures 2.3(a) and (b). Evaluation of the cholinium-based ionic liquids affinity towards $\mathrm{Xe}, \mathrm{O}_{2}$ and $\mathrm{N}_{2}$ was also performed in the same conditions as previously described for $\mathrm{CO}_{2}$. However, it was not observed any pressure decay over time (after 24h). For this reason, it is valid to assume that the cholinium-based ionic liquids possess no affinity for $\mathrm{Xe}, \mathrm{O}_{2}$ and $\mathrm{N}_{2}$. In the perspective of $\mathrm{CO}_{2}$ removal from gas streams with $\mathrm{Xe}, \mathrm{O}_{2}$ and $\mathrm{N}_{2}$ an extremely high selectivity towards $\mathrm{CO}_{2}$ is therefore expected.
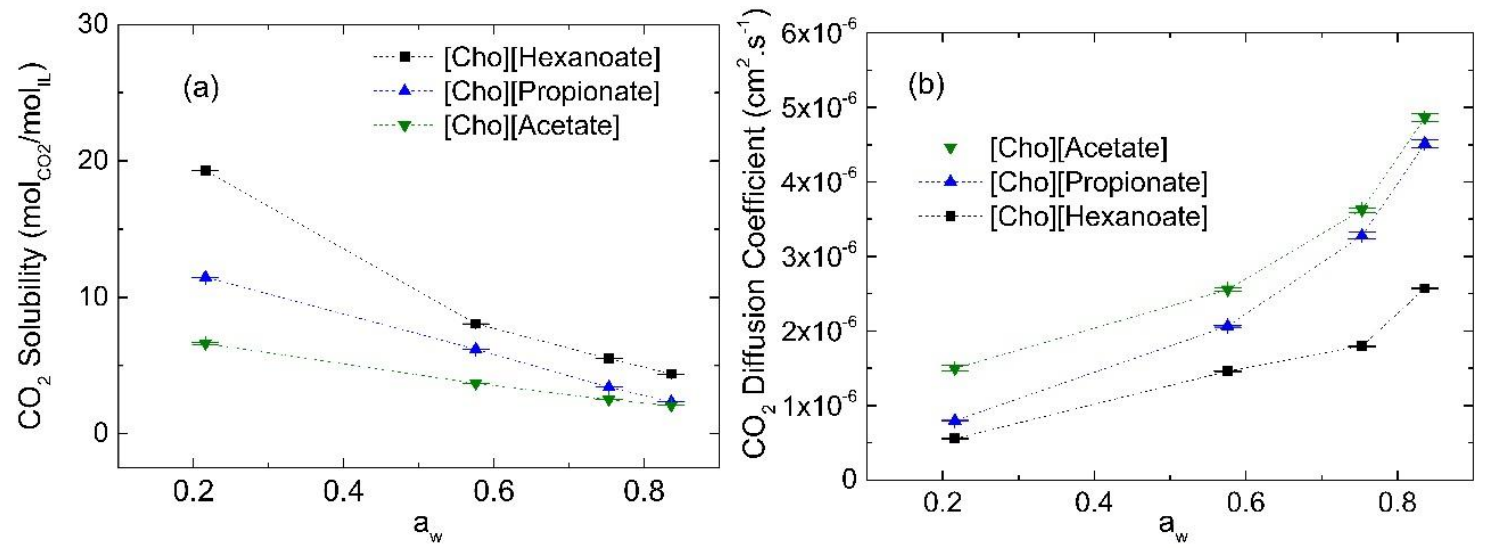

Figure 2.3 (a) Carbon dioxide solubility in cholinium-based ionic liquids as a function of water activity, at $30{ }^{\circ} \mathrm{C}$; (b) Carbon dioxide diffusion coefficient in cholinium-based ionic liquids as a function of water activity, at $30^{\circ} \mathrm{C}$. 
In Table 2.4 are expressed the values obtained, from Equation 2.2, for the Henry's constant for all ionic liquids. In a previous work [40] , a validation of the method to estimate solubility and diffusion coefficients was accomplished, where the values obtained for $\mathrm{CO}_{2}$ solubility in [BMIMTf$f_{2} \mathrm{~N}$ ] were in accordance with those reported in the literature. From observation of the results obtained the $\mathrm{CO}_{2}$ Henry's constant increases with the increase of water activity for each cholinium-based ionic liquid, which consequently implies that $\mathrm{CO}_{2}$ solubility decreases. This behaviour was expected because the ionic liquid ability to solubilise $\mathrm{CO}_{2}$ is diminished due to the weak affinity between water and $\mathrm{CO}_{2}$. Reported studies about $\mathrm{CO}_{2}$ removal with commercially available RTILs, are commonly performed with dried samples in order to avoid any water interference. Henry's constant for RTILs, obtained with identical method at 30 ${ }^{\circ} \mathrm{C}$, are between 22 - 68 bar for immidazolium ionic liquids [81]. For the cholinium-based ionic liquids used in this study, Henry's constant values are in the range between 7-144 bar, where the smallest value refers to [Cho][Hexanoate] at the lowest water activity value. These results are a good evidence of the high potential of these ionic liquids for carbon dioxide capture, since Henry's constant values are lower than the reported ones for dried RTILs were obtained.

Table 2.4 Carbon dioxide Henry's constant in the water equilibrated cholinium-based ionic liquids, at $30^{\circ} \mathrm{C}$.

\begin{tabular}{|c|c|c|c|c|}
\hline aw & 0.216 & 0.576 & 0.753 & 0.836 \\
\hline Ionic Liquid & & & I (bar) & \\
\hline [Cho][Hexanoate] & $7.19 \pm 0.01$ & $19.67 \pm 0.01$ & $36.36 \pm 0.03$ & $47.28 \pm 0.05$ \\
\hline [Cho][Propionate] & $15.52 \pm 0.01$ & $34.11 \pm 0.07$ & $65.59 \pm 0.11$ & $110.00 \pm 0.20$ \\
\hline [Cho][Acetate] & $22.23 \pm 0.31$ & $64.12 \pm 0.05$ & $116.70 \pm 0.22$ & $144.73 \pm 0.26$ \\
\hline
\end{tabular}


It is recognized that the anions alkyl chain size can influence positively the affinity of the ionic liquids towards $\mathrm{CO}_{2}$. This was previously described by other authors, stating that, solubility can be enhanced using anions with a strong basic nature $[37,51,53]$. Basic anions possess high capability to interact with $\mathrm{CO}_{2}$, because of the acidic nature of $\mathrm{CO}_{2}$ (Lewis acid). Acetate, propionate and hexanoate are anions derived from weak acids, which means that they possess strong basic character. For this reason, the results in Figure 2.3(a), show the highest solubility values for [Cho][Hexanoate], and the importance of the size of the alkyl chain of the anion is evidenced in this work. At the same water activity, $\mathrm{CO}_{2}$ affinity increases with the size of the anion alkyl chain according to the following order: [Cho][Acetate] $<$ [Cho][Propionate $]<[$ Cho][Hexanoate]. Despite the contribution of the anions alkyl chain size, it is recognized that gas solubility in bulk ionic liquids is also related to the IL molar volume [82]. In fact, the highest $\mathrm{CO}_{2}$ solubility values were obtained for [Cho][Hexanoate] which is the one with the highest molar volume value.

Figure 2.3(b) shows the dependence of $\mathrm{CO}_{2}$ diffusion coefficients with water activity for the three cholinium-based ionic liquids, at $30{ }^{\circ} \mathrm{C}$. As expected, $\mathrm{CO}_{2}$ diffusion increases with the increase of water activity. This behaviour is highly associated to the effect of water in the viscosity of the ILs (see Figure 2.1). The diffusion coefficients obtained are of the same order of typical RTILs reported in the literature $[68,69,71]$. [Cho][Acetate] possesses the highest $\mathrm{CO}_{2}$ diffusion coefficients for all range of water activity, comparing to [Cho][Propionate] and [Cho][Hexanoate]. This suggests that diffusion is facilitated when smaller anions are present. The diffusion of a gas is influenced by temperature, the molecular size of the gas and the viscosity of the ionic liquid [37]. Temperature and molecular size of the gas are constant parameters in this work, but viscosity is changing with water activity, as it was described in the previous section. For this reason, the difference in the obtained diffusion coefficients can also be attributed to the variation of the viscosity of the cholinium-based ionic liquids. Contrarily to the solubility dependence, diffusion coefficient decreases with the molar volume increase (see Table 2.3). This behaviour is highly associated with the free 
volume between the ionic framework of the solution; thus, if the molar volume is higher the volume available for diffusion is smaller [37].

\subsection{3 $\mathrm{CO}_{2}$ Diffusion coefficient correlation for cholinium-based ionic liquids}

Reported studies about diffusion coefficient correlations of gases in ionic liquids, show that gas diffusion $(D)$ is inversely proportional to the ionic liquid viscosity $(\mu)$, as represented by Equation 2.5. Depending on the experimental conditions, factor A considers the physical properties of the solute and solvent, such as molecular weight, molar volume, density, etc; temperature is also considered in the cases where a variation is measured. " $\mathrm{B}$ " named correlation power, is an indicator of how strongly dependent is the diffusion coefficient with the ionic liquid viscosity.

$$
D=A * \mu^{-B}
$$

For different ionic liquids families, the correlation power between diffusion coefficient and viscosity was found to have different values (see Table 2.5). Predictive models of gas diffusion in ionic liquids can be a powerful tool when attempting to develop new processes and applications. Though, there is a need for developing expressions for estimating gas diffusion coefficients in ionic liquids. Using an approach similar to other authors [67,69-72], an exclusively correlation between $\mathrm{CO}_{2}$ diffusion coefficient and viscosity for cholinium-based ionic liquids, with well-defined water activities, was developed.

Figure 2.4 represents a log-log plot of $\mathrm{CO}_{2}$ diffusion coefficient as a function of cholinium-based ionic liquids viscosity, at $30^{\circ} \mathrm{C} . \mathrm{CO}_{2}$ diffusion coefficient and ionic liquid viscosities were obtained experimentally according to the description in the previous sections. Also, the values of viscosities in the plot were obtained according to a specific water activity for each sample of cholinium ionic liquid. According to the results presented in Figure 2.4, the dependency of $\mathrm{CO}_{2}$ diffusion 
coefficient in the cholinium-based ionic liquids with viscosity is related to the power of -0.805 . With the value obtained, it is valid to affirm that in the case of cholinium-based ionic liquids, the carbon dioxide diffusion coefficient is stronger dependent on the viscosity than other commercially available RTILs, where lower absolute values of power factors were found.

Table 2.5 Viscosity correlation power of commercially available RTILs.

\begin{tabular}{ccc}
\hline Ionic liquids family & Correlation power & Reference \\
\hline Immidazolium & $-0.4,-0.66$ & {$[71],[70]$} \\
Phosphonium & -0.35 & {$[72]$} \\
Ammonium & -0.59 & \\
RTILs with $\left[\mathrm{Tf}_{2} \mathrm{~N}\right]^{-}$ & -0.6 & {$[67]$} \\
\hline
\end{tabular}

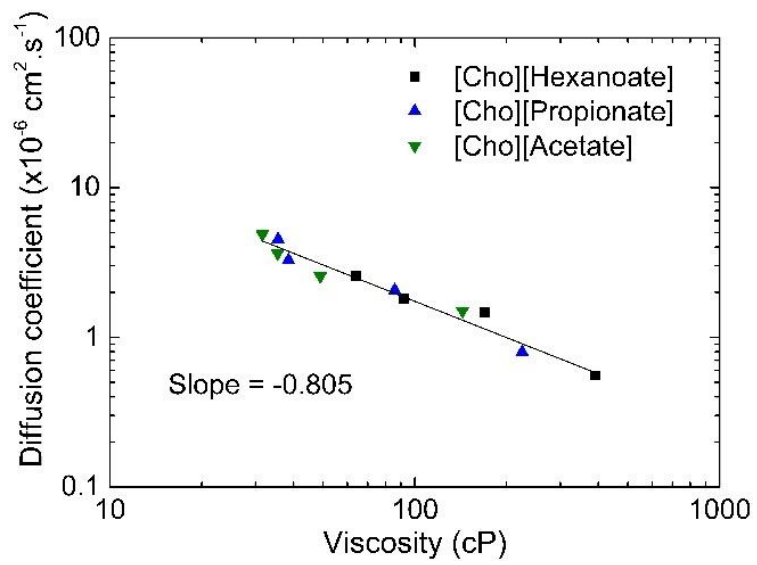

Figure 2.4 Log-log plot of carbon dioxide diffusion coefficient as function of cholinium-based ionic liquids viscosity. The coefficient of determination $\left(R^{2}\right)$ is 0.94 .

It is also recognized that gas diffusion in liquids, particularly in ionic liquids, does not depend exclusively on the viscosity of the liquid. In previously 
reported predictive correlations for ionic liquids other parameters were considered, such as, molecular weight, density and molar volumes [67,69-72]. In this study, these parameters were also considered in order to obtain the best predictive diffusion coefficient correlation. All diffusion coefficients in this work, were obtained from measurements exclusively with pure $\mathrm{CO}_{2}$. For this reason, gas properties were not considered in the correlation. Equation 2.6 was obtained using 12 diffusion coefficient values experimentally determined from the cholinium-based ionic liquids samples at different water activities, at $30{ }^{\circ} \mathrm{C}$. The viscosity $(\mu)$ of the ionic liquids considered in the correlation range from 32 to $391 \mathrm{cP}$, the ionic liquids molar volume $\left(V_{m L I}\right)$ and density $(\rho)$ from 84 to 182 $\mathrm{cm}^{3} \cdot \mathrm{mol}^{-1}$ and 1.024 to $1.094 \mathrm{~g} \cdot \mathrm{cm}^{-3}$, respectively. The power factors of the parameters and their deviation errors were obtained from a non-linear leastsquare minimization procedure with a global minimum target [83].

$$
D=6.569 \times 10^{-6} \frac{\mu^{-0.805 \pm 0.087} \times V_{m L I}^{0.508 \pm 0.009}}{\rho^{0.507 \pm 0.006}}
$$

Figure 2.5 shows a comparison between the diffusion coefficients measured and the predicted values through the correlation developed (Equation 2.6) for the cholinium-based ionic liquids in the present work. The deviation of predicted values in relation to the measured diffusion coefficient values is lower than $25 \%$. Hereupon, it is possible to predict the $\mathrm{CO}_{2}$ diffusion coefficients for the cholinium-based ionic liquids in the range of water activities considered.

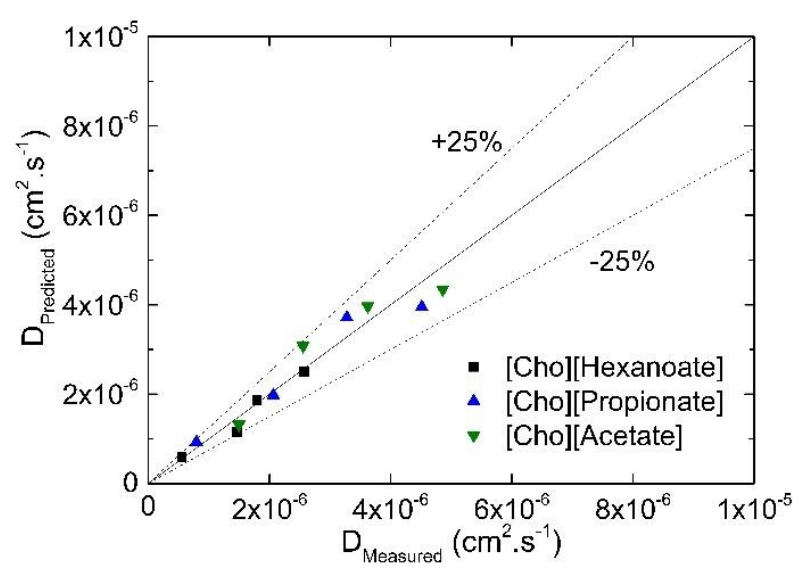

Figure 2.5 Comparison of carbon dioxide diffusion coefficient measured in cholinium-based ionic liquids, at $30^{\circ} \mathrm{C}$, with predictive values from the correlation proposed in this work. 


\subsubsection{Carbonic anhydrase: effect on carbon dioxide solubility and diffusion coefficient}

As previously mentioned, the present work also proposes the addition of an enzyme, carbonic anhydrase (CA), to the cholinium-based ionic liquids. In order to access the effect of the enzyme in the affinity of the ionic liquids towards $\mathrm{CO}_{2}$, solubility and diffusion coefficients were also determined for the choliniumbased ionic liquids with $0.1 \mathrm{mgCA} / \mathrm{gIL}$ at different water activity values.

The carbon dioxide Henry's constant obtained for the cholinium-based ionic liquids with $0.1 \mathrm{mgCA} / \mathrm{gIL}$, at $30{ }^{\circ} \mathrm{C}$ are represented in Table 2.6. Similarly to what was observed for the cholinium-based ionic liquids without $C A$, the Henry's constant values in the presence of CA are higher for higher values of water activity. The highest affinity towards $\mathrm{CO}_{2}$ was also obtained for [Cho][Hexanoate]. Comparing the results obtained for the cholinium-based ionic liquids with CA with the results for the ionic liquid samples without CA (see Tables 2.4 and 2.6), it is generally observed that the presence of the enzyme enhances the affinity towards $\mathrm{CO}_{2}$. However, there were punctual cases where that enhancement was not observed. Because cholinium-based ionic liquids are extremely hydrophilic, in the cases where no enhancement was observed, the amount of water present may have been insufficient for the solvation of the ionic liquid and of the enzyme, which impacts in its activity/stability. In those cases, the competition for water between the ionic liquid and the carbonic anhydrase, could take place. The highest $\mathrm{CO}_{2}$ affinity enhancement achieved, reflected on the Henry's constant was obtained for [Cho][Hexanoate] at the highest water activity, where a $\mathrm{H}_{\mathrm{CO} 2}$ decrease of $37 \%$ was found.

In Figure 2.6(a) it is represented a comparison between the carbon dioxide solubility values obtained using the cholinium-based ionic liquids samples and the samples with $0.1 \mathrm{mgCA} / \mathrm{gIL}$. As it can be observed, the highest $\mathrm{CO}_{2}$ solubility values were obtained for cholinium hexanoate samples, in all range of water activity considered. Moreover, the presence of the CA promotes a higher $\mathrm{CO}_{2}$ solubility enhancement in this ionic liquid. 
Table 2.6 Carbon dioxide Henry's constant for the cholinium-based ionic liquids with $0.1 \mathrm{mgCA} / \mathrm{gIL}$, at $30^{\circ} \mathrm{C}$.

\begin{tabular}{ccccc}
\hline aw & $\mathbf{0 . 2 1 6}$ & $\mathbf{0 . 5 7 6}$ & $\mathbf{0 . 7 5 3}$ & $\mathbf{0 . 8 3 6}$ \\
\hline Ionic Liquid & & \multicolumn{3}{c}{ H (bar) } \\
\hline [Cho][Hexanoate] & $7.17 \pm 0.01$ & $11.95 \pm 0.01$ & $22.50 \pm 0.01$ & $29.80 \pm 0.02$ \\
\hline Cho][Propionate] & $17.77 \pm 0.01$ & $51.21 \pm 0.07$ & $74.23 \pm 0.08$ & $96.95 \pm 0.16$ \\
& & & & \\
{$[$ Cho][Acetate] } & $33.20 \pm 0.03$ & $57.73 \pm 0.06$ & $131.31 \pm 0.17$ & $140.37 \pm 0.47$ \\
& & & & \\
\hline
\end{tabular}
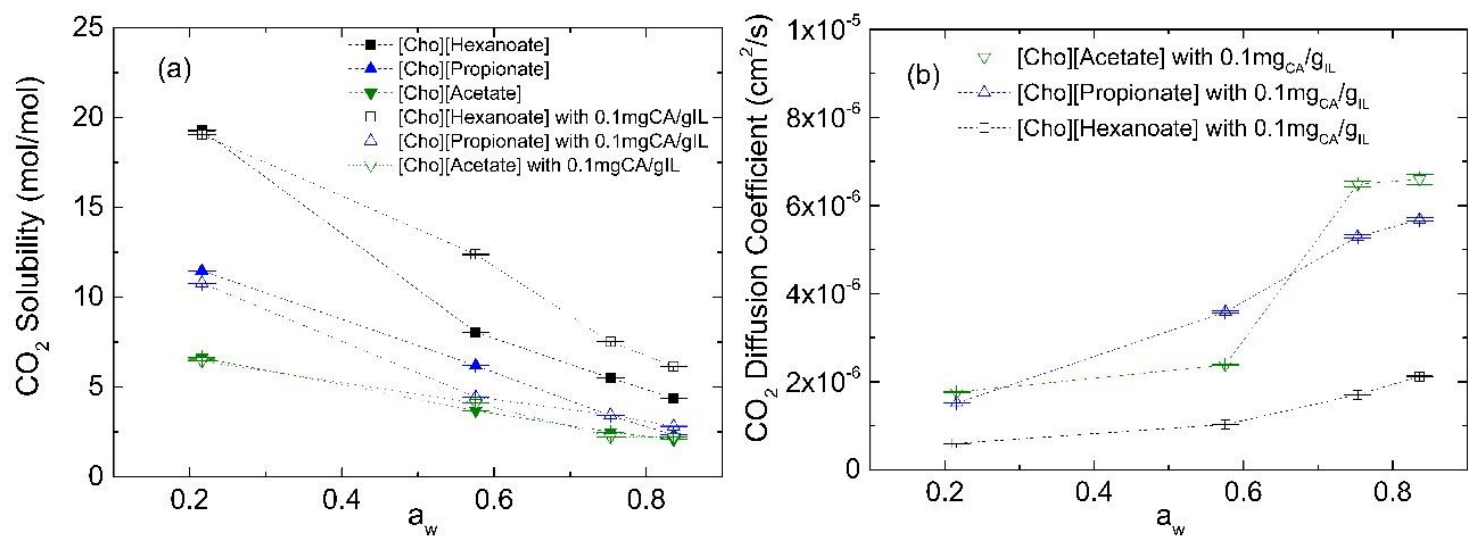

Figure 2.6 (a) Carbon dioxide solubility in cholinium-based ionic liquids with $0.1 \mathrm{mgCA} / \mathrm{gIL}$ and without $C A$ as a function of water activity, at $30^{\circ} \mathrm{C}$; (b) Carbon dioxide diffusion coefficient in cholinium-based ionic liquids with $0.1 \mathrm{mgCA} / \mathrm{gIL}$ as a function of water activity, at $30^{\circ} \mathrm{C}$.

In Figure 2.6(b) are represented the results for $\mathrm{CO}_{2}$ diffusion coefficients in the cholinium-based ionic liquids in the presence of CA. The determination method was similar to the one described in the previous section. The results obtained for the diffusion coefficients were not as consistent as the ones obtained for the cholinium-based ionic liquids without CA. Nevertheless, the diffusion coefficient increases with the increase of water activity as a result of the cholinium-based ionic liquids viscosity decrease. For [Cho][Acetate] with CA at 
$\mathrm{aw}=0.576$, the diffusion coefficient obtained was lower than the expected value. It is important to mention that, all samples were pre-equilibrated at a specific water activity after the addition of the enzyme. In this case, it is possible to consider that the water equilibrium is different from the pure samples, since the water affinity of the liquid system is altered due to the presence of CA. This fact is reflected on the amount of water incorporated in the cholinium-based ionic liquid samples with $\mathrm{CA}$, which consequently changes the viscosity and the diffusion coefficient. In general, the behaviour obtained for the $\mathrm{CO}_{2}$ diffusion is less pronounced at higher water activities, when comparing with the samples without the enzyme. Despite of this fact, higher $\mathrm{CO}_{2}$ diffusion coefficients were obtained, at higher values of water activity.

Aiming the application of these ionic liquids for the $\mathrm{CO}_{2}$ removal from gas mixture streams, it is extremely important to access the $\mathrm{CO}_{2}$ permeability in the cholinium-based ionic liquids. In this perspective, Figure 2.7 represents the $\mathrm{CO}_{2}$ ideal permeability $(P=S x D)$ for all samples of cholinium-based ionic liquids, without and with $0.1 \mathrm{mgCA} / \mathrm{gIL}$, at $30^{\circ} \mathrm{C}$.

The results obtained for $\mathrm{CO}_{2}$ permeability in the cholinium-based ionic liquids, without and with $\mathrm{CA}$, at $30^{\circ} \mathrm{C}$, ranging from $9.06 \times 10^{-6}$ to $1.82 \times 10^{-5} \mathrm{~cm}^{2} . \mathrm{s}^{-}$ 1 , are higher than the results reported for typical RTILs at lower water activities [67]. For example, Condemarin et al. [67] reported a permeability study with different gases in several RTILs based on ammonium, phosphonium and immidazolium cations, where the highest permeability achieved for $\mathrm{CO}_{2}$ at $30{ }^{\circ} \mathrm{C}$ was $7.8 \times 10^{-6} \mathrm{~cm}^{2} . \mathrm{s}^{-1}$, obtained for $\left[\mathrm{N}_{\left.(6) 111^{+}\right]}\left[\mathrm{Tf}_{2} \mathrm{~N}^{-}\right]\right.$. Although $\mathrm{CO}_{2}$ diffusion coefficients obtained in this work for the cholinium-based ionic liquids are similar to the ones reported for typical RTILs, the $\mathrm{CO}_{2}$ solubilities obtained are much higher and this is the reason why these ionic liquids possess higher $\mathrm{CO}_{2}$ permeabilities in comparison to typical RTILs.

Since diffusion increases with water activity increase and solubility decreases (see Figures 2.3(a), 2.3(b), 2.6(a) and 2.6(b)), there are cases were the decrease of solubility suppresses the effect of the diffusion increase, resulting on 
such variation in the $\mathrm{CO}_{2}$ permeability values. For this reason, the behaviour for $\mathrm{CO}_{2}$ permeability does not follow strictly the tendency of water activity increase. In addition, the error values obtained by error propagation are two orders of magnitude lower than the absolute values obtained for $\mathrm{CO}_{2}$ permeabilities.
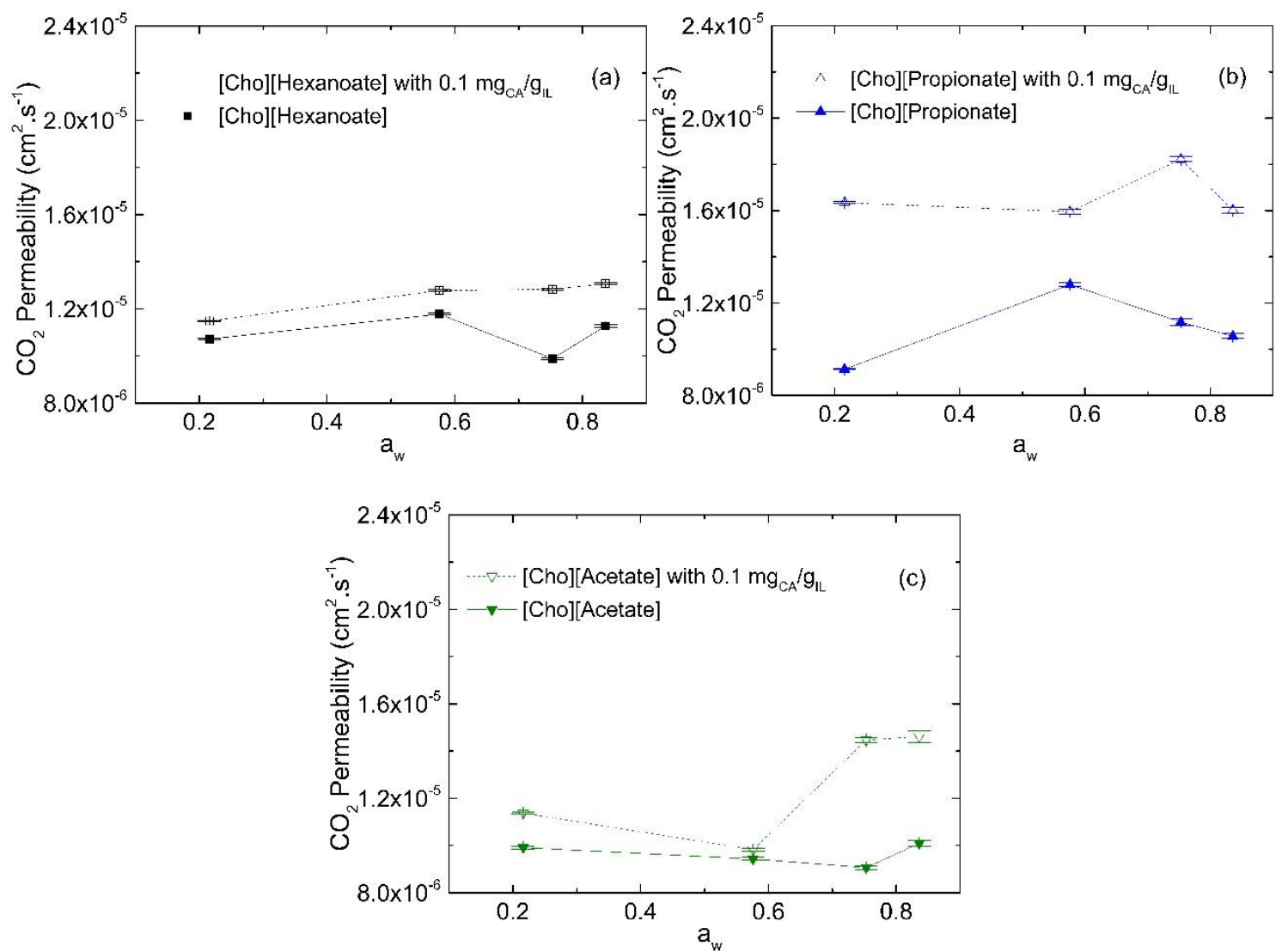

Figure 2.7 Carbon dioxide permeability in the cholinium-based ionic liquids, without and with $0.1 \mathrm{mgCA} / \mathrm{gIL}$ as function of water activity, at $30^{\circ} \mathrm{C}$. (a) Cholinium Hexanoate, (b) Cholinium Propionate and (c) Cholinium Acetate.

Regarding the effect of the enzyme, CA promotes a permeability enhancement in all cholinium-based ionic liquids for all water activities, meaning that the approach proposed in this work to enhance $\mathrm{CO}_{2}$ affinity towards cholinium-based ionic liquids using CA was well succeeded. The highest enhancement obtained (63\%) was observed for [Cho][Propionate] at a water activity of 0.753 . The results obtained, suggest that between all cholinium-based 
ionic liquids studied in this work, [Cho][Propionate] is the one that possess the highest potential for $\mathrm{CO}_{2}$ transport and removal. On-going studies of gas permeability using supported ionic liquid membranes are being performed, as well as, selective capture of carbon dioxide from gas mixtures streams.

\subsection{Conclusions}

Carbon dioxide solubility and diffusion coefficients were determined for cholinium hexanoate, cholinium propionate and cholinium acetate, as well as density and viscosity measurements, in order to access these parameters' behaviour as a function of water activity. A carbon dioxide diffusion coefficient correlation was achieved, allowing a good prediction of the diffusion coefficient in all range of water activities considered in the present work. It was shown that the dependency of $\mathrm{CO}_{2}$ diffusion coefficient with the viscosity in choliniumbased ionic liquids is correlated to a power of -0.805 , implying that its dependency is stronger than in other commercially available RTILs. In addition, carbon dioxide solubility and diffusion coefficients were also determined for the cholinium-based ionic liquids in the presence of carbonic anhydrase.

The ideal permeability results obtained suggest that cholinium propionate is the ionic liquid that possesses the highest potential for $\mathrm{CO}_{2}$ transport and removal, despite the fact that the highest values of solubility were obtained for cholinium hexanoate. The presence of carbonic anhydrase $(0.1 \mathrm{mgCA} / \mathrm{gIL})$, allows achieving a carbon dioxide transport enhancement for all water activities, with a maximum of $63 \%$ increase, for cholinium propionate at aw $=0.753$.

It was demonstrated that cholinium-based ionic liquids are potentially good alternatives for $\mathrm{CO}_{2}$ absorption and that it is possible to enhance their ability to transport $\mathrm{CO}_{2}$ using a biocatalytic reaction with carbonic anhydrase. In order to achieve an improved transport, higher concentrations of carbonic anhydrase should be considered in further studies. 


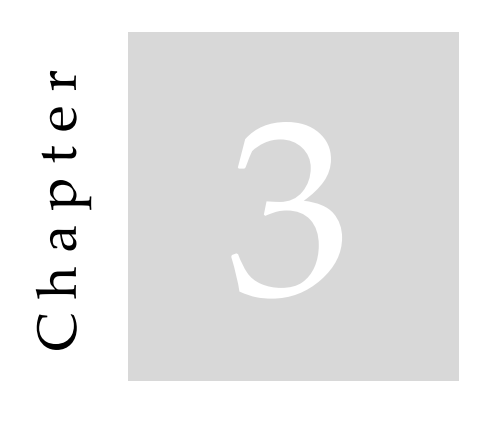

\section{Microfluidic Devices as Gas - Ionic Liquid Membrane Contactors for $\mathrm{CO}_{2}$ Removal from Anaesthesia Gases}

Published as: M. Malankowska, C.F. Martins, H.S. Rho, L.A. Neves, R.M. Tiggelaar, J.G. Crespo, M.P. Pina, R. Mallada, H. Gardeniers, I.M. Coelhoso, “Microfluidic Devices as Gas - Ionic Liquid Membrane Contactors for $\mathrm{CO}_{2}$ Removal from Anaesthesia Gases", Journal of Membrane Science, 2018, vol. 545, pp: 107-115.

The author was involved in the ionic liquid preparation, assembling the set-up and executing the gas permeation experiments, and data elaboration.

\section{Summary}

This work proposes a microfluidic gas - ionic liquid contactor for $\mathrm{CO}_{2}$ removal from anaesthesia gas, containing Xe. The working principle involves the transport of $\mathrm{CO}_{2}$ through a polymer flat membrane followed by its capture and enzymatic bioconversion in the ionic liquid solvent. Microfluidic devices enable a rapid and inexpensive screening of potential $\mathrm{CO}_{2}$ absorbers. The alveolar - type design of the ionic liquid chamber was adopted to reduce mass transfer limitations of $\mathrm{CO}_{2}$ through the liquid phase. Polydimethylsiloxane (PDMS) was 
the chosen polymer for dense membrane, as well as for the microfluidic device fabrication, mainly due to the high permeability of gases, $\mathrm{O}_{2}$ and $\mathrm{CO}_{2}$, and low cost. The selected ionic liquid was cholinium propionate $(\mathrm{CP})$ with a water activity of 0.753 , due to its high affinity towards $\mathrm{CO}_{2}$ and biocompatibility with the enzyme used for $\mathrm{CO}_{2}$ conversion to bicarbonate, carbonic anhydrase (CA).

The $\mathrm{CO}_{2}$ and Xe permeability and $\mathrm{CO}_{2} /$ Xe selectivity were determined in the microfluidic devices developed and compared to those exhibited by free standing PDMS membranes mounted on a standard permeation cell. The performance of the microfluidic devices as gas - ionic liquid contactors was evaluated for a given solvent flow rate with pure gas streams of $\mathrm{CO}_{2}$ and $\mathrm{Xe}$. The obtained results show that cholinium propionate with or without the enzyme has no effect on the Xe transport, but remarkably enhances the affinity towards carbon dioxide leading to enhancement factor up to 1.9 in the presence of $0.1 \mathrm{mg}$ CA/gIL.

\subsection{Introduction}

The most commonly used anaesthetic gas for surgical operations is nitrous oxide $\left(\mathrm{N}_{2} \mathrm{O}\right)$. The mixture of nitrous oxide and volatile anaesthetic compounds, mainly isoflurane, desflurane and sevoflurane, is introduced to the closed breathing system [6]. The main problem with such mixture is the risk of hypoxia. Hypoxia caused by the excessive amount of $\mathrm{N}_{2} \mathrm{O}$, also called a 'third gas effect', influences the partial pressure of $\mathrm{O}_{2}$ within the alveolar channels. When high quantity of nitrous oxide is present in the alveoli, $\mathrm{O}_{2}$ and $\mathrm{CO}_{2}$ are diluted by this gas which leads to the decrease of their respective partial pressures resulting in insufficient blood oxygenation [84].

An alternative approach in order to replace nitrous oxide is to use $\mathrm{Xe}$ as an anaesthetic gas. The anaesthetic properties of Xe were discovered, analysed and described in the early 1950s [18]. Xe possesses a number of characteristics that make it a perfect anaesthetic compound. It is hemodynamically stable, which results in lack of cardiac depression, it produces high regional blood flow and it 
possesses low solubility in liquids, greatly reducing the risk of hypoxia [84]. Xe is particularly attractive for the neonates as it attenuates isoflurane neurotoxicity [85]. Moreover, Xe is non - flammable, non - toxic, and does not contribute to the depletion of the ozone layer $[84,86]$ compared to $\mathrm{N}_{2} \mathrm{O}$; however, it is far more expensive (1 litre of produced liquid Xe consumes $792 \mathrm{~kJ}$ which costs approximately $1000 \$$, that is 100 times more than the price of $\mathrm{N}_{2} \mathrm{O}$ ) [86]. Hence, recycling of Xe from the anaesthesia exhaled gas rather than wasting it to the atmosphere is the only way to ensure economic and efficient Xe use.

The gas mixture exhaled from the patient during the surgical operation, where $\mathrm{Xe}$ is used as an anaesthetic gas, consists mainly of $\mathrm{Xe}(\approx 65 \%), \mathrm{O}_{2}(\approx 27 \%)$, $\mathrm{N}_{2}(\approx 3.3 \%)$ and $\mathrm{CO}_{2}(5 \%)$ [6]. The conventional method of removing $\mathrm{CO}_{2}$ from the exhaled gas mixture in a closed - circuit technology relies on the use of soda lime that is composed of: calcium hydroxide, water, sodium hydroxide and potassium hydroxide. In this system the removal of $\mathrm{CO}_{2}$ is limited by the size of the $\mathrm{CO}_{2}$ absorber canister [85]. Apart from this, the process is relatively efficient and commonly used, but it suffers from a number of problems. The soda lime, if allowed to dry up, can produce hydrogen and heat resulting in an explosion hazard; or can react with volatile anaesthetic compounds producing toxic side products (e.g. fluoromethyl-1-2,2-difluoro-a-(trifluoromethyl) vinyl ether [87] or carbon monoxide [6]) in the gas circuit. Therefore, several attempts, with alternative methods, are being investigated for the on - line removal of $\mathrm{CO}_{2}$ from anaesthetic closed circuits down to $0.5 \%$. Mendes et al. proposed the use of a membrane contactor technology with commercial carbon molecular sieve membranes (CMSM) in the form of hollow fibres [88] or flat sheets [6], and diamine as $\mathrm{CO}_{2}$ absorber. High permeation and ideal selectivities for $\mathrm{CO}_{2} / \mathrm{Xe}$ and $\mathrm{N}_{2} / \mathrm{Xe}$ were obtained in the case of single gas experiments. On the other hand, multicomponent performance was adversely affected by $\mathrm{Xe}$, that possesses a kinetic diameter of $4.04 \AA$, which is able to block the pores close to the CMSM surface (with diameters in the range of 3-5 $\AA$ ) resulting in the reduction of the free pore space and limitation of the diffusion of other species. Hollow-fibre based non-volatile liquid membranes have been also successfully applied for $\mathrm{CO}_{2}$ 
removal from $\mathrm{N}_{2} \mathrm{O}$ anaesthesia mixtures containing halogenated hydrocarbons [3].

Recently, Yong et al. have described the use of a hollow fibre membrane-based gas-liquid contactor for $\mathrm{CO}_{2}$ capture using potassium carbonate as a solvent [89]. The authors propose the coating of the membrane surface, non-porous PDMS-PS or porous $\mathrm{PP}$, with carbonic anhydrase (CA) enzyme by LbL technique to: i) increase mass transfer rates due to the reduction in pore wetting by the adsorbed polyelectrolytes; ii) to promote the $\mathrm{CO}_{2}$ absorption kinetics into $\mathrm{K}_{2} \mathrm{CO}_{3}$. However, a slight loss in enzyme activity due to immobilization is observed even during the short term kinetic studies.

Additionally to all the trials focused on the membrane type, material and morphology, it was discovered that some ionic liquids possess high affinity towards $\mathrm{CO}_{2}$ and the addition of carbonic anhydrase increases this property remarkably $[40,90]$. CA is a naturally occurring thermoresistant metalloenzyme that works as a catalyst for the reversible conversion of $\mathrm{CO}_{2}$ into bicarbonate $\left(\mathrm{HCO}_{3}{ }^{-}\right)$at extremely high turnover rates. It regulates important biological processes within humans and other living organisms. This catalytic activity has been exploited for promoting the absorption of $\mathrm{CO}_{2}$ from $\mathrm{N}_{2}$ containing gas streams $[40,60,91]$. Neves et al. [40] described the use of supported liquid membranes for the integrated $\mathrm{CO}_{2}$ capture and enzymatic bioconversion. A commercial hydrophobic porous membrane made of polyvinylidene fluoride (PVDF) was used as a support for the immobilization of $\mathrm{CO}_{2}$ absorbing solvents, i.e. polyethylene glycol (PEG) 300 and 1-butyl-3-methylimidazolium bis(trifluoromethanesulfonyl) imide ionic liquid. The $\mathrm{CO}_{2}$ solubility increased between $20 \%$ and $30 \%$, even at low enzyme concentration $(0.01 \% \mathrm{w} / \mathrm{w})$ due to the chemical reaction enhancement factor [40].

In the last decade, biodegradable, biocompatible and environmental-friendly ILs that are synthesized by naturally-derived materials such as sugars and amino acids are gaining increasing importance. This novel class of ILs may provide an optimum media to stabilize proteins (i.e. enzyme) [45] which is of our interest for 
the increase in $\mathrm{CO}_{2}$ capturing effect. Cholinium cations are quaternary ammonium cations ([N,N,N - trimethylethanolammonium $\left.]^{+}\right)$fully derived from natural products $[47,90]$. It was shown that the cholinium cations combined with a range of alkanoate anions or amino acids provide a media where living cells can actively grow $[38,48]$. Moreover, they show high $\mathrm{CO}_{2}$ capturing effect by absorption plus chemical reaction that take place due to their ammonium cations [49]. When compared to the commonly used ionic liquids for $\mathrm{CO}_{2}$ capture [92], the $\mathrm{CO}_{2}$ solubility values are lower, i.e. $0.209 \mathrm{~mol} / \mathrm{mol}$ for 1-ethyl-3methylimidazolium bis(trifluoromethylsulfonyl)imide compared to 0.152 $\mathrm{mol} / \mathrm{mol}$ for cholinium propionate at 10 bar and $303 \mathrm{~K}$. Nevertheless, cholinium based ILs show high biocompatibility and provide an environment where CA is active.

Martins et al. [90] evaluated the $\mathrm{CO}_{2}$ solubility and diffusivity values in cholinium based ionic liquids as a function of water activity content and in the presence of $\mathrm{CA}(0.01 \% \mathrm{w} / \mathrm{w})$. The highest $\mathrm{CO}_{2}$ solubility was obtained at the lowest water activity due to the lower solubility of $\mathrm{CO}_{2}$ in an ionic liquid with higher water content. However, in case of the ionic liquid combined with the enzyme, the highest enhancement in $\mathrm{CO}_{2}$ solubility was obtained with the largest aw because, under these conditions, the required water is available to assure the enzyme activity. As a result, the optimal water activity value was identified to be 0.753. Among the tested ILs, cholinium propionate (CP) exhibited the highest potential for $\mathrm{CO}_{2}$ capture with a maximum transport enhancement of $63 \%$ in the presence of CA [90].

The present work pursues the proof of concept validation of a PDMS based microfluidic device as a gas - liquid contactor, with cholinium propionate and $\mathrm{CA}$ as a liquid phase, for the removal of $\mathrm{CO}_{2}$ from Xe anaesthetic gas. A priori, the high gas permeability values of dense free standing PDMS membranes could allow to fully exploit the advantageous effect of the $\mathrm{CO}_{2}$ enzymatic reaction in the liquid phase. In addition, due to miniaturization, the volume of ionic liquid required to fill the micro - chamber and the amount of CA are notably reduced while providing high throughput for the preliminary screening of different ionic 
liquid-enzyme formulations at several working conditions. Furthermore, this approach could be of interest for Xe recovery systems that require low capacity as is the case of recirculating machines for neonates. Moreover, the general advantages of PDMS microfluidic devices in terms of fabrication (simplicity and cost), weight, size, easy integration and scaling up by replication and stacking by $\mathrm{O}_{2}$ plasma are also worthy to mention. The microdevice consists of two independent chambers (one dedicated to the liquid phase and the second one devoted to the gas phase) and a non-porous flat PDMS membrane in between. The gas, $\mathrm{CO}_{2}$ or $\mathrm{Xe}$, is introduced in one of the chambers, permeates through the membrane and dissolves in the ionic liquid on the other compartment. An alveolar design has been mainly adopted for the liquid chamber to ensure that mass transfer of $\mathrm{CO}_{2}$ through the liquid phase, in order to reach the CA active reaction sites, does not become rate controlling. As in previous works, enhanced $\mathrm{CO}_{2}$ transport is expected due to the high solubility of $\mathrm{CO}_{2}$ in cholinium propionate assisted by the enzymatic $\mathrm{CO}_{2}$ conversion, both leading to greater driving force. In order to confirm such hypothesis the following tasks were performed: 1 - design and fabrication of a polymeric membrane and a microfluidic device with different geometries depending on the chamber purpose (liquid or gas); 2 - characterisation of the fabricated chip in terms of leaks, membrane detachment and maximum tolerable pressure for its validation as G-L contactor; 3 - determination of the single gas permeability values of free standing membrane; and, 4 - evaluation of the G-L microcontactor performance for $\mathrm{CO}_{2}$ capture due to the presence of $\mathrm{CP}$ solvent flowing in the liquid chamber and the use of $\mathrm{CA}$ to accelerate $\mathrm{CO}_{2}$ transport.

\subsection{Materials and Methods}

\subsubsection{Materials}

\subsubsection{Ionic liquid tested}

Cholinium propionate (CP) was used in the $\mathrm{CO}_{2} / \mathrm{Xe}$ separation procedure. The ionic liquid was prepared by neutralization of propionic acid (purchased from 
Sigma-Aldrich, USA) in choline hydroxide. The resulting ionic liquid (IL) was equilibrated into a specific water activity, i.e. 0.753 , with a sodium chloride salt (Applichem, Panreac, Germany). The water content corresponding to a given water activity was measured with a Karl-Fisher coulometer (Metrohm, model 831 KF coulometer).

\subsubsection{Carbonic anhydrase enzyme}

Carbonic anhydrase (CA) lyophilized from bovine erythrocytes (ref: C3934, Sigma-Aldrich, USA), was used in this work without any further purification. 0.1 $\mathrm{mg}$ of the enzyme was added to $1 \mathrm{~g}$ of ionic liquid, and the resulting mixture was placed on the mixing plate till complete dissolution.

\subsubsection{Ionic liquid and enzyme preparation}

Taking into account that $\mathrm{CO}_{2}$ is a Lewis acid, the absorbents which are chemically reactive with $\mathrm{CO}_{2}$ are usually bases [49]. Thus, cholinium - based ionic liquids show high $\mathrm{CO}_{2}$ capturing effect due to their ammonium cations. One of the parameters affecting the performance of the ionic liquids is their water activity $\left(a_{w}\right)$. Henry's constant, which is the inverse of gas solubility, increases with the increase of $\mathrm{a}_{\mathrm{w}}$. The water activity selected for the permeation experiments was equal to 0.753 based on the results obtained by Martins et al. [90]. Table 3.1 shows the parameters of the ionic liquid and the enzyme selected for this work. The enzymatic activity of $\mathrm{CA}$ is derived from a $\mathrm{Zn}^{2+}$ ion that is coordinated to three histidine residues near the centre of the molecule in a cone-shaped cavity.

\subsubsection{Gases}

The gases used in the experiments were xenon, Xe (purity grade 99.999\%, Praxair, USA), carbon dioxide, $\mathrm{CO}_{2}$ (high-purity grade $99.998 \%$ Praxair, USA) and oxygen, $\mathrm{O}_{2}$ (purity grade $99.999 \%$, Praxair, USA). 
Table 3.1 Parameters of the liquid phase used for $\mathrm{CO}_{2}$ capturing experiments.

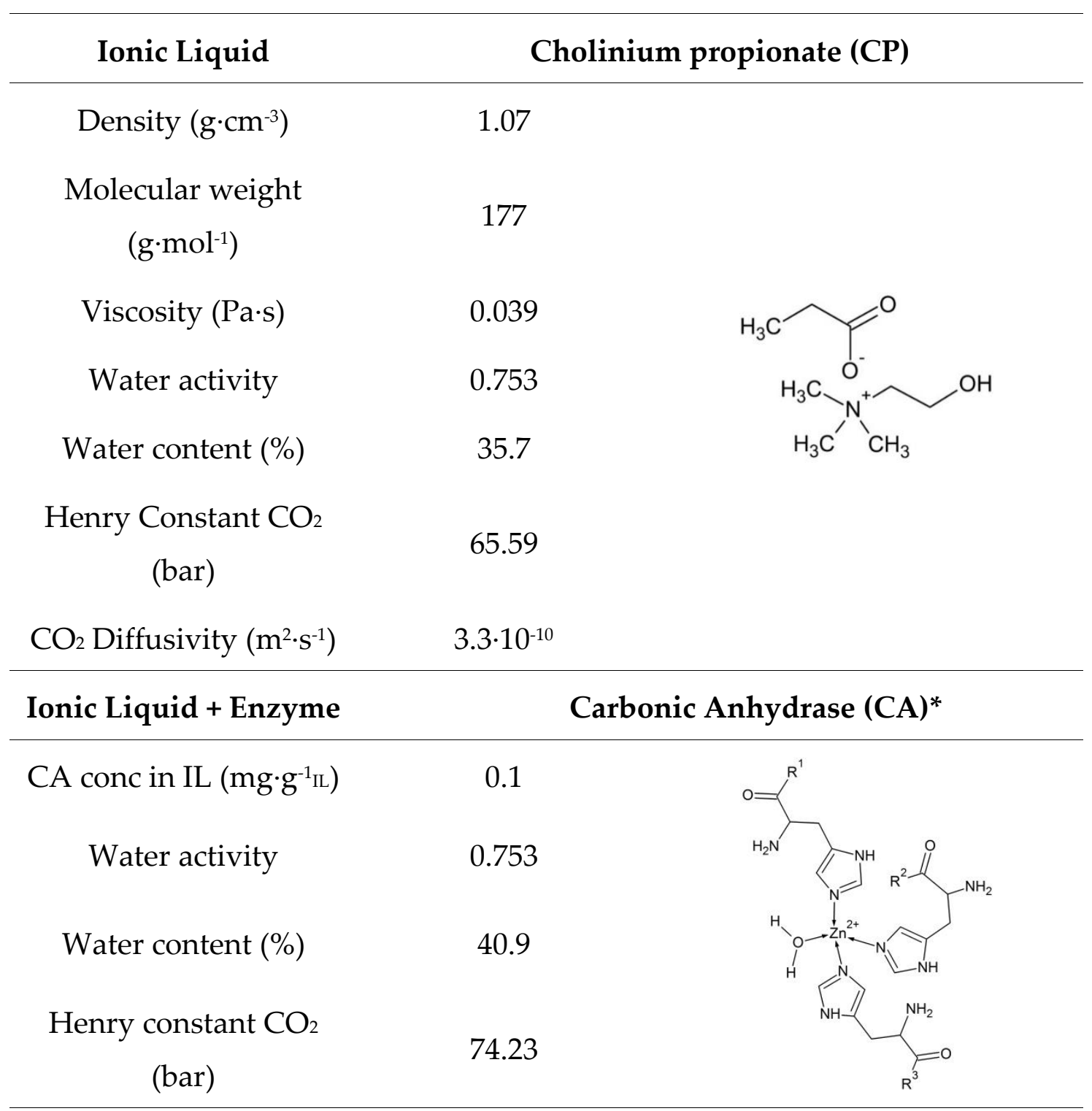

*The depicted chemical structure only corresponds to the central part of the molecule

\subsubsection{Methods}

\subsubsection{Design and fabrication of the PDMS chip}

The microfluidic device used in this work was entirely made of Polydimethylsiloxane (PDMS; Sylgard 184 Dow Corning, Midland, MI). PDMS was used due to its optical transparency, biocompatibility and mechanical properties which mean that it can be easily released from moulds and it conforms to surfaces. It consisted of two chambers, where one was dedicated to gas and 
the other to ionic liquid ( $\mathrm{CO}_{2}$ solvent). Both compartments were separated by a dense membrane (approximately $60 \mu \mathrm{m}$ thick) made of the same material. The gas chamber, in the form of an empty reservoir, possessed a number of supporting pillars in order to reduce the risk of membrane and chip collapse. Liquid channels were arranged in a branching-like-architecture, including flow distributors, so the ionic liquid could circulate in a homogenous flow regime to reduce dead volume (see Appendix B, Figure S1) and to avoid high pressure drop across the structure when dealing with high viscous fluids. Computer modelling in COMSOL Multiphysics 5.0 was done to calculate the pressure exerted on the walls of the liquid chamber for the $\mathrm{CP}$ ionic liquid at a liquid flow rate of 0.01 $\mathrm{mL} \cdot \mathrm{min}^{-1}$. The estimated $\Delta \mathrm{P}$ in the liquid chamber was equal to $0.14 \mathrm{mbar}$. Thus, the branching-like architecture allows to work with high viscous ionic liquids without the risk of pressure build up, channel blockage and chip collapse; unless fabrication defects or inadequate chip punching lead to obstructed channels. The depth of the liquid channel, i.e. $100 \mu \mathrm{m}$, also aimed to minimise mass transfer limitations in the permeate side.

The liquid as well as gas channel moulds were fabricated using a fabrication procedure reported previously by several authors [93-97] (See Appendix B, Figure S2). Briefly, the masters were prepared by standard photolithography to create a pattern in SU-8 photoresist (SU-8 50 DE MicroChem) deposited on a flat silicon substrate (Figure 3.1 A-B). SU-8 is a commonly used epoxy-based negative photoresist, which is a light sensitive material, that is used to form a patterned coating usually on a silicon wafer surface. Next, PDMS pre-polymer and curing agent were thoroughly mixed in a ratio 10:1 and placed in the vacuum chamber for degassing. PDMS was poured on the masters and placed in the oven for $45 \mathrm{~min}$ at $80{ }^{\circ} \mathrm{C}$ (Figure $3.1 \mathrm{C}$ ). The moulds were peeled off from the silicon wafer, cut to the required size and punched for inlet and outlet by a round punch (TiN Coated Round Punch, Syneo). Fabricated chambers were immersed in the solution of isopropanol (Sigma Aldrich) and placed in the ultrasound bath for approximately $2 \mathrm{~min}$ in 
order to remove any possible dust that could be attached to the inside of the channels or PDMS debris inside the punched holes prior any further procedure.

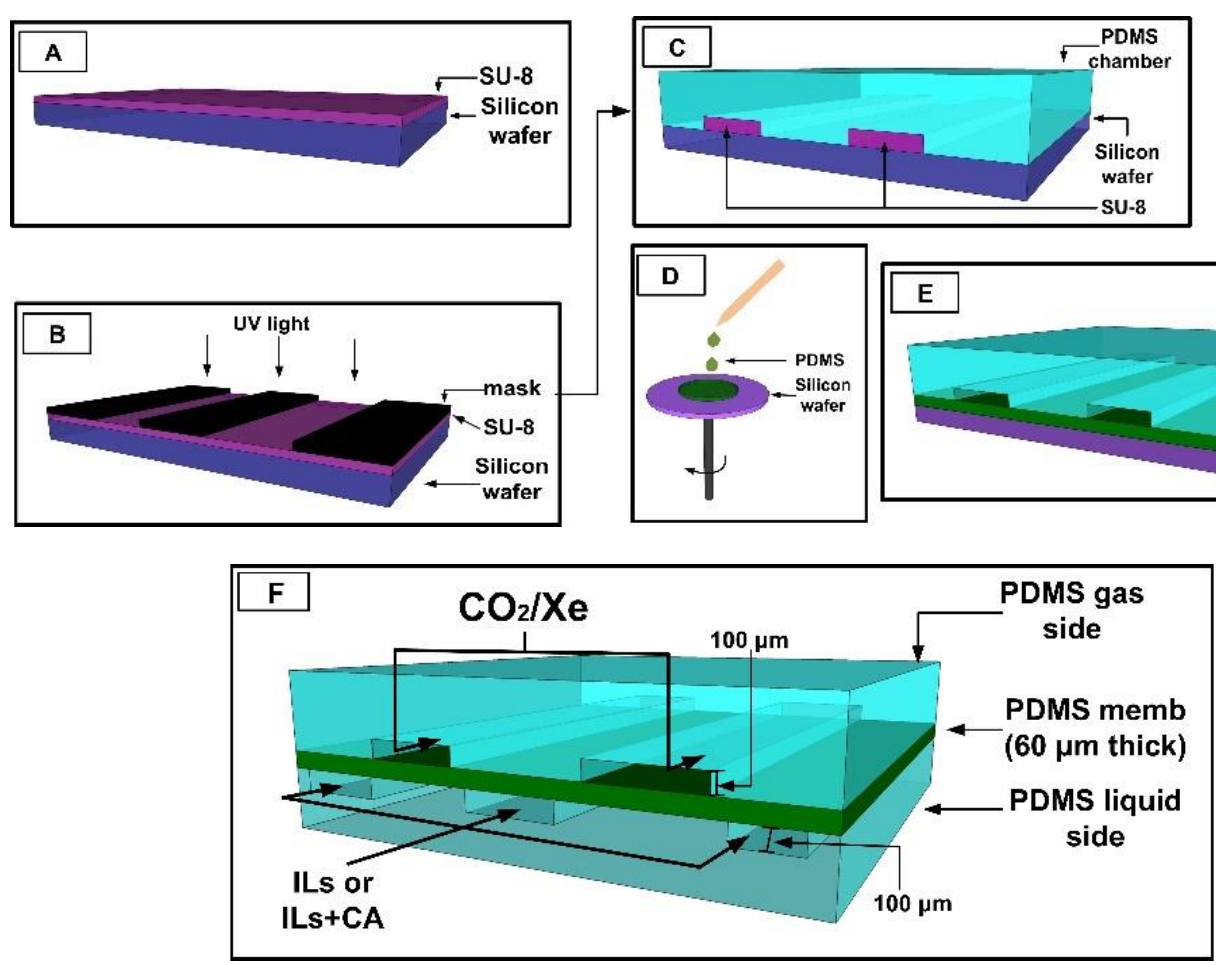

Figure 3.1 Process outline of the microfluidic chip fabrication. SU-8 negative photoresist was spin coated on the silicon wafer (A), mask alignment, UV exposure and SU-8 development (B), PDMS was poured on a created mould $(C)$ and peeled off after curing. The membrane was prepared by spin coating on a silicon wafer (D) and connected to the PDMS mould by $\mathrm{O}_{2}$ plasma procedure (E). After curing in the oven, the membrane and the chamber was peeled off of the wafer and connected to the other chamber $(F)$.

The PDMS membrane was made by spin coating (WS-400BZ, Laurell Technologies Corporation Spin Coater) on the surface of another wafer. The PDMS precursor solution was placed on the wafer and spincoated at $1000 \mathrm{rpm}$ during $1 \mathrm{~min}$ resulting in a membrane thickness of $60 \mu \mathrm{m}$ (Figure $3.1 \mathrm{D}$ ). The fabricated PDMS platform dedicated to liquid was placed inside the $\mathrm{O}_{2}$ plasma chamber (Diener electronic, Plasma-surface-technology) operating at 0.4 mbar, $120 \mathrm{~W}$ and $50 \%$ of $\mathrm{O}_{2}$ during $50 \mathrm{~s}$, in order to activate the surfaces, which will enable connecting the PDMS platform to the PDMS membrane [98] (Figure 3.1 
E). After the surface was functionalized with $\mathrm{O}_{2}$ plasma, the PDMS compartment was connected to the membrane and peeled off from the wafer. Next, the other platform was placed inside the $\mathrm{O}_{2}$ plasma chamber, functionalised and connected to the other side of a membrane resulting in a microfluidic device made of two independent PDMS compartments (Figure 3.1 F). The fabricated chips were free of dust and other particles and both chambers were well attached to the membrane, no leaking was observed. Figure 3.1 A-F shows the process flow of the PDMS chip fabrication.

\subsubsection{Characterisation of the microfluidic device}

The liquid chamber architecture enabled uniform flow of the ionic liquid through the branching construction of the microchannels while capturing $\mathrm{CO}_{2}$ permeating through the PDMS membrane. Use of PDMS elastomer facilitated chip fabrication and reproduction of the same design with thin non-porous membrane attached to the chambers. Four replicas of the same design were fabricated. All of them possess a membrane of approximately $60 \mu \mathrm{m}$ thickness, but slightly differ in the thickness of the PDMS mould compartment, varying from 0.8 to $1 \mathrm{~cm}$ due to the fabrication procedure. The four chips were built and tested; each device was capable to work for many hours under the conditions indicated below.

Figure 3.2 A shows the photograph of a microchip with the liquid chamber filled with blue dye and the gas compartment filled with pink dye to visualize the flow path. The image indicates that the filling of the gas and liquid channels was homogenous, demonstrating that there was no dead volume. Metallic pins (precision stainless steel dispense tips from Nordson, The Netherlands) with outer diameter of $0.025^{\prime \prime}$ and gauge 23 were inserted at the inlet and outlet of gas and liquid compartments to facilitate introduction of the piping into the microchip. Metallic pins and piping also contribute to the increase of a pressure drop across the entire system. To avoid deformations or leaks in the chip the maximum allowable pressure in the gas side was 0.1 bar. On the other hand, the 
maximum allowable liquid flow rate was equal to $0.01 \mathrm{~cm}^{3} \cdot \mathrm{min}^{-1}$, leading to the pressure drop of the liquid side, considering piping, pins and the chamber, to approximately 6 mbar. The SEM (CSEM-FEG INSPECT F50) picture of a cross section of the microdevice was taken after coating the PDMS with platinum by low vacuum coater (Leica EM ACE200). Figure 3.2 B indicates that the membrane is well attached to the microfluidic chambers.

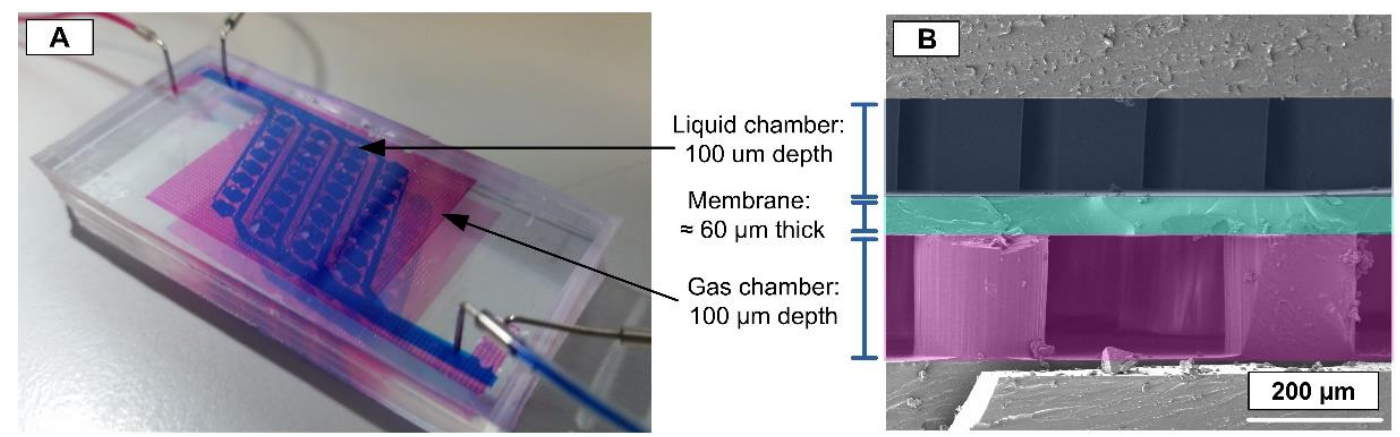

Figure 3.2 PDMS microfluidic device (A) with food dye for better visualisation of liquid and gas chamber and (B) SEM image of a microchip cross section.

The volume of the gas chamber was equal to $0.073 \mathrm{~cm}^{3}$ and volume of the liquid was $0.038 \mathrm{~cm}^{3}$, while the depth of each chamber was equal to $100 \mu \mathrm{m}$. The chip footprint, defined as the total size of the microfluidic device taking into account its width and length, was equal to $18.9 \mathrm{~cm}^{2}$ making it a very compact system. The membrane surface area was $3.87 \mathrm{~cm}^{2}$, resulting in a $3500 \mathrm{~m}^{-1}$ $\mathrm{S} / \mathrm{V}_{\text {liquid+gas }}$ ratio.

\subsubsection{Single gas permeation experiments on PDMS membranes}

Firstly, the permeability of a free-standing PDMS membrane was evaluated, according to the method previously described by Neves et al. [40]. The system was composed of a gas source, gas compartment, pressure transducers (Druck PDCR 910 models 99166 and 991675, England) and temperature controller which was immersed in a water bath. The stainless-steel cell was made of two identical chambers $\left(6 \mathrm{~cm}^{3}\right)$ dedicated to the feed and permeate with the membrane in 
between. The stainless-steel cell was placed in a water bath at $30{ }^{\circ} \mathrm{C}$. The permeability of three different pure gases was measured: $\mathrm{CO}_{2}, \mathrm{O}_{2}$ and Xe. The identical compartments were pressurized with pure gas, and after opening the permeate outlet (see Figure S3 in Appendix B) a pressure difference of about 0.7 bar was imposed. The pressure decay on the feed side and the pressure increase on the permeate side were recorded using two pressure transducers.

\subsubsection{Single gas permeation experiments on microfluidic devices containing ionic liquids and enzyme}

The experiments with ionic liquids were carried out in the experimental system shown in Figure 3.3. In this case, there was one pressure transducer connected to the gas chamber while the ionic liquid, without and with the enzyme, was fed by a syringe pump connected to the liquid chamber, i.e. permeate side, at 0.01 $\mathrm{cm}^{3} \cdot \mathrm{min}^{-1}$. The outlet of the liquid side was left open to the atmosphere so there was always a fresh portion of ionic liquid entering the compartment. The permeation of $\mathrm{Xe}$ and $\mathrm{CO}_{2}$ was measured. The gas compartment was pressurized up to approximately 0.1 bar. After equilibrium, valve V3 was opened while all the other valves were closed. The temperature was kept constant at $30{ }^{\circ} \mathrm{C}$.

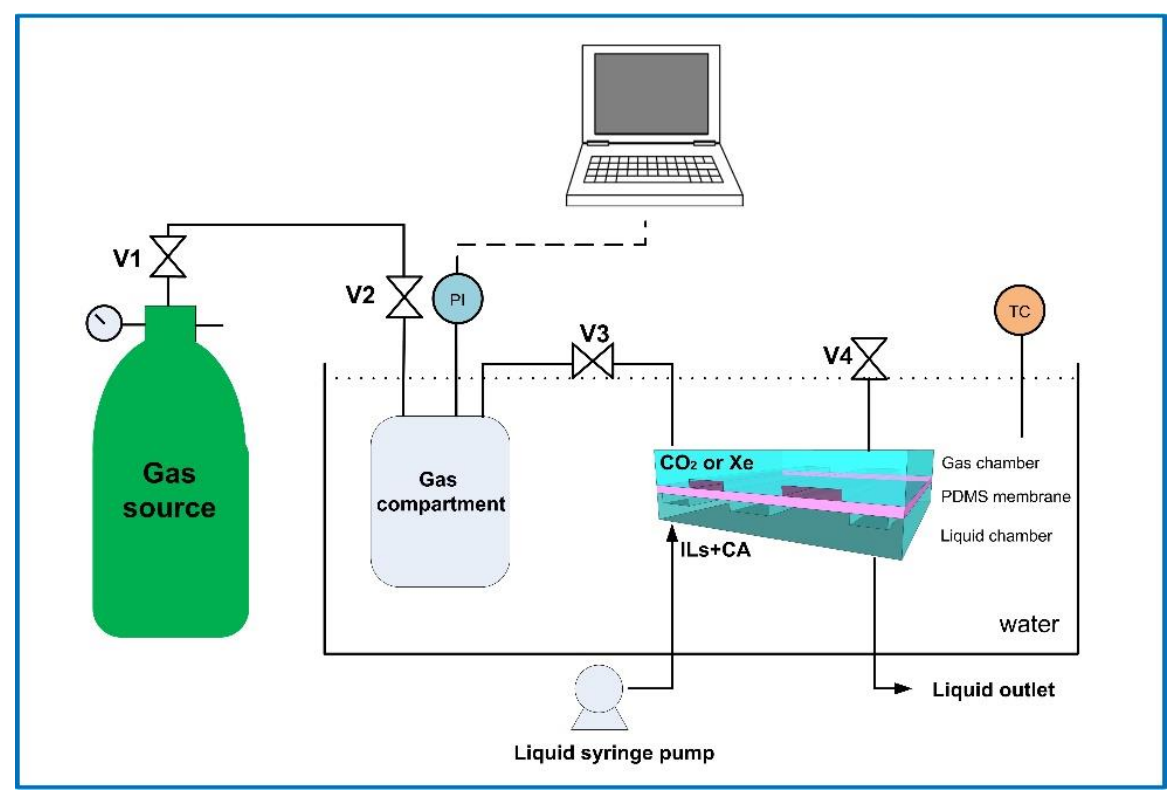

Figure 3.3 Experimental system for measuring the transport rate of $\mathrm{CO}_{2}$ and $\mathrm{Xe}$ in the presence of ionic liquid and ionic liquid containing carbonic anhydrase. 


\subsubsection{Calculations}

The equations presented below were used for calculating the permeability of a free-standing membrane. Moreover, the global mass transfer coefficients were also calculated for the chip under operation with the liquid compartment filled with ionic liquid or with ionic liquid and enzyme. The equations and assumptions used are presented below.

\subsubsection{Gas permeability calculation of a free-standing membrane}

Single gas permeability of a free-standing membrane was calculated according to Equation (3.1), which was derived from the mass balance equation under nonsteady state conditions [99] as described by Neves et al. [40]:

$$
\frac{1}{\beta} \ln \left(\frac{\left[P_{\text {feed }}-P_{\text {perm }}\right]_{0}}{\left[P_{\text {feed }}-P_{\text {perm }}\right]}\right)=p \frac{t}{l}
$$

where $\mathrm{P}_{\text {feed }}$ and $\mathrm{P}_{\text {perm }}$ are the pressures in the feed and permeate side, respectively (bar), $t$ is time (s), $l$ corresponds to the membrane thickness ( $m$ ), $\mathrm{p}$ is the membrane permeability $\left(\mathrm{m}^{2} \mathrm{~s}^{-1}\right)$ and $\beta\left(\mathrm{m}^{-1}\right)$ is a parameter which depends from the geometry of the compartment and is given by:

$$
\beta=A\left(\frac{1}{V_{\text {feed }}}+\frac{1}{V_{\text {perm }}}\right)
$$

where $V_{\text {feed }}$ and $V_{\text {perm }}$ are the volumes of the feed and permeate chambers, respectively $\left(\mathrm{m}^{3}\right)$, and $A$ is the membrane surface area $\left(\mathrm{m}^{2}\right)$. In the experimental system used for our measurements the value of $\beta$ was equal to $106.38\left(\mathrm{~m}^{-1}\right)$. The conversion of permeability expressed in $\mathrm{m}^{2} . \mathrm{s}^{-1}$, into units of barrer is described in detail in [99]. 
The permeability of the free-standing membrane, calculated by the presented method, was used for the evaluation of individual resistances in the liquid phase (see section below).

\subsubsection{Calculation of global mass transfer coefficient, individual resistances and enhancement factor}

The flux of $\mathrm{CO}_{2}$, denoted as $\mathrm{J}\left(\mathrm{mol} \cdot \mathrm{m}^{-2} \cdot \mathrm{s}^{-1}\right)$, from the gas to the liquid side in a membrane contactor is governed by Equation (3.3):

$$
J=K \Delta C=K\left(C_{G}-C_{G}^{*}\right)
$$

where $\mathrm{K}\left(\mathrm{m} \cdot \mathrm{s}^{-1}\right)$, is the overall mass transfer coefficient for $\mathrm{CO}_{2}$ transport, $\Delta \mathrm{C}$ is the driving force: $\mathrm{C}_{\mathrm{G}}$ is the concentration of $\mathrm{CO}_{2}$ in the gas phase and $\mathrm{CG}_{\mathrm{G}}{ }^{*}$ is the concentration of $\mathrm{CO}_{2}$ in the gas phase that is in equilibrium with the $\mathrm{CO}_{2}$ concentration in the bulk liquid phase. Under the experimental conditions chosen for the evaluation of $\mathrm{KCO}_{2}$, the hypothetical concentration of $\mathrm{CO}_{2}$ in equilibrium with the $\mathrm{CO}_{2}$ dissolved in the ionic liquid $\left(\mathrm{C}_{\mathrm{G}}{ }^{*}\right)$, can be considered negligible due to the $\mathrm{CO}_{2}$ Henry constant value of the selected cholinium-based ionic liquid (see Table 3.1) and the continuous feeding of fresh ionic liquid to the $\operatorname{chip}\left(0.01 \mathrm{~cm}^{3} \cdot \mathrm{min}^{-1}\right)$.

The mass transfer coefficient for the ionic liquid or ionic liquid with enzyme was calculated from the exponential fit of the normalized pressure decay curve based on Equation (3.4):

$$
-V \frac{d C_{G}}{d t}=K \cdot A \cdot\left(C_{G}-C_{G}^{*}\right)
$$

where, $\mathrm{A}$ is the membrane surface area $\left(\mathrm{cm}^{2}\right)$. 
The overall mass transfer coefficient for gas transport in a G-L membrane contactor can be described by the resistance in series model as shown below in Equation (3.5):

$$
\frac{1}{K}=\frac{1}{k_{G}}+\frac{1}{k_{M}}+\frac{1}{m E k_{L}^{0}}
$$

where $k_{G}$ is the individual mass transfer coefficient in the gas phase $\left(\mathrm{m} . \mathrm{s}^{-1}\right), k_{M}$ is the individual mass transfer coefficient associated with transport through the membrane $\left(\mathrm{m} . \mathrm{s}^{-1}\right), k_{L}^{0}$ is the individual liquid phase mass transfer coefficient (m.s ${ }^{1}$ ) in absence of chemical reaction, i.e. without the CA enzyme, $\mathrm{m}$ is the Henry's law constant (dimensionless) and $\mathrm{E}$ is the enhancement factor due to the enzymatic reaction (dimensionless) which can be expressed as in Equation 3.6 for first order reactions, which is reasonable to assume because the enzyme is far from being saturated:

$$
E=\frac{H a}{\tanh (H a)}
$$

where $\mathrm{Ha}$ is the Hatta number which relates the overall absorption rate to the physical absorption rate of $\mathrm{CO}_{2}$.

The membrane resistance $\left(R_{M}\right)$ is calculated simply by the inverse of the individual mass transfer coefficient inside the membrane $\left(\frac{1}{k_{M}}\right)$. Similarly, the resistances resulting from the presence of ionic liquid $\left(R_{C P}\right)$ or ionic liquid with the enzyme $\left(\mathrm{R}_{\mathrm{CP}+\mathrm{CA}}\right)$ are calculated from the inverse of the mass transfer coefficient of the IL $\left(\frac{1}{m k_{L}^{0}}\right)$ and mass transfer coefficient with the enzyme $\left(\frac{1}{m E k_{L}^{0}}\right)$ respectively. 
The overall mass transfer coefficient expression can be simplified further to be solely dependent on $k_{M}$ and $k_{L}^{0}$ because all the experiments herein performed have been carried out with pure gases resulting in:

$$
\frac{1}{K}=\frac{1}{k_{M}}+\frac{1}{m E k_{L}^{0}}
$$

\subsection{Results and Discussion}

\subsubsection{Permeability of a free-standing membrane}

Figure 3.4 shows the normalized $\Delta \mathrm{P} / \Delta \mathrm{P}_{0}$ decay (defined using $\mathrm{t}=0$ as reference) as a function of time divided by the membrane thickness, for two different freestanding membranes (60 $\mu \mathrm{m}$ thick and $126 \mu \mathrm{m}$ thick). The measurements were performed for $\mathrm{O}_{2}$, $\mathrm{Xe}$ and $\mathrm{CO}_{2}$. The raw data (see Figure S4, Appendix B) shows that the pressure decrease of the feed is equal to the increase of pressure at the permeate indicating that the volumes of the feed and permeate chambers are identical. As it was expected, the slowest $\Delta \mathrm{P} / \Delta \mathrm{P}_{0}$ decrease is observed in case of $\mathrm{O}_{2}$ which has the lowest permeability through the PDMS membrane and the fastest decrease is detected for $\mathrm{CO}_{2}$, which has the highest permeability through PDMS. This is in agreement with previous findings [100] and technical information provided by PDMS membrane suppliers. In all the cases, the mass balance is satisfied within $\pm 5 \%$.

The objective of the experiment with a free-standing membrane was to validate the experimental system, confirm the calculation procedure and to compute the permeability of the spin - coated non - commercial PDMS membranes (See Table 3.2). There are several factors influencing the permeation through PDMS membranes, being the two most important ones the mixing ratio and curing temperature during membrane preparation. The mixing ratio of the PDMS prepolymer to the curing agent used in this work was 10:1. This ratio is 
suggested by the polymer provider and leads to a good balance between permeability and mechanical stability of the material. In general, a higher amount of cross-linker leads to a more mechanically stable structure with lower permeability [101-104]. Thus, the optimal prepolymer: curing agent ratio depends on the final application.

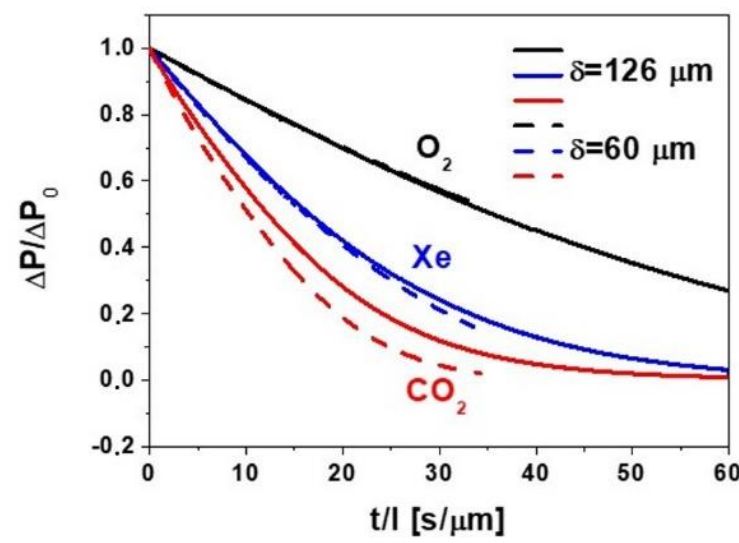

Figure 3.4 Normalized pressure drop in the experiments with three different gases $\left(\mathrm{O}_{2}\right.$, Xe and $\mathrm{CO}_{2}$ ) for two distinctive free-standing membranes (60 $\mu \mathrm{m}$ thickness and $126 \mu \mathrm{m}$ thickness).

Table $3.2 \mathrm{O}_{2}, \mathrm{CO}_{2}$ and Xe permeability values calculated for the prepared free-standing membranes.

\begin{tabular}{ccccc}
\hline $\begin{array}{c}\text { Thickness } \\
(\mu \mathrm{m})\end{array}$ & $\begin{array}{c}\text { Permeability } \\
\mathrm{O}_{2} \text { (barrer) }\end{array}$ & $\begin{array}{c}\text { Permeability } \\
\mathrm{CO}_{2} \text { (barrer) }\end{array}$ & $\begin{array}{c}\text { Permeability } \\
\text { Xe (barrer) }\end{array}$ & $\begin{array}{c}\text { Ideal } \\
\text { Selectivity } \\
\boldsymbol{\alpha}_{\mathrm{CO} / \mathrm{Xe}}\end{array}$ \\
\hline 60 & 357 & 854 & 620 & 1.4 \\
126 & 310 & 843 & 612 & 1.4 \\
\hline
\end{tabular}

Additionally, it is concluded from Table 3.2 that the permeability of Xe is only slightly lower than that of $\mathrm{CO}_{2}$ with an ideal selectivity of 1.4 . In fact, the values of the Lennard - Jones kinetic diameters are similar, $3.94 \AA$ and $4.04 \AA$ for 
$\mathrm{CO}_{2}$ and $\mathrm{Xe}$, respectively [105]. Merkel et al. [100] studied the permeability of different gases in PDMS and they concluded that, even though the kinetic diameters of gases are similar, permeabilities can be different as a result of relative solubility of a gas in PDMS. Typically, gases with higher critical temperatures, such as $\mathrm{CO}_{2}$, exhibit high condensability and are more soluble in polymers as well as in liquids.

\subsubsection{Gas transport in the microfluidic device}

The gas permeation experiments through the membrane integrated in the microfluidic chip were carried out in the experimental system shown in Figure 3.3. In this case, the liquid chamber was empty and the valves connecting the chamber to the atmosphere were closed. The pressure decay was recorded for Xe and $\mathrm{CO}_{2}$. Figure 3.5 shows the comparison of normalized pressure drop for four different chips in the case of $\mathrm{CO}_{2}$.

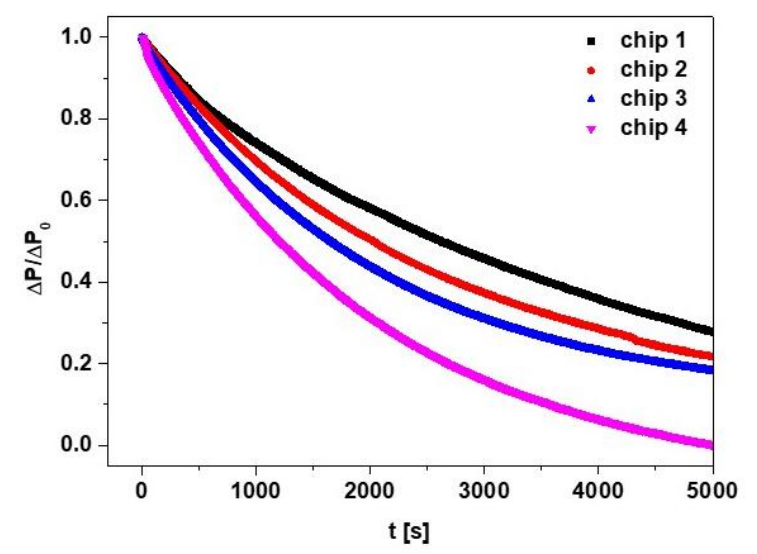

Figure 3.5 Normalized pressure drop of $\mathrm{CO}_{2}$ in the four different chips.

For raw data of the pressure decrease at the feed side and pressure increase at the permeate side for $\mathrm{CO}_{2}$ inside one of the chips, see Figure S5, Appendix B. The pressure in the feed side decreases slower than the pressure at the permeate 
increases. This is related to the difference in the volume of the two chambers. Considering that the feed chamber consists of a gas compartment made of a stainless steel connected to the gas side of the microdevice and accounting for all the connections, the total volume of the feed side is $72.83 \mathrm{~cm}^{3}$. On the other hand, the permeate side consists only of a liquid chamber of the microfluidic device and the piping resulting in a volume of $0.12 \mathrm{~cm}^{3}$. Additionally, in the proposed microdevice there is not only a membrane which is made of PDMS but also both chambers. Unlike free-standing membrane experiments, the amount of $\mathrm{CO}_{2}$ moles permeating from the feed side significantly differed from the amount of $\mathrm{CO}_{2}$ moles appearing on the permeate side. The contribution of $\mathrm{CO}_{2}$ sorption on the PDMS side walls accounts for up to $15 \%$. In other words, the gas permeates not only through the membrane but through the chamber walls as well, resulting in modified gas transport values. In this scenario, a significant contribution of the PDMS walls effect on the recorded pressure variation in the feed side is expected. To corroborate such hypothesis, the $\mathrm{CO}_{2}$ permeability measurements of chip 4 were carried out slightly different: before the pressure decay measurement, the microfluidic device was saturated with $\mathrm{CO}_{2}$ for about $3 \mathrm{~h}$. After that time, the measurement was performed as it was described above. The purpose of this procedure was to saturate the PDMS walls with $\mathrm{CO}_{2}$. Therefore, the total transport of $\mathrm{CO}_{2}$ occurred in the membrane rather than in the PDMS walls. This is visible in Figure 3.5 where the highest decay of the normalized pressure is observed in chip 4 . Hence, it was decided that to avoid the contribution of the PDMS walls in the gas permeation, the values of the PDMS membrane permeability and a membrane resistance for a given gas will be taken from the experiments presented in the previous section for a free - standing membrane (see Table 3.2) rather than from the measurements of gas permeation in the membrane integrated in the chip. 


\subsection{1 $\mathrm{CO}_{2}$ transport enhancement due to cholinium propionate ionic}

liquid and carbonic anhydrase enzyme

To increase the $\mathrm{CO}_{2}$ capturing effect, cholinium propionate ionic liquid, $\mathrm{CP}$, alone or combined with the carbonic anhydrase enzyme, $\mathrm{CA}$, was introduced in the liquid chamber by a syringe pump with the flow rate of $0.01 \mathrm{~cm}^{3} \cdot \mathrm{min}^{-1}$ (see Figure 3.3). The experiments were carried out for four different chips with PDMS dense membrane, $60 \mu \mathrm{m}$ thick. However, in order to ensure the selectivity of the process, which is the separation of $\mathrm{CO}_{2}$ from $\mathrm{Xe}$ in an anaesthesia gas stream, the transport of $\mathrm{Xe}$ in presence of cholinium propionate and cholinium propionate combined with carbonic anhydrase has to be investigated. Therefore, the same set of experiments were carried out in the case of Xe. As it was done in the previous measurements, pressure decay of the analysed gas was recorded and the calculation of the resistance of each process as well as the mass transfer coefficients were performed.

Figure 3.6 shows the normalized pressure decay in the feed side for all three experimental configurations as a function of time for $\mathrm{CO}_{2}(\mathrm{~A})$ and $\mathrm{Xe}(\mathrm{B})$, respectively. There is no visible effect of ionic liquid and the enzyme on the affinity to $\mathrm{Xe}$, in comparison to the measurements with the empty liquid chamber. Accounting from preliminary results of Xe solubility in bulk cholinium propionate ionic liquid, i.e. negligible [90] (see Figure S6 in Appendix B), the Xe pressure decay profiles depicted in Figure 3.6 B could be explained by the contribution of Xe sorption on the walls of the PDMS chambers.

On the other hand, there is a slight enhancement in the pressure decay in case of $\mathrm{CO}_{2}$ and ionic liquid. The $\mathrm{CO}_{2}$ pressure decreases even more rapidly as a result of the enzymatic reaction, i.e. due to the presence of the enzyme in the ionic liquid. Figure 3.7 represents the final decay of pressure in the feed side of the four different chips. The normalized pressure decay of the four chips is presented in 
the supplementary information (Appendix B, Figure S7). It is visible that the ionic liquid has an influence on the $\mathrm{CO}_{2}$ transport and it increases it moderately. However, a significant increase in $\mathrm{CO}_{2}$ transport is obtained when the enzyme is added to the IL, which is in agreement with previous works and results obtained by Martins et al. for the immobilization of carbonic anhydrase in cholinium propionate in a bulk system [90].

\section{A}

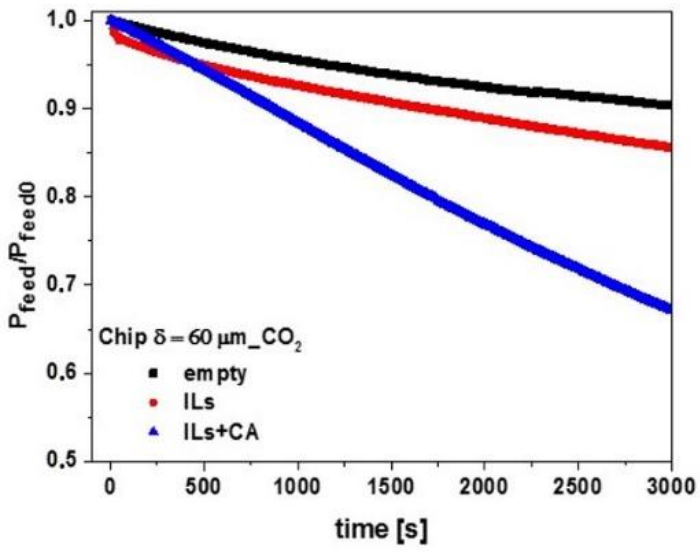

\section{B}

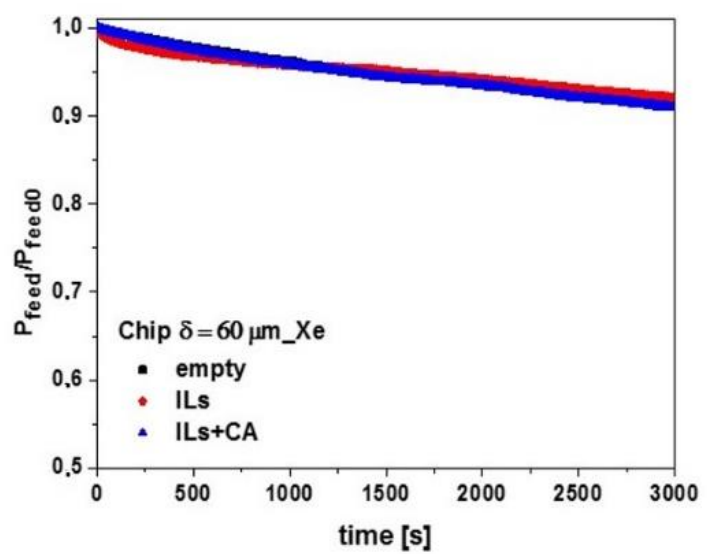

Figure 3.6 Normalized pressure decay in the feed side over time in the empty chip 1 (no IL), the chip 1 with cholinium propionate and the chip 1 filled with cholinium propionate and carbonic anhydrase for $\mathrm{CO}_{2}(A)$ and $\mathrm{Xe}(B)$.

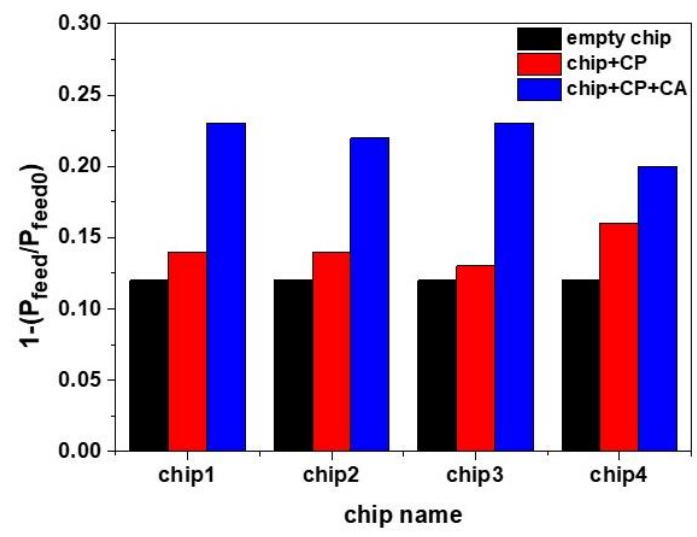

Figure 3.7 Enhanced $\mathrm{CO}_{2}$ transport due to the presence of ionic liquid and the enzyme in the liquid chamber: results for the 4 different chips prepared in this work. 
The individual mass transfer coefficient for transport through the membrane, $\mathrm{kM}$, and the global mass transfer coefficients for $\mathrm{CO}_{2}$ transport, $\mathrm{K}_{\mathrm{CO}_{2}}$ with ionic liquid and with ionic liquid combined with the enzyme are presented in Table 3.3. The mass transfer coefficient for the membrane, $\mathrm{k}_{\mathrm{m}}$ is calculated by dividing the permeability value by the thickness of each membrane integrated in the microfluidic device. The global mass transfer coefficients for $\mathrm{CO}_{2}$ transport, $\mathrm{K}_{\mathrm{CO}_{2}}$ is calculated from Equation (3.4). In the case of Xe, the calculation of the overall mass transfer coefficient cannot be performed following the same procedure since there is not a measurable absorption of Xe in the ionic liquid. Table 3.3 also shows the enhancement factor, as well as, the molar flux ratio between $\mathrm{CO}_{2}$ and $\mathrm{Xe}$, i.e. $J_{\mathrm{CO}_{2}} / J_{\mathrm{Xe}}$.

Above all, the results obtained indicate that the main controlling resistance to $\mathrm{CO}_{2}$ transport in the gas - liquid membrane contactor is located in the liquid phase. We found that individual liquid phase resistance values, $R_{C P}$, are in the range of $86-90 \%$ of the total resistance. The overall mass transfer coefficients are two orders of magnitude lower than the ones presented by Yong et al. due to the higher viscosity of the ionic liquid (39 mPa.s vs $2 \mathrm{mPa} \cdot \mathrm{s}$ ) and the much lower solvent Reynolds number (0.001 vs 20) used in this work. Additionally, in our case, it was decided to not increase the flow rate of the IL because this would augment the pressure drop in the entire system, above the limit of 0.1 bar, leading to deformation and leaks in the chambers. The enhancement factor on $\mathrm{CO}_{2}$ transport due to the presence of the enzyme increases up to an average value of 1.6. This value is rather positive when compared with published results [89], in particular if we take into consideration the low enzymatic concentration used in the microfluidic device, i.e. $0.1 \mathrm{mgCA} / \mathrm{gIL}$. The enhancement factor (E) results, after addition of carbonic anhydrase to the cholinium propionate ionic liquid, are 
in agreement with the results obtained by Martins et al. for bulk experiments [90], where an enhancement factor of 1.6 was also obtained. This observation supports the benefits of the alveolar type design for ensuring the facile access of $\mathrm{CO}_{2}$ to the $\mathrm{CA}$ active reaction sites. Moreover, the $\mathrm{CO}_{2} / \mathrm{Xe}$ molar flux ratio after addition of the ionic liquid and the enzyme is as high as 3.3 compared to 1.4 ideal selectivity obtained using the PDMS membrane.

Table 3.3 Mass transfer coefficients, resistances and enhancement factor for $\mathrm{CO}_{2}$ transport in cholinium propionate and cholinium propionate combined with carbonic anhydrase. $R_{C P}$ is the resistance in the ionic liquid, $R_{C P+C A}$ is the resistance in the ionic liquid combined with the enzyme, $E$ is the enhancement factor due to the chemical reaction.

\begin{tabular}{|c|c|c|c|c|c|c|c|}
\hline \multirow[b]{2}{*}{ Chip } & \multirow{2}{*}{$\begin{array}{l}\text { Chip } \\
K_{C O_{2}} \\
=k_{M} \\
\left(\mathrm{~m} \cdot \mathrm{s}^{-1}\right)\end{array}$} & \multicolumn{2}{|c|}{ Chip $+C P$} & \multicolumn{4}{|c|}{ Chip $+\mathrm{CP}+\mathrm{CA}$} \\
\hline & & $\begin{array}{c}=\frac{1}{\frac{1}{k_{M}}+\frac{1}{m k_{L}^{0}}} \\
\left(\mathrm{~m} \cdot \mathrm{s}^{-1}\right)\end{array}$ & $\begin{array}{l}R_{C P} \\
(\%)\end{array}$ & $=\frac{1}{\frac{1}{k_{M}}+\frac{1}{m E k_{L}^{0}}}$ & $\begin{array}{c}\mathrm{R}_{\mathrm{CP}+\mathrm{CA}} \\
(\mathbf{( \% )})\end{array}$ & $\mathrm{E}$ & $J_{\mathrm{CO}_{2}} / J_{X e}$ \\
\hline 1 & $1.19 \cdot 10^{-5}$ & $1.24 \cdot 10^{-6}$ & 89.6 & $2.11 \cdot 10^{-6}$ & 82.3 & 1.9 & 3.5 \\
\hline 2 & $1.17 \cdot 10^{-5}$ & $1.25 \cdot 10^{-6}$ & 89.3 & $2.07 \cdot 10^{-6}$ & 82.3 & 1.8 & 2.9 \\
\hline 3 & $1.10 \cdot 10^{-5}$ & $1.58 \cdot 10^{-6}$ & 85.6 & $2.11 \cdot 10^{-6}$ & 80.8 & 1.4 & 3.8 \\
\hline 4 & $1.14 \cdot 10^{-5}$ & $1.51 \cdot 10^{-6}$ & 86.8 & $1.87 \cdot 10^{-6}$ & 83.6 & 1.3 & 3.0 \\
\hline
\end{tabular}


Since there is no Xe absorption by the ionic liquid it can be totally recycled in a closed anaesthetic circuit as represented in Figure 3.8.

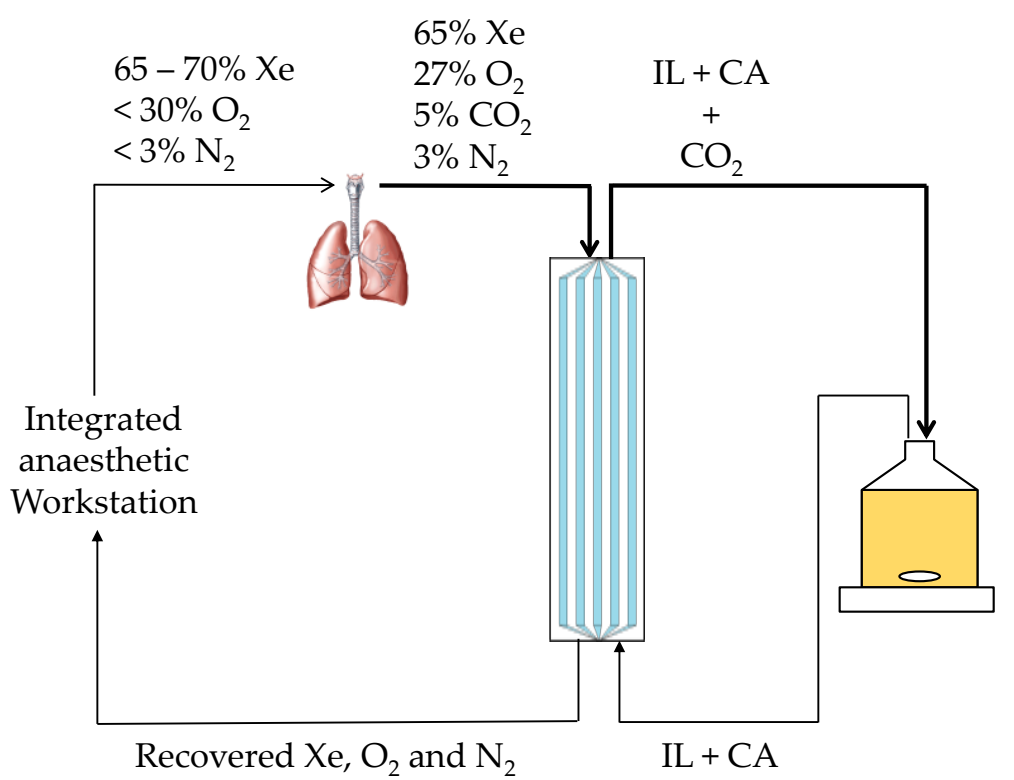

Figure 3.8 Simplified scheme for $\mathrm{CO}_{2}$ removal and Xe recycling in a closed anaesthetic circuit.

\subsection{Conclusions}

In summary, we have investigated the effect of an ionic liquid and its combination with carbonic anhydrase to remove $\mathrm{CO}_{2}$ from $\mathrm{Xe}$ used in anaesthesia. The microfluidic experimental system was designed as a membrane contactor working in a semi-continuous operation mode. Even though the permeability of PDMS for Xe and $\mathrm{CO}_{2}$ was similar, the cholinium propionate and cholinium propionate in combination with carbonic anhydrase showed the enhancement in the $\mathrm{CO}_{2}$ capturing effect, while there was no effect on the Xe transport rate.

Our work demonstrates the proof of concept for $\mathrm{CO}_{2}$ removal from anaesthesia gas circuits through a membrane contactor in the form of a microfluidic device. Thanks to miniaturization, the consumption of chemicals, i.e. ionic liquid and enzyme, is notably reduced. At the same time, it provides a 
significant enhancement factor and molar flux ratio of $\mathrm{CO}_{2} / \mathrm{Xe}$ using very small concentration of CA enzyme $0.1 \mathrm{mgCA} / \mathrm{gIL}$.

Further research should also consider: i) alternative non-permeable materials with higher mechanical resistance for the fabrication of the microfluidic chambers; ii) exploring novel membrane architectures (porous, corrugated) to increase the S/V ratio; and, iii) use of higher concentrations of the CA enzyme and solvent flow-rates for promoting $\mathrm{CO}_{2}$ transport. 


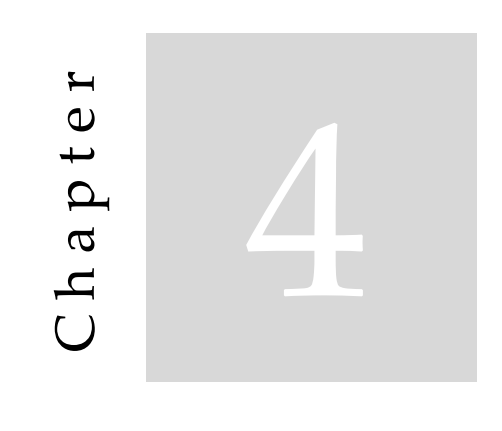

\section{$\mathrm{CO}_{2}$ removal from anaesthesia circuits using gas-ionic liquid membrane contactors}

Published as: C. F. Martins, L. A. Neves, R. Chagas, L. M. Ferreira, C. A. M. Afonso, J. G. Crespo, I. M. Coelhoso, " $\mathrm{CO}_{2}$ removal from anaesthesia circuits using gas-ionic liquid membrane contactors", Separation and Purification Technology, 2020, vol. 250,116983.

\section{Summary}

Nowadays, the reutilization of anaesthetic gases is accomplished by capturing carbon dioxide with soda lime, a solid adsorbent mostly composed by calcium and sodium hydroxide. To overcome the issues regarding the use of soda lime, this work proposes an alternative process to remove carbon dioxide through the use of a membrane contactor combined with a biocompatible ionic liquid (IL), cholinium lysinate, with high absorption capacity (5.9 molco2/ $\mathrm{kg}_{\mathrm{IL}}$ ). The carbon dioxide removal rate and IL solution regeneration, were assessed, varying the feed gas composition, relative humidity and ionic liquid flow rate conditions. Overall mass transfer coefficients and separation factors were determined. From the results obtained, the proposed system is feasible to remove carbon dioxide from anaesthetic gas circuits. Moreover, the system working operation time obtained was 63 hours, which in a mass basis comparison with soda lime (current technology), is 3 to 5 times higher. 


\subsection{Introduction}

In the conventional technology to remove carbon dioxide $\left(\mathrm{CO}_{2}\right)$ from inhalation anaesthesia circuits, a container with soda lime is used to adsorb and degrade the expired gases and anaesthetics [106]. Soda lime is composed mostly by calcium and sodium hydroxide, which is proved to remove $\mathrm{CO}_{2}$ efficiently [107]. Furthermore, it is used in anaesthetic circuits in a closed-loop operating mode, where the expired $\mathrm{CO}_{2}$ is removed to allow the recovering and recycling of the non-absorbed anaesthetics. Typically, the inhaled anaesthetic gas mixture is composed by $70 \%$ of the anaesthetic gas and $30 \%$ of oxygen, which results in an exhaled gas mixture with $65 \%$ of anaesthetic gas, $27 \%$ of oxygen, $5 \%$ of carbon dioxide and $3 \%$ of nitrogen. The reuse of the non-absorbed anaesthetics is only possible if the carbon dioxide concentration is lowered down to $0.5 \%[6,108]$.

Even though soda lime is used in these circuits, efforts must be done to replace the current technology, due to existent drawbacks. Several studies show that volatile halogenated hydrocarbons typically present in anaesthetic streams (e.g. sevoflurane, desflurane and isoflurane) can react with soda lime with low water content, being chemically degraded to vinyl-ether molecules known as compounds A-E [106,109]. These compounds, along with other toxic compounds, such as carbon monoxide, may present potential life-threatening complications [110,111].

The most used technique for $\mathrm{CO}_{2}$ capture (from diverse gas streams sources) is absorption using aqueous amine solutions, specially solutions containing monoethanolamine (MEA) [32]. This technique consists in scrubbing $\mathrm{CO}_{2}$ from a gas mixture with the aqueous amine solution in a packed column, followed by a liquid regeneration step with stripping water vapour at temperatures between 373 and $393 \mathrm{~K}$ [33]. However, drawbacks including corrosion, oxidative degradation, negative environmental impact, high volatility leading to considerable losses of the absorbent, chemical and thermal instabilities 
and low energy efficiency, motivate researchers to seek for more efficient and environment-friendly alternatives [32,112-114].

Studies on $\mathrm{CO}_{2}$ capture using different absorption systems increased progressively over the last three decades, where ionic liquids (ILs) are emerging as a potential alternative [34]. ILs are liquid salts with negligible volatility and their potential to capture $\mathrm{CO}_{2}$ is recognized due to their unique properties, such as the ability to be tuned for each specific process, excellent thermal stability, structural functionality, among others. Furthermore, ILs are able to work as solvents and also for this reason their potential is being explored to replace conventional $\mathrm{CO}_{2}$ absorbents [35]. $\mathrm{CO}_{2}$ capture and conversion studies using amino-acid based ILs combined with the cholinium cation, revealed their strong ability to react with $\mathrm{CO}_{2}$, are more resistant to oxidative degradation and exhibit higher thermal stability [90,108,115-118]. Additionally, this group of ILs is even more interesting due to their low toxicity, biocompatibility and biodegradability. Bhattacharyya et al. [117] synthesized novel ILs containing choline ([Cho+]) based on ether functionalized cations with amino acid ([AA]) anions, aiming an effective $\mathrm{CO}_{2}$ capture performance and stability in the presence of oxygen. The synthesized [ $\left.\mathrm{N}_{1,1,6,2 \mathrm{O}}\right]$ [Lys] IL presented a $\mathrm{CO}_{2}$ capture capacity of $4.31 \mathrm{~mol} \mathrm{CO}_{2} / \mathrm{kg}_{\mathrm{IL}}$ (at $293 \mathrm{~K}$ ). Li et al. [115] studied the absorption of $\mathrm{CO}_{2}$ in $30 \mathrm{wt} \%$ aqueous solutions of [Cho][AA]s ILs, obtaining a $\mathrm{CO}_{2}$ capture capacity of 0.89 molco2 $/ \mathrm{kg}_{\mathrm{IL}}$ for the cholinium lysinate $\left(\left[\mathrm{Cho}^{+}\right]\left[\mathrm{Lys}^{-}\right]\right) \mathrm{IL}$, at $303 \mathrm{~K}$ and close to the atmospheric pressure. Li et al. proposed the use of aqueous solutions of this family of ILs, in order to reduce the viscosity, the gas-liquid mass transfer resistance, as well as to turn the ILs more economically viable for the $\mathrm{CO}_{2}$ capture application, when compared to less expensive solutions such as aqueous amines.

The use of porous membrane contactors for $\mathrm{CO}_{2}$ capture using ionic liquids or amino acid salt solutions, as liquid absorbents has also been addressed [119122]. In this approach, a porous hydrophobic membrane is used to promote the contact between gas and liquid phases, without dispersion of one phase into the other. Furthermore, the hydrophobic character of the membrane prevents the liquid from entering the pores, minimizing the mass transfer resistance of the 
membrane. Thus, the membrane acts as a separation barrier providing an interfacial area for mass transfer, while the selectivity is given by affinity to the liquid phase [20, 24]. Portugal et al. [108] proposed this approach for the $\mathrm{CO}_{2}$ removal from anaesthetic gas circuits. A 2D numerical model was developed for the transport of $\mathrm{CO}_{2}$ through hollow fibres using potassium glycinate solutions, as the liquid absorbent, and a composite membrane made of a porous support of polyethylenimine (PEI) and a polydimethylsiloxane (PDMS) dense thin layer. For the same purpose, Sirkar et al. [3] proposed the use of hydrophilic porous hollow fibre membrane contactors, with different solutions of glycinate/glycerol immobilized inside the pores. In this work, the immobilized membranes were tested with simulated breathing gas mixtures containing halogenated hydrocarbons (HHCs), like sevoflurane, desflurane, enflurane and halothane. Another alternative process was presented by Malankowska et al. [124] using a microfluidic gas-ionic liquid contactor, with a cholinium propionate solution containing the carbonic anhydrase enzyme, for $\mathrm{CO}_{2}$ enhanced transport, to remove $\mathrm{CO}_{2}$ from anaesthetic circuits with xenon.

Following this concept, the present work discusses the removal of $\mathrm{CO}_{2}$ from a closed-loop system containing complex gas mixtures with anaesthetic agents, using a membrane contactor comprised of porous capillaries of polytetrafluoroethylene (PTFE) and a cholinium lysinate ionic liquid solution as a biocompatible and cost-effective $\mathrm{CO}_{2}$ absorbent. The IL solution contains 50 $\mathrm{wt} \%$ of water, to minimize operation constraints (i.e. overpressure inside the capillaries due to the high viscosity), as well as to reduce the cost when comparing to the operation with an IL with higher purity. Regarding the porous membrane selected, it is recognized that PTFE possesses high chemical resistance and retain their non-wetting behaviour even in the presence of corrosive chemicals [125]. For this reason, Eclipse ${ }^{\mathrm{TM}}$ membranes were selected for the present study. To validate the concept proposed, the following aspects were investigated: 1) Total $\mathrm{CO}_{2}$ capture capacity of the system;2) $\mathrm{CO}_{2}$ capture capacity, with humidified and dried simulated exhaled $\mathrm{N}_{2} \mathrm{O}$ streams, with low $\mathrm{CO}_{2}$ partial pressures; 3) IL solution regeneration efficiency using a sweep gas. The overall 
mass transfer coefficient and the $\mathrm{CO}_{2} / \mathrm{N}_{2} \mathrm{O}$ separation factor $(S F)$ were also evaluated and the proposed technology for $\mathrm{CO}_{2}$ removal was compared with the present technology using soda lime.

\subsection{Theory}

\subsection{1 $\mathrm{CO}_{2}$ absorption with chemical reaction}

$\left[\mathrm{Cho}^{+}\right]\left[\mathrm{Lys}^{-}\right]$is an IL derived from the cholinium family with the amino acid lysine as anion. Despite the existence of physical diffusion of $\mathrm{CO}_{2}$ in this IL, the dominant phenomenon of transport is attributed to the chemical reaction between the IL and $\mathrm{CO}_{2}$ [126]. [Lys] anion is an amphoteric species which, combined with the $\left[\mathrm{Cho}^{+}\right]$cation, acts as a Lewis acid due to the presence of the ammonium group in the cation. In the presence of water the [Lys-] anion with its two amino groups acts as a strong base and $\mathrm{CO}_{2}$ absorption occurs via bicarbonate and carbonate formation [126]. In Figure 4.1 are represented the chemical structures of the most important species in water and in the presence of $\mathrm{CO}_{2}$.<smiles>C[N+](C)(CCO)CCCCCN</smiles>

$\left[\mathrm{Cho}^{+}\right]\left[\mathrm{Lys}^{-}\right]$<smiles>C[N+](C)(CCO)CCCCCC(N)C(=O)[O-]</smiles>

$\left[\mathrm{Cho}^{+}\right]\left[\mathrm{Lys}^{-}\right] \mathrm{H}^{+}$<smiles></smiles>

$\left[\mathrm{Cho}^{+}\right]\left[\mathrm{Lys}^{-}\right] \mathrm{H}^{+} \mathrm{HCO}_{3}^{-}$<smiles>C[N+](C)(CCO)O[N+](C)(CCCCCN)C(=O)[O-]</smiles>

$\left[\mathrm{Cho}^{+}\right]\left[\mathrm{Lys}^{-}\right] 2 \mathrm{H}^{+} \mathrm{HCO}_{3-}^{-}$<smiles>C[N+](C)(CCO)O[N+](C)(CCCC[NH3+])CCCC(N)C(=O)[O-]</smiles>

$\left[\mathrm{Cho}^{+}\right]\left[\mathrm{Lys}^{-}\right] 2 \mathrm{H}^{+} 2 \mathrm{HCO}_{3}^{-}$

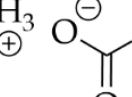<smiles>C1=CCC=C1</smiles>

Figure 4.1 Structure of the most important species in water and in the presence of $\mathrm{CO}_{2}$. 
Due to the strong basic character of $\left[\mathrm{Cho}^{+}\right]\left[\mathrm{Lys}^{-}\right] \mathrm{IL}$ solution ( $\left.\mathrm{pH} 13\right)$, the contact between the amino groups and bicarbonate is extremely reactive. At this $\mathrm{pH}$ the amine of the alkyl side chain of lysinate anion can be partially protonated since its pKa is 10.53 , consequently the $\mathrm{CO}_{2}$ molecules converted into bicarbonate ions bind first to this amine. $\mathrm{As}^{\mathrm{CO}_{2}}$ is absorbed and the $\mathrm{pH}$ decreases, the amine of the carboxylic acid functional group is able to protonate and bind the bicarbonate ion, as the $\mathrm{pH}$ approaches to its $\mathrm{pKa} \sim 8.95$ [127].

The following simplified model describes the $\mathrm{CO}_{2}$ absorption by chemical reaction in this IL:

$$
\begin{aligned}
& \mathrm{H}_{2} \mathrm{O} \stackrel{\mathrm{K}_{1}}{\leftrightarrow} \mathrm{H}^{+}+\mathrm{OH}^{-} \\
& \mathrm{CO}_{2}(\mathrm{aq})+\mathrm{OH}^{-} \stackrel{\mathrm{K}_{2}}{\leftrightarrow} \mathrm{HCO}_{3}^{-} \\
& {\left[\mathrm{Cho}^{+}\right]\left[\mathrm{Lys}^{-}\right]+\mathrm{HCO}_{3}^{-} \stackrel{\mathrm{K}_{3}}{\leftrightarrow} \mathrm{CO}_{3}^{2-}+\left[\mathrm{Cho}^{+}\right]\left[\mathrm{Lys}^{-}\right] \mathrm{H}^{+}} \\
& {\left[\mathrm{Cho}^{+}\right]\left[\mathrm{Lys}^{-}\right]+\mathrm{H}^{+} \stackrel{\mathrm{K}_{4}}{\leftrightarrow}\left[\mathrm{Cho}^{+}\right]\left[\mathrm{Lys}^{-}\right] \mathrm{H}^{+}} \\
& {\left[\mathrm{Cho}^{+}\right]\left[\mathrm{Lys}^{-}\right] \mathrm{H}^{+}+\mathrm{HCO}_{3}^{-} \stackrel{\mathrm{K}_{5}}{\leftrightarrow}\left[\mathrm{Cho}^{+}\right]\left[\mathrm{Lys}^{-}\right] \mathrm{H}^{+} \mathrm{HCO}_{3}^{-}} \\
& {\left[\mathrm{Cho}^{+}\right]\left[\mathrm{Lys}^{-}\right] 2 \mathrm{H}^{+} \mathrm{HCO}_{3}^{-}+\mathrm{HCO}_{3}^{-} \stackrel{\mathrm{K}_{6}}{\leftrightarrow}\left[\mathrm{Cho}^{+}\right]\left[\mathrm{Lys}^{-}\right] 2 \mathrm{H}^{+} 2 \mathrm{HCO}_{3}^{-}}
\end{aligned}
$$

In the described mechanism, all species are involved in reversible reactions. However, it is important to mention that regarding equation (4.2), $\mathrm{CO}_{2}$ (aq) concentration is always null, due to the fast conversion into bicarbonate, $\mathrm{HCO}_{3}^{-}$ and carbonate, $\mathrm{CO}_{3}^{2-}$ (depending on the $\mathrm{pH}$ ).

\subsection{2 $\mathrm{CO}_{2}$ mass transfer models}

In this work, the gas phase flows counter-currently with the liquid phase, promoting a maximum driving force between the phases along the membrane contactor. Furthermore, the high hydrophobic character of the PTFE membrane 
allows for operation in a non-wetted pore mode, avoiding the resistance promoted in the case of stagnant liquid inside the pores, as it is depicted in Figure $4.2[123]$.

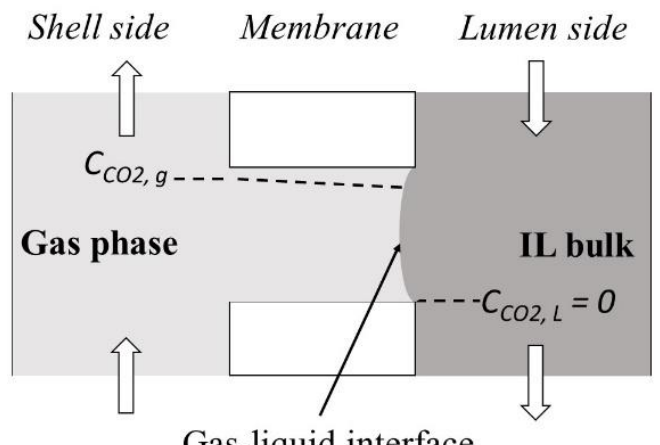

Gas-liquid interface

Figure $4.2 \mathrm{CO}_{2}$ mass transfer in a non-wetted pore mode.

$\mathrm{CO}_{2}$ mass transfer from the gas to the liquid phase includes diffusion from the gas stream through the membrane pores and diffusion in the liquid phase which, in this work, is accompanied by a fast chemical reaction. The $\mathrm{CO}_{2}$ flux $\left(J_{C O 2}\right.$, in mol. $\left.\mathrm{m}^{-2} \cdot \mathrm{s}^{-1}\right)$, from the gas to the liquid phase is described by:

$$
J_{\mathrm{CO} 2}=K_{o v} \times\left(\mathrm{CO}_{2}-\mathrm{CO}_{2}^{*}\right)
$$

where $\left(\mathrm{CO}_{2}-\mathrm{CO}_{2}^{*}\right)$ is the concentration driving force $\left(\mathrm{mol} . \mathrm{m}^{-3}\right), \mathrm{CO}_{2}$ is the carbon dioxide concentration in the gas phase, $\mathrm{CO}_{2}^{*}$ is the carbon dioxide concentration in equilibrium with the concentration of $\mathrm{CO}_{2}$ in the liquid phase, being null in this case, since $\mathrm{CO}_{2 \mathrm{IL}}=0 . K_{o v}$ is the overall mass transfer coefficient $\left(\mathrm{m} . \mathrm{s}^{-1}\right)$, which is obtained by the resistance-in-series approach [128].

$$
\frac{1}{K_{\text {ov }}}=\underbrace{\frac{1}{k_{g}}+}_{\text {gas phase resistance }}+\underbrace{\frac{d_{0}}{k_{m} \times d_{l m}}}_{\text {membrane resistance }}+\underbrace{\frac{d_{0}}{\varphi \times d_{i} \times k_{l}}}_{\text {liquid phase resistance }}
$$


where $\varphi$ is the product between the gas-liquid partition coefficient $-m$ - and an enhancement factor $-E$ - due to the chemical reaction contribution in the $\mathrm{CO}_{2}$ absorption, $d_{0}, d_{l m}$ and $d_{i}$ are the external, logarithm mean and internal diameters of the capillaries, $k_{g}, k_{m}$ and $k_{l}$ are the individual mass transfer coefficients in the gas, membrane and liquid. In a non-wetted pore operation mode, mass transfer resistances in the gas phase $\left(k_{g}^{-1}\right)$ and membrane $\left(d_{0} \cdot d_{l m}^{-1} \cdot k_{m}^{-1}\right)$ are negligible, and the liquid phase resistance controls the $\mathrm{CO}_{2}$ mass transfer in the module. In this work, the liquid phase flows in laminar regime inside the capillaries of the Eclipse ${ }^{\mathrm{TM}}$ module (Reynolds number, $\leq 2200$ ). Therefore, the liquid mass transfer coefficient $\left(k_{l}\right.$, in $\left.\mathrm{m} . \mathrm{s}^{-1}\right)$ can be estimated using the following equation $[99,128]$ :

$$
\frac{k_{l} \times d_{i}}{D_{\mathrm{CO} 2, l}}=1.62 \times\left(\frac{d_{i}^{2} \times u_{l}}{L \times D_{\mathrm{CO} 2, l}}\right)^{0.33}
$$

where $d_{i}$ is the capillaries internal diameter $(\mathrm{m}), D_{\mathrm{CO} 2, l}$ the $\mathrm{CO}_{2}$ diffusion coefficient in the liquid $\left(\mathrm{m}^{2} . \mathrm{s}^{-1}\right), u_{l}$ the average liquid velocity $\left(\mathrm{m} \cdot \mathrm{s}^{-1}\right)$ and $\mathrm{L}$ the capillaries length $(\mathrm{m})$. In a previous work, it was reported a predictive correlation between $\mathrm{CO}_{2}$ diffusion coefficient and viscosity for cholinium-based ILs [90]. To estimate the $\mathrm{CO}_{2}$ diffusion coefficient in[Cho+][Lys], the following assumptions were considered: the absorption capacity of the ionic liquid is dependent on the anion nature; the experiments must be performed under isothermal conditions; and the viscosity of the ionic liquid does not vary with the absorption of the gas. $\mathrm{CO}_{2}$ diffusion coefficient in the IL [Cho ${ }^{+}[\mathrm{Lys}]$ can be obtained through the following equation:

$$
D_{\mathrm{C} 02, l}=6.569 \times 10^{-6} \frac{\mu^{-0.805 \pm 0.087} \times V_{m, L L}^{0.508 \pm 0.009}}{\rho^{0.507 \pm 0.006}}
$$

where $\mu$ is expressed in Pa.s, $\mathrm{V}_{\mathrm{m}, \mathrm{LL}}$ in $\mathrm{m}^{3} \cdot \mathrm{mol}^{-1}$ and $\rho$ in $\mathrm{kg} \cdot \mathrm{m}^{-3}$ are the ionic liquid viscosity, molar volume and density, respectively. 


\subsection{Experimental}

\subsubsection{Materials}

The $\left[\mathrm{Cho}^{+}\right]\left[\mathrm{Lys}^{-}\right]$ionic liquid was synthesized from a choline hydroxide solution (45 wt\% aqueous solution, Acros Organics, USA) and L(+)-Lysine monohydrate (99\%, Acros Organics, USA), supplied by Thermofisher Scientific. The gases used in the experiments were carbon dioxide $\left(\mathrm{CO}_{2}\right.$, high-purity grade $99.998 \%$, Praxair, USA), oxygen ( $\mathrm{O}_{2}$, purity grade 99.999\%, Praxair, USA), nitrogen ( $\mathrm{N}_{2}$, purity grade $99.998 \%$, Praxair, USA), nitrous oxide $\left(\mathrm{N}_{2} \mathrm{O}\right.$, purity grade $99.6 \%$, Air Liquide, France) and helium (He, purity grade 99.998\%, Praxair). Two identical gas-liquid membrane contactors were used for the $\mathrm{CO}_{2}$ capture and IL solution isothermal regeneration. Membrane modules are composed by Eclipse ${ }^{\mathrm{TM}}$ capillary membranes, supplied by Markel Corporation (USA) and are made of porous polytetrafluoroethylene, assembled in a stainless-steel housing. Membrane and module specifications were provided by the supplier and are presented in Table 4.1.

Table 4.1 Eclipse ${ }^{T M}$ membrane modules specifications.

\begin{tabular}{lrlc}
\hline \multicolumn{1}{c}{ Capillaries } & \multicolumn{2}{c}{ Modules } \\
\hline Inner diameter $(\mathrm{mm})$ & 1.5 & Number of capillaries $(\mathrm{N})$ & 537 \\
Outer diameter $(\mathrm{mm})$ & 1.9 & Active area $\left(\mathrm{m}^{2}\right)$ & 1 \\
Porosity $(\%)$ & 53 & Inner diameter $(\mathrm{mm})$ & 60 \\
Maximum pore diameter $(\mu \mathrm{m})$ & 0.82 & Effective length $(\mathrm{mm})$ & 406 \\
Mean pore diameter $(\mu m)$ & 0.65 & & \\
Minimum pore diameter $(\mu \mathrm{m})$ & 0.61 & & \\
\hline
\end{tabular}




\subsection{2 [Cho][Lys] synthesis and characterisation}

$\mathrm{L}(+)$-Lysine monohydrate was dissolved in water and added directly to choline hydroxide via a neutralization reaction. The final product was an aqueous solution of $\left[\mathrm{Cho}^{+}\right]\left[\mathrm{Lys}^{-}\right]$ionic liquid, containing $50 \pm 2 \%(\mathrm{w} / \mathrm{w})$ of water. No dehydration step was performed in the IL solution. The reaction was followed by $\mathrm{pH}$ measurement, using a Mettler Toledo $\mathrm{pH}$ probe (model 1405-DPAS-SCK8S, USA) connected to an in-line tester (Jenco, model 3621, USA). The water content was measured by titration, using a Karl-Fischer coulometer without diaphragm (Metrohm, USA, model 831 KF coulometer). The [Cho+][Lys'] molecular structure was confirmed by proton nuclear magnetic resonance $(1 \mathrm{H}-$ NMR) and by attenuated total reflectance Fourier transform infra-red (ATRFTIR) analyses. Both spectra were recorded at room temperature on a Bruker AVANCE Digital operating at $400 \mathrm{MHz}$ and a Perkin Elmer Spectrum Two FTIR Spectrometer, respectively. [Cho+][Lys] thermal stability was accessed by thermogravimetric analysis (TGA), with $10 \mathrm{~K}$ per minute up to $873 \mathrm{~K}$ under nitrogen environment with a flow rate of $40 \mathrm{~mL}^{\mathrm{min}}{ }^{-1}$, using a Q50 thermogravimetric analyser from TA Instruments (USA). [Cho+][Lys'] viscosity and density were determined using a Stabinger viscometer ${ }^{\mathrm{TM}}$ SVM 3000 from Anton Paar (Austria), in the temperature range between 293 to $308 \mathrm{~K}$. The IL surface tension was also measured using a KSV sigma 702 tensiometer from KSV Instruments Ltd. (Finland), at 293 K. A goniometer (KSV Instruments Ltd., Finland) with image analysis software CAM 2008 was used to measure the contact angle between the IL and the surface of the Eclipse ${ }^{\mathrm{TM}}$ membrane. The contact angle was calculated as the average between the right and left contact angles.

\subsection{3 $\mathrm{CO}_{2}$ absorption and IL solution regeneration experimental procedures}

Prior the evaluation of $\mathrm{CO}_{2}$ absorption in the membrane contactor system, the saturation absorption capacity of the $\left[\mathrm{Cho}^{+}\right]\left[\mathrm{Lys}^{-}\right]$IL solution was evaluated. 
Experiments were carried out in a stainless steel cell, by monitoring the $\mathrm{CO}_{2}$ pressure decay with time in contact with a small volume of the IL solution, as described in previous works $[40,90]$. Different concentrations of [Cho+][Lys] aqueous solutions were tested, and the saturation absorption capacity was determined for each one.

Afterwards, $\mathrm{CO}_{2}$ absorption and IL solution regeneration were conducted in a gas-liquid membrane contactor system, as represented in Figure 4.3, at 295 \pm 2 K. Mass flow controllers (Alicat Scientific Inc., MC-series, USA), solenoid valves $\left(\mathrm{ASCO}{ }^{\circledR}, \mathrm{USA}\right)$ and pressure gauges $\left(\mathrm{Omega}^{\mathrm{TM}}, \mathrm{USA}\right)$, controlled the gas flow. Liquid flow was monitored using positive displacement pumps (Micropump ${ }^{\circledR}$, GJ series, USA) and digital pressure gauges (WIKA, DG-10 series, Germany). The IL solution was constantly stirred using a magnetic stirrer plate (Velp Scientifica ${ }^{\circledR}$, Germany), the $\mathrm{pH}$ was measured using a Mettler Toledo $\mathrm{pH}$ probe (model 1405-DPAS-SC-K8S, USA) connected to an in-line tester (Jenco, model 3621, USA) and the temperature measured with a digital thermometer (Huberlab, Switzerland).

Inside the $\mathrm{CO}_{2}$ absorption module (Figure 4.3, module 1), the gas phase flowed in the shell side of the contactor, with a constant flow rate of $250 \mathrm{~mL}$.min 1, simulating what is called minimal gas flow rate anaesthesia $[4,129]$. Since the system was operated in open circuit, the gas pressure was similar to the atmospheric pressure. The IL solution pressure was maintained higher than the gas pressure avoiding bubbling. The [Cho+][Lys'] solution circulated counter currently, with a constant flow rate of $790 \mathrm{~mL} \cdot \mathrm{min}^{-1}$, in the lumen of the capillaries to promote a high driving force between the phases throughout the membrane pores. The regeneration of the IL solution was performed in a second module, connected in series with the absorption module. $\mathrm{N}_{2}$ at atmospheric pressure with a flow rate of $30 \mathrm{~mL} \cdot \mathrm{min}^{-1}$ was used as sweeping gas. The sweep gas flowed counter currently in the shell side. $\left[\mathrm{Cho}^{+}\right]\left[\mathrm{Lys}^{-}\right]$solution circulated with the lowest flow rate possible ( $\left.570 \mathrm{~mL} \cdot \mathrm{min}^{-1}\right)$, assuring a liquid pressure higher than the sweep gas pressure, in order to avoid bubbling and allow for a higher 
residence time in the contactor. All the experimental conditions tested are shown in Table 4.2.

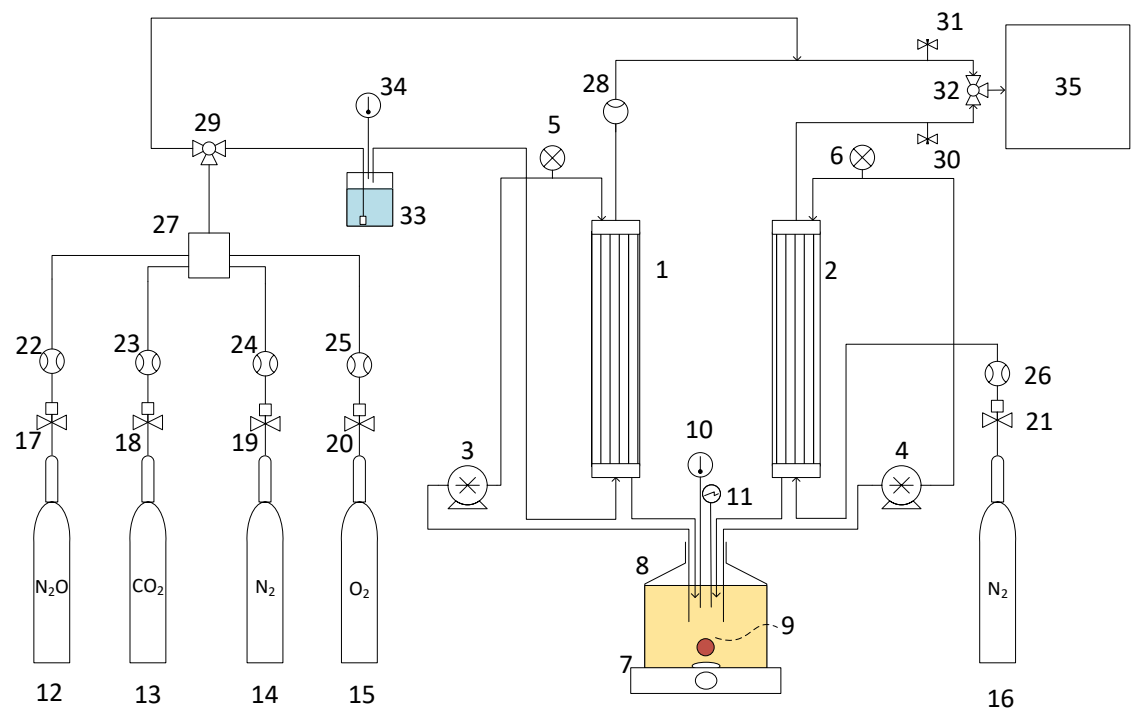

Figure 4.3. Schematic representation of the experimental set-up: 1, 2 - absorption and regeneration membrane modules, respectively; 3, 4 - positive displacement pumps; 5, 6 pressure gauges; 7 - stirrer plate; 8 - ionic liquid vessel; 9 - sampling point; 10 - digital thermometer; 11 - $p H$ meter; 12-16 - gas cylinders; 17-21 - solenoid valves; 22-26 - mass flow controllers; 27 - gas mixture unit; 28 - mass flow indicator; 29, 32 - 3 way manual valves; 30, 31 - needle valves, 33 - stainless steel boiler with a gas disperser, 34 - thermocouple, 35 - GC on-line.

Table 4.2 Experimental conditions in the absorption and regeneration modules.

\begin{tabular}{lcc}
\hline & Absorption module & Regeneration module \\
\hline Temperature $(\mathrm{K})$ & $295 \pm 2$ \\
Gas flow rate $\left({\left.\mathrm{mL} . \mathrm{min}^{-1}\right)}\right.$ & 250 & 30 \\
IL flow rate (mL.min $\left.{ }^{-1}\right)$ & 790 & 570 \\
Feed gas composition & $3 \% \mathrm{~N}_{2}, 5 \% \mathrm{CO}_{2}, 27 \% \mathrm{O}_{2}$, & $100 \% \mathrm{~N}_{2}$ \\
(mol\%) & $65 \% \mathrm{~N}_{2} \mathrm{O}$ & 0.09 \\
IL solution inlet pressure & & 0 \\
(bar) & $0.10-0.14$ & 0 \\
Pressure drop (bar) & 0.07 & \\
\hline
\end{tabular}


The regeneration efficiency was followed by monitoring the composition of the sweep gas stream at the outlet of the module. Aliquots of IL were collected over time and analysed by ATR-FTIR, to evaluate the effect of the $\mathrm{CO}_{2}$ absorption in the molecular structure of the ionic liquid. Also, accessing the FTIR spectrum over time allowed to monitor the absorption kinetics. Gas streams were analysed online using an Agilent gas chromatograph (GC) 7890B, equipped with a thermal conductivity detector (TCD). The GC carrier gas was helium and the samples were analysed using an isothermal method with a PoraPlot $\mathrm{U}$ column connected to a Molsieve 5A column, at $313 \mathrm{~K}$. The TCD detector temperature was maintained at $473 \mathrm{~K}$. Gas samples were introduced into the GC using an automated VICI-Valco gas valve.

To evaluate the maximum capacity of the proposed system, the absorption of $\mathrm{CO}_{2}$ was performed with a pure $\mathrm{CO}_{2}$ feed stream, without regenerating the ionic liquid solution. Afterwards, 3 cycles of $\mathrm{CO}_{2}$ absorption / IL regeneration were conducted aiming to access the regeneration efficiency, from the limit situation where the IL solution was fully saturated. Finally, aiming real conditions simulation, experiments with a gas mixture of $65 \mathrm{~mol} \% \mathrm{~N}_{2} \mathrm{O}, 5 \% \mathrm{CO}_{2}$, $27 \% \mathrm{O}_{2}$ and $3 \% \mathrm{~N}_{2}$, either $100 \%$ humidified or dried, were performed to evaluate the $\mathrm{CO}_{2}$ removal efficiency, determine the separation factor, as well as determine the effect of water vapour in the process efficiency. The absorption flux of $\mathrm{CO}_{2}$ and the overall mass transfer coefficient were also determined.

\subsubsection{Evaluation of experimental mass transfer coefficients}

The parameters obtained by running the experimental set-up, allow to calculate the overall mass transfer coefficient, $K_{o v}$, according to the following equation:

$$
K_{o v}=\frac{Q_{g} \times\left(C_{C O 2, i n, g}-C_{C O 2, o u t, g}\right)}{A \times \Delta C_{C O 2, g, l m}}
$$


where the $Q_{g}$ is the gas flow rate $\left(\mathrm{m}^{3} \cdot \mathrm{s}^{-1}\right)$ inside the module, $C_{C O 2, \text { in }, g}$ and $C_{C O 2, o u t, g}$ are the gas phase inlet and outlet $\mathrm{CO}_{2}$ concentrations (mol.m-3), $A$ is the gas-liquid contact area $\left(\mathrm{m}^{2}\right)$ and $\Delta C_{C O 2, g, l m}$ is the logarithmic mean driving force based on the gas phase concentrations $\left(\right.$ mol. $\left.\mathrm{m}^{-3}\right)$, described as:

$$
\Delta C_{\mathrm{CO}, \mathrm{lm}}=\frac{\left(C_{\mathrm{CO} 2}-C_{\mathrm{CO} 2}^{*}\right)_{g, \text { in }}-\left(C_{\mathrm{CO} 2}-C_{\mathrm{CO} 2}^{*}\right)_{g, \text { out }}}{\ln \left[\left(C_{\mathrm{CO} 2}-C_{\mathrm{CO} 2}^{*}\right)_{g, \text { in }} /\left(C_{\mathrm{CO} 2}-C_{\mathrm{CO} 2}^{*}\right)_{g, \text { out }}\right]}
$$

$C_{C O 2, \text { in }}^{*}$ and $C_{C O 2, o u t}^{*}$ are the equilibrium concentrations at the interface between the gas and liquid phases. Due to the fast chemical reaction, $\mathrm{CO}_{2}$ concentration in the liquid phase is equal to 0 , and $C_{C O 2, g}^{*}$ is 0 . Therefore, the equation is simplified as follows:

$$
\Delta C_{C O 2, \operatorname{lm}}=\frac{C_{C O 2, \text {, in }}-C_{C O 2, \text { g,out }}}{\ln \left[{ }^{C_{C O 2, g, \text { in }}} / C_{C O 2, \text { out }}\right]}
$$

Moreover, to determine the process efficiency, a separation factor $(S F)$ between $\mathrm{CO}_{2}$ and $\mathrm{N}_{2} \mathrm{O}$ was determined. Considering the ratio between the permeable species in the feed and the permeate side, $S F$ was determined according to the following equation:

$$
S F=\frac{n_{i, p} / n_{j, p}}{n_{i, f} / n_{j, f}}
$$

where, $p$ and $f$ are the permeate and feed streams and $i$ and $j$ the permeable species, in particular i the most permeable one. 


\subsection{Results and discussion}

\subsection{1 [Cho+][Lys] $]$ characterisation}

In this work, due to the low toxicity and low production cost, when compared to other traditional ILs, and recognized efficiency to capture $\mathrm{CO}_{2}$, [Cho+][Lys-] was the IL selected to absorb $\mathrm{CO}_{2}$ using a membrane contactor system, aiming the operation in a closed-loop anaesthetic circuit. To increase the cost-effectiveness of this IL, it is proposed the use of an aqueous solution of [Cho+][Lys]. As referred in Section 4.3.3, a pre-screening study of $\mathrm{CO}_{2}$ absorption with different $\left[\mathrm{Cho}^{+}\right][\mathrm{Lys}] \mathrm{IL}$ concentrations was performed. According to the results obtained, the highest $\mathrm{CO}_{2}$ absorption was achieved for the IL solution with $60 \mathrm{wt} \%$ of [Cho+][Lys] (Figure 4.4a). However, the solution must possess low viscosity to minimise the gas-liquid mass transfer resistance and increased pressure in the capillaries. Therefore, the dynamic viscosities of the IL solutions were measured, as shown in Figure 4.4b. The viscosity obtained for the IL solution with $60 \mathrm{wt} \%$ of [Cho+][Lys] was $36 \mathrm{mPa} . \mathrm{s}$, at $293 \mathrm{~K}$, while for the $50 \mathrm{wt} \%$ [Cho+][Lys-] was significantly lower (15 mPa.s). Since a slight difference in the $\mathrm{CO}_{2}$ absorption between both IL solutions was obtained, $50 \mathrm{wt} \%$ [Cho+][Lys] was the concentration selected to perform the present study. Additionally, in the case of the $50 \mathrm{wt} \%$ solution, the $\mathrm{CO}_{2}$ absorption kinetics is faster when compared to the $60 \mathrm{wt} \%$ solution, which leads to a faster $\mathrm{CO}_{2}$ removal rate, as it can be observed in Figure 4.4a, that presents the pressure profiles for the first hours of the experiments.

The thermal stability of the $\mathrm{CO}_{2}$ absorbents is exceptionally relevant and must be taken into account, as it can affect their absorption and desorption behaviour [115]. In a typical hospital surgery room, temperature ranges between 293 and $297 \mathrm{~K}$ [130], [Cho+][Lys] is stable against temperature variations, as it is demonstrated in Figure 4.5. Furthermore, in a perspective of possible thermal regeneration, the temperatures should not go higher than $453 \mathrm{~K}$, which corresponds to the onset temperature where weight loss was registered due to thermal degradation. 

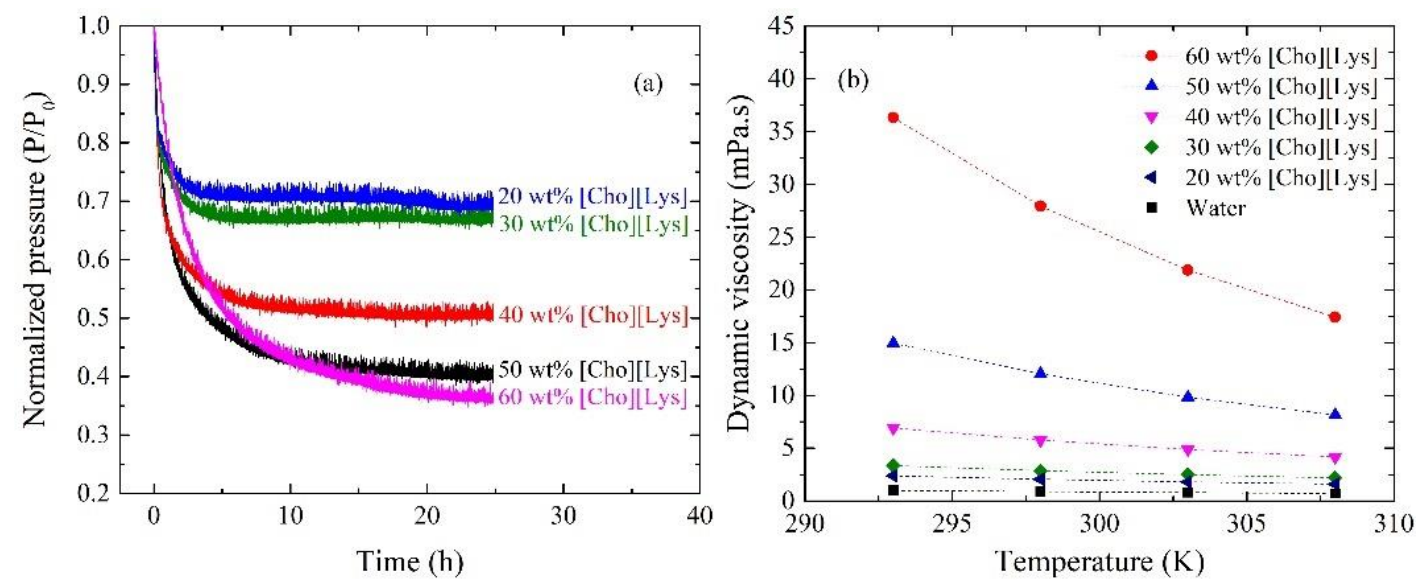

Figure 4.4 (a) Screening of $\mathrm{CO}_{2}$ absorption in different [Cho+][Lys] aqueous solutions; (b) Dynamic viscosity of different [ $\left.\mathrm{Cho}^{+}\right]\left[\mathrm{Lys}^{-}\right]$aqueous solutions as a function of temperature.

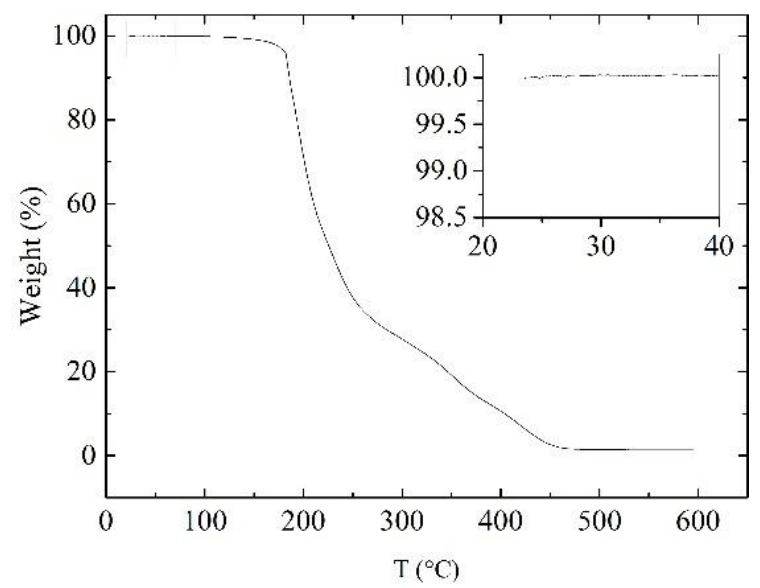

Figure 4.5 Thermogravimetric curve for [Cho+][Lys-] as a function of temperature.

The contact angle obtained between the $50 \mathrm{wt} \%\left[\mathrm{Cho}^{+}\right]\left[\mathrm{Lys}^{-}\right]$solution and the PTFE membrane was $97^{\circ}$, at $295 \mathrm{~K}$. Contact angles higher than $90^{\circ}$ are associated to hydrophobic surfaces and usually used as a reference to operate membrane modules in a non-wetted pore mode, avoiding liquid penetration and stagnation inside the pores [131]. Therefore, the PTFE modules selected for this work assure that the pores of the membrane are not affected by wetting with the 
liquid phase. This is an important feature which allows the operation of the system without resistance to mass transfer due to the presence of the membrane.

\subsection{2 $\mathrm{CO}_{2}$ capture maximum absorption capacity}

The absorption of $\mathrm{CO}_{2}$ was performed using a pure $\mathrm{CO}_{2}$ feed stream, to access the maximum absorption capacity of the $\left[\mathrm{Cho}^{+}\right]\left[\mathrm{Lys}^{-}\right]$solution $(50 \mathrm{wt} \%)$. The $\mathrm{CO}_{2}$ flow rate was adjusted to $250 \mathrm{~mL} \cdot \mathrm{min}^{-1}$, which is analogous to the minimal-flow anaesthesia mode [129]. The $\mathrm{CO}_{2}$ absorption by the ionic liquid occurs across the gas-liquid interface, due to the contact between the stabilised phases inside the pores of the PTFE capillaries of the membrane contactor.
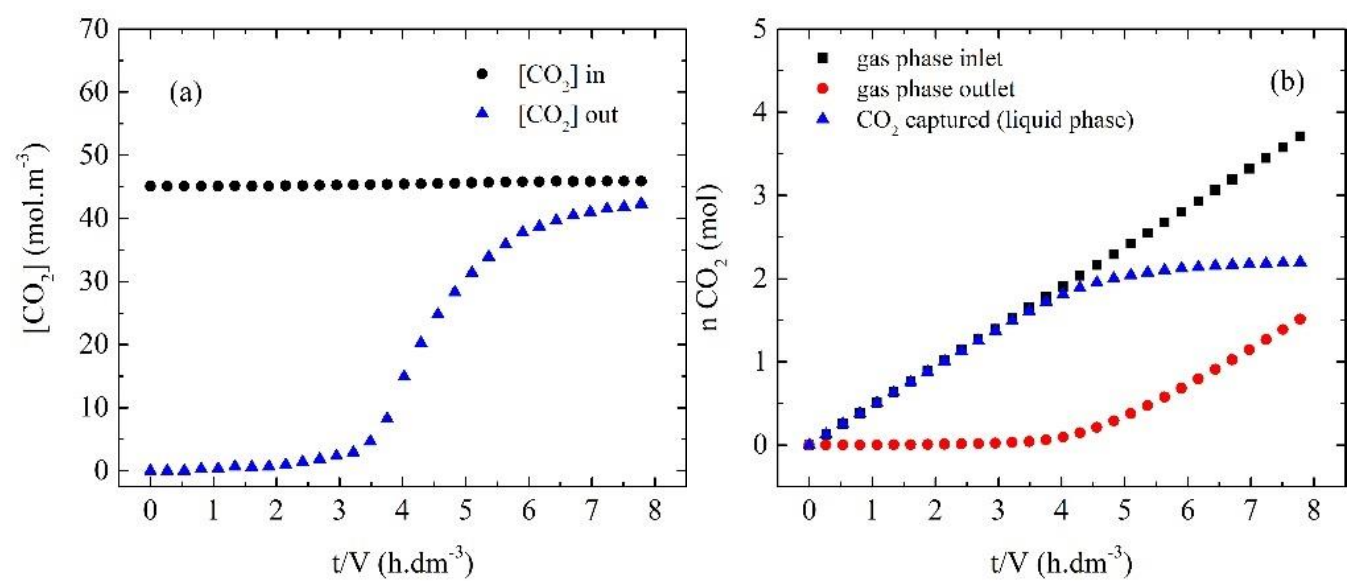

Figure 4.6 Experimental $\mathrm{CO}_{2}$ absorption curves: (a) inlet and outlet $\left[\mathrm{CO}_{2}\right]$ in the gas phase as a function of time per IL solution volume; (b) Accumulated $\left[\mathrm{CO}_{2}\right]$ in gas and liquid phases as a function of time per IL solution volume.

In Figure 4.6a is represented the $\mathrm{CO}_{2}$ concentration of the inlet and outlet streams in the gas phase as a function of time per volume of IL. Since the process is completely controlled by the liquid phase, the duration of the experiments is dependent of the volume of the IL solution used, thus in the present work, the time variable is always shown by the ratio time per IL volume used in each experiment. The profile obtained for the $\mathrm{CO}_{2}$ concentration in the gas outlet stream is the result of an absorption accompanied by chemical reaction. Once the 
liquid phase approaches saturation, we started to observe the presence and increase of $\mathrm{CO}_{2}$ concentration in the gas outlet stream. The number of $\mathrm{CO}_{2}$ moles captured by the liquid phase was obtained assuming the difference between the inlet and outlet streams in the gas phase, which is related with the $\mathrm{CO}_{2}$ absorption by the IL (Figure 4.6b). The absorption of $\mathrm{CO}_{2}$, in this case, was performed using $700 \mathrm{~mL}$ of $50 \mathrm{wt} \%$ [Cho $\left.{ }^{+}\right]\left[\mathrm{Lys}^{-}\right]$solution and a liquid flow rate of $524 \mathrm{~mL} \cdot \mathrm{min}^{-1}$. Saturation was achieved after 5.5 hours of operation, corresponding to a time per IL volume of $7.8 \mathrm{~h} . \mathrm{dm}^{-3}$. According to Equation (4.10), the overall mass transfer coefficient can be calculated through the ratio between the $\mathrm{CO}_{2}$ absorption flux and the mean logarithmic $\mathrm{CO}_{2}$ concentration in the gas phase (driving force). The value obtained for $K_{o v}$ was $2.16 \times 10^{-5} \mathrm{~m} . \mathrm{s}^{-1}$ with a $\mathrm{CO}_{2}$ flux of $1.82 \times 10^{-4} \mathrm{~mol} . \mathrm{m}^{-2} . \mathrm{s}^{-1}$. The total amount of $\mathrm{CO}_{2}$ captured was $5.9 \mathrm{molCO}_{2} / \mathrm{kgIL}$, which is superior to the maximum absorption capacity of soda lime reported in literature $(19 \mathrm{wt} \%$, which corresponds to $4.32 \mathrm{~mol} / \mathrm{kg}$ ) [132].

The absorption of $\mathrm{CO}_{2}$ was followed by measuring the $\mathrm{pH}$ in situ and performing an IR spectra analysis of the IL samples. In Figure 4.7a, the pH variation during the $\mathrm{CO}_{2}$ absorption is represented. [Cho+][Lys-] solution possess a strong basic character which is confirmed through the extremely high initial $\mathrm{pH}(\sim 13)$. Due to this strong basicity, the IL is very reactive towards $\mathrm{CO}_{2}$. The $\mathrm{pH}$ decreases over time as a consequence of the neutralization reaction between $\mathrm{CO}_{2}$ and $\left[\mathrm{Cho}^{+}\right]\left[\mathrm{Lys}^{-}\right]$solution due to the formation of the bicarbonate anion. The saturation state of the IL solution is represented by the plateau obtained at $\mathrm{pH}$ $\sim 8$. Figure $4.7 \mathrm{~b}$ is a representation of the $\mathrm{CO}_{2}$ absorption impact at a molecular level. Representative differences were obtained in the FTIR spectra of the samples before and after $\mathrm{CO}_{2}$ absorption, characterised by an increase of the absorbance bands at $1647 \mathrm{~cm}^{-1}, 1558 \mathrm{~cm}^{-1}, 1478 \mathrm{~cm}^{-1}, 1408 \mathrm{~cm}^{-1}$ and $1358 \mathrm{~cm}^{-1}$. The absorbance band corresponding to the $-\mathrm{NH}_{3}^{+}$group is observed at the region $1600-1750 \mathrm{~cm}^{-1}$ [133]. Therefore, the band at $1647 \mathrm{~cm}^{-1}$ is attributed to the protonated amino groups, which formation was predicted by the chemical model as described in Section 4.2.1. An absence of a band in the $2500-3000 \mathrm{~cm}^{-1}$ region after the $\mathrm{CO}_{2}$ absorption (spectra available in the Appendix B), indicates no 
formation of carbamic acid. Generally, the interaction between amino groups and $\mathrm{CO}_{2}$ can proceed through carbamate or carbamic acid formation pathways. Hence, the pathway of carbamic acid formation was not considered in the chemical mechanism described in the present work [126,133]. The two bands at $1558 \mathrm{~cm}^{-1}$ and $1408 \mathrm{~cm}^{-1}$ correspond to the asymmetric and symmetric stretching vibrations of $\mathrm{COO}^{-}$, respectively. Depending on the molecular constituents, carboxylates bands are generally present in the $1650-1540 \mathrm{~cm}^{-1}$ and $1450-1360 \mathrm{~cm}^{-}$ 1 regions. Inorganic carbonates do not possess $\mathrm{C}-\mathrm{O}$ and $\mathrm{C}=\mathrm{O}$ stretching vibrations. Thus, the " $\mathrm{C}-\mathrm{O}$ " bond order of the inorganic carbonates is between one and two, possessing a stretching vibration band in the region $1410-1510 \mathrm{~cm}^{-}$ 1. The identified band at $1478 \mathrm{~cm}^{-1}$ is then attributed to the vibration of the carbonate ion $\mathrm{CO}_{3}^{2-}[134,135]$. Therefore, the FTIR spectra analysis of the IL solution after $\mathrm{CO}_{2}$ absorption confirmed the formation of the ionic species bicarbonate ion $\mathrm{HCO}_{3}^{-}$, protonated amine $\mathrm{NH}_{3}^{+}$and carbonate ion $\mathrm{CO}_{3}^{2-}$, as described by the proposed chemical mechanism (Equations (4.1) to (4.6) in Section 4.2).
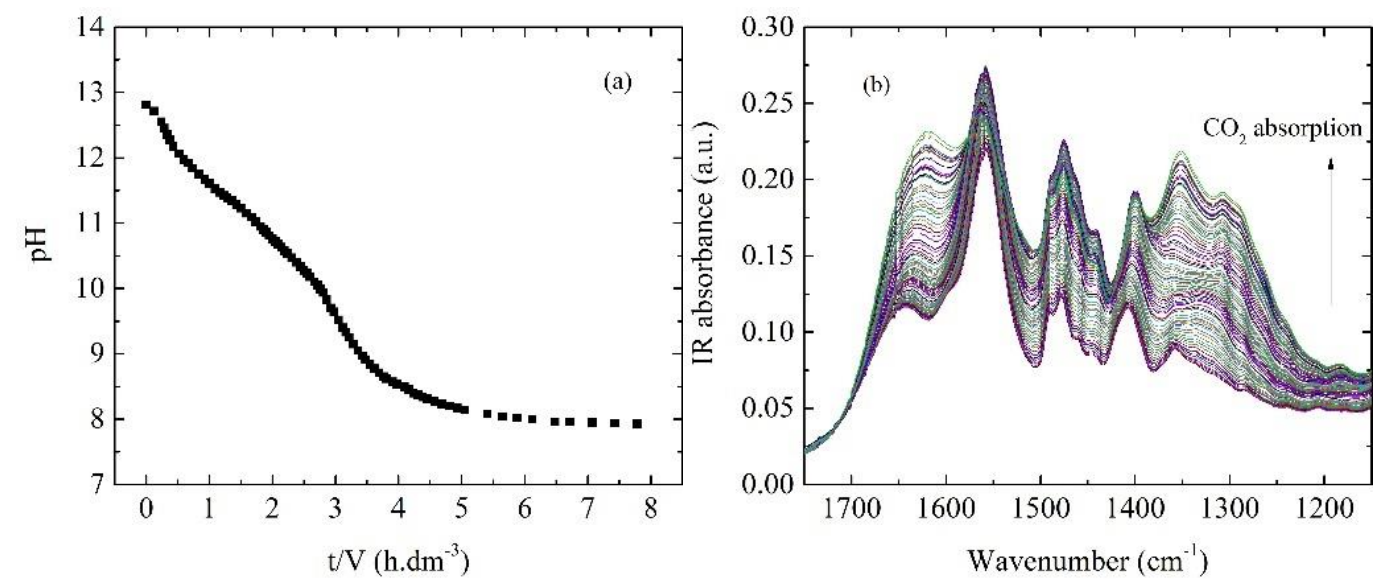

Figure $4.7 \mathrm{CO}_{2}$ absorption in [Cho+][Lys] IL solution, monitored by $\mathrm{pH}$ measurement and ATRFTIR analysis: (a) $p H$ variation as a function of time per IL solution volume; (b) IR absorbance as a function of the wavenumber. 
Regarding to analytical methods, especially in cases of process monitoring, it is important to mention that both $\mathrm{pH}$ measurements and IR spectra analysis are fast techniques, clean and easy to use, which allow for an efficient monitoring of the $\mathrm{CO}_{2}$ loading in the ionic liquid solution.

\subsection{3 $\mathrm{CO}_{2}$ maximum absorption capacity and IL solution regeneration cycles}

Regeneration of the IL solution integrated with the $\mathrm{CO}_{2}$ absorption can be a step forward when comparing to the current technology, since soda lime is disposed after reaching its saturation, adding an extra cost to the hospitals. In Figure 4.8 are represented the $\mathrm{CO}_{2}$ maximum absorption and IL regeneration cycles, with the $\mathrm{pH}$ evolvement as a function of time per IL volume (a) and the $\mathrm{CO}_{2}$ loading as a function of time per IL volume (b).
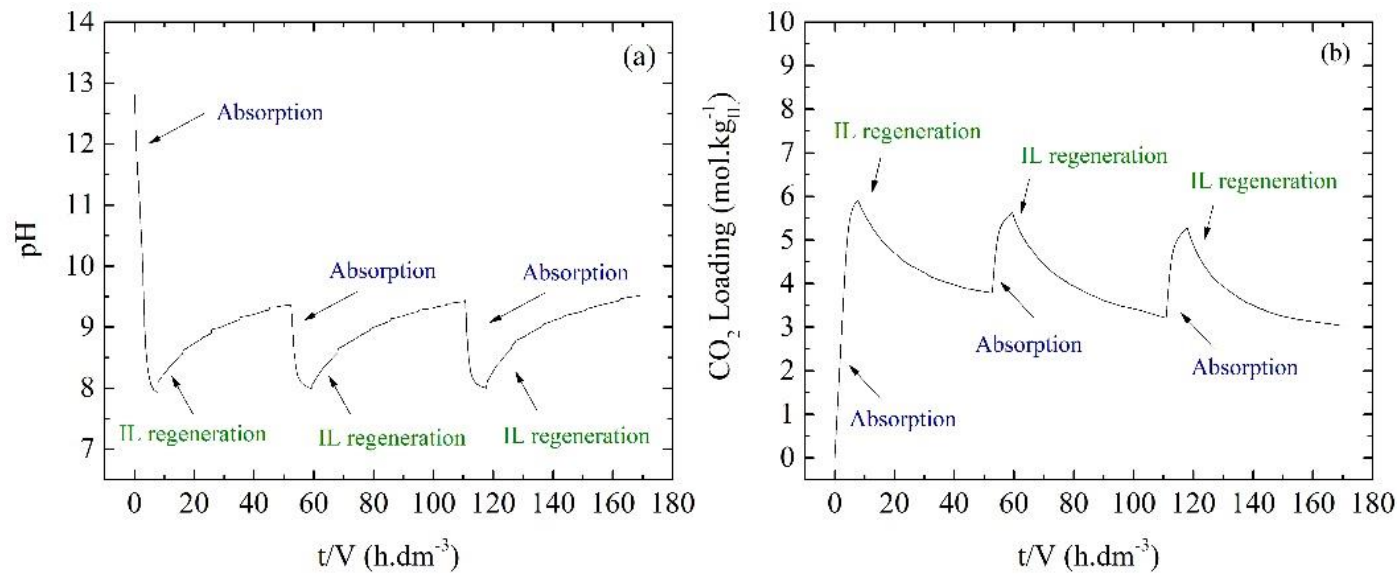

Figure $4.8 \mathrm{CO}_{2}$ absorption and IL regeneration cycles: (a) $\mathrm{pH}$ as a function of time per IL solution volume; (b) $\mathrm{CO}_{2}$ loading as a function of time per IL solution volume.

Cycles of $\mathrm{CO}_{2}$ absorption/IL regeneration were performed, where the $\mathrm{CO}_{2}$ absorption was accomplished feeding as gas stream pure $\mathrm{CO}_{2}$ and the IL regeneration with $\mathrm{N}_{2}$ as the sweep gas. In the first cycle, the complete saturation of the IL was achieved, corresponding to a $\mathrm{CO}_{2}$ loading value of 5.9 molco2 $/ \mathrm{kg}_{\mathrm{IL}}$. 
The IL regeneration efficiency, after the saturation state was $36 \%$, which corresponds to the disruption of the weaker chemical bond between the amine in the carboxylic acid functional group of the lysinate anion and bicarbonate. In the second cycle, the resulting $\mathrm{CO}_{2}$ absorption capacity corresponded to what was reverted in the first regeneration cycle. In the second and third absorption/regeneration cycles, the regeneration was complete, since the amount of $\mathrm{CO}_{2}$ absorbed in the previous absorption step was totally reverted, as it is demonstrated in Figure 4.8b. Therefore, if a complete regeneration is desired starting from the first cycle, that will probably be possible by performing a thermal regeneration step, in order to revert the remaining bond between bicarbonate and the amino group in the alkyl side chain of lysinate anion and, by this mean, exploit the full potential of the IL solution. Since we are in the presence of an IL solution with high water content, the thermal regeneration must be performed at temperatures below $100{ }^{\circ} \mathrm{C}$.

\subsection{4 $\mathrm{CO}_{2}$ removal from anaesthetic gas mixtures}

In a closed-loop operation perspective, the content of $\mathrm{CO}_{2}$ in the recirculated anaesthetic gas mixture must be lower than $0.5 \%$, to avoid hypercapnia (high levels of $\mathrm{CO}_{2}$ in blood), hypoxemia or hypoxia (low levels of $\mathrm{O}_{2}$ in blood and tissue). The anaesthetic gas mixture to be recovered contain around $5 \%$ of $\mathrm{CO}_{2}$, thus, the following results correspond to experiments aiming an operation efficiency superior to $90 \%$.

To evaluate the $\mathrm{CO}_{2}$ capture from anaesthetic gas mixtures, experiments considering nitrous oxide as the anaesthetic gas were conducted, simulating realistic conditions. Therefore, a gas mixture composition of $65 \% \mathrm{~N}_{2} \mathrm{O}, 5 \% \mathrm{CO}_{2}$, $27 \% \mathrm{O}_{2}$ and $3 \% \mathrm{~N}_{2}$ was used to feed the module, mimicking the exhalation of a patient. In addition, experiments with $100 \%$ humidified feed gas stream and with simultaneous IL regeneration were also performed. In Table 4.3 the experimental and calculated mass transfer parameters obtained are shown. 
Table 4.3. Experimental and calculated mass transfer parameters.

\begin{tabular}{|c|c|c|c|}
\hline $\begin{array}{r}\text { Gas feed } \\
\text { conditions }\end{array}$ & Dried & $100 \%$ RH & $100 \% \mathrm{RH}+$ IL regeneration \\
\hline \multicolumn{4}{|l|}{ Parameters } \\
\hline$u_{l}\left(m \cdot s^{-1}\right)$ & & & \\
\hline$k_{l} \times 10^{-6}\left(\mathrm{~m} \cdot \mathrm{s}^{-1}\right)$ & & & \\
\hline $\begin{array}{l}\text { Volume of.IL } \\
\left(\mathrm{dm}^{3}\right)\end{array}$ & 0.75 & 0.80 & 1.35 \\
\hline Time $(h)$ & 36 & 39 & 63 \\
\hline $\begin{array}{l}\text { Time/IL volume } \\
\left(h . d m^{-3}\right)\end{array}$ & 47.7 & 48.5 & 46.9 \\
\hline $\begin{array}{l}\mathrm{JCO}_{2} \times 10^{-6} \\
\left(\mathrm{~mol} \cdot \mathrm{m}^{-2} \cdot \mathrm{s}^{-1}\right)\end{array}$ & 8.34 & 8.55 & 8.46 \\
\hline $\begin{array}{l}J \mathrm{~N}_{2} \mathrm{O} \times 10^{6} \\
\left(\mathrm{~mol} \cdot \mathrm{m}^{-2} \cdot \mathrm{s}^{-1}\right)\end{array}$ & 4.43 & 4.83 & 5.75 \\
\hline $\begin{array}{l}\text { K cO2,overall } x 10^{-6} \\
\left(m \cdot s^{-1}\right)\end{array}$ & 9.15 & 9.36 & 9.33 \\
\hline$\varphi$ & 1.25 & 1.28 & 1.28 \\
\hline$S F$ & 21.36 & 18.59 & 14.61 \\
\hline $\begin{array}{l}\mathrm{CO}_{2} \text { Loading } \\
\left(\mathrm{mol} \mathrm{kg}^{-1}\right)\end{array}$ & 3.14 & 2.92 & 2.86 \\
\hline
\end{tabular}

The obtained flux of $\mathrm{CO}_{2}$ was identical for all experiments, using $\mathrm{N}_{2} \mathrm{O}$ in the gas mixture as the anaesthetic gas. Therefore, the presence of water in the gas mixture and the simultaneous IL regeneration do not compromise the $\mathrm{CO}_{2}$ mass 
transfer. The regeneration step does not affect the $\mathrm{CO}_{2}$ transport, since the driving force was already the maximum possible, due to the fast reaction between $\mathrm{CO}_{2}$ and the liquid phase, resulting in an immediate consumption of $\mathrm{CO}_{2}$. The experimental time obtained for all cases, shown in Table 4.3, correspond to an operation efficiency above $90 \%$, meaning a $\mathrm{CO}_{2}$ content in the recycled gas mixtures lower than $0.5 \%$, as required. This experimental condition explains why the values obtained for the $\mathrm{CO}_{2}$ loadings expressed in Table 4.3 are inferior to the reported in Section 4.4.3, since the $\mathrm{CO}_{2}$ content of $0.5 \%$ in the recycled gas stream is detected before the IL solution reaches its complete saturation.

On the other hand, $\mathrm{N}_{2} \mathrm{O}$ flux increases in the presence of the humidified feeding gas mixture. The presence of water vapour in the gas phase leads to water transfer from the gas to the ionic liquid phase, due to the higher water activity of the saturated gas $\left(a_{w}=1\right)$ when compared to the liquid phase $\left(a_{w} \sim 0.75\right)$. The increase of water content in the ionic liquid phase facilitates the aqueous solvation of $\mathrm{N}_{2} \mathrm{O}$, leading to an increase of its transfer to the ionic liquid phase. This additional transport has no impact on the transport of $\mathrm{CO}_{2}$ because, due to its fast reaction at the gas-liquid interface, its concentration in a free form inside the liquid phase is negligible. A similar behaviour was already reported in the literature $[55,136]$. Still, the overall selective removal of $\mathrm{CO}_{2}$ from the gas phase, when compared with the transport of $\mathrm{N}_{2} \mathrm{O}$, is rather impressive if we remember that these molecules possess similar properties, such as molecular mass, chemical configuration, molecular volume, electronic structure and kinetic diameters (Table 4.4), that explain their similar solubility and diffusivity in water.

Table 4.4. Lennard-Jones and kinetic diameters.

\begin{tabular}{ccc}
\hline & $\begin{array}{c}\text { Lennard-Jones diameter } \\
(\AA)\end{array}$ & Kinetic diameter \\
\hline $\mathrm{CO}_{2}$ & $3.941[99]$ & $3.330[137]$ \\
& & \\
$\mathrm{N}_{2} \mathrm{O}$ & $3.828[99]$ & $3.330[138]$ \\
\hline
\end{tabular}


Also, it is important to mention the very low partial pressure of $\mathrm{CO}_{2}(5 \%$ mol) compared with the partial pressure of $\mathrm{N}_{2} \mathrm{O}(65 \% \mathrm{~mol})$ in the feed stream, and even though there was a transport of $\mathrm{N}_{2} \mathrm{O}$ to the liquid phase, the removal of $\mathrm{CO}_{2}$ was not affected. The separation factors obtained $(S F)$, shown in Table 4.3, are considerable high for all cases, which is a proof that the proposed system is very selective towards $\mathrm{CO}_{2}$. For the experimental procedure mimicking the real conditions, i.e., containing $65 \%$ of the anaesthetic gas humidified, the system proposed with simultaneous IL regeneration, was able to operate efficiently for 63 hours.

In the current technology, that utilises containers with $1 \mathrm{~kg}$ of soda lime for $\mathrm{CO}_{2}$ capture in anaesthetic closed circuits, it is recommended to replace the container after 8 to 14 hours of continuous operation, depending on the supplier recommendations and the usage. Furthermore, the maximum absorption capacity of soda lime to capture $\mathrm{CO}_{2}$ is $4.32 \mathrm{~mol} / \mathrm{kg}$ [132]. Based on the results obtained in this work, the proposed system was able to operate over 63 hours

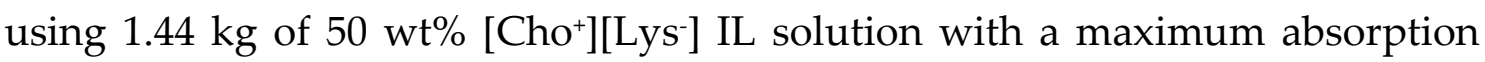
capacity of $5.9 \mathrm{~mol} / \mathrm{kg}$. Comparing with the use of a container with $1 \mathrm{~kg}$ of soda lime, the proposed system possesses a working operation time 3 to 5 times higher of $1 \mathrm{~kg}$ of [Cho+ ${ }^{+}\left[\mathrm{Lys}^{-}\right]$IL solution is used ( 43 hours of operation).

\subsection{Conclusions}

Experiments of $\mathrm{CO}_{2}$ capture from gas mixture with anaesthetic agents have been performed, using a $50 \mathrm{wt} \%$ [Cho+][Lys $]$ IL solution. The system was composed by polytetrafluoroethylene porous membrane contactors with the IL solution circulating in counter current with the gas phase in the lumen of the capillaries. Additionally, a regeneration unit composed by a second membrane contactor was simultaneously operated. The results obtained revealed a $\mathrm{CO}_{2}$ capture maximum capacity of the system of $5.9 \mathrm{~mol} / \mathrm{kgIL}$. In the experiments in which simulated conditions using $65 \%$ of nitrous oxide and $5 \%$ of carbon dioxide, the results revealed an efficient system able to operate over 63 hours. However, 
the regeneration of the IL solution using $\mathrm{N}_{2}$ as sweep gas, was not completely efficient for the reversion of the $\mathrm{CO}_{2}$ absorption. Due to this fact, a thermal regeneration study is recommended as future work. Additionally, the proposed system should be tested using a feed stream mimicking real conditions, using the exhaled composition as well as with pulsed flow, simulating the expiratory frequency. 


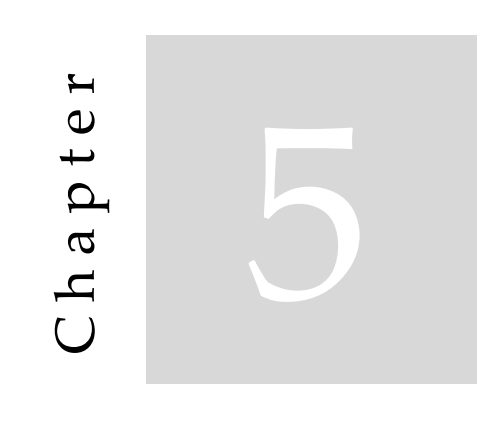

\section{Modelling $\mathrm{CO}_{2}$ absorption in aqueous solutions of cholinium lysinate ionic liquid}

Published as: C. F. Martins, L. A. Neves, R. Chagas, L. M. Ferreira, C. A. M. Afonso, I. M. Coelhoso, J. G. Crespo, J. P. B. Mota, "Modelling $\mathrm{CO}_{2}$ absorption in aqueous solutions of cholinium lysinate ionic liquid", Chemical Engineering Journal, 2020, 127875.

\section{Summary}

Ionic liquids (ILs) with quaternary ammonium cations combined with biocompatible anions from renewable sources result in low-toxic, biocompatible, cost-efficient sorbent media that can efficiently capture carbon dioxide $\left(\mathrm{CO}_{2}\right)$. The understanding of the equilibrium and kinetics of $\mathrm{CO}_{2}$ absorption in these media is relevant for the design of new absorption processes in many application areas, such as the removal of $\mathrm{CO}_{2}$ from post-combustion streams, biogas refinery waste gases, or confined spaces. Here $\mathrm{CO}_{2}$ absorption in an aqueous solution of cholinium lysinate IL is studied both theoretically, via mechanistic modelling, and experimentally in a membrane contactor operated in closed loop with online $\mathrm{pH}$ measurement and attenuated total reflectance Fourier transform infrared spectroscopy (ATR-FTIR) analysis of discrete sampling of the circulating aqueous IL solution. It is shown that both techniques are effective tools for $\mathrm{CO}_{2}$ quantification in the liquid phase. The IL yields an absorption capacity of 
2.20 moles of $\mathrm{CO}_{2}$ per mole of IL for an IL concentration of $2.13 \mathrm{M}$ (or $50 \mathrm{wt} \%$ solution). A comprehensive model of chemisorption thermodynamics and absorption dynamics is proposed and validated experimentally. It provides not only the equilibrium constants of the reversible reactions of protonation of the amine groups and bicarbonate binding and overall mass-transfer coefficient based on liquid-phase concentrations, but is also the basis for a chemometric analysis of the experimental ATR-FTIR data. The potential use of ATR-FTIR as a monitoring tool of $\mathrm{CO}_{2}$ in aqueous solutions of cholinium lysinate IL is also demonstrated.

\subsection{Introduction}

The development of new and more efficient carbon dioxide $\left(\mathrm{CO}_{2}\right)$ capture processes has been gaining interest of both industry and academia over the years. According to the Scopus ${ }^{\circledR}$ database, the main areas where $\mathrm{CO}_{2}$ capture is more relevant are energy, engineering - especially chemical engineering environmental and materials science, agricultural, and biological sciences. In medicine, $\mathrm{CO}_{2}$ capture agents (e.g. soda lime) are essential for commercial application of inhaled anaesthetics, and thus, to the modern practice of anaesthesia [7].

There has been significant research on $\mathrm{CO}_{2}$ capture and separation, but despite the emergence of new $\mathrm{CO}_{2}$ capture agents, aqueous amine solutions (e.g., monoethanolamine, diethanolamine) are still the most commonly used absorbers $[139,140]$. There are, however, some niche applications where $\mathrm{CO}_{2}$ cannot be captured using traditional aqueous amine solutions, such as hospital and medical clinic environments (i.e., surgical rooms), where the rules are extremely restrictive, especially regarding temperature, humidity, and cleaning conditions. The chemical degradation of aqueous amine solutions and vapour emissions that are produced during $\mathrm{CO}_{2}$ capture hinder their use in hospital environments. Therefore, the selection and synthesis of a particular $\mathrm{CO}_{2}$ capture agent depends 
on the type of application, and this has motivated researchers to seek alternatives to amine scrubbing [141,142].

Biocompatible amine-based agents possessing negligible volatility and excellent thermal stability, such as ionic liquids (ILs) with amine functionality, are desirable for the abovementioned niche applications, as is the case of medical environments. ILs with quaternary ammonium cations, of which the cholinium cation is a prominent example, are biocompatible and are much less toxic than most conventional room-temperature ILs (e.g., ILs with imidazolium cations). Moreover, unlike conventional ILs, those with quaternary ammonium cations are not limited to physical absorption since the amino groups can react with $\mathrm{CO}_{2}$, allowing its chemisorption and thereby improving their $\mathrm{CO}_{2}$ absorption capacity. The combination of the cholinium cation with biocompatible anions from renewable sources, such as amino acids, results in low toxic, biocompatible, and cost-effective ILs with recognised efficiency for $\mathrm{CO}_{2}$ capture [90,143-146]. Furthermore, amino acid salts are known to have better oxidative stability than traditional aqueous amine solutions [119,147,148]. Figure 5.1 shows the molecular structures of the cholinium cation and a generic amino acid anion, where $\mathrm{R}$ denotes an alkyl side chain with a functional group.
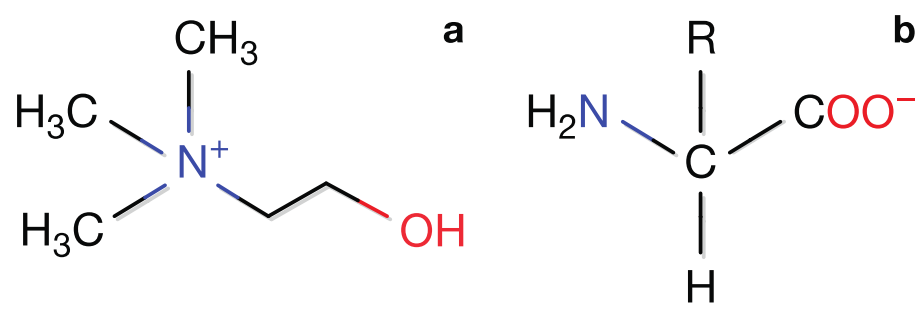

Figure 5.1 Molecular structures of (a) cholinium cation and (b) generic amino acid anion.

In addition to such desirable attributes as low environmental impact, high thermal and chemical stabilities, and fast absorption rate, the production cost of a new and efficient IL for $\mathrm{CO}_{2}$ capture is also of great importance. For these reasons, cholinium-based ILs combined with amino acid anions are emerging as alternative absorption media for $\mathrm{CO}_{2}$ capture. Additionally, the strategy of using 
aqueous solutions of functionalised ILs along with biocompatible and biodegradable compounds is gaining projection in the $\mathrm{CO}_{2}$ capture field, due to all the well-known environmental impact problems.

Many authors have investigated $\mathrm{CO}_{2}$ absorption in IL solutions with increased content of functional amino groups with promising results [133,144,149-151]. Zhou et al. [149] developed a novel triamino-functionalized IL and measured the $\mathrm{CO}_{2}$ absorption capacity in a $0.5 \mathrm{M}$ IL aqueous solution, reporting a very reasonable loading value of 1.59 moles of $\mathrm{CO}_{2}$ per mole of IL. Yuan et al. [144] investigated $\mathrm{CO}_{2}$ absorption in aqueous solutions with 5-30 wt\% of three cholinium-based amino acid ILs. These authors observed an increase of the apparent absorption rate constant, a decrease of the solution viscosity, and reduction of the $\mathrm{CO}_{2}$ absorption loading with the increase in water content. Additionally, the replacement of some of the IL by water reduces the cost of the aqueous IL solution. Therefore, to develop an efficient IL-based absorption medium competitive with current technologies, a trade-off must be found between the $\mathrm{CO}_{2}$ loading and absorption rate.

Here we study $\mathrm{CO}_{2}$ absorption in an aqueous solution with $50 \mathrm{wt} \%$ of cholinium lysinate $\left(\left[\mathrm{Cho}^{+}\right]\left[\mathrm{Lys}^{-}\right]\right)$IL, where $\left[\mathrm{Cho}^{+}\right]$is the 2-hydroxy-N,N,Ntrimethylethanaminium cation, commonly called cholinium cation, and [Lys ${ }^{-}$] the $\alpha$-amino-acid anion $\left(\mathrm{C}_{6} \mathrm{H}_{13} \mathrm{~N}_{2} \mathrm{O}_{2}^{-}\right)$that is the conjugate base of lysine, obtained from the deprotonation of the carboxyl group. The aqueous $\left[\mathrm{Cho}^{+}\right]\left[\mathrm{Lys}^{-}\right] \mathrm{IL}$ solution has an extremely high alkalinity $(\mathrm{pH} \sim 13)$. Cholinium is a quaternary ammonium cation, an essential micronutrient, which was chosen because of its recognized biocompatibility. Lysine is a basic amino acid that has two amino groups. In addition to the amino group of the carboxylic acid, the lysine's alkyl side chain contains another amino group that can also work as a base. Due to the high pKa values of the functional amino groups, lysine easily gains positive charge through proton binding at physiological $\mathrm{pH}$. Because lysine can stablish acid-base Lewis interactions with $\mathrm{CO}_{2}$ in aqueous media, allowing the capture of two molecules of $\mathrm{CO}_{2}$ molecules per host molecule, it possesses favourable characteristics for $\mathrm{CO}_{2}$ capture. 
In addition to lysine, there are two other basic amino acids available, namely, histidine and arginine. Sistla and Khanna [133] combined several amino acid anions with the [bmim] cation and tested them for $\mathrm{CO}_{2}$ solubility. Of all the amino acid-ILs studied, [bmim][argininate] showed the highest $\mathrm{CO}_{2}$ solubility (0.62 moles of $\mathrm{CO}_{2}$ per mole of IL), followed by [bmim][lysinate] ( 0.48 moles of $\mathrm{CO}_{2}$ per mole of IL), and [bmim][histidinate] (0.45 moles of $\mathrm{CO}_{2}$ per mole of IL). Lysine and arginine are very similar in terms of toxicity, biodegradability, and cost [146]. However, the low water solubility of arginine is a serious limitation for $\mathrm{CO}_{2}$ capture [152]. Dry cholinium-amino acid based ILs have high viscosities, which can only be overcome by combining them with water. Furthermore, the stronger interaction between $\mathrm{CO}_{2}$ and arginine may invalidate the possibility of subsequent regeneration of the IL. For all of the mentioned reasons, lysine was the selected amino acid for the present study.

In our experimental setup for $\mathrm{CO}_{2}$ absorption studies, the aqueous $\left[\mathrm{Cho}^{+}\right]\left[\mathrm{Lys}^{-}\right]$IL solution circulates in the lumen side of a polytetrafluoroethylene membrane contactor, in closed-loop, while $\mathrm{CO}_{2}$ circulates counter currently, in the shell side of the contactor. In a typical experimental run, the total amount of absorbed $\mathrm{CO}_{2}$ is monitored in real-time up to the saturation conditions of the IL solution. The $\mathrm{CO}_{2}$ concentration in the gas phase is monitored by gas chromatography and that in the aqueous IL solution by $\mathrm{pH}$ measurements and attenuated total reflectance Fourier-transform infrared spectroscopy (ATRFTIR).

FTIR, along with nuclear magnetic resonance (NMR) and UV-vis spectroscopy (ultraviolet-visible), are techniques that can be used to obtain information about chemical equilibrium in solution. Besides being a nondestructive technique and requiring a small amount of sample, IR spectroscopy is much more reliable for the quantitative analysis of a compound that is physically or chemically similar to others in a mixture. Molecular differences between the structures of many chemical compounds can be identified and quantified in the mid-IR region between 4000-400 $\mathrm{cm}^{-1}[153,154]$. We have used 
this technique to analyse variations in the molecular structure and composition of the aqueous $\left[\mathrm{Cho}^{+}\right]\left[\mathrm{Lys}^{-}\right]$IL solution as a function of $\mathrm{CO}_{2}$ loading.

The mechanisms by which $\mathrm{CO}_{2}$ is absorbed in aqueous IL systems, where capture occurs by chemisorption, are not yet sufficiently understood. The study of the reactions involving (bi)carbonate and carbamate or carbamic acid formation is important for describing the reaction chemistry of $\mathrm{CO}_{2}$ absorption in IL solutions. In this context, the present work reports a detailed modelling study of $\mathrm{CO}_{2}$ absorption in aqueous $\left[\mathrm{Cho}^{+}\right]\left[\mathrm{Lys}^{-}\right]$IL solutions. To this end, a chemical model for the $\mathrm{CO}_{2}-\mathrm{H}_{2} \mathrm{O}-\left[\mathrm{Cho}^{+}\right]\left[\mathrm{Lys}^{-}\right]$system is proposed and validated using the experimentally measured $\mathrm{pH}$. Additionally, the use of ATR-FTIR and $\mathrm{pH}$ analysis as quantitative techniques for monitoring $\mathrm{CO}_{2}$ absorption in the IL liquid solution is described. Our findings can be useful for other systems or processes, such as the removal of $\mathrm{CO}_{2}$ from post-combustion streams, biogas refinery waste gases, or confined spaces (e.g. mines, spacecraft, and others).

\subsection{Absorption model}

The $\left[\mathrm{Lys}^{-}\right.$] anion is an amphoteric compound that acts as a Lewis acid when combined with the $\left[\mathrm{Cho}^{+}\right]$cation due to the presence of the ammonium group in the latter. However, in the presence of water and $\mathrm{CO}_{2}$ the $\left[\mathrm{Lys}^{-}\right]$anion acts as a base, leading to $\mathrm{CO}_{2}$ chemisorption via a mechanism involving the direct formation of bicarbonate $\left(\mathrm{HCO}_{3}^{-}\right)$and carbonate $\left(\mathrm{CO}_{3}^{2-}\right)$ and excluding the formation of carbamic acid [126,155]. There are reported evidences that carbamates can be formed with the carboxylic acid functional group of [Lys ${ }^{-}$, due to an intramolecular proton transfer from the $\alpha$-ammonium ion to the carboxylate group $[149,156]$. Nevertheless, the carboxylic acid protonation occurs at acidic $\mathrm{pH}$, where stable carbamates can be formed. However, the carboxylic acid group interacts with the cholinium cation through ionic coupling. Because of the high $\mathrm{pH}$ of the $\left[\mathrm{Cho}^{+}\right]\left[\mathrm{Lys}^{-}\right]$IL solution, the carbamate/carbonic acid formation mechanism is considered negligible in the present work. In aqueous media lysine is sensitive to $\mathrm{pH}$ and can assume four different ionisation states. 
Due to the presence of the three functional groups, there are three $\mathrm{p} K_{\mathrm{a}}$ dissociation constants: their values for lysine are $\mathrm{p} K_{\mathrm{a} 1}=2.15, \mathrm{p} K_{\mathrm{a} 2}=9.16, \mathrm{p} K_{\mathrm{a} 3}=$ 10.67 [157], where $\mathrm{p} K_{\mathrm{a} 1}$ refers to the $\alpha$-carboxylate group $(-\mathrm{COOH}), \mathrm{p} K_{\mathrm{a} 2}$ to the $\alpha-$ ammonium ion $\left(-\mathrm{NH}_{3}^{+}\right)$, and $\mathrm{p} K_{\mathrm{a} 3}$ to the $-\mathrm{NH}_{3}^{+}$side-chain group. Figure 5.2 shows the different ionic states of lysine in aqueous solution.

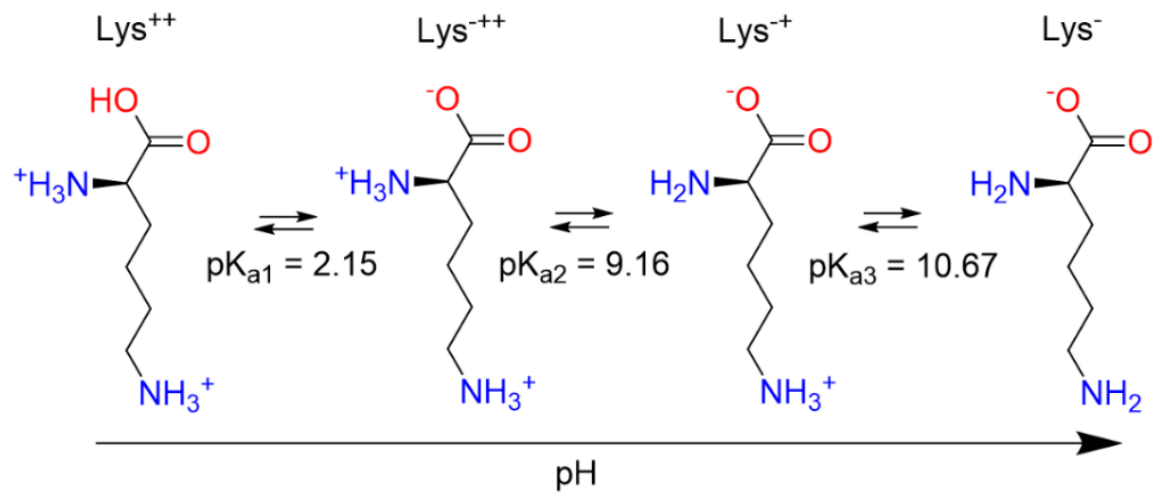

Figure 5.2 Dissociation states of lysine in aqueous solution.

Due to the formation of the bicarbonate in the presence of water, the interaction of $\mathrm{CO}_{2}$ with the $\left[\mathrm{Cho}^{+}\right]\left[\mathrm{Lys}^{-}\right] \mathrm{IL}$ in aqueous solution is assumed to take place exclusively with the ionic forms of the lysinate anion. The bicarbonate anion can bind to the amine groups of lysine; thus, theoretically two molecules of $\mathrm{CO}_{2}$ can be captured by one molecule of $\left[\mathrm{Cho}^{+}\right]\left[\mathrm{Lys}^{-}\right]$via chemisorption. The Lys $^{++}$ionic form is not present in our aqueous IL system, since Lys ${ }^{++}$occurs only in acidic media, which is not the case here (the $\mathrm{pH}$ is always higher than ca. 8.0). Figure 5.3 shows the possible forms of $\left[\mathrm{Cho}^{+}\right]\left[\mathrm{Lys}^{-}\right]$in aqueous solution during $\mathrm{CO}_{2}$ absorption. 
<smiles>C[N+](C)(CCO)CCCCCN</smiles>

[Cho][Lys]<smiles>C[N+](C)(CCO)CCCCCN</smiles>

$\left[\right.$ Cho][Lys] $\mathrm{H}^{+}$<smiles>C[N+](C)(CCO)OC(=O)C(N)CCCC[18O]</smiles>

$[$ Cho][Lys $] \mathrm{H}^{+} \mathrm{HCO}_{3}^{-}$<smiles>C[N+](C)(CCO)OC(=O)[C@@H](N)CCCC[NH3+]</smiles>

$\left[\right.$ Cho] $[$ Lys $] 2 \mathrm{H}^{+} \mathrm{HCO}_{3}^{-}$

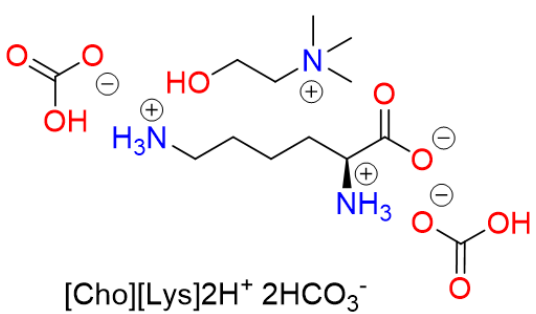

$[\mathrm{Cho}][\mathrm{Lys}] 2 \mathrm{H}^{+} 2 \mathrm{HCO}_{3}$

Figure 5.3 Structure of $\left[\mathrm{Cho}^{+}\right]\left[\mathrm{Lys}^{-}\right]$in water and in the presence of dissolved $\mathrm{CO}_{2}$.

Based on these observations, we propose the reaction pathways pictured in Figure 5.4 for the system $\mathrm{CO}_{2}-\mathrm{H}_{2} \mathrm{O}-\left[\mathrm{Cho}^{+}\right]\left[\mathrm{Lys}^{-}\right]$, which are supported by the hybrid quantum chemistry calculations based on density functional theory reported by Sun et al. [126]. It is assumed that all reaction pathways are reversible, but due to the fast conversion of the dissolved $\mathrm{CO}_{2}$ into $\mathrm{HCO}_{3}^{-}$and $\mathrm{CO}_{3}^{2-}$ in the aqueous IL medium (depending on the $\mathrm{pH}$ ), its concentration is very low until near saturation conditions when it attains its solubility value. The set of governing reaction equations describing the proposed mechanism is

$$
\begin{aligned}
& 2 \mathrm{H}_{2} \mathrm{O} \stackrel{K_{1}}{\leftrightarrow} \mathrm{H}_{3} \mathrm{O}^{+}+\mathrm{OH}^{-}, \\
& \mathrm{CO}_{2}+2 \mathrm{H}_{2} \mathrm{O} \stackrel{K_{2}}{\leftrightarrow} \mathrm{HCO}_{3}^{-}+\mathrm{H}_{3} \mathrm{O}^{+}, \\
& \mathrm{HCO}_{3}^{-}+\mathrm{H}_{2} \mathrm{O} \stackrel{K_{3}}{\leftrightarrow} \mathrm{CO}_{3}^{2-}+\mathrm{H}_{3} \mathrm{O}^{+}, \\
& \mathrm{R}+\mathrm{H}_{3} \mathrm{O}^{+} \stackrel{K_{4}}{\leftrightarrow} \mathrm{RH}^{+}+\mathrm{H}_{2} \mathrm{O}, \\
& \mathrm{RH}^{+}+\mathrm{H}_{3} \mathrm{O}^{+} \stackrel{K_{5}}{\leftrightarrow} \mathrm{RH}_{2}^{2+}+\mathrm{H}_{2} \mathrm{O},
\end{aligned}
$$


$\mathrm{RH}^{+}+\mathrm{HCO}_{3}^{-} \stackrel{K_{6}}{\leftrightarrow} \mathrm{P}_{1}$,

$\mathrm{P}_{1}+\mathrm{H}_{3} \mathrm{O}^{+} \stackrel{K_{7}}{\leftrightarrow} \mathrm{P}_{1}^{+}+\mathrm{H}_{2} \mathrm{O}$,

$\mathrm{P}_{1}^{+}+\mathrm{HCO}_{3}^{-} \stackrel{K_{8}}{\leftrightarrow} \mathrm{P}_{2}$,

where $\mathrm{R}$ denotes the $\left[\mathrm{Cho}^{+}\right]\left[\mathrm{Lys}^{-}\right] \mathrm{IL}, \mathrm{RH}^{+}$and $\mathrm{RH}_{2}^{2+}$ the positively charged forms $\left[\mathrm{Cho}^{+}\right]\left[\mathrm{Lys}^{-+}\right] \quad$ and $\left[\mathrm{Cho}^{+}\right]\left[\mathrm{Lys}^{-++}\right], \quad \mathrm{P}_{1} \equiv\left[\mathrm{Cho}^{+}\right]\left[\mathrm{Lys}^{-+} \mathrm{HCO}_{3}^{-}\right], \quad \mathrm{P}_{2} \equiv$ $\left[\mathrm{Cho}^{+}\right]\left[\mathrm{Lys}^{-++} 2 \mathrm{HCO}_{3}^{-}\right]$the final products, and $\mathrm{P}_{1}^{+} \equiv\left[\mathrm{Cho}^{+}\right]\left[\mathrm{Lys}^{-++} \mathrm{HCO}_{3}^{-}\right]$an intermediate species.

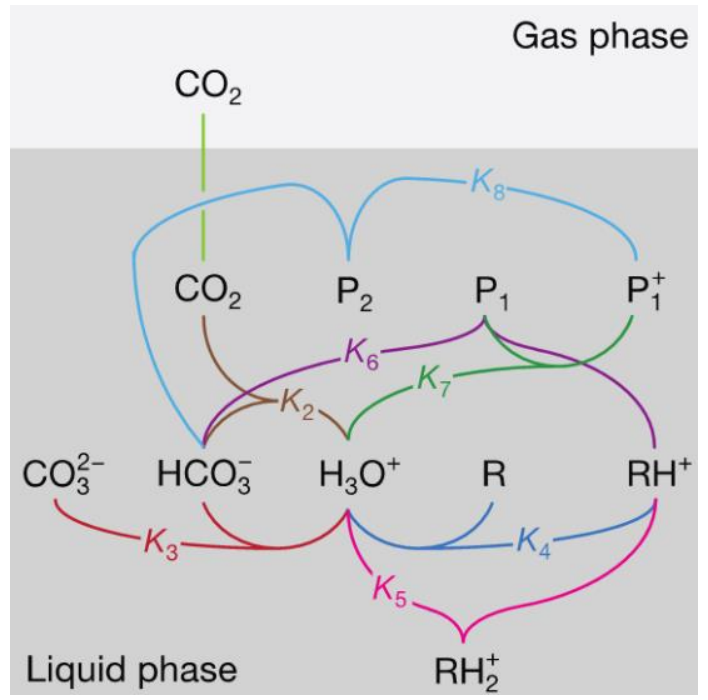

Figure 5.4 Proposed reaction pathways for the system $\mathrm{CO}_{2}-\mathrm{H}_{2} \mathrm{O}-\left[\mathrm{Cho}^{+}\right]\left[\mathrm{Lys}^{-}\right]$(water dissociation reaction not included). $\mathrm{R}$ denotes the $\left[\mathrm{Cho}^{+}\right]\left[\mathrm{Lys}^{-}\right] \mathrm{IL}, \mathrm{RH}+$ and $\mathrm{RH}_{2}^{2+}$ the positively charged forms $\left[\mathrm{Cho}^{+}\right]\left[\mathrm{Lys}^{-+}\right]$and $\left[\mathrm{Cho}^{+}\right]\left[\mathrm{Lys}^{-++}\right], \mathrm{P}_{1} \equiv\left[\mathrm{Cho}^{+}\right]\left[\mathrm{Lys}^{-+} \mathrm{HCO}_{3}^{-}\right]$, $\mathrm{P}_{2} \equiv\left[\mathrm{Cho}^{+}\right]\left[\mathrm{Lys}^{-++} 2 \mathrm{HCO}_{3}^{-}\right]$the final products, and $\mathrm{P}_{1}^{+} \equiv\left[\mathrm{Cho}^{+}\right]\left[\mathrm{Lys}^{-++} \mathrm{HCO}_{3}^{-}\right]$an intermediate species.

Additionally, if the $\mathrm{CO}_{2}$ transfer rate to the liquid phase reactor is low enough, a quasi-equilibrium kinetic approximation can be invoked: the reactions are so much faster than the $\mathrm{CO}_{2}$ transfer rate that they continuously equilibrate after a differential displacement from their previous equilibrium condition 
triggered by the small addition of $\mathrm{CO}_{2}$. Thus, at each instant during and absorption experiment the concentrations of the various species in solution are governed by the corresponding chemical equilibrium constants. For each reaction, say

$$
\sum_{i \in \mathcal{R}} v_{i} R_{i}=\sum_{j \in \mathcal{P}} v_{j} P_{j}
$$

where $\mathcal{R}$ is the set of reagents, $\mathcal{P}$ the set of products, and the $v^{\prime}$ s the stoichiometric coefficients. The corresponding equilibrium constant is defined as

$$
K=\frac{\prod_{j \in \mathcal{P}}\left(\gamma_{j} x_{j}\right)^{v_{j}}}{\prod_{i \in \mathcal{R}}\left(\gamma_{i} x_{i}\right)^{v_{i}}}
$$

where $x_{i}$ and $\gamma_{i}$ are the mole fraction and activity coefficient of species $i$ in solution.

If $\sum_{i \in \mathcal{R}} v_{i}=\sum_{j \in \mathcal{P}} v_{j}$, the mole fractions $x_{i}$ and $x_{j}$ can be replaced by the corresponding molar concentrations, $\left[R_{i}\right]$ and $\left[P_{j}\right]$, yielding

$$
K=\frac{\prod_{j \in \mathcal{P}} \gamma_{j}^{v_{j}}}{\prod_{i \epsilon \mathcal{R}} \gamma_{i}^{v_{i}}} \times \frac{\prod_{j \in \mathcal{P}}\left[P_{j}\right]^{v_{j}}}{\prod_{i \in \mathcal{R}}\left[R_{i}\right]^{v_{i}}}
$$

This happens in all cases except reactions (5.2), (5.6), and (5.8), whose equilibrium constants are expressed as

$$
\begin{gathered}
K_{2}=\frac{\left(\gamma_{\mathrm{HCO}_{3}^{-}}\right)\left(\gamma_{\mathrm{H}_{3} \mathrm{O}^{+}}\right)}{\left(\gamma_{\mathrm{CO}_{2}}\right)\left(\gamma_{\mathrm{H}_{2} \mathrm{O}}\right)^{2}} \times \frac{\left[\mathrm{HCO}_{3}^{-}\right]\left[\mathrm{H}_{3} \mathrm{O}^{+}\right][\mathrm{S}]}{\left[\mathrm{CO}_{2}\right]\left[\mathrm{H}_{2} \mathrm{O}^{2}\right.} \\
K_{6}=\frac{\gamma_{\mathrm{P}_{1}}}{\left(\gamma_{\mathrm{RH}^{+}}\right)\left(\gamma_{\mathrm{HCO}_{3}^{-}}\right)} \times \frac{\left[\mathrm{P}_{1}\right][\mathrm{S}]}{\left[\mathrm{RH}^{+}\right]\left[\mathrm{HCO}_{3}^{-}\right]}
\end{gathered}
$$




$$
K_{8}=\frac{\gamma_{\mathrm{P}_{2}}}{\left(\gamma_{\mathrm{P}_{1}}\right)\left(\gamma_{\mathrm{HCO}_{3}^{-}}\right)} \times \frac{\left[\mathrm{P}_{2}\right][\mathrm{S}]}{\left[\mathrm{P}_{1}\right]\left[\mathrm{HCO}_{3}^{-}\right]}
$$

where $[\mathrm{S}]=\sum_{i \in \mathcal{R}}\left[R_{i}\right]+\sum_{j \in \mathcal{P}}\left[P_{j}\right]=\left[\mathrm{H}_{2} \mathrm{O}\right]+\left[\mathrm{OH}^{-}\right]+\cdots\left[\mathrm{P}_{2}\right]$ is the "total" molar concentration of the solution. The water equilibrium constant, $K_{1}$, and those for the $\mathrm{CO}_{2}$ dissociation, $K_{2}$ and $K_{3}$, were taken from the Aspen Plus library (ver. 10.2) and are listed in Table 5.1. The unknown equilibrium constants are $K_{4}, K_{5}, K_{6}, K_{7}$ and $K_{8}$.

Table 5.1 Equilibrium constants for the absorption reactions of $\mathrm{CO}_{2}$ in water.

\begin{tabular}{cc}
\hline Equilibrium constant & Value \\
\hline$K_{1}$ & $2.208 \times 10^{-18}$ \\
$K_{2}$ & $7.350 \times 10^{-9}$ \\
$K_{3}$ & $7.499 \times 10^{-13}$ \\
\hline
\end{tabular}

The liquid-phase properties and activity coefficients are estimated using the unsymmetrical electrolyte NRTL property method (eNRTL) [158-160] and the gas-phase properties with the Redlich-Kwong equation of state [161] as implemented in Aspen Plus (ver. 10.2).

Although $\left[\mathrm{Cho}^{+}\right]\left[\mathrm{Lys}^{-}\right], \quad\left[\mathrm{Cho}^{+}\right]\left[\mathrm{Lys}^{-+}\right], \quad\left[\mathrm{Cho}^{+}\right]\left[\mathrm{Lys}^{-++}\right]$, $\left[\mathrm{Cho}^{+}\right]\left[\mathrm{Lys}^{-+} \mathrm{HCO}_{3}^{-}\right]$, and $\left[\mathrm{Cho}^{+}\right]\left[\mathrm{Lys}^{-++} 2 \mathrm{HCO}_{3}^{-}\right]$are not in the Aspen Plus database, we proceed as follows. Because the logarithm of the activity coefficient can be split into the sum of a term accounting to local interactions that exist at the immediate neighbourhood of any species and the other from the long-range ion-ion interactions that exist beyond the immediate vicinity of an ionic species, and each segment of a molecule contributes nearly additively to those two terms, the ratios of activity coefficients for the equilibrium constants involving the IL or its derivatives can be simplified as follows: 


$$
\begin{aligned}
& \frac{\left(\gamma_{\mathrm{RH}^{+}}\right)\left(\gamma_{\mathrm{H}_{2} \mathrm{O}}\right)}{\left(\gamma_{\mathrm{R}}\right)\left(\gamma_{\mathrm{H}_{3} \mathrm{O}^{+}}\right)} \approx \frac{\left(\gamma_{\mathrm{Lys}^{-+}}\right)\left(\gamma_{\mathrm{H}_{2} \mathrm{O}}\right)}{\left(\gamma_{\mathrm{Lys}^{-}}\right)\left(\gamma_{\mathrm{H}_{3} \mathrm{O}^{+}}\right)} \\
& \frac{\left(\gamma_{\mathrm{RH}_{2}^{2+}}\right)\left(\gamma_{\mathrm{H}_{2} \mathrm{O}}\right)}{\left(\gamma_{\mathrm{RH}^{+}}\right)\left(\gamma_{\mathrm{H}_{3} \mathrm{O}^{+}}\right)} \approx \frac{\left(\gamma_{\mathrm{Lys}^{\mp+}}\right)\left(\gamma_{\mathrm{H}_{2} \mathrm{O}}\right)}{\left(\gamma_{\mathrm{Lys}^{\mp}}\right)\left(\gamma_{\mathrm{H}_{3} \mathrm{O}^{+}}\right)} \\
& \frac{\gamma_{\mathrm{P}_{1}}}{\left(\gamma_{\mathrm{RH}^{+}}\right)\left(\gamma_{\mathrm{HCO}_{3}^{-}}\right)} \approx \frac{\gamma_{\mathrm{Lys}^{-+}}}{\left(\gamma_{\mathrm{Lys}^{\mp+}}\right)\left(\gamma_{\mathrm{HCO}_{3}^{-}}\right)} \\
& \frac{\left(\gamma_{\mathrm{P}_{1}^{+}}\right)\left(\gamma_{\mathrm{H}_{2} \mathrm{O}}\right)}{\left(\gamma_{\mathrm{P}_{1}}\right)\left(\gamma_{\mathrm{H}_{3} \mathrm{O}^{+}}\right)} \approx \frac{\left(\gamma_{\mathrm{Lys}^{\mp+}}\right)\left(\gamma_{\mathrm{H}_{2} \mathrm{O}}\right)}{\left(\gamma_{\mathrm{Lys}^{\mp}}\right)\left(\gamma_{\mathrm{H}_{3} \mathrm{O}^{+}}\right)} \\
& \frac{\gamma_{\mathrm{P}_{2}}}{\left(\gamma_{\mathrm{P}_{1}}\right)\left(\gamma_{\mathrm{HCO}_{3}^{-}}\right)} \approx \frac{\left(\gamma_{\mathrm{Lys}^{\mp+}}\right)\left(\gamma_{\mathrm{HCO}_{3}^{-}}\right)}{\gamma_{\mathrm{Lys}^{-+}}}
\end{aligned}
$$

These equations involve the ratios $\left(\gamma_{\mathrm{Lys}^{-+}}\right) /\left(\gamma_{\mathrm{Lys}^{-}}\right)$and $\left(\gamma_{\mathrm{Lys}^{-++}}\right) /\left(\gamma_{\mathrm{Lys}^{-+}}\right)$, which in both cases correspond to the protonation of an amine group, $-\mathrm{NH}_{2} \Rightarrow$ $-\mathrm{NH}_{3}^{+}$. Using the unsymmetrical Pitzer-Debye-Huckel formula [162] (on which the eNRTL model rests) to account for the long-range (electrostatic) interactions, each of these $\gamma^{\prime} s$ can be approximated as

$$
\ln \gamma_{i}=-\left(\frac{1000}{M_{s}}\right)^{1 / 2} A_{\varphi}\left[\left(\frac{2 z_{i}^{2}}{\rho}\right) \ln \left(1+\rho I_{x}^{1 / 2}\right)+\frac{z_{i}^{2} I_{x}^{1 / 2}-2 I_{x}^{1 / 2}}{1+\rho I_{x}^{1 / 2}}\right]
$$

Here, $I_{x}=\frac{1}{2} \sum z_{j}^{2} x_{j}$ is the ionic strength of the aqueous IL solution on a mole fraction basis, where $z_{j}$ and $x_{j}$ are the charge number and mole fraction of ionic segment $j\left(\mathrm{H}_{3} \mathrm{O}^{+}, \mathrm{OH}^{-}, \mathrm{HCO}_{3}^{-}, \mathrm{CO}_{3}^{2-},-\mathrm{O}^{-}\right.$, and $\left.-\mathrm{NH}_{3}^{+}\right), \rho$ the closest approach 
parameter, $A_{\varphi}$ the Debye-Hckel parameter, and $M_{S}$ the molecular weight of the solvent [162]. Applying Equation (5.20) to the ratio of two $\gamma^{\prime}$ s, say $\gamma_{b} / \gamma_{a}$, gives

$$
\ln \frac{\gamma_{b}}{\gamma_{a}}=-\left(\frac{1000}{M_{s}}\right)^{1 / 2} A_{\varphi}\left[\frac{2}{\rho} \ln \left(1+\rho I_{x}^{1 / 2}\right)+\frac{I_{x}^{1 / 2}}{1+\rho I_{x}^{1 / 2}}\right]\left(z_{b}^{2}-z_{a}^{2}\right) .
$$

In Aspen Plus we use n-dimethylethanolamine $\left(\mathrm{C}_{4} \mathrm{H}_{12} \mathrm{NO}^{+}\right)$as a surrogate for $\mathrm{Cho}^{+}$and octanoate $\left(\mathrm{C}_{7} \mathrm{H}_{15} \mathrm{COO}^{-}\right)$for $\mathrm{Lys}^{-}$; these components are the ones with characteristics closest to the IL's cation and anion that could be found in the database.

Since a quasi-equilibrium kinetic approximation is used for the absorption model, it is convenient to introduce the extent of reaction, $\xi$, a quantity that measures the extent at which a reaction proceeds [163], for it makes it easier to write down the differential material balances.

Let $\xi_{n}$ be the extent of reaction $n$. The differential material for each species in the system, say the $i^{\text {th }}$ one, $S_{i}$, can then be written in terms of its molar concentration, $\left[S_{i}\right]$, and the extents of the reactions in which it participates either as a reagent or product. Applying this procedure to all species in the system gives rise to the following differential material balances:

$$
\begin{aligned}
& d\left[\mathrm{H}_{2} \mathrm{O}\right]=-2 d \xi_{1}-2 d \xi_{2}-d \xi_{3}+d \xi_{4}+d \xi_{5}+d \xi_{7}, \\
& d\left[\mathrm{H}_{3} \mathrm{O}^{+}\right]=d \xi_{1}+d \xi_{2}+d \xi_{3}-d \xi_{4}-d \xi_{5}-d \xi_{7}, \\
& d\left[\mathrm{OH}^{-}\right]=d \xi_{1}, \\
& d\left[\mathrm{HCO}_{3}^{-}\right]=d \xi_{2}-d \xi_{3}-d \xi_{6}-d \xi_{8}, \\
& d\left[\mathrm{CO}_{3}^{2-}\right]=d \xi_{3}, \\
& d[\mathrm{R}]=-d \xi_{4},
\end{aligned}
$$




$$
\begin{aligned}
& d\left[\mathrm{RH}^{+}\right]=d \xi_{4}-d \xi_{5}-d \xi_{6}, \\
& d\left[\mathrm{RH}_{2}^{2+}\right]=d \xi_{5}, \\
& d\left[\mathrm{P}_{1}\right]=d \xi_{6}-d \xi_{7}, \\
& d\left[\mathrm{P}_{1}^{+}\right]=d \xi_{7}-d \xi_{8}, \\
& d\left[\mathrm{P}_{2}\right]=d \xi_{8} .
\end{aligned}
$$

Note that no differential material balance is written for $\left[\mathrm{CO}_{2}\right]$ (dissolved carbon under $\mathrm{CO}_{2}$ form); instead, the material balances are subjected to the additional condition

$\left[\mathrm{CO}_{2}\right]+\left[\mathrm{HCO}_{3}^{-}\right]+\left[\mathrm{CO}_{3}^{2-}\right]+\left[\mathrm{P}_{1}\right]+\left[\mathrm{P}_{1}^{+}\right]+2\left[\mathrm{P}_{2}\right]=\left[\mathrm{C}_{\text {tot }}\right]$

where $\left[\mathrm{C}_{\text {tot }}\right]$ is the total concentration of $\mathrm{CO}_{2}$-derived species in the reaction medium at each instant. $\left[\mathrm{C}_{\text {tot }}\right]$ is obtained from the differential material balance to the $\mathrm{CO}_{2}$ fed to the system:

$\frac{d\left[V C_{\text {tot }}\right]}{d t}=\Delta \dot{n}_{\mathrm{CO}_{2}}, \Delta \dot{n}_{\mathrm{CO}_{2}} \equiv \dot{n}_{\mathrm{CO}_{2}}^{(\text {in })}-\dot{n}_{\mathrm{CO}_{2}}^{\text {(out) }}, \quad$ s.t. $\left[C_{\mathrm{tot}}\right]_{\mathrm{t}=0}=0$

or in integrated form,

$$
\left[\mathrm{C}_{\text {tot }}\right](t)=\frac{1}{V} \int_{0}^{\mathrm{t}} \Delta \dot{\mathrm{n}}_{\mathrm{CO}_{2}} d t \text {, }
$$


where $V$ is the volume of the reaction medium in the membrane contactor (which remains practically constant over the course of the absorption experiment) and $\dot{n}_{\mathrm{CO}_{2}}^{\text {(in) }}$ and $\dot{n}_{\mathrm{CO}_{2}}^{\text {(out) }}$ the inlet and outlet molar flowrates of $\mathrm{CO}_{2}$ in the shell side of the membrane contactor.

The initial conditions of the experiment are those before the injection of $\mathrm{CO}_{2}$ when the amount of dissolved $\mathrm{CO}_{2}$ is negligible, which in turn implies that the only species in solution are $\mathrm{H}_{2} \mathrm{O}, \mathrm{OH}^{-}, \mathrm{H}_{3} \mathrm{O}^{+}, \mathrm{R}, \mathrm{RH}^{+}$and $\mathrm{RH}_{2}^{2+}$, and $\left[\mathrm{CO}_{2}\right]_{0}=$ $\left[\mathrm{HCO}_{3}^{-}\right]_{0}=\left[\mathrm{CO}_{3}^{2-}\right]_{0}=\left[\mathrm{P}_{1}\right]_{0}=\left[\mathrm{P}_{1}^{+}\right]_{0}=\left[\mathrm{P}_{2}\right]_{0}=0$. Taking this into account, the integration of the differential equations yields

$$
\begin{aligned}
& {\left[\mathrm{H}_{2} \mathrm{O}\right]=\left[\mathrm{H}_{2} \mathrm{O}\right]_{0}-2 \xi_{1}-2 \xi_{2}-\xi_{3}+\xi_{4}+\xi_{5}+\xi_{7},} \\
& {\left[\mathrm{H}_{3} \mathrm{O}^{+}\right]=\left[\mathrm{H}_{3} \mathrm{O}^{+}\right]_{0}+\xi_{1}+\xi_{2}+\xi_{3}-\xi_{4}-\xi_{5}-\xi_{7},} \\
& {\left[\mathrm{OH}^{-}\right]=\left[\mathrm{OH}^{-}\right]_{0}+\xi_{1},} \\
& {\left[\mathrm{HCO}_{3}^{-}\right]=\xi_{2}-\xi_{3}-\xi_{6}-\xi_{8},} \\
& {\left[\mathrm{CO}_{3}^{2-}\right]=\xi_{3},} \\
& {[\mathrm{R}]=[\mathrm{R}]_{0}-\xi_{4},} \\
& {\left[\mathrm{RH}^{+}\right]=\left[\mathrm{RH}^{+}\right]_{0}+\xi_{4}-\xi_{5}-\xi_{6},} \\
& {\left[\mathrm{RH}_{2}^{2+}\right]=\left[\mathrm{RH}_{2}^{2+}\right]_{0}+\xi_{5},} \\
& {\left[\mathrm{P}_{1}\right]=\xi_{6}-\xi_{7},} \\
& {\left[\mathrm{P}_{1}^{+}\right]=\xi_{7}-\xi_{8},} \\
& {\left[\mathrm{P}_{2}\right]=\xi_{8}} \\
& {\left[\mathrm{CO}_{2}\right]=\left[\mathrm{C}_{\mathrm{tot}}\right]-\left[\mathrm{HCO}_{3}^{-}\right]-\left[\mathrm{CO}_{3}^{2-}\right]-\left[\mathrm{P}_{1}\right]-\left[\mathrm{P}_{1}^{+}\right]-2\left[\mathrm{P}_{2}\right],}
\end{aligned}
$$


where $\left[\mathrm{H}_{2} \mathrm{O}\right]_{0},\left[\mathrm{OH}^{-}\right]_{0},\left[\mathrm{H}_{3} \mathrm{O}^{+}\right]_{0}, \quad[\mathrm{R}]_{0}, \quad\left[\mathrm{RH}^{+}\right]_{0}, \quad\left[\mathrm{RH}_{2}^{2+}\right]_{0}$ are the initial concentrations of the various species in solution. The initial conditions for the extents of reaction are simply $\left(\xi_{n}\right)_{t=0}=0 \forall n$. Although these equations can be solved as a function of reaction time, it is best to solve them for increasing values of $\left[\mathrm{C}_{\mathrm{tot}}\right]$; that is, to use $\left[\mathrm{C}_{\mathrm{tot}}\right]$ as the independent variable instead of time because the system is assumed to be equilibrium driven, as mentioned before. In this case the equations are

$$
\begin{array}{ll}
{\left[\mathrm{H}_{2} \mathrm{O}\right]^{\prime}=\left(-2 \xi_{1}-2 \xi_{2}-\xi_{3}+\xi_{4}+\xi_{5}+\xi_{7}\right)^{\prime},} & {\left[\mathrm{H}_{2} \mathrm{O}\right]_{t=0}=\left[\mathrm{H}_{2} \mathrm{O}\right]_{0},} \\
{\left[\mathrm{H}_{3} \mathrm{O}^{+}\right]^{\prime}=\left(\xi_{1}+\xi_{2}+\xi_{3}-\xi_{4}-\xi_{5}-\xi_{7}\right)^{\prime},} & {\left[\mathrm{H}_{3} \mathrm{O}^{+}\right]_{t=0}=\left[\mathrm{H}_{3} \mathrm{O}^{+}\right]_{0},} \\
{\left[\mathrm{OH}^{-}\right]^{\prime}=\left(\xi_{1}\right)^{\prime},} & {\left[\mathrm{OH}^{-}\right]_{t=0}=\left[\mathrm{OH}^{-}\right]_{0}} \\
{\left[\mathrm{HCO}_{3}^{-}\right]^{\prime}=\left(\xi_{2}-\xi_{3}-\xi_{6}-\xi_{8}\right)^{\prime},} & {\left[\mathrm{HCO}_{3}^{-}\right]_{t=0}=0,} \\
{\left[\mathrm{CO}_{3}^{2-}\right]^{\prime}=\left(\xi_{3}\right)^{\prime},} & {\left[\mathrm{CO}_{3}^{2-}\right]_{t=0}=0} \\
{[\mathrm{R}]^{\prime}=\left(-\xi_{4}\right)^{\prime},} & {[\mathrm{R}]_{t=0}=[\mathrm{R}]_{0}} \\
{\left[\mathrm{RH}^{+}\right]^{\prime}=\left(\xi_{4}-\xi_{5}-\xi_{6}\right)^{\prime},} & {\left[\mathrm{RH}^{+}\right]_{\mathrm{t}=0}=\left[\mathrm{RH}^{+}\right]_{0}} \\
{\left[\mathrm{RH}_{2}^{2+}\right]^{\prime}=\left(\xi_{5}\right)^{\prime},} & {\left[\mathrm{RH}_{2}^{2+}\right]_{t=0}=0} \\
{\left[\mathrm{P}_{1}\right]^{\prime}=\left(\xi_{6}-\xi_{7}\right)^{\prime},} & {\left[\mathrm{P}_{1}\right]_{t=0}=0} \\
{\left[\mathrm{P}_{1}^{+}\right]^{\prime}=\left(\xi_{7}-\xi_{8}\right)^{\prime},} & {\left[\mathrm{P}_{1}^{+}\right]_{t=0}=0} \\
{\left[\mathrm{P}_{2}\right]^{\prime}=\left(\xi_{8}\right)^{\prime},} & {\left[\mathrm{P}_{2}\right]_{t=0}=0} \\
&
\end{array}
$$

where $\left[\mathrm{H}_{2} \mathrm{O}\right]^{\prime}$ is a shorthand notation for $d\left[\mathrm{H}_{2} \mathrm{O}\right] / d\left[\mathrm{C}_{\text {tot }}\right],\left(\xi_{n}\right)^{\prime}$ for $d \xi_{n} / d\left[\mathrm{C}_{\text {tot }}\right]$, and so forth. These equations are further subjected to the condition given by Equation (5.47). 


\subsection{Experimental}

$\left[\mathrm{Cho}^{+}\right]\left[\mathrm{Lys}^{-}\right]$ionic liquid was synthesised from choline hydroxide solution (45 $w t \%$ aqueous solution, Acros Organics, USA) and L(+)-Lysine monohydrate (99\%, Acros Organics, USA), supplied by Thermofisher Scientific. The $\mathrm{CO}_{2}$ used in the experiments was high-purity grade (99.998\%) from Praxair, USA.

$\mathrm{CO}_{2}$ was captured from the gas phase into the aqueous IL solution flowing in a membrane contactor counter currently to the gas phase, as represented in Figure 5.5. The membrane module consists of a set of Eclipse ${ }^{\mathrm{TM}}$ capillary membranes, supplied by Markel Corporation (USA), and made of microporous polytetrafluoroethylene, assembled in a stainless-steel housing. Since the focus of the present work is the theoretical study of $\mathrm{CO}_{2}$ capture by the aqueous IL solution, with emphasis on the chemical equilibrium behind the absorption process, the setup is not described in much detail here; a comprehensive description can be found elsewhere [164].

The $\mathrm{CO}_{2}$ absorption reaction was followed by $\mathrm{pH}$ measurement, using a Mettler Toledo pH probe (model 1405-DPAS-SC-K8S, USA) connected to an inline tester (Jenco, model 3621, USA). ATR-FTIR analysis was used as well to monitor the absorption reaction off-line, using a Perkin Elmer Spectrum Two FTIR Spectrometer at room temperature. Small samples $\left(5 \times 10^{-5}\right.$ moles $)$ of the liquid phase were collected periodically at a sampling rate of $3 \mathrm{~min}$ and later analysed by ATR-FTIR. The molecular structure of the synthesised $\left[\mathrm{Cho}^{+}\right]\left[\mathrm{Lys}^{-}\right]$ IL was confirmed by proton nuclear magnetic resonance ( $\left.{ }^{1} \mathrm{H}-\mathrm{NMR}\right)$ on a Bruker AVANCE Digital operating at $400 \mathrm{MHz}$. The water content of the IL solution was measured by titration, using a Karl-Fischer coulometer without diaphragm (Metrohm, USA, model 831 KF coulometer). 


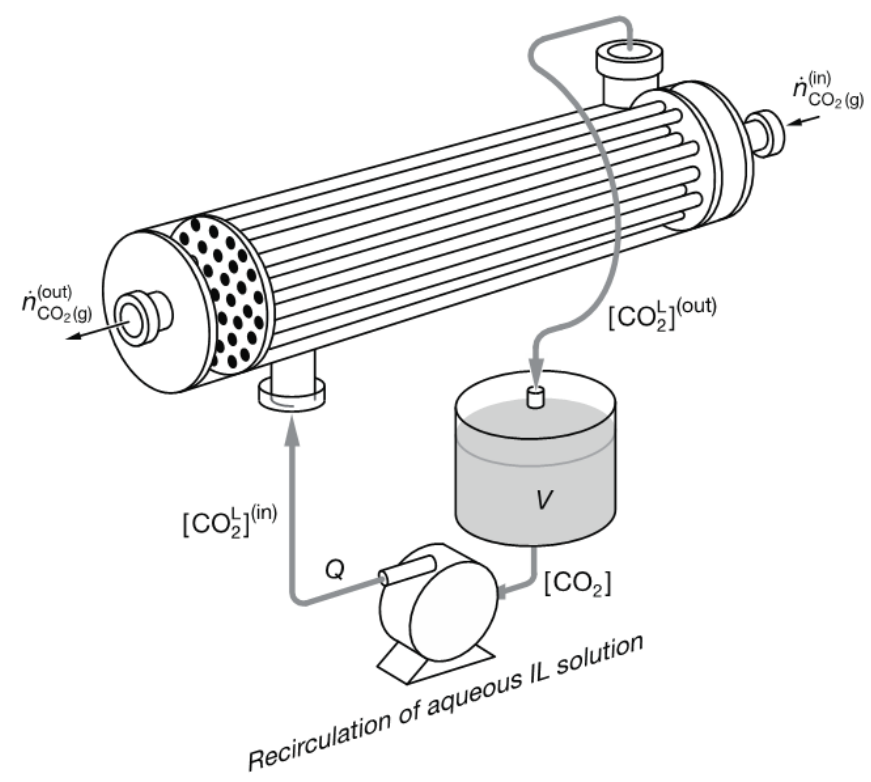

Figure 5.5 Schematic of the experimental set-up. The IL solution circulates in the lumen side of a polytetrafluoroethylene membrane contactor, while $\mathrm{CO}_{2}$ circulates countercurrently in the shell side of the contactor. The system is operated in closed loop. $\dot{n}_{\mathrm{CO}_{2}(\mathrm{~g})}^{(\mathrm{in})}$ and $\dot{n}_{\mathrm{CO}_{2}(\mathrm{~g})}^{(\mathrm{out})}$ are the inlet and outlet molar flowrates of gaseous $\mathrm{CO}_{2}$ in the lumen side of the contactor; $\left[\mathrm{CO}_{2}^{L}\right]^{(i n)}$ and $\left[\mathrm{CO}_{2}^{L}\right]^{\text {(out) }}$ the inlet and outlet concentrations of aqueous $\mathrm{CO}_{2}$ in the lumen $(L)$ side of the membrane; $V$ the volume of aqueous IL solution and $Q$ the volumetric recirculation flow rate in the lumen side of the membrane. By definition $\left[\mathrm{CO}_{2}^{L}\right]^{(i n)}=\left[\mathrm{CO}_{2}\right]$, where $\left[\mathrm{CO}_{2}\right]$ is the concentration of dissolved $\mathrm{CO}_{2}$ (i.e. $\mathrm{CO}_{2}, \mathrm{HCO}_{3}^{-}$and $\mathrm{CO}_{3}^{2-}$ ) in the bulk of the aqueous IL solution, because the volume $\mathrm{V}$ is assumed to be perfectly mixed.

\subsection{Results and discussion}

\subsubsection{Infrared characterisation of aqueous [Cho+][Lys $]$ solution}

To monitor $\mathrm{CO}_{2}$ absorption into aqueous $\left[\mathrm{Cho}^{+}\right]\left[\mathrm{Lys}^{-}\right]$IL solution with ATR-FTIR spectroscopy, a prior understanding of $\left[\mathrm{Cho}^{+}\right]\left[\mathrm{Lys}^{-}\right]$forms in the aqueous system is needed. ATR-FTIR spectra were obtained between $4000-400 \mathrm{~cm}^{-1}$ because the molecular deformations are detectable in the mid-IR region. Over this IR range, it is possible to identify and quantify the various species and functional groups relevant to the $\mathrm{CO}_{2}-$ water- $\left[\mathrm{Cho}^{+}\right]\left[\mathrm{Lys}^{-}\right]$system.

The IR spectra were obtained under different water activity $\left(a_{w}\right)$ conditions, which correspond to different cholinium lysinate concentrations; $a_{\mathrm{w}}=\gamma_{\mathrm{w}} x_{\mathrm{w}}$, 
where $\gamma_{\mathrm{w}}$ is the activity coefficient of water and $x_{\mathrm{w}}$ the mole fraction of water in the aqueous fraction [90]. Changing $a_{\mathrm{w}}$ alters the water content of the cholinium lysinate IL and consequently the $\mathrm{pH}$ of the medium. As mentioned in Section 5.2, the lysinate anion assumes different protonated forms in the amine sites according to the $\mathrm{pH}$. Figure 5.6 shows the spectra of four different aqueous $\left[\mathrm{Cho}^{+}\right]\left[\mathrm{Lys}^{-}\right]$IL solutions for which representative differences were obtained over the range $1700-1200 \mathrm{~cm}^{-1}$ of wavenumbers. The main differences are characterised by deviations of the absorbance bands intensities at $1647 \mathrm{~cm}^{-1}$, $1558 \mathrm{~cm}^{-1}, 1478 \mathrm{~cm}^{-1}, 1408 \mathrm{~cm}^{-1}$, and $1358 \mathrm{~cm}^{-1}$. A very broad band between $3700-3000 \mathrm{~cm}^{-1}$ was also obtained, but it which is not shown here because it corresponds to the $\mathrm{O}-\mathrm{H}$ stretching of water.

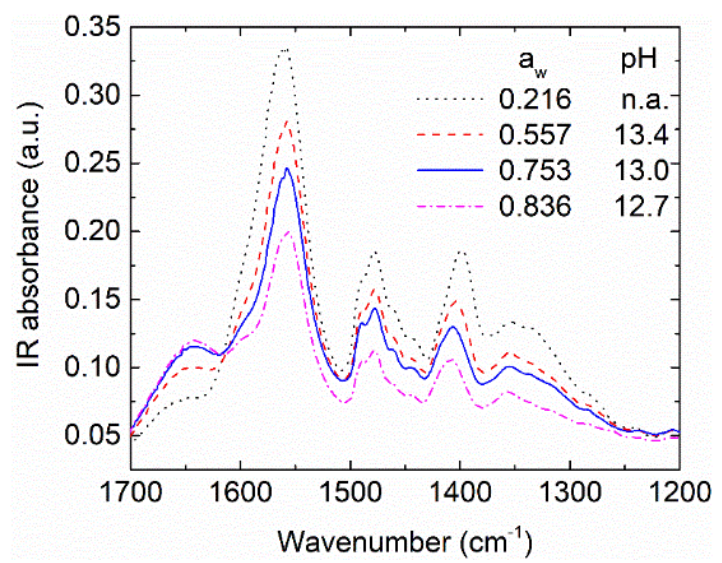

Figure 5.6 FTIR spectra of four $\left[\mathrm{Cho}^{+}\right]\left[\mathrm{Lys}^{-}\right]$IL solutions equilibrated at different values of water activity, $a_{w}$.

With the exception of the absorbance band at $1647 \mathrm{~cm}^{-1}$, all the others increase as $a_{\mathrm{w}}$ decreases for more concentrated samples. The absorbance band ascribed to the $-\mathrm{NH}_{3}^{+}$group is usually observed in the region $1750-1600 \mathrm{~cm}^{-1}$ [133]. Therefore, the band at $1647 \mathrm{~cm}^{-1}$ is attributed to the protonated amino groups, whose formation in the Lys anion is expected with the decrease of the $\mathrm{pH}$, as demonstrated in Section 5.2 and shown in Figure 5.6. Depending on the molecular constituents, carboxylate bands are generally present in the 
$1650-1540 \mathrm{~cm}^{-1}$ and $1450-1360 \mathrm{~cm}^{-1}$ regions. Therefore, the bands at $1558 \mathrm{~cm}^{-1}$ and $1408 \mathrm{~cm}^{-1}$ correspond to asymmetric and symmetric stretching vibrations of the $\mathrm{C}=\mathrm{O}$ bond, respectively, which are present in the acidic group of the lysinate anion. Finally, the bands at $1478 \mathrm{~cm}^{-1}$ and $1358 \mathrm{~cm}^{-1}$ are associated with the $\mathrm{C}-\mathrm{H}$ stretching vibrations of the methyl groups $\left(-\mathrm{CH}_{3}\right)$ $[154,165]$.

\subsection{2 $\mathrm{CO}_{2}$ absorption monitoring}

The absorption kinetics of $\mathrm{CO}_{2}$ into an aqueous solution containing $50 \mathrm{wt} \%$ of $\left[\mathrm{Cho}^{+}\right]\left[\mathrm{Lys}^{-}\right]$was measured at $22{ }^{\circ} \mathrm{C}\left( \pm 2{ }^{\circ} \mathrm{C}\right)$ up to the conditions corresponding to the complete saturation. The transport of $\mathrm{CO}_{2}$ in this solution is dominantly controlled by the chemical reaction equilibria, despite physical diffusion being present. Due to the strong basicity, the IL solution is very reactive towards $\mathrm{CO}_{2}$ which behaves as Lewis acid. Therefore, $\mathrm{CO}_{2}$ chemisorption in the present system occurs as a neutralisation reaction accompanied by a decrease in $\mathrm{pH}$. In fact, the pH measurement throughout the whole absorption process proved to be quite useful for model validation, as will be demonstrated further ahead. Figure 5.7 shows the experimentally measured $\mathrm{pH}$ as a function of reaction time, as well as the total amount of $\mathrm{CO}_{2}$ absorbed by the aqueous IL solution, the latter computed from a material balance to the gas phase, Equation (5.34), from the measured values of $\Delta \dot{n}_{\mathrm{CO}_{2}}$. The aqueous IL solution was completely saturated with $\mathrm{CO}_{2}$ at $\mathrm{pH} \sim 8$; under these conditions the $\mathrm{CO}_{2}$ capture capacity was found to be $\sim 2.2$ mol $\mathrm{CO}_{2} / \mathrm{mol} \mathrm{IL}$.

The strong basicity of the IL solution is confirmed by the initial $\mathrm{pH}$ shown in Figure $5.7(\mathrm{pH} \sim 13)$. At this $\mathrm{pH}$ the amine of the alkyl side chain of Lys anion can be partially protonated since the corresponding $\mathrm{p} K_{\mathrm{a}}$ is 10.67 ; consequently, the $\mathrm{CO}_{2}$ molecules converted into $\mathrm{HCO}_{3}^{-}$ions bind first to this amine. As $\mathrm{CO}_{2}$ is progressively absorbed and the $\mathrm{pH}$ decreases towards its $\mathrm{p} K_{\mathrm{a}}$ value of ca. 9.16, the amine of the carboxylic acid functional group will be able to protonate and bind to the bicarbonate ion. 


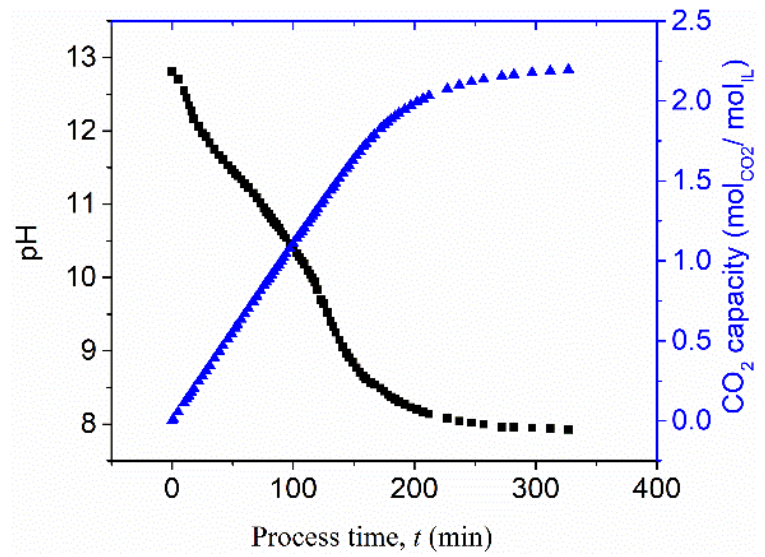

Figure $5.7 \mathrm{pH}$ and total $\mathrm{CO}_{2}$ solubility in the aqueous solution of $50 \mathrm{wt} \%\left[\mathrm{Cho}^{+}\right]\left[\mathrm{Lys}^{-}\right]$as function of process time at $22^{\circ} \mathrm{C}$.

As mentioned before, theoretically two molecules of $\mathrm{CO}_{2}$ can react with one molecule of $\left[\mathrm{Cho}^{+}\right]\left[\mathrm{Lys}^{-}\right]$, because $\mathrm{CO}_{2}$ in the bicarbonate ion form can bind to both amines of the lysinate anion. From the results shown in Figure 5.7, half of the total $\mathrm{CO}_{2}$ capacity of the $50 \mathrm{wt} \%$ of $\left[\mathrm{Cho}^{+}\right]\left[\mathrm{Lys}^{-}\right]$IL solution $(\sim 1 \mathrm{~mol} \mathrm{CO} / \mathrm{mol}$ IL) is attained near $\mathrm{p} K_{\mathrm{a} 3}=10.67$, which means that around $50 \%$ of the amines of the lysinate anion are in solution, and in particular those of the alkyl side chain, established a bond with the bicarbonate ions. As these amines are being "occupied" and $\mathrm{CO}_{2}$ continues to be absorbed, the $\alpha$-amine of the carboxylic acid functional group starts to receive the bicarbonate ions as a second absorption wave, until the saturation state of the IL solution is reached. The complete saturation state was confirmed by the experimentally measured $\mathrm{CO}_{2}$ capacity, which was determined using Equation (5.34) from the moment the outlet molar flow rate, $\dot{n}_{\mathrm{CO}_{2}}^{\text {(out) }}$, attained and stabilised at the inlet value, $\dot{n}_{\mathrm{CO}_{2}}^{\text {(in) }}$.

In addition to $\mathrm{pH}$ measurements, samples of the aqueous IL solution were periodically collected during the $\mathrm{CO}_{2}$ absorption experiment and later analysed by ATR-FTIR. Figure 5.8 shows the IR spectra of the aqueous IL solution with different $\mathrm{CO}_{2}$ loadings. The observed variations in the spectrum are correlated with the different $\mathrm{CO}_{2}$ loadings. The IR absorbance increases as more $\mathrm{CO}_{2}$ is captured, which is a consequence of the increasing number of absorbing species 
in the aqueous $\left[\mathrm{Cho}^{+}\right]\left[\mathrm{Lys}^{-}\right]$IL solution. It is possible to assign IR absorbance bands to different characteristic species for the interactions between $\mathrm{CO}_{2}$ and $\left[\mathrm{Cho}^{+}\right]\left[\mathrm{Lys}^{-}\right]$. It is challenging to unambiguously assign all the absorbance bands because of band overlapping due to the coexistence of many absorbing species in solution. Nevertheless, the absorbance bands at $1647 \mathrm{~cm}^{-1}, 1478 \mathrm{~cm}^{-1}$, and $1358 \mathrm{~cm}^{-1}$ were selected as the less prone to uncertainty and assigned to $-\mathrm{NH}_{3}^{+}$, $\mathrm{CO}_{3}^{2-}$ and $\mathrm{HCO}_{3}^{-}$, respectively.
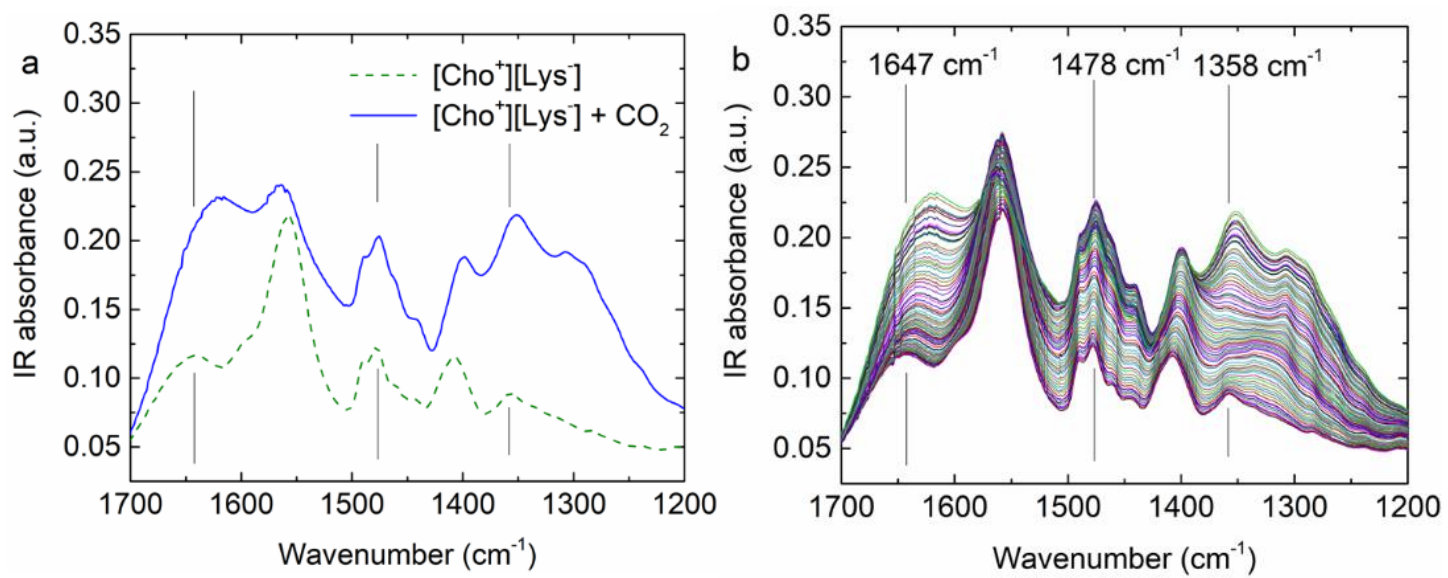

Figure 5.8 ATR-FTIR spectra. (a) Before and after $\mathrm{CO}_{2}$ absorption into aqueous solution of 50 $w t \%\left[\mathrm{Cho}^{+}\right]\left[\mathrm{Lys}^{-}\right] \mathrm{IL}$. (b) Aqueous solution of $50 \mathrm{wt} \%\left[\mathrm{Cho}^{+}\right]\left[\mathrm{Lys}^{-}\right]$IL with different $\mathrm{CO}_{2}$ loadings.

As mentioned in Section 5.4.1, the absorbance band assigned to $-\mathrm{NH}_{3}^{+}$is usually located in the $1750-1600 \mathrm{~cm}^{-1}$ region; therefore, changes in the peak at $1647 \mathrm{~cm}^{-1}$ are assumed to correlate with the protonation of the amines of the lysinate anion. Since the order of the $\mathrm{C}-\mathrm{O}$ bond of the inorganic carbonates is between one and two, it exhibits a stretching vibration band in the $1510-1410 \mathrm{~cm}^{-1}$ region; thus, the identified band at $1478 \mathrm{~cm}^{-1}$ is attributed to the vibration of the carbonate ion, $\mathrm{CO}_{3}^{2-}$. Finally, during the absorption $\mathrm{CO}_{2}$ is converted into bicarbonate ion, whose formation is observed with the increase of the absorbance band at $1358 \mathrm{~cm}^{-1}$, as reported elsewhere [154,166]. 
The most commonly proposed reaction mechanism for $\mathrm{CO}_{2}$ capture in traditional aqueous amine solutions with high water content considers the path carbamate $\rightarrow$ bicarbonate $\rightarrow$ carbonate formation [156]. This pathway considers amine to be the primary nucleophile for an attack on $\mathrm{CO}_{2}$. Nevertheless, it has been reported that amino acid anions like $\left[\mathrm{Lys}^{-}\right]$can take an alternative path. The proposed mechanism in this study considers the direct formation of bicarbonate where the first step is the amine protonation, which is confirmed by the results obtained. On the other hand, the carbamate/carbamic acid formation is excluded from the proposed chemical mechanism because no changes in the absorbance band in the $3000-2500 \mathrm{~cm}^{-1}$ region were observed.

\subsubsection{Model fitting and validation}

The chemical reactions governing $\mathrm{CO}_{2}$ absorption in the aqueous [Cho $\left.{ }^{+}\right]\left[\mathrm{Lys}^{-}\right] \mathrm{IL}$ solution are assumed to be given by the set of Equations (5.1-5.8). The equilibrium constants $K_{1}, K_{2}$ and $K_{3}$, which characterise the water equilibrium and reversible reactions for $\mathrm{CO}_{2}$ dissociation in aqueous solution were taken from the Aspen Plus (ver. 10.2) library and not subjected to any data fitting. The other equilibrium constants, namely $K_{4}, K_{5}$, and $K_{7}$ which characterise the reversible reactions of amine protonation of the lysinate anion, and $K_{6}$ and $K_{8}$, governing the bicarbonate ion binding, were fitted to the experimental $\mathrm{pH}$ and IR absorbance data.

The initial absorption medium consisted of $700 \mathrm{~mL}$ of an aqueous solution with 1.49 moles of IL dissolved into 21.18 moles of water, where $[\mathrm{R}]_{0}=$ $2.13 \mathrm{M}$ and $\left[\mathrm{H}_{2} \mathrm{O}\right]_{0}=30.26 \mathrm{M}$. The initial $\mathrm{pH}$ was 12.88 . Hence, the model described in Section 5.2 should satisfy the following initial conditions:

$$
\begin{aligned}
& {\left[\mathrm{H}_{2} \mathrm{O}\right]_{0}=30.26 \mathrm{M},} \\
& \mathrm{pH}_{0}=12.88,
\end{aligned}
$$


$[\mathrm{R}]_{0}+\left[\mathrm{RH}^{+}\right]_{0}+\left[\mathrm{RH}_{2}^{2+}\right]_{0}=2.13 \mathrm{M}$,

$\left[\mathrm{CO}_{2}\right]_{0}=\left[\mathrm{HCO}_{3}^{-}\right]_{0}=\left[\mathrm{CO}_{3}^{2-}\right]_{0}=\left[\mathrm{P}_{1}\right]_{0}=\left[\mathrm{P}_{1}^{+}\right]_{0}=\left[\mathrm{P}_{2}\right]_{0}=0$.

The $\mathrm{CO}_{2}$ solubility in the aqueous solution of $\left[\mathrm{Cho}^{+}\right]\left[\mathrm{Lys}^{-}\right]$, at $1 \mathrm{~atm}$ and 20 ${ }^{\circ} \mathrm{C}$, is estimated to be $\left[\mathrm{CO}_{2}\right]_{\max }=0.019 \mathrm{M}$; this value was determined in Aspen Plus (ver. 10.2) using the unsymmetrical electrolyte NRTL property method (eNRTL-RK) and Redlich-Kwong equation of state for the gas phase. At the end of the experiment, the solution is known to be fully saturated because by then the inlet and outlet molar flowrates of gaseous $\mathrm{CO}_{2}$ are identical. The measured $\mathrm{pH}$ under saturation conditions was 7.93. Moreover, by applying Equation (5.35) to the experimental data, the total amount of absorbed $\mathrm{CO}_{2}$ under saturation conditions was found to be $3.13 \mathrm{M}$. Under these saturation conditions the concentration of aqueous $\mathrm{CO}_{2}$ should be $0.019 \mathrm{M}$. Thus, the model should satisfy the following conditions at the end $(t \rightarrow \infty)$ of the simulated experiment: $\left[\mathrm{CO}_{2}\right]_{\infty}=0.019 \mathrm{M}, \mathrm{pH}_{\infty}=7.93$ and $\left[\mathrm{C}_{\text {tot }}\right]_{\infty}=3.13 \mathrm{M}$. It is instructive to analyse the degrees of freedom of the problem. The equations governing the initial conditions of the experiment are ${ }^{1}$

$$
\begin{aligned}
& {\left[\mathrm{CO}_{2}\right]_{0}=\left[\mathrm{HCO}_{3}^{-}\right]_{0}=\left[\mathrm{CO}_{3}^{2-}\right]_{0}=\left[\mathrm{P}_{1}\right]_{0}=\left[\mathrm{P}_{1}^{+}\right]_{0}=\left[\mathrm{P}_{2}\right]_{0}=0,} \\
& {\left[\mathrm{H}_{2} \mathrm{O}\right]_{0}=30.26 \mathrm{M},} \\
& \mathrm{pH}_{0}=12.88 \\
& {[\mathrm{R}]_{0}+\left[\mathrm{RH}^{+}\right]_{0}+\left[\mathrm{RH}_{2}^{2+}\right]_{0}=2.13 \mathrm{M},} \\
& {\left[\mathrm{H}_{3} \mathrm{O}^{+}\right]_{0}+\left[\mathrm{RH}^{+}\right]_{0}+2\left[\mathrm{RH}_{2}^{2+}\right]_{0}=\left[\mathrm{OH}^{-}\right]_{0},}
\end{aligned}
$$

${ }^{1}$ For simplicity the activity coefficients have been omitted from these equations but considered in the actual model. 


$$
\begin{aligned}
& \frac{\left[\mathrm{H}_{3} \mathrm{O}^{+}\right]_{0}\left[\mathrm{OH}^{-}\right]_{0}}{\left(\left[\mathrm{H}_{2} \mathrm{O}\right]_{0}\right)^{2}}=K_{1}, \\
& \frac{\left[\mathrm{RH}^{+}\right]_{0}\left[\mathrm{H}_{2} \mathrm{O}\right]_{0}}{[\mathrm{R}]_{0}\left[\mathrm{H}_{3} \mathrm{O}^{+}\right]_{0}}=K_{4}, \\
& \frac{\left[\mathrm{RH}_{2}^{2+}\right]_{0}\left[\mathrm{H}_{2} \mathrm{O}\right]_{0}}{\left[\mathrm{RH}^{+}\right]_{0}\left[\mathrm{H}_{3} \mathrm{O}^{+}\right]_{0}}=K_{5} .
\end{aligned}
$$

This set of equations has one degree of freedom: it has five unknown variables $-[\mathrm{R}]_{0},\left[\mathrm{RH}^{+}\right]_{0},\left[\mathrm{RH}_{2}^{2+}\right]_{0}, K_{4}$ and $K_{5}-$ and four Equations - (5.66), (5.67), (5.69), and (5.70). Hence, if say the ratio of equilibrium constants

$$
\frac{K_{5}}{K_{4}}=\frac{\left[\mathrm{RH}_{2}^{2+}\right]_{0}[\mathrm{R}]_{0}}{\left(\left[\mathrm{RH}^{+}\right]_{0}\right)^{2}}
$$

are known, $[\mathrm{R}]_{0},\left[\mathrm{RH}^{+}\right]_{0},\left[\mathrm{RH}_{2}^{2+}\right]_{0}, K_{4}$, and $K_{5}$ can be determined from the initial conditions of the experiment.

The final conditions of the experiment reduce the number of degrees of freedom by two, because the values of $\mathrm{pH}_{\infty}$ and $\left[\mathrm{CO}_{2}\right]_{\infty}$ are known. This means that the three equilibrium constants $K_{6}, K_{7}$, and $K_{8}$ can be determined if the value of one of them is known. To summarise, the model has two degrees of freedom: e.g., the ratio $K_{5} / K_{4}$ and $K_{6}$.

The unknown equilibrium constants were determined by nonlinear least squares fitting of the experimental $\mathrm{pH}$ curve as a function of $\left[\mathrm{C}_{\text {tot }}\right]$. That is, the optimisation problem

$\min _{K_{4} / K_{5}, K_{6}} \int_{0}^{\left[\mathrm{C}_{\text {tot }}\right]_{\infty}}\left(\mathrm{pH}_{\mathrm{exp}}-\mathrm{pH}_{\text {sim }}\right)^{2} d\left[\mathrm{C}_{\text {tot }}\right]$, s.t. $\left[S_{i}\right] \geq 0 \forall S_{i} \in\{$ species in solution $\}$, (5.72) 
was solved. The condition of positiveness of all concentrations makes sure the obtained solution is physically meaningful.

This is a nontrivial optimisation problem because it involves fitting the set of first-order differential Equations (5.41-5.52) in $\left[\mathrm{C}_{\mathrm{tot}}\right]$ to the experimental $\mathrm{pH}$ data subjected to the algebraic constraint given by Equation (5.39), initial conditions given by Equation (5.53-5.56) and matching the final conditions of $\mathrm{pH}_{\infty}$ and $\left[\mathrm{CO}_{2}\right]_{\infty}$. The constrained, nonlinear least squares fitting of this set of differential-algebraic equations was formulated and solved in gPROMS version 4.1 (Process Systems Enterprise Ltd., UK; https://www.psenterprise.com/products/gproms) using gO:CAPE-OPEN to access the physical properties of the Aspen Plus database via the CAPE-OPEN interface standard [167-171].

External physical property packages are interfaced to gPROMS as Foreign Objects. Each distinct Physical Property Foreign Object used by a Model is declared as a Parameter of type FOREIGN_OBJECT. The latter keyword is normally followed by the class of the Foreign Object which identifies the external physical properties software that will be used to implement this instance of the Foreign Object. The standard way of referring to physical property calculations within the Model is as ForeignobjectName.PhysicalProperty for constant properties (mainly those relating to pure components properties such as molecular weights) and ForeignobjectName.PhysicalProperty (InputList) for variable physical properties. Each input of a physical property is a scalar or vector-valued variable or expression. Each property returns a single scalar or vector-valued quantity. The latter may be of type integer, logical or real. A method may be used anywhere in the Model where an expression of the corresponding dimensionality and type is allowed.

gPROMS comes as standard with the COThermoFO Foreign Object [172] which allows gPROMS models to make use of external thermodynamic and physical properties software that comply with version 1.1 of the CAPE-OPEN Thermodynamic and Physical Properties specification [173]. To do this, in the 
PROCESS entity the Foreign Object is declared to belong to class COThermoFO. Figure 5.9 summarizes the major steps required to interface Aspen Plus with gPROMS.

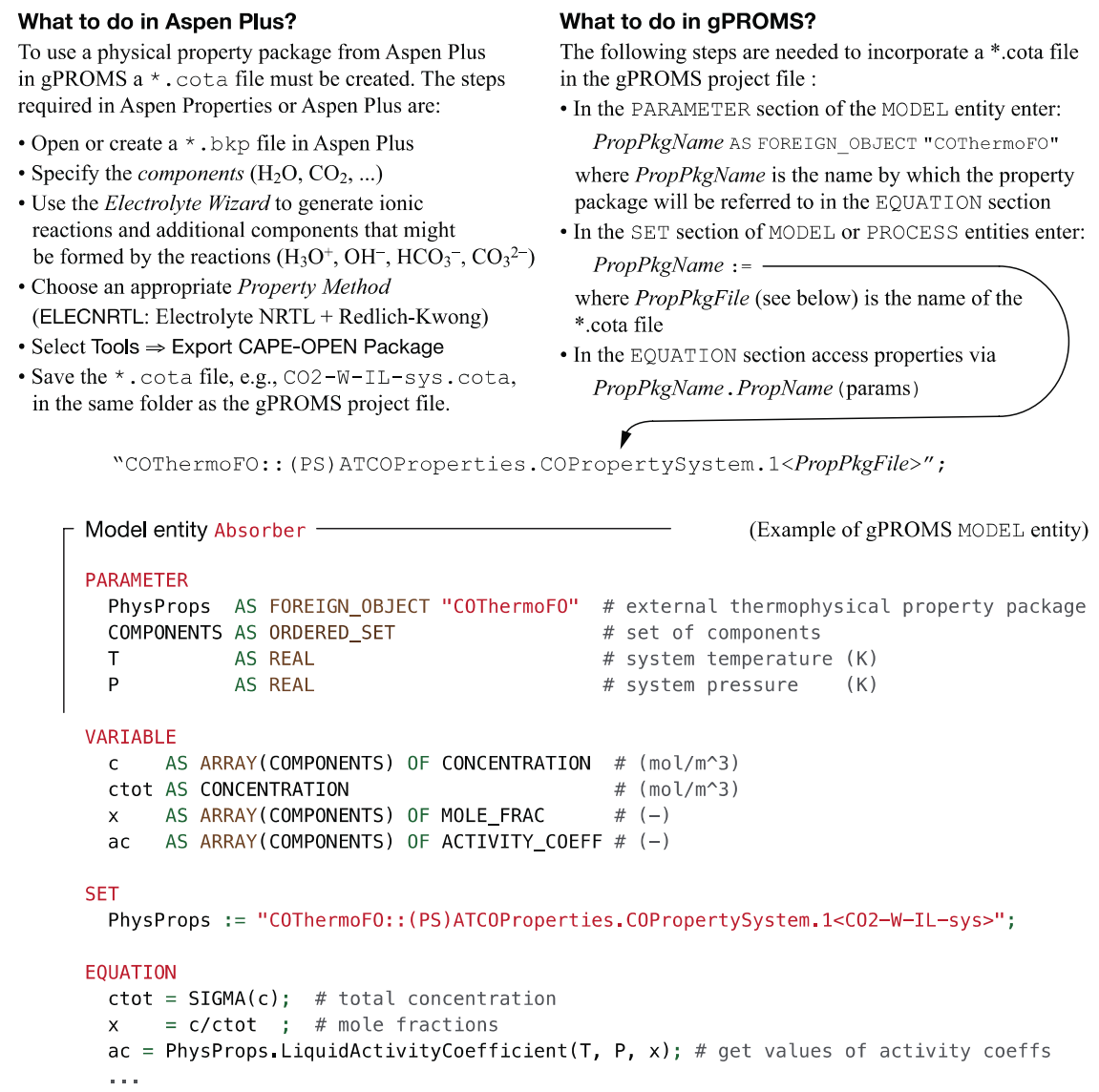

Figure 5.9 Summary of the workflow required for interfacing gPROMS and an Aspen Plus Property Package (interface direction: Aspen Plus $\rightarrow g P R O M S$ ) that complies with version 1.1 of the CAPE-OPEN Thermodynamic and Physical Properties specification.

Table 5.2 lists the equilibrium constants that best fit the experimental pH curve. The equilibrium constant $K_{6}$ was estimated with a small standard deviation (95\% confidence interval equal to 0.42 ). However, the ratio $K_{5} / K_{4}$ is difficult to estimate with an equally small relative standard error. Despite this, the fitting results indicate that $K_{5} \ll K_{4}$ and $\left[\mathrm{RH}_{2}^{2+}\right] \approx 0$; thus it is not possible to determine with certainty the value of $K_{5}$ because the reaction (5) has little impact 
on the results. It is thus concluded that the concentration of $\mathrm{RH}_{2}^{2+}$ in solution is $\approx 0$, due to the high reactivity between the bicarbonate ion and the anion [Lys ${ }^{-}$]. Therefore, the second protonation occurs simultaneously with the bicarbonate binding to the amine of the side chain. Nevertheless, the simulated results show the existence of a small amount of $\mathrm{RH}_{2}^{2+}$ at the end of the experiment, when no more $\mathrm{CO}_{2}$ is absorbed, owing to the presence of some free amine groups in the medium.

Table 5.2. Equilibrium constants obtained from data fitting. For completeness, the values of all constants are listed, although only the ratio $K_{5} / K_{4}$ and $K_{6}$ were adjusted.

\begin{tabular}{cc}
\hline Equilibrium constant & Value \\
\hline$K_{4}$ & $1.480 \times 10^{13}$ \\
$K_{5} / K_{4}$ & $\sim 10^{-5}$ \\
$K_{6}$ & 264.1 \\
$K_{7}$ & $6.957 \times 10^{8}$ \\
$K_{8}$ & 187.9 \\
\hline
\end{tabular}

Figure 5.10 shows the simulated and fitted pH curves plotted against the $\mathrm{CO}_{2}$ loading concentration. The simulated $\mathrm{pH}$ curve is in excellent agreement with the experimental data. In particular, the model simulates quite nicely the smooth concave and convex curvatures of the experimental $\mathrm{pH}$ curve, which can be attributed to the protonation kinetics of the amines of [Lys $\left.{ }^{-}\right]$. 


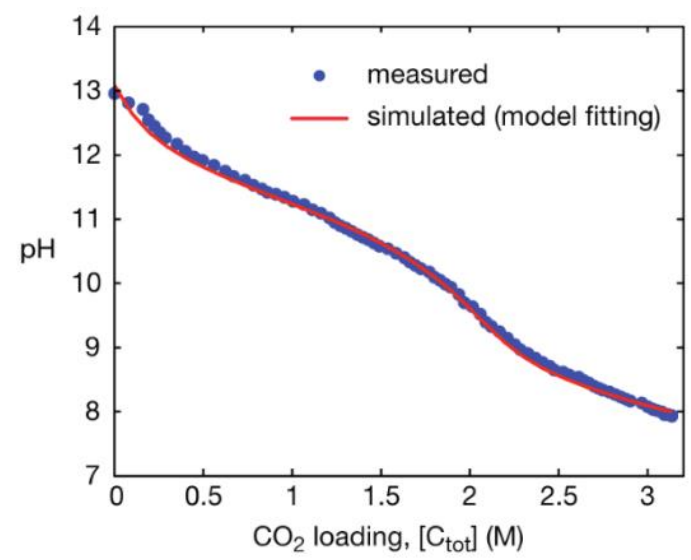

Figure 5.10 Experimental (symbols) and fitted (line) curves of $\mathrm{pH}$ as a function of $\mathrm{CO}_{2}$ loading, $\left[C_{t o t}\right](M)$.

Since it is assumed that at each instant along the absorption experiment the concentrations of the various species in solution are governed by the corresponding chemical equilibrium constants then the overall absorption kinetics must be controlled by mass transfer from the gas to the liquid phase. Since the gaseous $\mathrm{CO}_{2}$ flowing in the shell side of the contactor suffered a negligible pressure drop during the experiment $(<0.07 \mathrm{bar})$, it is safe to assume that the conditions prevailing in the shell side of the contactor were $1 \mathrm{~atm}$ and 20 ${ }^{\circ} \mathrm{C}$, and what varied throughout the experiment was the volumetric (or molar) outlet flow rate of $\mathrm{CO}_{2}, \dot{n}_{\mathrm{CO}_{2}}^{\text {(out) }}$. Moreover, given that pure gas transport through the $0.65 \mu \mathrm{m}$ pores of the Eclipse ${ }^{\mathrm{TM}}$ membrane filled with gas phase is a much faster process than bulk mixing and diffusion of the dissolved gas in the liquidphase, the overall absorption kinetics should be controlled by mass transfer in the liquid phase. In this case, the overall differential material balance to the $\mathrm{CO}_{2}$ can be written as

$$
\frac{d\left(V\left[\mathrm{C}_{\mathrm{tot}}\right]\right)}{d t}=k_{\mathrm{L}} A_{\mathrm{m}}\left(\left[\mathrm{CO}_{2}\right]_{\infty}-\left[\mathrm{CO}_{2}\right]\right)
$$

where $A_{\mathrm{m}}$ is the membrane contact area, $k_{\mathrm{L}}$ the mass transfer coefficient in the liquid phase, and, recall, $\left[\mathrm{CO}_{2}\right]_{\infty}$ the $\mathrm{CO}_{2}$ solubility in the aqueous solution of $\left[\mathrm{Cho}^{+}\right]\left[\mathrm{Lys}^{-}\right]$at $1 \mathrm{~atm}$ and $20^{\circ} \mathrm{C}$. This equation is more general than may seem at 
first glance. With reference to Figure 5.5, the differential material balance to the $\mathrm{CO}_{2}$ can also be expressed as

$$
\frac{d\left(V\left[\mathrm{C}_{\mathrm{tot}}\right]\right)}{d t}=Q\left(\left[\mathrm{CO}_{2}^{\mathrm{L}}\right]^{(\text {out })}-\left[\mathrm{CO}_{2}^{\mathrm{L}}\right]^{(\mathrm{in})}\right)
$$

where $\left[\mathrm{CO}_{2}^{\mathrm{L}}\right]^{(\mathrm{in})}$ and $\left[\mathrm{CO}_{2}^{\mathrm{L}}\right]^{\text {(out) }}$ are the inlet and outlet concentrations of aqueous $\mathrm{CO}_{2}$ in the lumen $(\mathrm{L})$ side of the membrane and $Q$ the volumetric recirculation flow rate in that same side. Given that the aqueous IL solution is assumed to be well mixed, by definition $\left[\mathrm{CO}_{2}^{\mathrm{L}}\right]^{(\mathrm{in})}=\left[\mathrm{CO}_{2}\right]$, where, as above, $\left[\mathrm{CO}_{2}\right]$ is the $\mathrm{CO}_{2}$ concentration in the bulk of volume $V$. Using a quasi-steady approximation, the differential material balance to the recirculating aqueous $\mathrm{CO}_{2}$ can be written as

$$
Q \frac{d\left[\mathrm{CO}_{2}^{\mathrm{L}}\right]}{d A_{\mathrm{m}}}=k_{\mathrm{L}}\left(\left[\mathrm{CO}_{2}\right]_{\infty}-\left[\mathrm{CO}_{2}^{\mathrm{L}}\right]\right)
$$

Integrating this equation over the whole membrane area, $A_{\mathrm{m}}$, over which $\left[\mathrm{CO}_{2}^{\mathrm{L}}\right]$ changes from to $\left[\mathrm{CO}_{2}^{\mathrm{L}}\right]^{(\mathrm{in})}$ to $\left[\mathrm{CO}_{2}^{\mathrm{L}}\right]^{\left({ }^{(o u t)}\right.}$, gives

$$
\frac{\left[\mathrm{CO}_{2}\right]_{\infty}-\left[\mathrm{CO}_{2}^{\mathrm{L}}\right]^{(\mathrm{in})}}{\left[\mathrm{CO}_{2}\right]_{\infty}-\left[\mathrm{CO}_{2}^{\mathrm{L}}\right]^{(\mathrm{out})}}=\phi, \phi \equiv \exp \left(\frac{k_{\mathrm{L}} A_{\mathrm{m}}}{Q}\right)
$$

and

$$
\left[\mathrm{CO}_{2}^{\mathrm{L}}\right]^{(\mathrm{out})}-\left[\mathrm{CO}_{2}^{\mathrm{L}}\right]^{(\mathrm{in})}=\left(1-\frac{1}{\phi}\right)\left(\left[\mathrm{CO}_{2}\right]_{\infty}-\left[\mathrm{CO}_{2}^{\mathrm{L}}\right]^{(\mathrm{in})}\right) .
$$

But since $\left[\mathrm{CO}_{2}^{\mathrm{L}}\right]^{(\mathrm{in})}=\left[\mathrm{CO}_{2}\right]$, Equation (5.73) becomes

$$
\frac{d\left(V\left[\mathrm{C}_{\mathrm{tot}}\right]\right)}{d t}=Q\left(1-\frac{1}{\phi}\right)\left(\left[\mathrm{CO}_{2}\right]_{\infty}-\left[\mathrm{CO}_{2}\right]\right),
$$


which is the same as Equation (5.73) with $k_{\mathrm{L}} A_{\mathrm{m}}$ replaced by $Q\left(1-\phi^{-1}\right)$. Moreover, $\lim _{Q \rightarrow \infty} Q\left(1-\phi^{-1}\right)=k_{\mathrm{L}} A_{\mathrm{m}}$. Thus, even if there is a concentration gradient along the extent of the lumen side of the membrane, Equation (5.73) is still valid but with a slight change of the meaning of the product $k_{\mathrm{L}} A_{\mathrm{m}}$. The latter was determined by nonlinear least squares fitting of the experimental $\left[\mathrm{C}_{\text {tot }}\right]$ curve as a function of time. This entailed solving the following optimisation problem:

$$
\min _{k_{\mathrm{L}} A_{\mathrm{m}}} \int_{0}^{t_{\text {end }}}\left(\left[\mathrm{C}_{\mathrm{tot}}\right]_{\exp }-\left[\mathrm{C}_{\mathrm{tot}}\right]_{\operatorname{sim}}\right)^{2} d t
$$

where the subscripts exp and sim denote the experimental and simulated $\left[\mathrm{C}_{\mathrm{tot}}\right]$ curves and $t_{\text {end }}$ the duration of the experiment. The estimated parameter value was $k_{\mathrm{L}} A_{\mathrm{m}} / V=0.834 \mathrm{~min}^{-1}$ (95\% confidence interval of $2.3 \times 10^{-6}$ and a standard deviation of $\left.1.2 \times 10^{-6}\right)$. Figure 5.11 shows the simulated and fitted $\left[\mathrm{C}_{\text {tot }}\right]$ curves plotted against process time. The simulated $\left[\mathrm{C}_{\text {tot }}\right]$ curve is in excellent agreement with the experimental data.

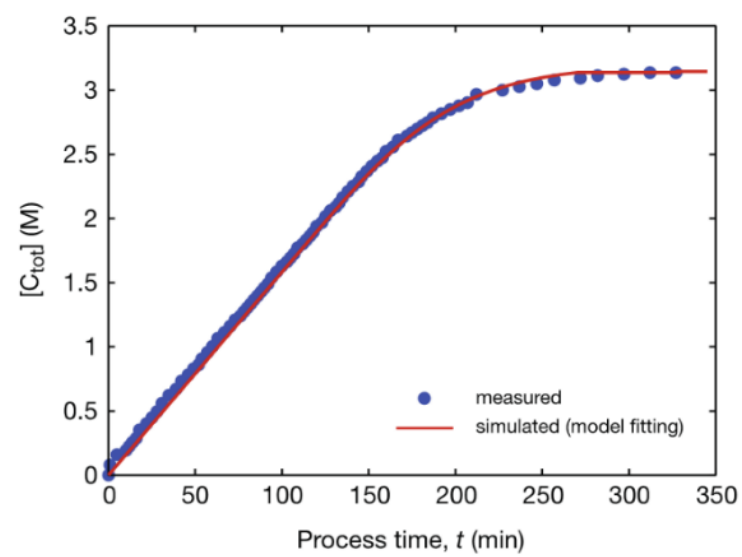

Figure 5.11 Experimental (symbols) and fitted (line) curves of $\mathrm{CO}_{2}$ loading, $\left[\mathrm{C}_{\text {tot }}\right](\mathrm{M})$, as a function of process time.

Further simulated concentration profiles are plotted in Figures 5.12-5.14. These are meant to illustrate the sort of quantitative information provided by the 
model. These profiles are not comparable with those published for the wellstudied, traditional aqueous amine solutions. Moreover, since there is no reported theoretical study in the literature on this system, it is not possible to make a comparison with data from other sources. Nevertheless, the good agreement between the simulated and experimental values, the likelihood of the trends displayed by the simulated concentration profiles, and reasonableness of the assumptions behind the chemical reaction equilibria support the validation of our model.

Figure 5.12 shows the simulated $\left[\mathrm{Cho}^{+}\right]\left[\mathrm{Lys}^{-}\right]$concentration profile and its protonated forms as a function of the total $\mathrm{CO}_{2}$ loading. The shape of the concentration profile for the single-protonated form is convex passing through a maximum and then tending towards progressively smaller values. This behaviour is consistent with the increase of $P_{1}$ concentration (Figure 5.14), as a consequence of the bicarbonate ion attachment, evidenced in Figure 5.13. As stated above, the concentration of $\mathrm{R}^{2+}$ is negligible throughout the experiment. The amount of free bicarbonate increases until it reaches a peak and then is progressively consumed until the end of the experiment when no more $\mathrm{CO}_{2}$ is absorbed. The concentration profile of dissolved, unreacted $\mathrm{CO}_{2}$ starts from near zero and increases monotonically towards the saturation value achieved with physical absorption, which is much smaller than the loading achieved by chemical absorption.

Some recent works [134,174] have reported on the qualitative identification of amine, carbamate, and bicarbonate species during the absorption of $\mathrm{CO}_{2}$ in aqueous solutions of various types of amines, but not in solutions of ILs with quaternary ammonium cations. Infrared monitoring allows quantitative measurements of multicomponent solutions provided the concentrations are within the range of validity of the Beer-Lambert law, but typically requires timeconsuming calibration of pure components or mixtures at different concentrations $[153,166,175]$. 


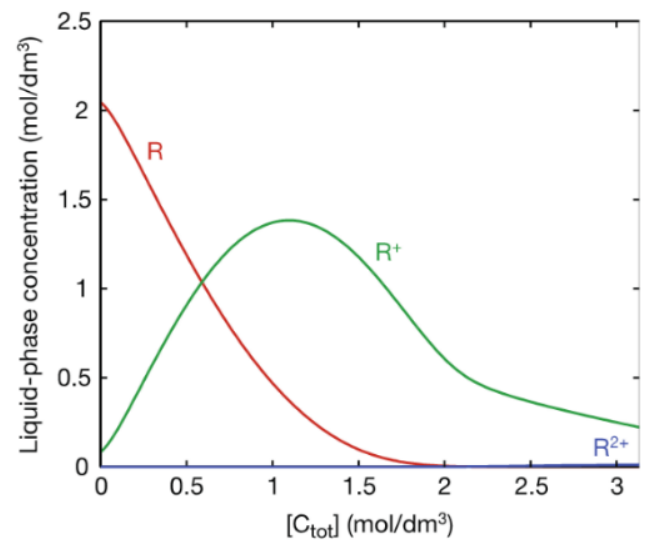

Figure 5.12 Simulated curves of $[R] \equiv\left[\mathrm{Cho}^{+}\right]\left[\mathrm{Lys}^{-}\right]$IL and its two positively charged forms, $\left[R^{+}\right] \equiv\left[\mathrm{Cho}^{+}\right]\left[\right.$Lys $\left.^{-+}\right]$and $\left[\mathrm{R}^{2+}\right] \equiv\left[\mathrm{Cho}^{+}\right]\left[\right.$Lys $\left.^{-++}\right]$, as a function of total $\mathrm{CO}_{2}$ loading, $\left[C_{\text {tot }}\right]$.

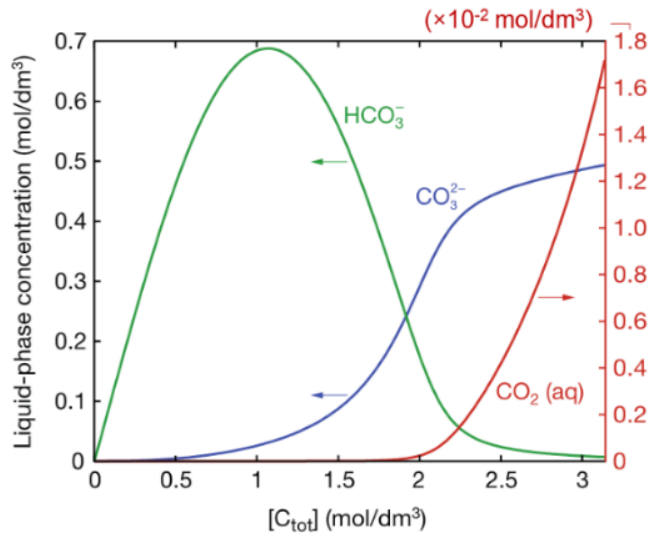

Figure 5.13 Simulated curves of $\left[\mathrm{CO}_{2}(\mathrm{aq})\right],\left[\mathrm{HCO}_{3}^{-}\right]$, and $\left[\mathrm{CO}_{3}^{2-}\right]$ as a function of total $\mathrm{CO}_{2}$ loading, $\left[\mathrm{C}_{\text {tot }}\right]$.

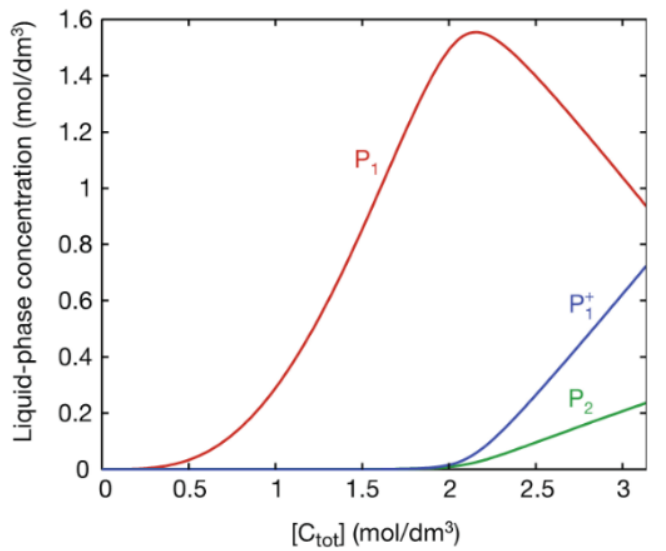

Figure 5.14 Simulated concentration curves of the final products, $\mathrm{P}_{1} \equiv\left[\mathrm{Cho}^{+}\right]\left[\mathrm{Lys}^{-+} \mathrm{HCO}_{3}^{-}\right]$ and $\mathrm{P}_{2} \equiv\left[\mathrm{Cho}^{+}\right]\left[\right.$Lys $\left.^{-++} 2 \mathrm{HCO}_{3}^{-}\right]$, and intermediate species $\mathrm{P}_{1}^{+} \equiv\left[\mathrm{Cho}^{+}\right]\left[\right.$Lys $\left.^{-++} \mathrm{HCO}_{3}^{-}\right]$as a function of total $\mathrm{CO}_{2}$ loading, $\left[\mathrm{C}_{\text {tot }}\right]$. 
Although the experimental ATR-FTIR absorbance spectrum, $A^{\exp }$, was measured as a function of $\mathrm{CO}_{2}$ loading, $A^{\exp }=A^{\exp }\left(\left[\mathrm{C}_{\mathrm{tot}}\right]\right)$, it is in reality a multivariable function of the experimental species concentrations in solution, $[\underline{S} \in \mathcal{S}]^{\exp }$, where $\mathcal{S}=\left\{\mathrm{H}_{2} \mathrm{O}, \mathrm{OH}^{-}, \ldots, \mathrm{P}_{2}\right\}$ represents the set of chemical species. Here we adopt a procedure somewhat similar to the calibration-free spectroscopic technique proposed by Richner and Puxty [154] for determining the speciation of $\mathrm{CO}_{2}-\mathrm{H}_{2} \mathrm{O}$-alkanolamine systems. Their method is based on in situ infrared monitoring of the liquid phase during $\mathrm{CO}_{2}$ absorption by an aqueous amine solution in a stirred vessel, combined with mathematical hard modelling of the reaction mechanism. The species concentrations are calculated by fitting a thermodynamic model to multivariate spectroscopic measurements using nonlinear regression. In our procedure, however, the thermodynamic equilibrium constants of the $\mathrm{CO}_{2}-\mathrm{H}_{2} \mathrm{O}-\left[\mathrm{Cho}^{+}\right]\left[\mathrm{Lys}^{-}\right]$system are those determined independently using our validated chemical reaction model, and the simulated profiles of species concentration as a function of $\mathrm{CO}_{2}$ loading shown in Figures 5.12-5.14, $[\underline{S}]=[\underline{S}]\left(\left[\mathrm{C}_{\text {tot }}\right]\right)$, considered to be a good approximation of their experimental counterparts. This, in turn, allows us to replace the analysis of $A^{\exp }\left(\left[\mathrm{C}_{\mathrm{tot}}\right]\right)$ by a multivariable analysis of $A^{\exp }([\underline{S} \in \mathcal{S}])$, where $[\underline{S}]=[\underline{S}]\left(\left[\mathrm{C}_{\text {tot }}\right]\right)$ is given by the thermodynamic model. It is shown next that $A^{\exp }([\underline{S} \in \mathcal{S}])$ can be explained by a multivariable linear model and therefore the nonlinearities in $A^{\exp }$ $\left[\mathrm{C}_{\text {tot }}\right]$ completely described by the thermodynamic model.

If the Beer-Lambert law is valid, the measured absorbance at any given wavenumber, say $\lambda$, in a multicomponent solution of $\mathcal{S}$ components can be expressed as

$$
A_{\lambda}=\ell \sum_{S_{i} \in \mathcal{S}} \epsilon_{\lambda, i}\left[S_{i}\right]
$$

where $\ell$ is the path length, $\left[S_{i}\right]$ the molar concentration of species $S_{i}$, and $\epsilon_{\lambda, i}$ the molar attenuation coefficient (or molar absorptivity) of $S_{i}$ at wavelength $\lambda$. Despite the limitations of this law, in particular its failure to maintain a linear relationship between attenuation and concentration of analyte over the full range 
of concentration, here it is assumed that the change in the measured absorbance of the $\mathrm{CO}_{2}-$ water- $\left[\mathrm{Cho}^{+}\right]\left[\mathrm{Lys}^{-}\right]$solution at any given wavenumber, say $\lambda$, can be expressed as

$d A_{\lambda}=\sum_{S_{i} \in \mathcal{S}} a_{\lambda, i} d\left[S_{i}\right]+d e_{\lambda}$

or, in integral form,

$$
\Delta A_{\lambda}(t)=\sum_{S_{i} \in \mathcal{S}} a_{\lambda, i} \Delta\left[S_{i}\right](t)+e_{\lambda}(t),
$$

where $\mathcal{S}=\left\{\mathrm{H}_{2} \mathrm{O}, \mathrm{OH}^{-}, \ldots, \mathrm{P}_{2}\right\}$ is the set of chemical species that make up the solution, $\Delta A_{\lambda}(t)=A_{\lambda}(t)-A_{\lambda}(0)$ and so forth, $a_{\lambda, i} \geq 0$ a nonnegative constant empirically related to the molar attenuation coefficient $\epsilon_{\lambda, i}$ and which for simplicity we shall refer to as an absorptivity coefficient, and $e_{\lambda} \sim \mathcal{N}\left(0, \sigma^{2}\right)$ a random residual or error assumed to be normally distributed with zero mean and standard deviation $\sigma$. In matrix notation,

$\underline{A}=\boldsymbol{\Xi} \times[\underline{S}]+\underline{e}$,

$\left[\begin{array}{c}A_{\lambda_{1}} \\ \ldots \\ A_{\lambda_{m}}\end{array}\right]=\left[\begin{array}{ccc}\alpha_{\lambda_{1}, 1} & \ldots & \alpha_{\lambda_{1}, n} \\ \ldots & & \ldots \\ \alpha_{\lambda_{m}, 1} & \ldots & \alpha_{\lambda_{m}, n}\end{array}\right]\left[\begin{array}{c}{\left[S_{1}\right]} \\ \vdots \\ {\left[S_{n}\right.}\end{array}\right]+\left[\begin{array}{c}e_{\lambda_{1}} \\ \vdots \\ e_{\lambda_{m}}\end{array}\right]$,

where $\underline{A}$ is the $m$-vector of measured absorbances (i.e., the absorbance spectrum), $\Xi$ the $m \times n$ matrix of absorptivities, $[\underline{S}]=\left[\left[\mathrm{CO}_{2}(\mathrm{aq})\right],\left[\mathrm{HCO}_{3}^{-}\right],[\mathrm{R}], \ldots,\left[\mathrm{P}_{2}\right]\right]^{T}$ the $n-$ vector of species concentrations, and $\underline{e}$ the $m$-vector of residual errors. The matrix $\Xi$ can be determined by constrained multiple linear regression with a nonnegative least squares estimation technique: 
$\min _{\Xi}\|\underline{e}\|^{2}$ s.t. $\Xi \geq 0$

(the elements of matrix $\Xi$ must all be nonnegative). This parameter estimation problem was formulated and solved in gPROMS. To improve the robustness of the estimation, any absorptivity $a_{\lambda, i}$ whose $\sigma_{\lambda, i} / a_{\lambda, i}$ ratio is larger than five times the average value of $\sigma_{\lambda, i} / a_{\lambda, i}$ for each wavenumber $\lambda$, where $\sigma_{\lambda, i}$ is the standard deviation of the estimated value of $a_{\lambda, i}$, is discarded, and then the nonnegative linear regression is repeated but without the eliminated parameters. One iteration is enough to discard the absorptivities that contribute little to the objective function.
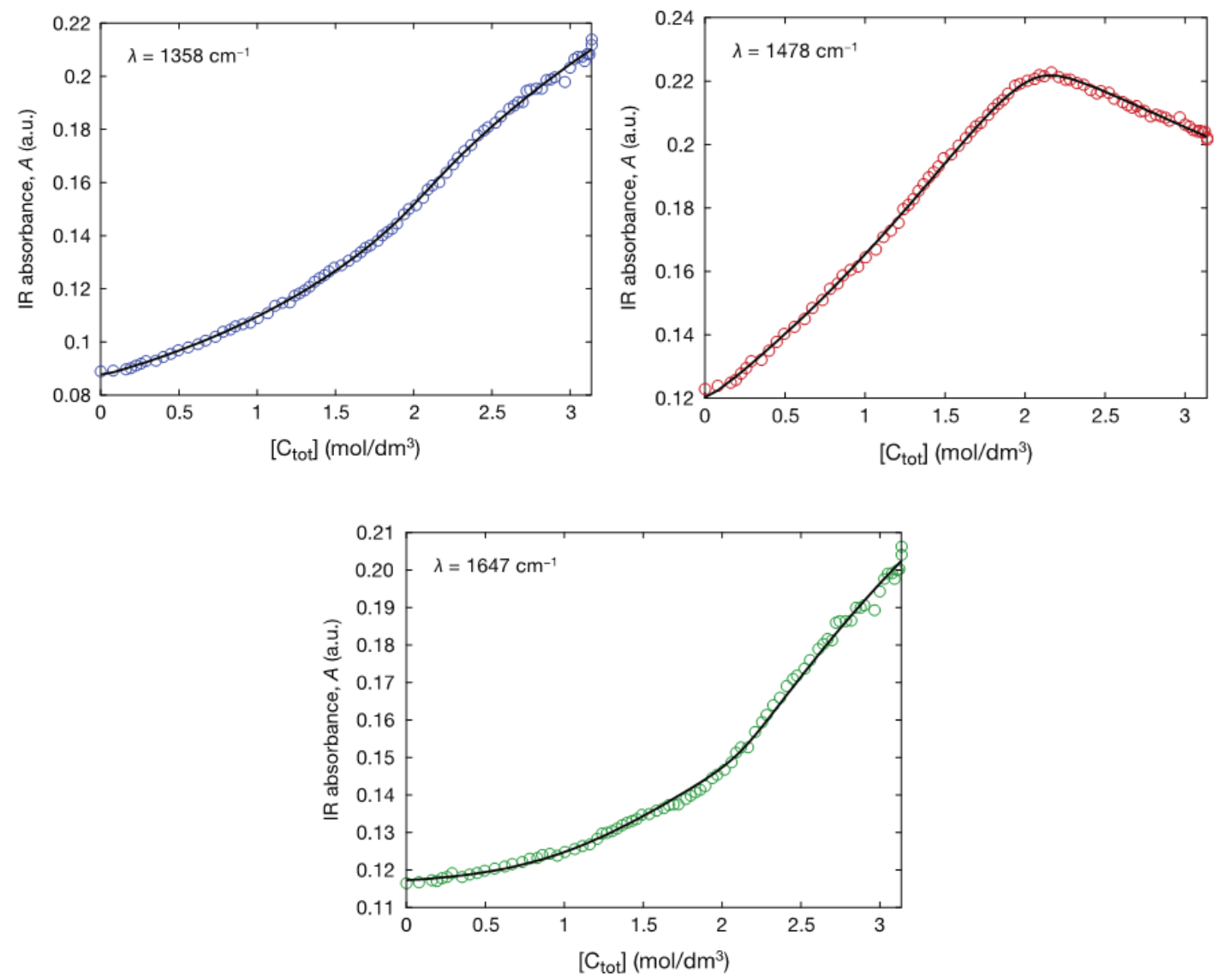

Figure 5.15 Experimental and simulated $I R$ absorbances as function of $\mathrm{CO}_{2}$ loading, $\left[C_{\text {tot }}\right]$, at $1647 \mathrm{~cm}^{-1}, 1478 \mathrm{~cm}^{-1}$, and $1358 \mathrm{~cm}^{-1}$.

Table 5.3 summarises the obtained results and Figure 5.15 compares the fitted and measured absorbances at the three selected wavenumbers plotted 
against the $\mathrm{CO}_{2}$ loading concentration. The results clearly show that the chemical model and the corresponding fitted equilibrium constants are compatible with the ATR-FTIR data measured experimentally. The estimated values of $a_{\lambda, i}$ for $\mathrm{HCO}_{3}^{-}$and $\mathrm{CO}_{3}^{2-}$ were either zero or their standard deviations very large and, therefore, discarded before further refitting. The estimated contribution of $\mathrm{CO}_{2}$ (aq) to the measured ATR-FTIR signal is negligible because its concentration is very small in the aqueous IL solution. Also, the estimated value of $a_{\lambda, i}$ for $\mathrm{RH}_{2}^{2+}$ was either zero or very close to it. The standard deviations of the estimates of the remaining absorptivities are all small and, therefore, appear to contribute significantly to explain the experimental ATR-FTIR data.

Table 5.3 Values of the absorptivities for each component in the aqueous IL solution that best fit the experimental FTIR spectra. The 95\% confidence interval of each estimated absorptivity is equal to $2 \sigma$.

\begin{tabular}{|c|c|c|c|c|c|c|}
\hline \multirow{2}{*}{$\frac{\lambda\left(\mathbf{c m}^{-1}\right)}{S_{i}}$} & \multicolumn{2}{|c|}{1647} & \multicolumn{2}{|c|}{1478} & \multicolumn{2}{|c|}{1358} \\
\hline & $a_{\lambda, i}$ & $\sigma_{\lambda, i} / a_{\lambda, i}$ & $a_{\lambda, i}$ & $\sigma_{\lambda, i} / a_{\lambda, i}$ & $a_{\lambda, i}$ & $\sigma_{\lambda, i} / a_{\lambda, i}$ \\
\hline $\mathrm{CO}_{2}(\mathrm{aq})$ & 0 & * & 0 & $*$ & 0 & $*$ \\
\hline $\mathrm{HCO}_{3}^{-}$ & 0 & $* *$ & 0 & * & 0 & $* *$ \\
\hline $\mathrm{CO}_{3}^{2-}$ & 0 & $*$ & 0 & $* *$ & 0 & $*$ \\
\hline $\mathrm{R}$ & 70.7 & 0.004 & 0.509 & 0.004 & 90.6 & 0.008 \\
\hline $\mathrm{RH}^{+}$ & 70.7 & 0.004 & 0.528 & 0.003 & 90.6 & 0.008 \\
\hline $\mathrm{RH}_{2}^{2+}$ & 0 & $*$ & 0 & $*$ & 0 & $*$ \\
\hline$P_{1}$ & 70.6 & 0.003 & 0.568 & 0.002 & 90.7 & 0.004 \\
\hline $\mathrm{P}_{1}^{+}$ & 78.1 & 0.003 & 0.207 & 0.002 & 100.0 & 0.005 \\
\hline $\mathrm{P}_{2}$ & 69.5 & 0.004 & 0.656 & 0.005 & 90.0 & 0.004 \\
\hline
\end{tabular}

* Optimum value at lower bound. ${ }^{* *}$ Discarded. 

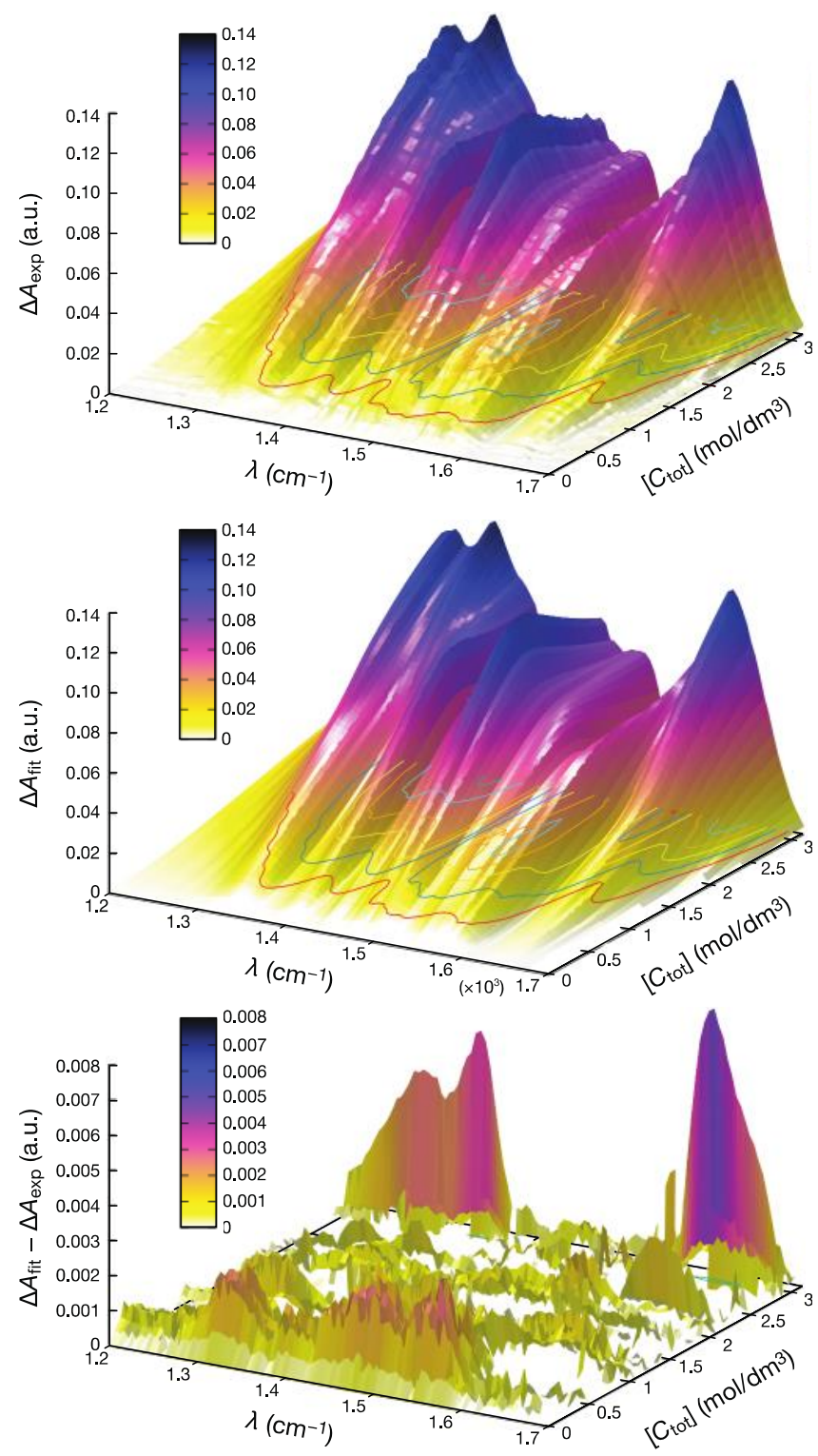

Figure 5.16 Comparison of the experimental and fitted ATR-FTIR absorbance spectra, $\Delta A_{\lambda}^{(\text {exp })}$ and $\Delta A_{\lambda}^{(f i t)}$, and their difference, $\Delta A_{\lambda}^{(f i t)}-\Delta A_{\lambda}^{(\text {exp })}$, as a function $\mathrm{CO}_{2}$ loading over the wavelength range $1200 \leq \lambda \leq 1700 \mathrm{~cm}^{-1}$.

Interestingly, the proposed model is able to accurately fit the experimental ATR-FTIR absorbance profile as a function of $\mathrm{CO}_{2}$ loading not only at the three selected wavelengths, but also over the entire wavelength range. This is demonstrated in Figure 5.16, which compares the experimental and fitted ATRFTIR absorbance spectra, $\Delta A_{\lambda}^{(\mathrm{exp})}$ and $\Delta A_{\lambda}^{(\mathrm{fit})}$, as a function $\mathrm{CO}_{2}$ loading over the wavelength range $1200 \leq \lambda \leq 1700 \mathrm{~cm}^{-1}$. For a better assessment of the quality of the fitting, the absorbance difference, $\Delta A_{\lambda}^{(\mathrm{fit})}-\Delta A_{\lambda}^{(\text {exp })}$, is also plotted. Notice 
that absorbance scale of the 3D plots of $\Delta A_{\lambda}^{(\exp )}$ and $\Delta A_{\lambda}^{(\mathrm{fit})}$ is $0 \leq \Delta A \leq 0.12$ a.u., whereas that of $\Delta A_{\lambda}^{\text {(fit) }}-\Delta A_{\lambda}^{(\text {exp) }}$ is 15 times smaller: $0 \leq \Delta \Delta A_{\lambda} \leq 0.008$ a.u.

It can be argued that the excellent fitting of the ATR-FTIR absorbance profile $\Delta A_{\lambda}\left(\left[C_{\text {tot }}\right]\right)$ for each fixed wavelength $\lambda$ is the result of a somewhat large number of fitting parameters: the five $a_{\lambda, i}$ for $i \in\left\{\mathrm{R}, \mathrm{RH}^{+}, \mathrm{P}_{1}, \mathrm{P}_{1}^{+}, \mathrm{P}_{2}\right\}$. However, Figure 5.17 shows that this is not the case. The plots in Figure 5.17 of the five $a_{\lambda, i}$ 's as a function of wavelength over the range $1200 \leq \lambda \leq 1700 \mathrm{~cm}^{-1}$ show that, for all purposes, the experimental ATR-FTIR absorbance profile as a function $\mathrm{CO}_{2}$ loading can be explained by the multivariate linear regression of just three concentrations: $\left[\mathrm{P}_{1}^{+}\right],\left[\mathrm{P}_{2}\right]$, and the aggregate concentration $[\mathrm{R}]+\left[\mathrm{RH}^{+}\right]+\left[\mathrm{P}_{1}\right]$. Figure 5.17 also shows the regions of the spectrum where the absorbance is less sensitive to changes in the composition and molecular structure of the solution. The values of $a_{\lambda, i}$ are significantly smaller over the wavelength region $1390 \leq \lambda \leq$ $1570 \mathrm{~cm}^{-1}$ (except for a small peak centred at $1511 \mathrm{~cm}^{-1}$ ) than elsewhere in the explored domain $1200 \leq \lambda \leq 1700 \mathrm{~cm}^{-1}$, implying that for $1390 \leq \lambda \leq$ $1570 \mathrm{~cm}^{-1}$ the absorbance is less sensitive to changes in the composition and concentration of the aqueous IL solution.

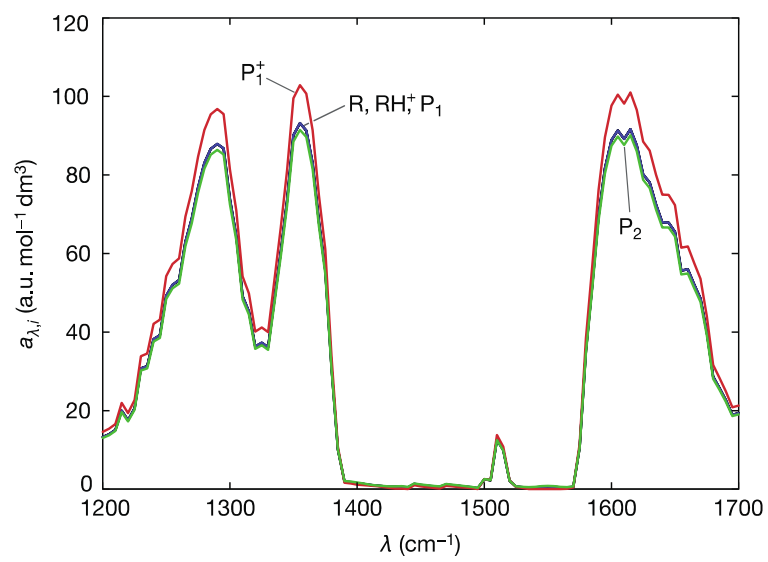

Figure 5.17 Plots of the five fitting parameters $a_{\lambda, i}, i \in\left\{R, R H^{+}, P_{1}, P_{1}^{+}, P_{2}\right\}$, as a function of the wavelength over the range $1200 \leq \lambda \leq 1700 \mathrm{~cm}^{-1}$. For all purposes, the curves of $a_{\lambda, R}$ $a_{\lambda, R H^{+}}$, and $a_{\lambda, P_{1}}$ are superposed. 
Overall, the proposed model and solution procedure to explain the chemical absorption mechanism using the $\mathrm{pH}$ and ATR-FTIR data appear to be robust. On the one hand, the model provides not only the equilibrium constants of the reversible reactions of protonation of the amine groups and bicarbonate binding, concentration profiles of the compounds involved in the reactions for the $\mathrm{CO}_{2}-$ $\left[\mathrm{Cho}^{+}\right]\left[\right.$Lys $\left.^{-}\right]$-water system, and overall mass-transfer coefficient based on liquid-phase concentrations, but also a better understanding of the chemical absorption mechanism. On the other hand, the model is also the basis for a chemometric analysis of the experimental ATR-FTIR data and the proposed procedure corroborates the possibility of using ATR-FTIR analysis for $\mathrm{CO}_{2}$ monitoring in this complex aqueous medium. In addition, the method is applicable to a wide range of $\mathrm{CO}_{2}$ loadings, since it combines the sensitivity of two different analytical methods.

\subsection{Conclusions}

We have performed experiments of $\mathrm{CO}_{2}$ capture into a $50 \mathrm{wt} \%\left[\mathrm{Cho}^{+}\right]\left[\mathrm{Lys}^{-}\right] \mathrm{IL}$ solution up to saturation conditions, using a PTFE membrane contactor to promote the contact between the gas and liquid phases. The absorption mechanism of $\mathrm{CO}_{2}$ in the aqueous [ $\left.\mathrm{Cho}^{+}\right]\left[\mathrm{Lys}^{-}\right]$solution was investigated, and a chemical model was proposed for the $\mathrm{CO}_{2}-\left[\mathrm{Cho}^{+}\right]\left[\mathrm{Lys}^{-}\right]-$water system. The unknown chemical equilibrium constants - those of the reversible reactions of amine groups protonation and bicarbonate binding - were determined by fitting the experimental $\mathrm{pH}$ curve as a function of $\mathrm{CO}_{2}$ loading. The validated model provides, among other information, the equilibrium constants of the reversible reactions of protonation of the amine groups and bicarbonate binding, concentration profiles of the compounds involved in the reactions for the $\mathrm{CO}_{2}-$ $\left[\mathrm{Cho}^{+}\right]\left[\mathrm{Lys}^{-}\right]$-water system as function of $\mathrm{CO}_{2}$ loading, and overall mass-transfer coefficient based on liquid-phase concentrations. From the analysis of the ATRFTIR spectra, we identified peaks and observed changes in their absorbances with $\mathrm{CO}_{2}$ loading. The variations observed in the entire FTIR spectrum are due 
to the increased concentration of IR absorbing ionic moieties in the aqueous IL medium; in particular, it is shown that the changes in the ATR-FTIR spectra with $\mathrm{CO}_{2}$ loading can be explained by the multivariate linear regression of just three concentrations: $\left[\mathrm{P}_{1}^{+}\right],\left[\mathrm{P}_{2}\right]$, and the aggregate concentration $[\mathrm{R}]+\left[\mathrm{RH}^{+}\right]+\left[\mathrm{P}_{1}\right]$. The results presented in this study corroborate the potential of using ATR-FTIR as a tool for monitoring $\mathrm{CO}_{2}$ absorption in this complex aqueous medium. 


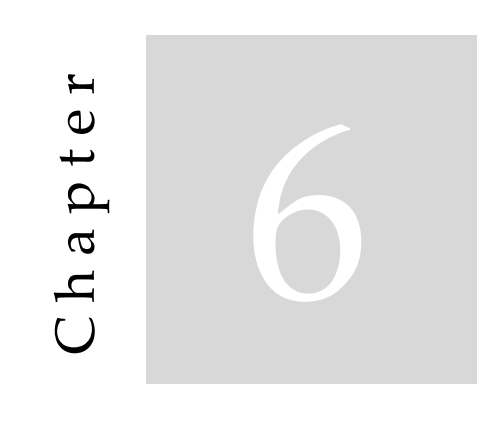

\section{Removal of $\mathrm{CO}_{2}$ from Xenon anaesthesia circuits using an amino acid ionic liquid solution in a membrane contactor}

\section{Summary}

The noble gas xenon possesses many characteristics of an ideal anaesthetic agent. However, its application is limited in daily clinical routine due to the elevated prices. The present work proposes the use of a gas-ionic liquid membrane contactor system in anaesthesia closed-circuits, for the removal of carbon dioxide, to allow the recycling of the anaesthetic agents, as a route to enable the widespread use of xenon. In the current technology, soda lime is used to absorb carbon dioxide, when the anaesthetics are delivered in closed circuits, to allow the recycling of the anaesthetic mixture. Nevertheless, the current solution presents several drawbacks, including the production of carbon monoxide (CO) and fluoromethyl-2,2-difluoro-1-(trifluoromethyl)vinyl ether (usually referred as Compound A), from the action of soda lime with volatile liquids used in anaesthesia. The ionic liquid solution is composed by cholinium lysinate and water in a 1:1 proportion. The results obtained in this work, using cholinium 
lysinate for the $\mathrm{CO}_{2}$ removal, express a high efficiency, especially when xenon was used as the inhalational anaesthetic. Additionally, the proposed work evaluates the use of thermal and chemical regeneration of the ionic liquid solution. The thermal regeneration method is not adequate for regeneration and reuse of the IL. However, the use of ion-exchange resins proved to be an efficient and simple strategy for integration in the proposed system.

\subsection{Introduction}

Anaesthesia is usually provided as a combination of intravenous and inhalational agents to create an unconscious state and to relief the pain during surgical interventions. The inhalational anaesthetic agents are administered through artificial ventilation and are a combination of inorganic gases (nitrous oxide or xenon) and volatile liquids (isoflurane, desflurane, halothane, enflurane and sevoflurane) $[1,2]$. One of the major concerns regarding the use of these anaesthetic systems is their cost-effectiveness. Therefore, the anaesthetic gas commonly used is nitrous oxide $\left(\mathrm{N}_{2} \mathrm{O}\right)$, due to its low cost $(0.80 € / \mathrm{L})$. Moreover, the use of $\mathrm{N}_{2} \mathrm{O}$ allows to reduce the costs per operation, by reducing the amount of volatile anaesthetics necessary to induce the anaesthetic state, which are significantly more expensive (Isoflurane $-126 € / \mathrm{L}$, sevoflurane $-756 € / \mathrm{L}$, Desflurane $-806 € / \mathrm{L}$ ) [12-15]. Other approach to reduce the costs is to rebreathe the remainder inhalational anaesthetics, performing the operation in a closedcircuit mode. After the patient exhales the anaesthetic mixture, containing $\mathrm{CO}_{2}$, oxygen, nitrogen, volatile anaesthetics and water, this is recovered by replenishing the oxygen and removing the $\mathrm{CO}_{2}$ content $(<0.5 \mathrm{vol} \%$ to allow rebreathe). Currently, soda lime is the absorber compound used to remove $\mathrm{CO}_{2}$ from the gas stream. The combination of both approaches significantly reduces costs. However, some disadvantages emerge. Concerns regarding the production of carbon monoxide ( $\mathrm{CO}$ ) and Compound A (fluoromethyl-2,2-difluoro-1(trifluoromethyl)vinyl ether), from the action of soda lime on desflurane and sevoflurane, restrains the performance in a closed-circuit mode [7]. 
Xenon $(\mathrm{Xe})$ is regarded as a more interesting anaesthetic gas than $\mathrm{N}_{2} \mathrm{O}$ due to its safer properties. In 1951, Cullen et al. [18] reported for the first time the use of xenon as an anaesthetic for an operative procedure in a human being. In their study, the effects obtained in humans through mixtures of $\mathrm{Xe}: \mathrm{O}_{2}$ and $\mathrm{N}_{2} \mathrm{O}: \mathrm{O}_{2}$, administered using a closed system with soda lime to permit conservation of the gases, were compared. The patients reported more pronounced subjective sensations of dizziness and incipient loss of consciousness, which are evidences of higher anaesthetic effect, with the Xe mixture than with the $\mathrm{N}_{2} \mathrm{O}$ mixture. Later, it was found that Xe causes minimal effects on the cardiovascular system, producing less haemodynamic depression, which enables its use in patients with cardiac pathologies [16,19]. Xe minimum alveolar concentration (MAC), that defines the minimal level of anaesthesia to allow surgery, is 71 while the MAC value of $\mathrm{N}_{2} \mathrm{O}$ is 104 . Additionally, the blood-gas partition coefficient, that indicates the onset time and recovery speed, of Xe is 0.115 which is the lowest of all known anaesthetics [19-22]. Thus, with less amount of gas a faster induction of the anaesthetic effect is achieved. Moreover, the analgesic potency of Xe allows omission of further volatile inhalation agents [23]. Due to a recovery rate higher than the other anaesthetics, Xe utilisation reduces the time patients spend in the hospital, which benefits the health care costs [24]. In terms of environmental impact, the anaesthetics are vented to the atmosphere, which can be prejudicial when using $\mathrm{N}_{2} \mathrm{O}$, because this has been related to the destruction of the ozone layer and also leads to greenhouse effects, while Xe is not associated with either [25]. Despite all the advantages mentioned, Xe does not have a widespread use due to its high cost $(11 € / \mathrm{L})$. To be economically viable, efforts must be made to reduce the costs both in the manufacture process (cryogenic distillation of air) and in the process of anaesthesia delivery. Nakata et al. [13] performed a cost analysis of $\mathrm{Xe}$, in comparison with $\mathrm{N}_{2} \mathrm{O}$-isoflurane and $\mathrm{N}_{2} \mathrm{O}$-sevoflurane. The authors were able to reduce the costs of Xe anaesthesia due to its low blood-gas partitioning and by performing the operation in closed-circuit mode. As outcome, the cost of Xe anaesthesia was comparable with the semi-closed circuit using $\mathrm{N}_{2} \mathrm{O}$-volatile anaesthetics, excluding the priming and flushing steps. 
Membrane-based technology has been proposed as a possible alternative for the recycling of the inhalational anaesthetics. The investigated alternatives included the use of membrane contactors for $\mathrm{CO}_{2}$ absorption with a reactive liquid phase [108,124,164], hollow fibre contactors [5,27], carbon molecular sieve membranes [6], immobilized liquid membranes [3] and zeolite membranes [29]. When compared to other membrane configurations, hollow-fibre contactors have larger membrane area per unit volume resulting in higher overall throughput, high self-mechanical support, good flexibility and easy system operation.

In the present work, a polytetrafluoroethylene (PTFE) membrane contactor with a cholinium lysinate $\left(\left[\mathrm{Cho}^{+}\right]\left[\mathrm{Lys}^{-}\right]\right)$ionic liquid (IL) solution is proposed to remove $\mathrm{CO}_{2}$, as alternative to the soda lime absorber, aiming the costeffectiveness and further widespread use of xenon. In our previous work [164], the same system was proposed and validated for the use of $\mathrm{N}_{2} \mathrm{O}$. As outcome, we were able to purify a continuous flow of an anaesthetic stream containing $\mathrm{N}_{2} \mathrm{O}$, $\mathrm{O}_{2}, \mathrm{~N}_{2}, \mathrm{CO}_{2}$ and water vapour, with a minimum operating time of 63 hours, granting a $\mathrm{CO}_{2}$ content bellow 0.5 vol\%. Although this solution has revealed to be very efficient for the removal of $\mathrm{CO}_{2}$, there is a need to consider close-to-reality conditions, such as the inhalation/exhalation breathing cycles of the patients under anaesthesia. Therefore, one of the goals of the present study is to recover the remainder anaesthetic stream containing xenon, under dynamic flow conditions, such as pulsed flow simulating the breathing cycles.

ILs with quaternary ammonium cations, of which the cholinium cation is a prominent example, are biocompatible and possess much lower toxicity than most conventional absorbents. For this reason, $\left[\mathrm{Cho}^{+}\right]\left[\mathrm{Lys}^{-}\right] \mathrm{IL}$ is particularly suitable for this application, in terms of toxicity levels, which already proved to be highly selective towards $\mathrm{CO}_{2}$ [164]. However, to achieve comparable costs with soda lime, a regeneration unit for the IL solution is required and therefore proposed, as shown in Figure 6.1. 


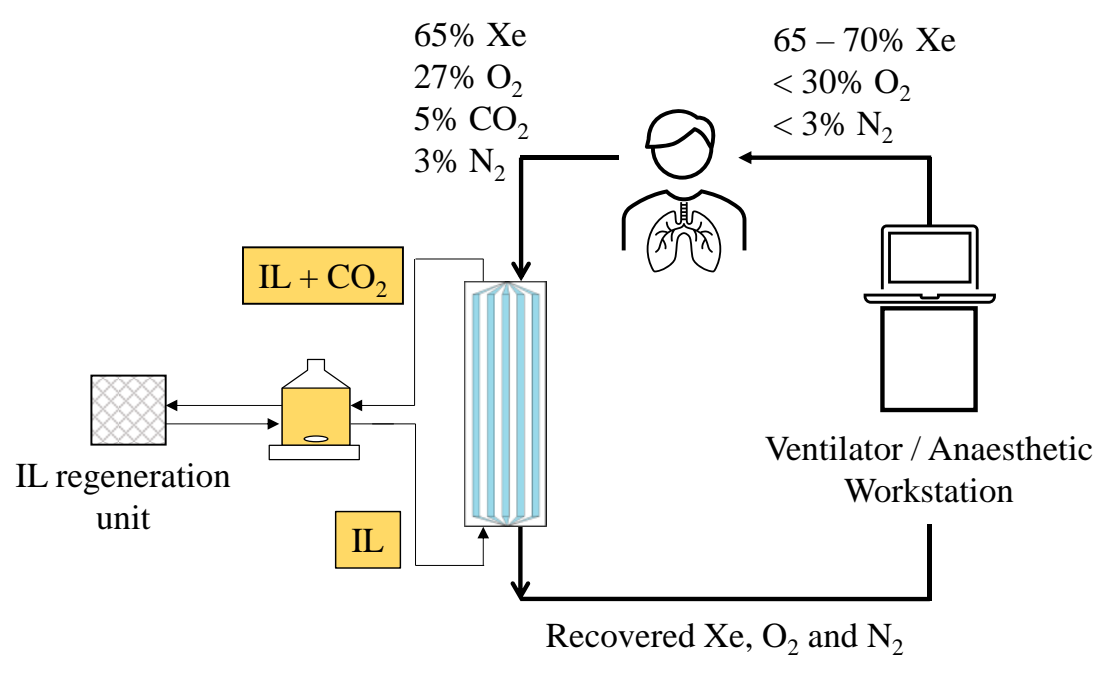

Figure 6.1 Proposed process scheme.

Due to the strong basic character of the $\left[\mathrm{Cho}^{+}\right]\left[\mathrm{Lys}^{-}\right]$IL solution ( $\left.\mathrm{pH} 13\right)$, the contact between the amino groups of the lysinate anion and $\mathrm{CO}_{2}$, in the form of bicarbonate and carbonate anions, is extremely reactive. At this $\mathrm{pH}$, the amine of the alkyl side chain of lysinate anion can be partially protonated since its $\mathrm{pKa}$ is 10.53. Consequently, the $\mathrm{CO}_{2}$ molecules, converted into bicarbonate and carbonate anions, bind first to the amine of the alkyl side chain to get charge neutralisation. Along with the absorption of $\mathrm{CO}_{2}$, the $\mathrm{pH}$ of the $\left[\mathrm{Cho}^{+}\right]\left[\mathrm{Lys}^{-}\right]$ solution decreases, approaching to the $\mathrm{pKa} \sim 8.95$ of the second amine, the amine of the carboxylic acid functional group. Therefore, a second protonation of the lysinate anion occurs in this amine, as well as, a second site for bicarbonate binding [127]. [Cho $\left.{ }^{+}\right]\left[\mathrm{Lys}^{-}\right]$IL solution reaches its saturation state when both amines of the lysinate anion are attached to bicarbonate anions. In our previous work, the maximum loading capacity of this ionic liquid solution in contact with the anaesthetic gas stream, was $5.9 \mathrm{~mol} \mathrm{CO}_{2} / \mathrm{kg} \mathrm{IL} \mathrm{(or} 3.1 \mathrm{~mol} \mathrm{CO}_{2} / \mathrm{dm}^{3}$ ).

In the present work, different conditions were explored for the regeneration of the $\left[\mathrm{Cho}^{+}\right]\left[\mathrm{Lys}^{-}\right]$solution after absorption of $\mathrm{CO}_{2}$. The regeneration methods for $\mathrm{CO}_{2}$ absorbents are, in general, thermal regeneration and/or desorption under vacuum [176]. Traditionally, thermal regeneration is the selected method in amine scrubbing after $\mathrm{CO}_{2}$ absorption. The amine solution is regenerated by 
stripping with water vapour at 100 to $120^{\circ} \mathrm{C}$. In the present case, it is not possible to explore the full potential of this method, due to the high amount of water present in the IL solution (50 w/w\%), which leads to high losses of water under high temperature conditions. The loss of water could be overcome by the addition of water after regeneration to assure the IL concentration, but this procedure would introduce a high degree of complexity to the system proposed. Therefore, a different approach was considered for regeneration of the IL solution. The method consists of using ion-exchange resins as $\mathrm{pH}$ modifiers. Adding a cation exchange resin, the $\mathrm{pH}$ decreases, the bicarbonate bond with the amines breaks, while protonation of the bicarbonate and amine groups of the lysinate anion occurs. After the release of $\mathrm{CO}_{2}$, the regeneration procedure is completed by a subsequent contact of the IL with a basic anion exchange resin, which acts as $\mathrm{aH}^{-}$donor, bringing the IL to its original deprotonated condition, ready to initiate a new absorption cycle.

In brief, the main goal of the present work is the study and development of procedures that lead to a decrease of the costs of using Xe as an anaesthetic agent. The following aims are considered: (1) create an efficient operation for the $\mathrm{CO}_{2}$ removal from Xe anaesthesia, using a combined system of a membrane contactor and a highly $\mathrm{CO}_{2}$ selective ionic liquid; (2) assemble the system to allow operation in a closed circuit for xenon recycling; (3) develop a regeneration unit for the ionic liquid solution, after absorption of $\mathrm{CO}_{2}$, to permit its prolonged use as a route to attain an economically viable alternative system for the current technology.

\subsection{Materials and methods}

\subsubsection{Preparation of the IL solution}

The $\left[\mathrm{Cho}^{+}\right]\left[\mathrm{Lys}^{-}\right]$IL solution was prepared from a choline hydroxide solution (45wt\% aqueous solution, Acros Organics, USA) and L(+)-Lysine monohydrate (99\%, Acros Organics, USA), supplied by Thermo fisher Scientific. The details regarding the synthesis and characterisation of the $\left[\mathrm{Cho}^{+}\right]\left[\mathrm{Lys}^{-}\right]$solution are described in a previous work [164]. 


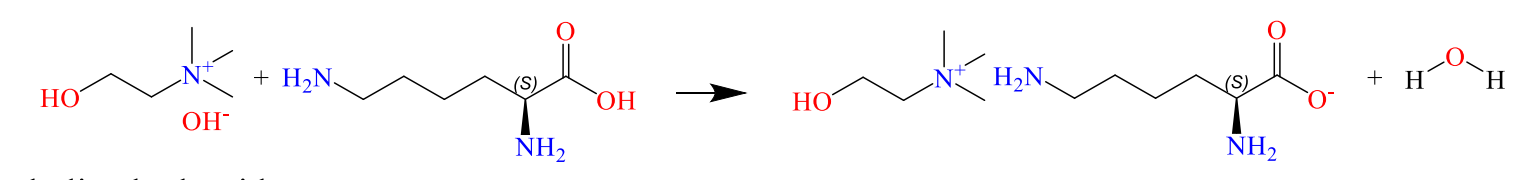

choline hydroxide lysine monohydrate

Figure 6.2 Synthesis of [Cho+][Lys-] ionic liquid.

\subsubsection{Removal of $\mathrm{CO}_{2}$ from anaesthetic mixtures}

Different gases, namely, carbon dioxide $\left(\mathrm{CO}_{2}\right.$, purity grade $\left.99.998 \%\right)$, oxygen $\left(\mathrm{O}_{2}\right.$, purity grade $99.999 \%$ ), nitrogen ( $\mathrm{N}_{2}$, purity grade $99.998 \%$ ) and xenon (Xe, purity grade 99.998\%), all supplied by Praxair (USA), were used. The gas mixture, which composition was prepared to simulate the exhalation of an adult patient under anaesthetised state, was fed to the membrane contactor in two different modes: constant and pulsed flow. The pulsed gas flow experiments, simulating the inhalation and exhalation cycle, were performed using an electrically actuated 2-way ball valve (FIP, Casella, Genova), with an electric actuator (AVA Smart actuators, model B35, Worcestershire, England) commuting each 8 seconds. The selected membrane module was supplied by Markel Corporation (USA). The membrane, in the form of capillaries, was made of porous polytetrafluoroethylene (Eclipse ${ }^{\mathrm{TM}}$ membrane) and assembled in a stainless-steel housing. The membrane module active area was $1.03 \mathrm{~m}^{2}$, with a capillary inner diameter of $1.5 \mathrm{~mm}$ (membrane thickness of $0.2 \mathrm{~mm}$ ) and an effective length of $40.6 \mathrm{~cm}$. The module has a $6 \mathrm{~cm}$ inner diameter and comprises 537 capillaries. The experimental set-up for the pulsed feed flow experiments is shown in Figure 6.3. Details regarding the experimental configuration used in the continuous flow experiments, are described in our previous work [164].

In all experiments, small volume samples of ionic liquid solution were collected periodically every 1 hour, for further Fourier-transform infrared (FTIR) spectroscopy analysis. The FTIR analysis was performed using an attenuated total reflectance (ATR) accessory in a Perkin Elmer Spectrum Two FT-IR Spectrometer, at room temperature. Simultaneously, the $\mathrm{pH}$ of the ionic liquid solution was measured in situ with a Mettler Toledo $\mathrm{pH}$ probe (model 1405-DPAS- 
SC-K8S, USA) connected to an in-line tester (Jenco, model 3621, USA), as represented in Figure 6.3.

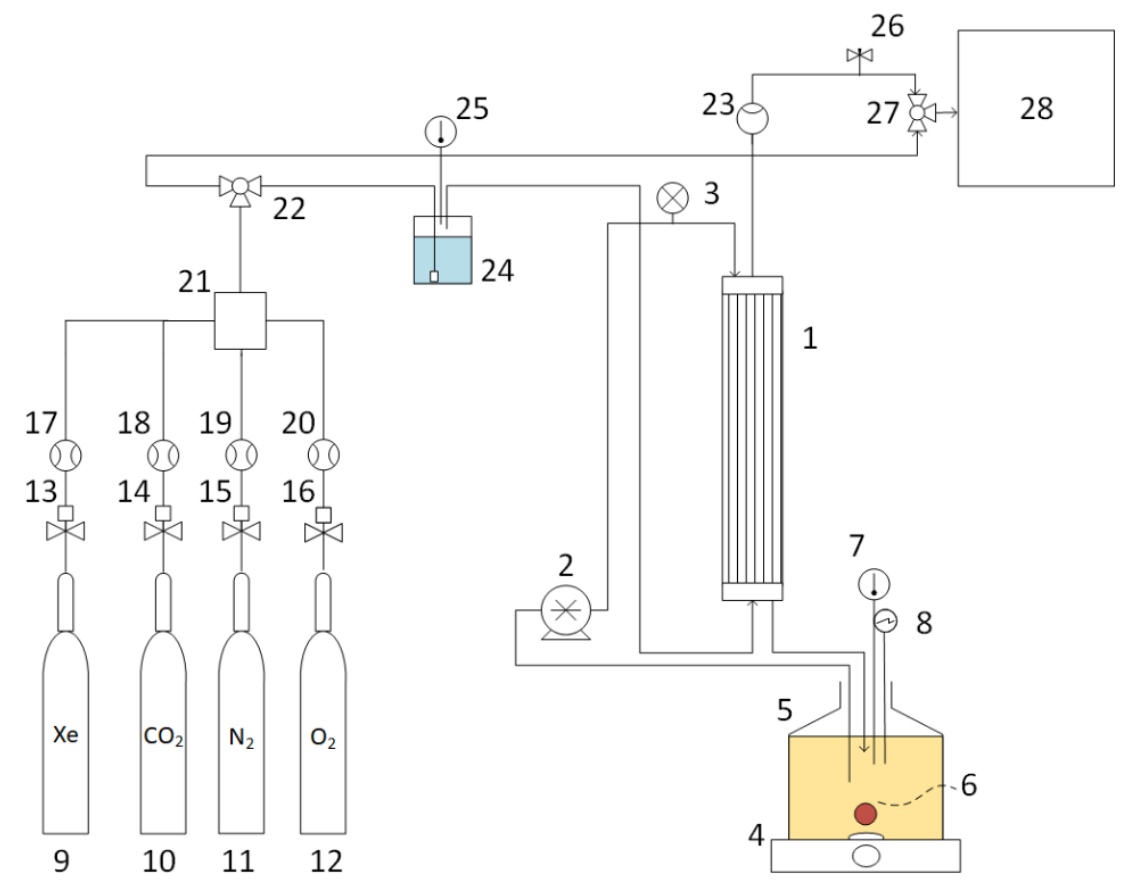

Figure 6.3 Schematic representation of the experimental set-up for the pulsed feed gas mixture experiments: 1 -membrane module; 2 - positive displacement pump; 3 - pressure gauge; 4 stirrer plate; 5 -ionic liquid vessel; 6 - sampling point; 7 - digital thermometer; 8 - pH meter; 9-11 - gas cylinders; 12-14 - solenoid valves; 15-17 - mass flow controllers; 18 - gas mixture unit; 19 - electrically actuated 2-way ball valve; 20 - mass flow indicator; 21 - stainless steel humidifier with a gas disperser; 22 - thermocouple; 23 - needle valves; 24 - three way manual valve; 25 - GC on-line.

\subsubsection{Regeneration of the [Cho+][Lys] ionic liquid solution}

The regeneration of the ionic liquid solution was studied using three different approaches: thermal regeneration, thermal regeneration under reduced pressure and chemical regeneration with ion-exchange resins. The regeneration was performed using samples of $\left[\mathrm{Cho}^{+}\right]\left[\mathrm{Lys}^{-}\right]$ionic liquid, obtained from the $\mathrm{CO}_{2}$ removal experiments. In the case of the thermal regeneration approach, the IL sample was placed in a three necked round-bottom flask and heated using an oil bath and a Arex hot plate stirrer, from VELP Scientifica (Italy). The regeneration experiments were performed under 50, 70, 80 and $110{ }^{\circ} \mathrm{C}$. A glass condenser 
connected to a refrigerated circulator (Julabo, model Corio CD, Germany) was used to condense the water vapour released, for the purpose of ensuring the concentration of the ionic liquid solution during the heating process. The temperature in the refrigeration fluid of the circulator was set at $-8{ }^{\circ} \mathrm{C}$.

For the thermal regeneration under reduced pressure, a $50 \mathrm{~mL}$ sample of the ionic liquid solution to be regenerated was placed in a round-bottom flask. Afterwards, the flask was connected to a rotary evaporator (Büchi, Switzerland) for 1 hour, under an absolute pressure of 15 mbar. The temperature of the equipment was set at $70{ }^{\circ} \mathrm{C}$, to avoid excessive loss of water. Nevertheless, a further addition of water was required to restore the concentration of the IL in solution. Later, the samples were analysed by ATR-FTIR.

The IL solution regeneration approach with ion-exchange resins was performed in two steps. First, a strong acidic cation (SAC) type resin, Amberlyst 15, supplied by BDH Chemicals Ltd. (England), was added to a sample of $\left[\mathrm{Cho}^{+}\right]\left[\mathrm{Lys}^{-}\right]$ionic liquid solution after absorption of $\mathrm{CO}_{2}$, in a weight ratio of 2:1 of resin:ionic liquid solution. The sample solution with the SAC resin was stirred over 3 hours and later analysed by ATR-FTIR spectroscopy. Afterwards, the SAC resin was decanted from de ionic liquid solution. In a second step, the IL solution recovered after contact with the SAC was added to a strong basic anion (SBA) type resin, DOWEX 1 chloride form, from Sigma-Aldrich (USA) in its $\mathrm{OH}^{-}$form (the resin was washed with a $2 \mathrm{M}$ sodium hydroxide solution, to exchange the original chloride anions by hydroxide anions). The contact between the resin and the IL solution was performed for 1 hour and later the sample was analysed by ATR-FTIR spectroscopy. Additionally, the water content before and after each step was measured by titration with a Karl-Fischer coulometer without diaphragm, from Metrohm (model 831 KF coulometer, USA). 


\subsection{Results and discussion}

\subsection{1 $\mathrm{CO}_{2}$ removal from anaesthetic gas mixtures}

The $\mathrm{CO}_{2}$ removal was performed with different anaesthetic mixtures, to assess the efficiency of the proposed system, under conditions close to real. A mixture containing $65 \%$ of $\mathrm{Xe}, 5 \%$ of $\mathrm{CO}_{2}, 3 \%$ of $\mathrm{N}_{2}$ and $27 \%$ of $\mathrm{O}_{2}$, was prepared and saturated with water vapour (at $37^{\circ} \mathrm{C}$ ), to simulate the composition of an exhaled gas mixture by an adult patient under anaesthesia state. In some cases, when the inhalation gas is not used, a fresh stream of medicinal air $\left(21 \%\right.$ of $\mathrm{O}_{2}$ and $79 \%$ of $\mathrm{N}_{2}$ ) is administered to provide clean air in the ventilator. Therefore, a medicinal air mixture containing $5 \%$ of $\mathrm{CO}_{2}$ and saturated in water vapour, was also considered in the present study.

The proposed system was operated under minimum flowrate of the anaesthetic gas, i.e. 250 mL.min ${ }^{-1}$ [4]. The anaesthetic gas mixture and the $\left[\mathrm{Cho}^{+}\right]\left[\mathrm{Lys}^{-}\right]$ionic liquid solution circulated in counter-current mode to maximise the mass transfer, with the gas phase in the shell side of the module, avoiding preferential flow and dead zones in the liquid phase in the shell side. The inlet and outlets of the module were maintained opened during the experiments, sidestepping a pressurized gas phase inside the module, assuring a $\mathrm{CO}_{2}$ removal driven exclusively by the chemical reaction between the IL solution and $\mathrm{CO}_{2}$. Consequently, the absorption process was accomplished with a gas phase pressure close to the atmospheric, and with an ionic liquid solution circulating in closed loop at a low and constant flow rate $\left(790 \mathrm{~mL} \cdot \mathrm{min}^{-1}\right)$. The ionic liquid solution circulated with a minimum flow rate, to avoid liquid overpressure at the pores' mouth of the capillaries. The $\mathrm{CO}_{2}$ content in the gas phase was monitored through on-line Gas Chromatography (GC), while in the liquid phase, $\mathrm{pH}$ measurements and IR spectroscopy were used. The monitoring of the liquid phase allowed to assess the concentration profile of protonated amines, bicarbonate and carbonate anions in the system $\mathrm{CO}_{2}$-water-[Cho $\left.{ }^{+}\right]\left[\mathrm{Lys}^{-}\right]$.

As mentioned before, the saturation state of the solution is achieved when the bicarbonates are attached to all amine groups available in the lysinate anions. 
However, the rebreathing of the recycled anaesthetic gas is only possible if the condition of a $\mathrm{CO}_{2}$ content below $0.5 \%$ is assured. Along the $\mathrm{CO}_{2}$ absorption, the availability of the alkyl side chain amine of the lysinate anion decreases, as well as the driving force between gas and liquid phases, which reduces the $\mathrm{CO}_{2}$ flux across the membrane. Therefore, to assure the condition for the rebreathing of the anaesthetic gas, the complete saturation of the ionic liquid solution is intentionally not reached.

The $\mathrm{CO}_{2}$ flux $\left(J_{\mathrm{CO}_{2}}\right.$, in mol.m- $\left.\mathrm{m}^{-2} \cdot \mathrm{s}^{-1}\right)$ across the membrane is described by:

$$
J_{\mathrm{CO} 2}=K_{o v} \times\left(\mathrm{CO}_{2}-\mathrm{CO}_{2}^{*}\right)
$$

where $\left(\mathrm{CO}_{2}-\mathrm{CO}_{2}^{*}\right)$ is the concentration driving force $\left(\mathrm{mol} . \mathrm{m}^{-3}\right), \mathrm{CO}_{2}$ is the carbon dioxide concentration in the gas phase, $\mathrm{CO}_{2}^{*}$ is the carbon dioxide concentration in equilibrium with the concentration of $\mathrm{CO}_{2}$ in the liquid phase, which is null in this case due to the fast and direct conversion into bicarbonate. $K_{o v}$ is the overall mass transfer coefficient $\left(\mathrm{m} . \mathrm{s}^{-1}\right)$, obtained as follows:

$$
K_{o v}=\frac{Q_{g} \times\left(C_{C O 2, i n, g}-C_{C O 2, o u t, g}\right)}{A \times \Delta C_{C O 2, g, l m}}
$$

where the $Q_{g}$ is the gas flow rate $\left(\mathrm{m}^{3} . \mathrm{s}^{-1}\right)$ inside the module, $C_{C O 2, \text { in, }}$ and $C_{C O 2, \text { out }, g}$ are the $\mathrm{CO}_{2}$ concentrations $\left(\mathrm{mol} \cdot \mathrm{m}^{-3}\right)$ in the gas phase inlet and outlet, $A$ is the gas-liquid contact area $\left(\mathrm{m}^{2}\right)$ and $\Delta C_{\mathrm{CO}, g, l m}$ is the logarithmic mean driving force based on the gas phase concentrations $\left(\mathrm{mol}^{-3}\right)$, described as:

$$
\Delta C_{\mathrm{CO}, \mathrm{lm}}=\frac{\left(C_{\mathrm{CO} 2}-C_{\mathrm{CO} 2}^{*}\right)_{g, \text { in }}-\left(C_{\mathrm{CO} 2}-C_{\mathrm{CO} 2}^{*}\right)_{g, \text { out }}}{\ln \left[\left(C_{\mathrm{CO} 2}-C_{\mathrm{CO} 2}^{*}\right)_{g, \text { in }} /\left(C_{\mathrm{CO} 2}-C_{\mathrm{CO} 2}^{*}\right)_{g, \text { out }}\right]}
$$


$C_{C O 2, \text { in }}^{*}$ and $C_{C O 2, \text { out }}^{*}$ are the equilibrium concentrations at the interface between the gas and liquid phases. Additionally, the process efficiency was also assessed, through the separation factor $(S F)$ between $\mathrm{CO}_{2}$ and Xe. Considering the ratio between the permeable species in the feed and the permeate side, $S F$ was determined according to the following equation:

$$
S F=\frac{n_{i, p} / n_{j, p}}{n_{i, f} / n_{j, f}}
$$

where, $p$ and $f$ are the permeate and feed streams and $i$ and $j$ the permeable species, in particular $i$ the most permeable one.

\subsubsection{Comparison of constant and pulsed flow}

Artificial ventilation includes setting the duration of both inspiration and expiration periods, which together determine the respiratory rate and the inspiration/expiration ratio, which is normally between $1: 2$ and 1:4, giving respiratory frequencies in the range of 12 to 20 breaths per minute, moving about $500 \mathrm{~mL}$ of air into and out of the lungs $[177,178]$. Hereupon, to assess the performance of the proposed system in conditions close to real, experiments were performed considering a pulsed feed flow. The gas mixture, with medicinal air and $5 \%$ of $\mathrm{CO}_{2}$, saturated with water vapour, was pulsed and fed to the system to simulate the inhalation/exhalation breathing cycles. The pulsed feed mode was also compared with the continuous feed mode, using the same gas composition. In Table 6.1 are listed the results obtained.

Despite the similarity obtained for the mass transfer coefficients and $\mathrm{CO}_{2}$ fluxes in both cases, the gas residence time inside the module was higher in the case of the pulsed feed. In this case, the feeding stream was interrupted in between pulses and the gas mixture remained longer inside the module, which allowed for a higher contact time between $\mathrm{CO}_{2}$ and the ionic liquid. This difference is expressed by the $\mathrm{CO}_{2}$ loading and by the operation time, in which 
the system was able to guarantee an effective removal of $\mathrm{CO}_{2}$ granting an outlet concentration below to $0.5 \%$ (vol.). Hence, according to the results obtained, the proposed system is more efficient for $\mathrm{CO}_{2}$ removal when operated under closeto-real conditions.

Table 6.1 Comparison of the mass transfer parameters for constant and pulsed feed flow conditions.

\begin{tabular}{|c|c|c|c|c|}
\hline Feed mode & $\begin{array}{c}\text { Kco2 overall } \\
\left(\mathrm{m} . \mathrm{s}^{-1}\right)\end{array}$ & $\begin{array}{c}\text { JcO2 } \\
\left(\mathrm{mol} \cdot \mathrm{m}^{-2} \cdot \mathrm{s}^{-1}\right)\end{array}$ & $\begin{array}{c}\mathrm{CO}_{2} \text { loading } \\
\left(\mathrm{mol} . \mathrm{kg}^{-1}\right)\end{array}$ & $\begin{array}{l}\text { Operation time } \\
\text { (h) }\end{array}$ \\
\hline Constant flow & $1.11 \times 10^{-5}$ & $9.01 \times 10^{-6}$ & 3.50 & 42 \\
\hline Pulsed flow & $1.44 \times 10^{-5}$ & $9.15 \times 10^{-6}$ & 4.97 & 119 \\
\hline
\end{tabular}

The $\mathrm{pH}$ of the ionic liquid solution was measured along with the absorption of $\mathrm{CO}_{2}$. In Figure 6.4, it is represented the $\mathrm{pH}$ of the solution against the time $\mathrm{CO}_{2}$ was removed from the simulated anaesthetic stream.

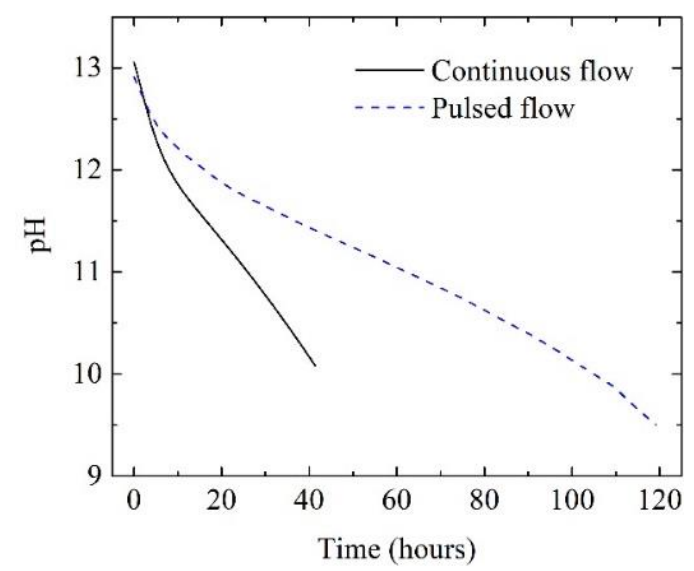

Figure 6.4 Experimental $\mathrm{pH}$ as function of time.

As the $\mathrm{CO}_{2}$ was absorbed, the $\mathrm{pH}$ of the $\left[\mathrm{Cho}^{+}\right]\left[\mathrm{Lys}^{-}\right]$solution decreased, due to the formation of bicarbonate and carbonate anions. In the pulsed feed 
mode, the proposed system is capable to maintain longer the $\mathrm{CO}_{2}$ content of the anaesthetic stream below $0.5 \%$ vol., comparing with the operation in the continuous flow mode. Consequently, the amount of $\mathrm{CO}_{2}$ captured was higher and the final $\mathrm{pH}(9.5)$ lower.

To assess the chemical behaviour of $\mathrm{CO}_{2}$ absorption in the liquid phase, under pulsed feed conditions, various samples of ionic liquid were collected along $\mathrm{CO}_{2}$ absorption and analysed by IR spectroscopy. The chemical reaction between $\mathrm{CO}_{2}$ and the $\left[\mathrm{Cho}^{+}\right]\left[\mathrm{Lys}^{-}\right]$ionic liquid led to the formation of bicarbonate ions, carbonate ions and protonated amines. According to our previous study [164], the characteristic bands of the protonated amines, carbonate and bicarbonate ions are present at $1647 \mathrm{~cm}^{-1}, 1478 \mathrm{~cm}^{-1}$ and $1358 \mathrm{~cm}^{-1}$, respectively. Therefore, the $\mathrm{CO}_{2}$ absorption was monitored following the increase of the absorbance at these wavenumbers (Figure 6.5).
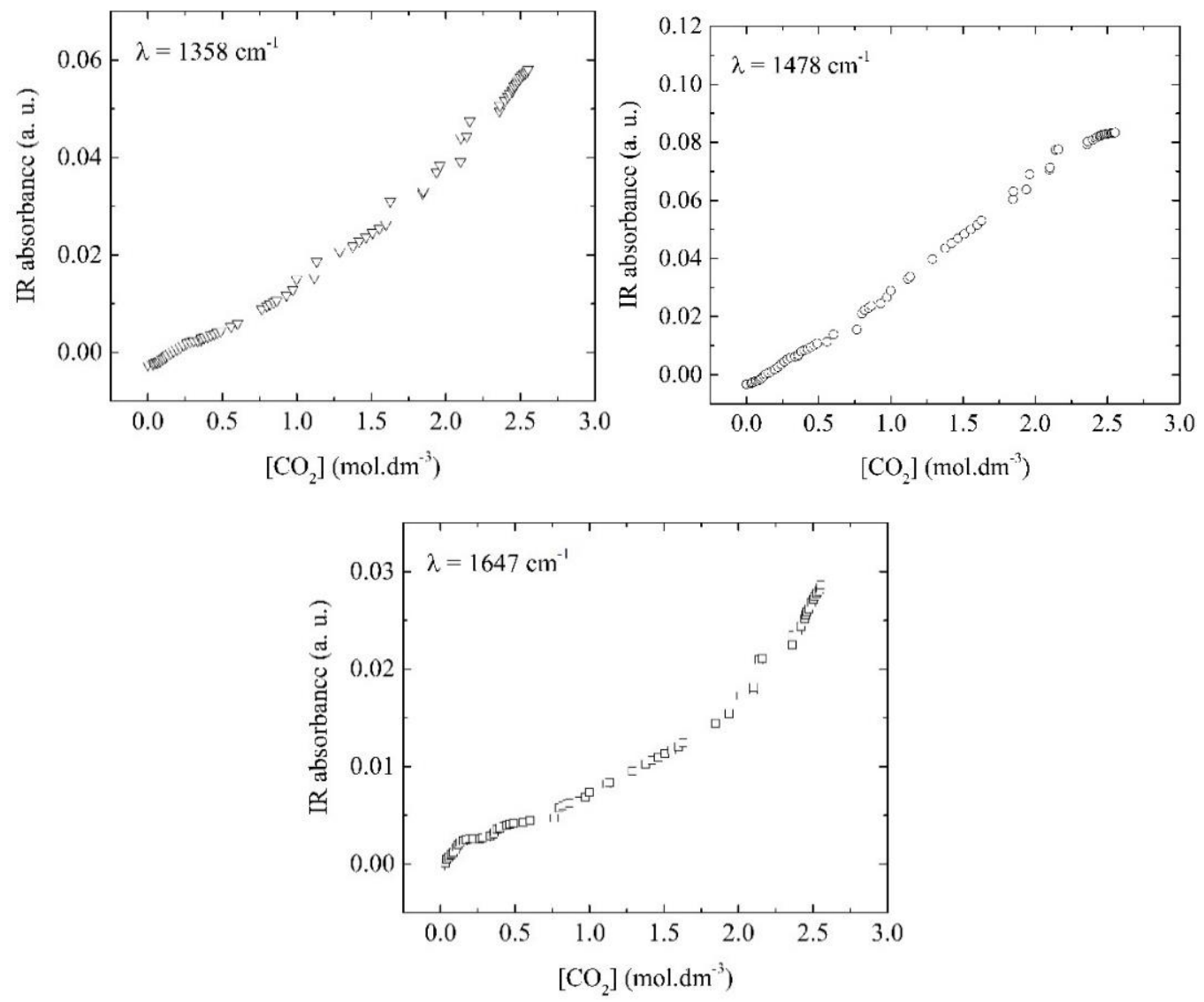

Figure 6.5 Experimental IR absorbances as function of $\mathrm{CO}_{2}$ captured by the ionic liquid solution under pulsed feed flow, at $1358 \mathrm{~cm}^{-1}, 1478 \mathrm{~cm}^{-1}$ and $1647 \mathrm{~cm}^{-1}$ wavenumbers, which bands correspond respectively to bicarbonate, carbonate ions and protonated amine. 
The IR absorbances obtained were plotted against the $\mathrm{CO}_{2}$ captured by the ionic liquid solution (mole of $\mathrm{CO}_{2}$ captured per $\mathrm{dm}^{3}$ of ionic liquid). All the IR absorbance curves show an increasing profile, expressing the rise of the concentration of each compound, i.e., protonated amine groups, bicarbonate and carbonate ions, along with the $\mathrm{CO}_{2}$ absorption. Moreover, data at $1478 \mathrm{~cm}^{-1}$ corresponding to carbonate ions, shows a slight flattening at the end of the curve. This profile might be explained by the $\mathrm{CO}_{2}$ dissociation in aqueous media according to $\mathrm{pH}$, described in the corresponding Bjerrum plot [179]. The concentration of carbonate ions in the $\left[\mathrm{Cho}^{+}\right]\left[\mathrm{Lys}^{-}\right]$solution, corresponds to the free amount dissolved, according to the chemical reaction described in Equation (6.5), while the bicarbonate ion concentration is the sum of the bicarbonate ions dissolved in the free form and the ones attached to the amines. The chemical mechanism of the system $\mathrm{CO}_{2}$-water-[Cho $\left.{ }^{+}\right]\left[\mathrm{Lys}^{-}\right]$is described by reversible reactions, including the reaction of bicarbonate and carbonate formation $\left(\mathrm{CO}_{2}\right.$ dissociation in water), as follows:

$$
\begin{aligned}
& \mathrm{CO}_{2}+2 \mathrm{H}_{2} \mathrm{O} \rightleftharpoons \mathrm{HCO}_{3}^{-}+\mathrm{H}_{3} \mathrm{O}^{+} \\
& \mathrm{HCO}_{3}^{-}+\mathrm{H}_{2} \mathrm{O} \rightleftharpoons \mathrm{CO}_{3}^{2-}+\mathrm{H}_{3} \mathrm{O}^{+}
\end{aligned}
$$

The amount of carbonate anions dissolved in the system, find its maximum at $\mathrm{pH}=12$. As $\mathrm{pH}$ decreases, the chemical reaction moves towards the formation of bicarbonate ion, consuming free carbonates. Therefore, the formation of free carbonates concentration is exclusively determined by the $\mathrm{pH}$ of the media, while, the formation mechanism of bicarbonate ions is potentiated by their attachment to the protonated amines, leading to concentration increase along with the $\mathrm{CO}_{2}$ absorption. 


\subsubsection{Comparison of different anaesthetic mixtures}

As mentioned, a mixture containing $65 \%$ of $\mathrm{Xe}, 5 \%$ of $\mathrm{CO}_{2}, 3 \%$ of $\mathrm{N}_{2}$ and $27 \%$ of $\mathrm{O}_{2}$, was prepared and saturated with water vapour (at $37^{\circ} \mathrm{C}$ ) and tested in the proposed system. In Table 6.2 are listed the $\mathrm{CO}_{2}$ overall mass transfer constant, the $\mathrm{CO}_{2}$ and anaesthetic gas total fluxes across the membrane and the separation factor $(S F)$, obtained in the present work, as well as the mass transfer parameters obtained in our previous work, when the inhalational anaesthetic was $\mathrm{N}_{2} \mathrm{O}$ [164]. It is important to mention that, $\mathrm{CO}_{2}$ was removed from a gas mixture containing mostly the anaesthetic gas, having $5 \%$ of $\mathrm{CO}_{2}$. Even though, $\mathrm{CO}_{2}$ was efficiently removed. In an overall perspective, the system operated more efficiently when $\mathrm{N}_{2} \mathrm{O}$ was replaced by $\mathrm{Xe}$. The loss of $\mathrm{Xe}$, through diffusion to the ionic liquid solution, was almost half of the $\mathrm{N}_{2} \mathrm{O}$ loss, leading to a higher separation factor for $\mathrm{CO}_{2} / \mathrm{Xe}$.

Table 6.2 Experimental mass transfer parameters in the presence of different anaesthetic mixtures.

\begin{tabular}{|c|c|c|c|c|}
\hline Anaesthetic gas & $\begin{array}{c}\text { KCO2 overall } \\
\left(m \cdot s^{-1}\right)\end{array}$ & $\begin{array}{c}\text { JCO2 } \\
\left(m o l . m^{-2} \cdot s^{-1}\right)\end{array}$ & $\begin{array}{l}\text { Janaesthetic gas }^{2} \\
\left(\mathrm{~mol} \cdot \mathrm{m}^{-2} \cdot \mathrm{s}^{-1}\right)\end{array}$ & $S F$ \\
\hline Xenon & $1.26 \times 10^{-5}$ & $1.11 \times 10^{-5}$ & $3.20 \times 10^{-6}$ & 27.70 \\
\hline Medicinal air & $1.19 \times 10^{-5}$ & $9.04 \times 10^{-6}$ & - & 14.02 \\
\hline $\mathrm{N}_{2} \mathrm{O}[164]$ & $9.33 \times 10^{-6}$ & $8.46 \times 10^{-6}$ & $5.75 \times 10^{-6}$ & 14.60 \\
\hline
\end{tabular}

From the mass transfer parameters obtained, we can easily calculate the costs of using $\mathrm{N}_{2} \mathrm{O}$ or Xe as inhalational anaesthetic gas, considering operation with the proposed system. The values presented in Table 6.3 were calculated for 1 hour of operation. As mentioned, the gas mixture was fed at $250 \mathrm{~mL}^{\mathrm{min}}{ }^{-1}$, containing $65 \%$ of anaesthetic gas. Therefore, the corresponding anaesthetic flow

\footnotetext{
2 The flux accross the membrane was not determined for the experiments with medicinal air.
} 
was 160 mL.min ${ }^{-1}\left(9.75\right.$ L.h $\left.^{-1}\right)$. Due to the flux of inhalational anaesthetics across the membrane, by diffusion to the aqueous IL solution, the gases were not recovered completely (considering the total amount diffused as losses). Converting those molar fluxes in volumes of gas, the system is able to recover 94.72 vol.\% of $\mathrm{N}_{2} \mathrm{O}$ and 97.06 vol.\% of Xe. This is a relevant feature for the cost effectiveness of the rebreathing process. For operation in open circuit mode (without recycling to the patient), the cost of $\mathrm{N}_{2} \mathrm{O}$ per hour is $7.8 €$, while the use of Xe reaches a cost of $107.25 €$ per hour. Independently from the gas used, the proposed system impacts very positively in the costs of operation. Additionally, with the propose system, the widespread use of Xe may become viable because it is possible to reduce costs down to $3.15 € / \mathrm{h}$.

Table 6.3 Cost comparison between $\mathrm{Xe}$ and $\mathrm{N}_{2} \mathrm{O}$ anaesthesia, per hour of operation using the proposed system.

\begin{tabular}{|c|c|c|c|c|c|}
\hline $\begin{array}{c}\text { Anaesthetic } \\
\text { Gas }{ }^{(i)}\end{array}$ & $\begin{array}{l}\text { Feed } \\
\text { flow } \\
(\mathrm{L} / \mathrm{h})\end{array}$ & $\begin{array}{l}\text { Volume of } \\
\text { gas } \\
\text { recovered } \\
\text { (L) }\end{array}$ & $\begin{array}{c}\text { Gas } \\
\text { recovered } \\
(\%)\end{array}$ & $\begin{array}{c}\text { Cost wo/ } \\
\text { recovering } \\
(€ / h)\end{array}$ & $\begin{array}{c}\text { Cost w/ } \\
\text { recovering } \\
(€ / \mathbf{h})\end{array}$ \\
\hline $\mathrm{N}_{2} \mathrm{O}$ & 9.75 & 9.24 & 94.72 & 7.8 & 0.41 \\
\hline Xenon & & 9.46 & 97.06 & 107.25 & 3.15 \\
\hline
\end{tabular}

(i) Prices assumed: $0.80 € / \mathrm{L}$ for $\mathrm{N}_{2} \mathrm{O}$ and $11 € / \mathrm{L}$ for $\mathrm{Xe}$.

\subsubsection{Ionic liquid regeneration}

The utilisation of a carbon dioxide absorbent on medical interventions with inhalational anaesthetics, was previously mentioned as a route to strongly reduce the global costs. An effective $\mathrm{CO}_{2}$ removal unit coupled to a ventilator significantly reduces the costs, due to the rebreathing of the remainder anaesthetic gases expelled by the patient. The current technology uses a mixture of sodium hydroxide and calcium hydroxide (soda lime) for the capture of $\mathrm{CO}_{2}$. 
However, there are unwanted side products from the contact of soda lime with volatile anaesthetic compounds, besides the release of carbon monoxide. Therefore, the present work proposes the use of a $\left[\mathrm{Cho}^{+}\right]\left[\mathrm{Lys}^{-}\right]$ionic liquid solution as a safer and more efficient choice to absorb $\mathrm{CO}_{2}$. However, the low cost of soda lime makes difficult to find a cost competitive alternative. Therefore, the self-regeneration of the absorbent seems to be the most adequate approach for the replacement of lime soda.

In our previous work [164], $\mathrm{CO}_{2}$ was removed from anaesthesia mixtures and the ionic liquid solution was partially regenerated using a sweep gas, in a closed-circuit configuration, using a second PTFE membrane contactor for IL regeneration and removal of $\mathrm{CO}_{2}$. As outcome, it was proposed to invest more efforts to study the IL regeneration, since the sweep gas methodology was not sufficient to obtain the complete IL regeneration. Additionally, in the same work, it was reported that $\mathrm{CO}_{2}$ absorption is achieved through chemical reaction with the cholinium lysinate aqueous solution, particularly, the $\mathrm{CO}_{2}$ in the bicarbonate form binds to both amines of the lysinate anion. A weaker bond is established with the amine of the carboxylic acid functional group, which allows for the reversion of the $\mathrm{CO}_{2}$ attachment in this site through the contact with the sweep gas. The stronger bond, i.e. the bond between bicarbonate and the amine of the alkyl side chain, does not break by imposing a concentration difference with the sweeping gas. Therefore, to achieve a complete regeneration of the ionic liquid, three approaches are herein proposed for the regeneration of the $\left[\mathrm{Cho}^{+}\right]\left[\mathrm{Lys}^{-}\right]$ ionic liquid solution, namely: thermal regeneration, thermal regeneration under reduced pressure and chemical regeneration using ion-exchange resins. The regeneration experiments were performed after $\mathrm{CO}_{2}$ capture with the ionic liquid solution.

In the present work, the ionic liquid solution was heated at different temperatures, i.e. $50,70,80$ and $110^{\circ} \mathrm{C}$. Moreover, the solution was submitted to reduced pressure conditions, using a rotary evaporator, at a constant temperature of $70{ }^{\circ} \mathrm{C}$. Samples of the IL solution were collected during the heating process and were analysed through ATR-FTIR to access the impact of 
temperature on the reversion of the $\mathrm{CO}_{2}$ capture. In Figure 6.6 are represented the IR spectra obtained to evidence the changes on the characteristic peaks, after the heating process.

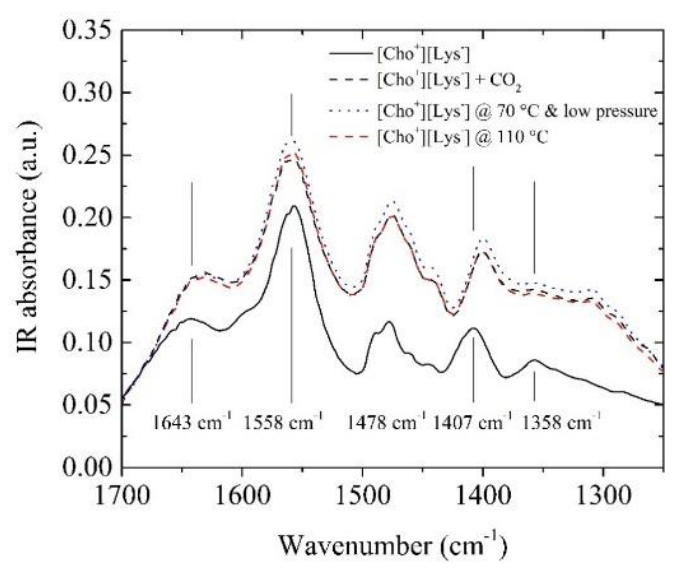

Figure 6.6 IR spectra of the [Cho+][Lys-] ionic liquid solution before and after being submitted to heating regeneration under controlled temperature/pressure conditions.

The IR spectra obtained from the experiments at 50, 70 and $80^{\circ} \mathrm{C}$, are not represented due to the lack of significant differences obtained after the heating process. The IR spectrum at $110^{\circ} \mathrm{C}$ is representative of the absence of temperature impact when the $\left[\mathrm{Cho}^{+}\right]\left[\mathrm{Lys}^{-}\right]$solution was heated. In practice, this means that the bond between $\mathrm{CO}_{2}$ and the amine group is not disrupted by applying temperatures up to $110^{\circ} \mathrm{C}$. As mentioned before, it is not desirable to increase the temperature to avoid high water losses from the $\left[\mathrm{Cho}^{+}\right]\left[\mathrm{Lys}^{-}\right]$solution and increasing complexity and costs for the proposed system. Thus, thermal regeneration (with $\mathrm{T} \leq 110^{\circ} \mathrm{C}$ ) and heating under reduced pressure, were found to be inefficient for a complete regeneration of the ionic liquid solution.

Chemical regeneration, using ion-exchange resins was then investigated. An important feature for regeneration through chemical reaction is the need to avoid the formation of new compounds, which could unable the reuse of the ionic liquid. Therefore, the chemical regeneration procedure must be as neutral as possible. The use of ion-exchange resins intends to change the $\mathrm{pH}$ of the media, 
exchanging bicarbonate by hydroxide, to promote the release of $\mathrm{CO}_{2}$. After absorption of $\mathrm{CO}_{2}$, i.e. after $\mathrm{CO}_{2}$ capture from the simulated inhalational gas streams mentioned in Subsection 6.3.2, where the maximum $\mathrm{CO}_{2}$ loading obtained was $4.97 \mathrm{~mol} / \mathrm{kg}$, the ionic liquid solution was brought into contact with a cation exchange resin, which acts as a proton donor $\left(\mathrm{H}^{+}\right)$, to allow protonation of the amines and bicarbonate anion, thus causing the release of carbon dioxide. After this procedure, the IL solution is brought into contact with an anion exchange resin, which acts as a hydroxide anions' donor, to restore $\mathrm{pH}$ and deprotonate the lysine into its original anionic form.

The IL regeneration was confirmed through IR analysis. In Figure 6.7 is represented the spectra before and after contact between the ionic liquid solution loaded with carbon dioxide and the ion-exchange resins. The ionic liquid solution was added first to the SAC resin, to provide high concentration of hydrogen protons to the media. The $\mathrm{pH}$ decreased and the bicarbonate anions detached from the amines through the formation of water and the release of $\mathrm{CO}_{2}$. This was confirmed by the increase of the band at $1643 \mathrm{~cm}^{-1}$, which peak is characteristic of the protonated amines. On the other hand, the decrease of the peaks at 1478 and $1407 \mathrm{~cm}^{-1}$, was an indication of the decrease of carbonates, which confirms the release of $\mathrm{CO}_{2}$. As the second step, in a sequential mode, the acidic solution was added to the SBA resin, to deprotonate the amines and restore the alkaline $\mathrm{pH}$. From the spectrum obtained after the contact with the SBA resin, the concentration of protonated amines decreased significantly according to the decrease of the peak at $1647 \mathrm{~cm}^{-1}$. This spectrum was expected to coincide with the spectrum of the original $\left[\mathrm{Cho}^{+}\right]\left[\mathrm{Lys}^{-}\right]$ionic liquid solution before absorption of $\mathrm{CO}_{2}$. There is still a noticeable difference, which can be explained from the change observed in water content that occurs during the process.

The regeneration with ion exchange resins, performed in the present work, still requires optimisation, in order to identify the best liquid to resin ratio and contact time. Nevertheless, this study opens a new direction for regeneration of the ionic liquid solution which has not been explored yet, which will lead to a more efficient and economic regeneration process. 


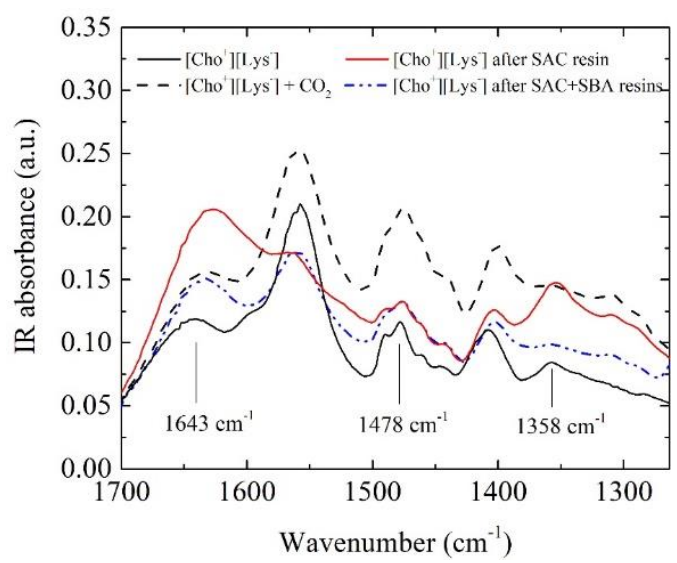

Figure 6.7 IR spectra of the ionic liquid, before and after regeneration with ion-exchange resins.

\subsection{Conclusions}

The $\mathrm{CO}_{2}$ capture from gas mixtures with inhalational gas, i.e. Xe, has been performed, using a $50 \mathrm{wt} \% \quad\left[\mathrm{Cho}^{+}\right]\left[\mathrm{Lys}^{-}\right] \mathrm{IL}$ solution and a polytetrafluoroethylene porous membrane contactor. Different operating protocols were performed to assess the efficiency of the proposed system. $\mathrm{A} \mathrm{CO}_{2}$ capture capacity of $3.50 \mathrm{~mol} / \mathrm{kg}$ IL, was obtained when the gas mixture, simulating the exhaled air composition of an adult patient, was fed continuously to the system. The capacity increased to $4.97 \mathrm{~mol} / \mathrm{kg}$ IL when the breathing cycles were simulated.

Xenon was used as the inhalational anaesthetic. The system was operated in close-to-real conditions, considering an expired breath composition of $65 \%$ of the anaesthetic gas, $5 \%$ of $\mathrm{CO}_{2}, 27 \%$ of $\mathrm{O}_{2}$ and $3 \%$ of $\mathrm{N}_{2}$, saturated with water vapour. The anaesthetic gas may be recycled by removing the $\mathrm{CO}_{2}$ from the gas mixture. The system efficiency was assessed according to the amount of $\mathrm{CO}_{2}$ captured per weight of ionic liquid, over time, respecting a maximum $\mathrm{CO}_{2}$ output in the recycled stream of $0.5 \%$. According to the results obtained, it was found that a higher amount of anaesthetic gas can be recycled when Xe was used, in comparison with $\mathrm{N}_{2} \mathrm{O}$ or medicinal air. This is a positive outcome for the widespread use of $\mathrm{Xe}$, as inhalational anaesthetic, since a considerable cost reduction per unit time of operation was achieved. 
An ionic liquid regeneration unit was also considered along with the $\mathrm{CO}_{2}$ removal. Thermal and chemical regenerations methods were addressed. The thermal regeneration approach was not able to revert the $\mathrm{CO}_{2}$ absorption, which was confirmed by the IR spectra obtained for the ionic liquid solutions. However, the use of ion-exchange resins allowed for releasing $\mathrm{CO}_{2}$, without the formation of new compounds, which enables further use of the $\left[\mathrm{Cho}^{+}\right]\left[\mathrm{Lys}^{-}\right]$IL solution. Moreover, this is a simple methodology which can be easily incorporated in the proposed system and implement in an hospital environment. 


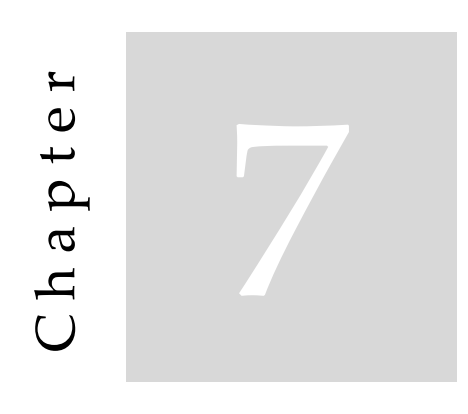

\section{General conclusions and Future work}

\subsection{General Conclusions}

The main scope of the work performed during this $\mathrm{PhD}$ project was the development of a compact medical device, for recycling anaesthesia gases in closed rebreathing circuits. The prototype was designed and evaluated under as much as possible close-to-real conditions.

The work can be divided into three main stages. The first stage attempted the selection of the most suitable ionic liquid to be used as $\mathrm{CO}_{2}$ liquid absorbent, the second stage studied the appropriate membrane separation process to carry out the $\mathrm{CO}_{2}$ removal from anaesthesia mixtures and the third stage explored the chemisorption and absorption dynamics of $\mathrm{CO}_{2}$ in the ionic liquid solution.

The $\mathrm{CO}_{2}$ transport in cholinium-based ionic liquids was experimentally evaluated. Aiming to benefit from the action of an efficient biocatalyst, a carbonic anhydrase enzyme was solubilised in the ionic liquids to catalyse the conversion of $\mathrm{CO}_{2}$ into bicarbonate, in order to enhance $\mathrm{CO}_{2}$ transport. By means of a predictive correlation, the $\mathrm{CO}_{2}$ solubility, diffusion coefficient and ideal permeability in the ionic liquids and in the ionic liquids with carbonic anhydrase were estimated. Based on the results obtained, cholinium ionic liquids were found to be potentially good alternatives for $\mathrm{CO}_{2}$ absorption. Furthermore, their recognized biocompatibility makes them suitable for biomedical applications. Of 
all cholinium-based ionic liquids with alkanoate anions tested, the highest $\mathrm{CO}_{2}$ absorption transport was obtained for cholinium propionate, where the presence of the carbonic anhydrase $(0.1 \mathrm{mgCA} / \mathrm{gIL})$, promoted an enhancement on the $\mathrm{CO}_{2}$ transport for the water activities tested ( $a w=0.216,0.576,0.753$ and 0.836), with a maximum of $63 \%$ enhancement at a water activity of 0.753 . Additionally, a correlation between $\mathrm{CO}_{2}$ diffusion coefficient and ionic liquids' viscosity was obtained. It was demonstrated that the $\mathrm{CO}_{2}$ diffusion coefficient dependency with the viscosity is correlated to a power of -0.805 , implying a stronger dependency than in other commercially available ionic liquids.

Cholinium propionate was used in a microfluidic device, which acted as a membrane contactor. The alveolar-type design of the ionic liquid chamber of the micro-contactor, was adopted to reduce mass transfer limitations of $\mathrm{CO}_{2}$ through the ionic liquid phase. The micro-contactor with a PDMS dense membrane demonstrated how effective the miniaturized devices can be for the fundamental studies of anaesthesia gas recovery. Due to miniaturization, the volume of ionic liquid required to fill the micro - chamber was significantly reduced. Despite the fact the permeability of PDMS for $\mathrm{Xe}$ and $\mathrm{CO}_{2}$ was similar, both cholinium propionate and cholinium propionate with carbonic anhydrase $(0.1 \mathrm{mgCA} / \mathrm{gIL})$ showed an enhancement in the $\mathrm{CO}_{2}$ capture, while there was no effect on the Xe transport rate. The $\mathrm{CO}_{2} / \mathrm{Xe}$ molar flux ratio after addition of the ionic liquid and the enzyme was as high as 3.3 compared to 1.4 obtained using the PDMS membrane.

Despite cholinium-based ionic liquids with alkanoate anions exhibited suitable $\mathrm{CO}_{2}$ absorption capacity, including enhanced affinity promoted by the presence of carbonic anhydrase, amino acid anions combined with the cholinium cation proved to possess higher $\mathrm{CO}_{2}$ loading capacities. Moreover, amino acid anions are recognizably more stable than alkanoates. Therefore, a prototype designed with eclipse ${ }^{\mathrm{TM}}$ membrane contactors and using an aqueous solution of cholinium lysinate as absorbent was evaluated. The system was composed by two Eclipse ${ }^{\mathrm{TM}}$ membrane contactors, containing polytetrafluoroethylene porous capillaries, with a $50 \mathrm{wt} \%$ [Cho+][Lys-] IL solution circulating in the lumen of the capillaries. Both contactors were operated simultaneously, removing $\mathrm{CO}_{2}$ from 
the gas phase in one contactor, and regenerating the aqueous cholinium lysinate through sweeping $\mathrm{N}_{2}$ in the other contactor. Experiments of $\mathrm{CO}_{2}$ capture were performed with the [Cho+][Lys-] IL solution up to saturation conditions. The system efficiency was assessed according to the amount of $\mathrm{CO}_{2}$ captured per mass of ionic liquid, over time, assuring the target concentration of $0.5 \%$ for $\mathrm{CO}_{2}$ at the contactor outlet. The results obtained revealed a $\mathrm{CO}_{2}$ maximum capacity of $5.9 \mathrm{~mol} / \mathrm{kgIL}$ for the proposed system. Under conditions of flow rate and gas composition, simulating the exhalation of an anesthetized patient, i.e. a gas mixture containing $65 \%$ of $\mathrm{N}_{2} \mathrm{O}$ and $5 \%$ of $\mathrm{CO}_{2}$, the system was able to operate efficiently over 63 hours, which in a mass basis comparison, is 3-5 times more than the current technology, using soda lime. The regeneration of the cholinium lysinate solution after the absorption of $\mathrm{CO}_{2}$, using $\mathrm{N}_{2}$ as the sweep gas, proved to be inefficient. From the results obtained, the reversion of the $\mathrm{CO}_{2}$ absorption was only partially accomplished. After each cycle of absorption/regeneration, the $\mathrm{CO}_{2}$ loading obtained was half of the maximum for the proposed system. Structurally, only the weaker bond between $\mathrm{CO}_{2}$ and the lysinate anion could be reverted by concentration difference.

The absorption mechanism of $\mathrm{CO}_{2}$ in the aqueous [Cho+][Lys-] solution was investigated, and a chemical absorption model was proposed for the $\mathrm{CO}_{2}-$ [Cho+][Lys-]-water system. The unknown chemical equilibrium constants were determined by fitting the experimental $\mathrm{pH}$ curve as a function of $\mathrm{CO}_{2}$ loading. From the analysis of the ATR-FTIR spectra, peaks have been identified and changes observed in their absorbances with loading of $\mathrm{CO}_{2}$. The variations observed in the entire FTIR spectrum are due to the increased concentration of IR absorbing ionic moieties in the aqueous IL medium. The results obtained validate the potential of using ATR-FTIR as a tool for monitoring $\mathrm{CO}_{2}$ absorption in aqueous media containing a reactive absorbent, as the case of cholinium lysinate.

The $\mathrm{CO}_{2}$ capture from gas mixtures with xenon as the inhalational gas, was also evaluated. The same system, with Eclipse ${ }^{\mathrm{TM}}$ membrane contactors, was operated under conditions close-to-real, considering an expired breath composition of $65 \%$ of xenon, $5 \%$ of $\mathrm{CO}_{2}, 27 \%$ of $\mathrm{O}_{2}$ and $3 \%$ of $\mathrm{N}_{2}$, saturated with 
water vapour. According to the results obtained, it was found that a higher amount of anaesthetic gas was recycled when Xe was used, in comparison with $\mathrm{N}_{2} \mathrm{O}$ or medicinal air. This is a positive outcome for the widespread use of Xe as inhalational anaesthetic since a considerable cost reduction per hour of operation was achieved. Aiming the complete regeneration of the cholinium lysinate solution, after the absorption of $\mathrm{CO}_{2}$, thermal and chemical regeneration procedures were addressed. The thermal regeneration approach was not able to revert the $\mathrm{CO}_{2}$ absorption, which was confirmed by the IR spectra obtained for the ionic liquid solutions. On the other hand, the innovative proposal of using ion-exchange resins, proved to be effective on the reversion of the $\mathrm{CO}_{2}$ absorption, without the formation of new compounds, which allows the later use of the [Cho+][Lys-] IL solution. Moreover, the simplicity of the method allows for an easy incorporation in the proposed system and further implementation in an hospital environment.

The work developed in this PhD showed that membrane contactors combined with cholinium-based ionic liquids are suitable for $\mathrm{CO}_{2}$ removal from anaesthesia circuits and the amount of recycled anaesthetics significantly reduces the costs per operation, leaving space for a widespread use of more efficient, although expensive, gases like xenon.

\subsection{Future work}

The system proposed in the present dissertation, allows for the efficient removal of $\mathrm{CO}_{2}$ from anaesthesia circuits, aiming the recovering and rebreathing of the inhalational anaesthetic gases. Moreover, the system was designed and different methods were addressed, considering a self-regenerative unit for the ionic liquid used for $\mathrm{CO}_{2}$ absorption. As a more fundamental outcome, a mechanistic model based on the chemisorption and absorption kinetics was developed and validated. Several relevant accomplishments were obtained, opening new questions that should be addressed. The following recommendations for future work are proposed. 
○ The use of cholinium-based ionic liquids proved to be highly efficient to capture $\mathrm{CO}_{2}$, however they present a characteristic amine-like odour. Therefore, further research should consider the development of inodorous liquid absorbents, or the development of a simple method to eliminate the characteristic odour of the cholinium-based ionic liquids.

- Further research should consider improvements of the microfluidic device, including materials' development, such as non-permeable materials with higher mechanical resistance for the fabrication of microfluidic chambers. Moreover, the experimental procedure may be improved considering the use of several microfluidic devices operating in series to capture the $\mathrm{CO}_{2}$ from anaesthesia circuits.

- Regarding the operating conditions for the system proposed with Eclipse $^{\mathrm{TM}}$ membrane contactors, there is space for improvements. Experimental investigation of the effect of gas flow rate, liquid phase flow rate and long-term stability of the capillaries should be performed. These studies will help to understand the limitations of the operating conditions, extending the process to optimal operation conditions.

- Different methods were addressed for the ionic liquid regeneration. The only approach capable to revert efficiently the absorption of $\mathrm{CO}_{2}$, was the use of ion exchange resins. Yet, a better understanding on how the resin acts in the ionic liquid solution is needed. Which is the dominant mechanism to exchange the cations with the acid resin? Is it the water, which is acting as an acid in this liquid media, or is it through attachment to the amine groups, or through the choline cation, or a combination of these mechanisms? Additionally, a quantitative analysis must be performed to optimise the amount of resin needed to revert completely the $\mathrm{CO}_{2}$ absorbed.

- Validate the proposed system in a ventilator machine with a lung simulator, at different operating conditions, e.g. high, low and minimum flow ventilation, with or without inhalational anaesthesia.

- Finally, the aqueous cholinium lysinate ionic liquid performance must be evaluated under the presence of the volatile halogenated hydrocarbons. 


\section{Bibliography}

[1] J. Xi, J. Kim, X.A. Si, Transport and Absorption of Anesthetic Vapors in a Mouth-Lung Model Extending to G9 Bronchioles, Int. J. Anesthesiol. Res. 1 (2013) 6-19. doi:10.14205/2310-9394.2013.01.01.2.

[2] G. Morgan, M. Mikhail, M. Murray, Clinical Anesthesiology, 4th ed., McGraw-Hill Medical, 2005.

[3] G. Obuskovic, K.K. Sirkar, Liquid membrane-based $\mathrm{CO}_{2}$ reduction in a breathing apparatus, J. Memb. Sci. $389 \quad$ (2012) 424-434. doi:10.1016/j.memsci.2011.11.008.

[4] M.R. Nel, J.D. Watts, G.G. Lockwood, An alternative method of nitrous oxide delivery into a minimal-flow circle breathing system, Anaesthesia. 52 (1997) 57-61. doi:10.1111/j.1365-2044.1997.009-az009.x.

[5] M. V. McNeil, F.M. Wilfart, J.B. Haelssig, Modelling hollow fiber membrane modules for anesthesia gas separation, Chem. Eng. Sci. 191 (2018) 479-489. doi:10.1016/j.ces.2018.06.058.

[6] S. Lagorsse, F.D. Magalhães, A. Mendes, Xenon recycling in an anaesthetic closed-system using carbon molecular sieve membranes, J. Memb. Sci. 301 (2007) 29-38. doi:10.1016/j.memsci.2007.05.032.

[7] C.R. Stabernack, R. Brown, M.J. Laster, R. Dudziak, E.I. Eger, Absorbents differ enormously in their capacity to produce compound A and carbon monoxide, Anesth. Analg. 90 (2000) 1428-1435. doi:10.1097/00000539200006000-00033.

[8] M. Morio, K. Fujii, N. Satoh, M. Imai, U. Kawakami, T. Mizuno, Y. Kawai, Y. Ogasawara, T. Tamura, A. Negishi, Y. Kumagai, T. Kawai, Reaction of Sevoflurane and Its Degradation Products with Soda Lime: Toxicity of the Byproducts, Anesthesiology. 77 (1992) 1155-1164. doi:10.1097/00000542199212000-00017.

[9] H.H. Luttropp, A. Johansson, Soda lime temperatures during low-flow 
sevoflurane anaesthesia and differences in dead-space, Acta Anaesthesiol. Scand. 46 (2002) 500-505. doi:10.1034/j.1399-6576.2002.460505.x.

[10] M.A. Olympio, Carbon Dioxide Absorbent Desiccation Safety Conference Convened by Anesthesia Patient Safety Foundation, Off. J. Anesth. Patient Saf. Found. 20 (2005) 25-44.

[11] O. Ahmed, S. Mannion, The Cost Implications of Replacing Soda Lime with Amsorb Plus in Clinical Practice, ISRN Anesthesiol. 2011 (2011) 1-4. doi:10.5402/2011/730483.

[12] M. Naco, I. Ohri, H. Gani, A. Mandi, E. Petrela, Comparison of cost effectiveness using low flow anesthesia with an oxygen/nitrous oxide carrier gas sevoflurane versus using high flow anesthesia with an oxygen/nitrous oxide carrier gas sevoflurane during 2 hours anesthesia in abdominal surgery, Eur. J. Anaesthesiol. 27 (2010) 19-20.

[13] Y. Nakata, T. Goto, Y. Niimi, S. Morita, Cost analysis of xenon anesthesia: A comparison with nitrous oxide-isoflurane and nitrous oxide-sevoflurane anesthesia, J. Clin. Anesth. 11 (1999) 477-481. doi:10.1016/s09528180(99)00087-2.

[14] P. Hanne, T. Marx, S. Musati, M. Santo, K. Suwa, S. Morita, Xenon: Uptake and costs, Int. Anesthesiol. Clin. 39 (2001) 43-61. doi:10.1097/00004311200104000-00006.

[15] J. Golembiewski, Economic considerations in the use of inhaled anesthetic agents, Am. J. Heal. Pharm. 67 (2010). doi:10.2146/ajhp100093.

[16] W. Buhre, N. Disma, J. Hendrickx, S. DeHert, M.W. Hollmann, R. Huhn, J. Jakobsson, P. Nagele, P. Peyton, L. Vutskits, European Society of Anaesthesiology Task Force on Nitrous Oxide: a narrative review of its role in clinical practice, Br. J. Anaesth. 122 (2019) 587-604. doi:10.1016/j.bja.2019.01.023.

[17] R. Chaturvedi, R.L. Gogna, Ether day: An intriguing history, Med. J. Armed Forces India. 67 (2011) 306-308. doi:10.1016/S0377-1237(11)60098-1.

[18] S.C. Cullen, E.G. Gross, The anesthetic properties of xenon in animals and human beings, with additional observations on krypton, Science (80-. ). 113 (1951) 580-582. doi:10.1126/science.113.2942.580.

[19] T. Goto, P. Hanne, Y. Ishiguro, F. Ichinose, Y. Niimi, S. Morita, Cardiovascular effects of xenon and nitrous oxide in patients during fentanyl-midazolam anaesthesia, Anaesthesia. 59 (2004) 1178-1183. doi:10.1111/j.1365-2044.2004.03900.x.

[20] D.E. Becker, M. Rosenberg, Nitrous oxide and the inhalation anesthetics, Anesth. Prog. 55 (2008) 124-131. doi:10.2344/0003-3006-55.4.124. 
[21] R.W.D. Nickalls, W.W. Mapleson, Age-related iso-MAC charts for isoflurane, sevoflurane and desflurane in man, Br. J. Anaesth. 91 (2003) 170-174. doi:10.1093/bja/aeg132.

[22] M. Somvanshi, A. Tripathi, A. Gupta, F. Satpathy, Xenon: The Future Anaesthetic Agent, Indian J. Anesth. Analg. 5 (2018) 493-499. doi:10.1093/bja/aeg232.

[23] S. Petersen-Felix, M. Luginbühl, T.W. Schnider, M. Curatolo, L. ArendtNielsen, A.M. Zbinden, Comparison of the analgesic potency of xenon and nitrous oxide in humans evaluated by experimental pain, Br. J. Anaesth. 81 (1998) 742-747. doi:10.1093/bja/81.5.742.

[24] B. Hou, F. Li, S. Ou, L. Yang, S. Zhou, Comparison of recovery parameters for xenon versus other inhalation anesthetics: Systematic review and metaanalysis, J. Clin. Anesth. 29 (2016) 65-74. doi:10.1016/j.jclinane.2015.10.018.

[25] Y. Nakata, T. Goto, S. Morita, Xenon and future anesthesia, Japanese J. Anesthesiol. 46 Suppl (1997) 1-4.

[26] A. Portugal, Carbon dioxide removal from anaesthetic gas circuits using absorbent membrane contactors, University of Oporto, 2009.

[27] F.M. Wilfart, M. V. McNeil, J.B. Haelssig, H. Hanafi, D.C. Roach, G. Maksym, M.K. Schmidt, Validation and optimization of a membrane system for carbon dioxide removal in anesthesia circuits under realistic patient scenarios, J. Memb. Sci. $601 \quad$ (2020) 117887. doi:10.1016/j.memsci.2020.117887.

[28] S.L. Pontes, Removal of carbon dioxide and nitrogen from a xenon based closed-circuit anaesthetic system, University of Oporto, 2006.

[29] X. Wang, Y. Zhang, X. Wang, E. Andres-Garcia, P. Du, L. Giordano, L. Wang, Z. Hong, X. Gu, S. Murad, F. Kapteijn, Xenon Recovery by DD3R Zeolite Membranes: Application in Anaesthetics, Angew. Chemie - Int. Ed. 58 (2019) 15518-15525. doi:10.1002/anie.201909544.

[30] S.D. Bazhenov, A. V. Bildyukevich, A. V. Volkov, Gas-liquid hollow fiber membrane contactors for different applications, Fibers. 6 (2018). doi:10.3390/fib6040076.

[31] S. Zhao, P.H.M. Feron, L. Deng, E. Favre, E. Chabanon, S. Yan, J. Hou, V. Chen, H. Qi, Status and progress of membrane contactors in postcombustion carbon capture: A state-of-the-art review of new developments, J. Memb. Sci. $511 \quad$ (2016) 180-206. doi:10.1016/j.memsci.2016.03.051.

[32] G.T. Rochelle, Amine Scrubbing for CO2 Capture, Science. 325 (2009) 16521654. doi:10.1126/science.1176731. 
[33] R.R. Bottoms, Process for separating acidic gases, US Pat. 1783901. (1930).

[34] S.D. Kenarsari, D. Yang, G. Jiang, S. Zhang, J. Wang, A.G. Russell, Q. Wei, M. Fan, Review of recent advances in carbon dioxide separation and capture, RSC Adv. 3 (2013) 22739-22773. doi:10.1039/C3RA43965H.

[35] O. Cabeza, Chapter 1 - Properties and Green Aspects of Ionic Liquids, Elsevier, 2014. doi:10.1016/B978-0-444-63257-9.00001-8.

[36] Z. Lei, C. Dai, B. Chen, Gas solubility in ionic liquids, Chem. Rev. 114 (2014) 1289-1326. doi:10.1021/cr300497a.

[37] J. Huang, T. Rther, Why are ionic liquids attractive for $\mathrm{CO}_{2}$ absorption? An overview, Aust. J. Chem. 62 (2009) 298-308. doi:10.1071/CH08559.

[38] M. Petkovic, J.L. Ferguson, H.Q.N. Gunaratne, R. Ferreira, M.C. Leitão, K.R. Seddon, L.P.N. Rebelo, C.S. Pereira, Novel biocompatible choliniumbased ionic liquids - toxicity and biodegradability, Green Chem. 12 (2010) 643-64. doi:10.1039/b922247b.

[39] S. Yuan, Y. Chen, X. Ji, Z. Yang, X. Lu, Experimental study of $\mathrm{CO}_{2}$ absorption in aqueous cholinium-based ionic liquids, Fluid Phase Equilib. 445 (2017) 14-24. doi:10.1016/j.fluid.2017.04.001.

[40] L.A. Neves, C. Afonso, I.M. Coelhoso, J.G. Crespo, Integrated $\mathrm{CO}_{2}$ capture and enzymatic bioconversion in supported ionic liquid membranes, Sep. Purif. Technol. 97 (2012) 34-41. doi:10.1016/j.seppur.2012.01.049.

[41] P. Luis, T. Van Gerven, B. Van der Bruggen, Recent developments in membrane-based technologies for $\mathrm{CO}_{2}$ capture, Prog. Energy Combust. Sci. 38 (2012) 419-448. doi:10.1016/j.pecs.2012.01.004.

[42] V. RM, F. KJ, F. K, M. DR, E. GD, Biocompatible ionic liquids: a new approach for stabilizing proteins in liquid formulation, J Biomech Eng. 131 (2009) 074514. doi:10.1115/1.3156810.

[43] L.C. Tomé, D.J.S. Patinha, R. Ferreira, H. Garcia, C. Silva Pereira, C.S.R. Freire, L.P.N. Rebelo, I.M. Marrucho, Cholinium-based supported ionic liquid membranes: a sustainable route for carbon dioxide separation, ChemSusChem. (2014) 110-113. doi:10.1002/cssc.201300613.

[44] H. Ohno, K. Fukumoto, J. Kagimoto, New Class of Ionic Liquids Synthesized from Amino Acid and Other Bioderived Materials, Ion. Liq. IV. (2007) 351-361. doi:10.1021/bk-2007-0975.ch024.

[45] X. Jia, Y. Yang, C. Wang, C. Zhao, R. Vijayaraghavan, D.R. Macfarlane, M. Forsyth, G.G. Wallace, Biocompatible ionic liquid-biopolymer electrolyteenabled thin and compact magnesium-Air batteries, ACS Appl. Mater. Interfaces. 6 (2014) 21110-21117. doi:10.1021/am505985z. 
[46] W. Gouveia, T.F. Jorge, S. Martins, M. Meireles, M. Carolino, C. Cruz, T. V. Almeida, M.E.M. Araújo, Toxicity of ionic liquids prepared from biomaterials, Chemosphere. $104 \quad$ (2014) 51-56. doi:10.1016/j.chemosphere.2013.10.055.

[47] J.K. Blusztajn, Choline, a Vital Amine, Science. 281 (1998) 794 LP - 795. doi:10.1126/science.281.5378.794.

[48] F.A. e Silva, F. Siopa, B.F.H.T. Figueiredo, A.M.M. Gonçalves, J.L. Pereira, F. Gonçalves, J.A.P. Coutinho, C.A.M. Afonso, S.P.M. Ventura, Sustainable design for environment-friendly mono and dicationic cholinium-based ionic liquids, Ecotoxicol. Environ. Saf. 108 (2014) 302-310. doi:10.1016/j.ecoenv.2014.07.003.

[49] C. Wu, T.P. Senftle, W.F. Schneider, First-principles-guided design of ionic liquids for $\mathrm{CO}_{2}$ capture, Phys. Chem. Chem. Phys. 14 (2012) 13163-13170. doi:10.1039/c2cp41769c.

[50] G.N. Wang, Y. Dai, X.B. Hu, F. Xiao, Y.T. Wu, Z.B. Zhang, Z. Zhou, Novel ionic liquid analogs formed by triethylbutylammonium carboxylate-water mixtures for $\mathrm{CO}_{2}$ absorption, J. Mol. Liq. 168 (2012) 17-20. doi:10.1016/j.molliq.2011.12.006.

[51] M.J. Muldoon, S.N.V.K. Aki, J.L. Anderson, J.K. Dixon, J.F. Brennecke, Improving carbon dioxide solubility in ionic liquids, J. Phys. Chem. B. 111 (2007) 9001-9009. doi:10.1021/jp071897q.

[52] E. Santos, J. Albo, A. Irabien, Acetate based Supported Ionic Liquid Membranes (SILMs) for $\mathrm{CO}_{2}$ separation: Influence of the temperature, J. Memb. Sci. 452 (2014) 277-283. doi:10.1016/j.memsci.2013.10.024.

[53] J. Blath, N. Deubler, T. Hirth, T. Schiestel, Chemisorption of carbon dioxide in imidazolium based ionic liquids with carboxylic anions, Chem. Eng. J. 181-182 (2012) 152-158. doi:10.1016/j.cej.2011.11.042.

[54] P. Luis, I. Ortiz, R. Aldaco, A. Irabien, A novel group contribution method in the development of a QSAR for predicting the toxicity (Vibrio fischeri EC50) of ionic liquids, Ecotoxicol. Environ. Saf. 67 (2007) 423-429. doi:10.1016/j.ecoenv.2006.06.010.

[55] R. Fortunato, M.J. González-Muñoz, M. Kubasiewicz, S. Luque, J.R. Alvarez, C.A.M. Afonso, I.M. Coelhoso, J.G. Crespo, Liquid membranes using ionic liquids: The influence of water on solute transport, J. Memb. Sci. 249 (2005) 153-162.

[56] M. Moniruzzaman, K. Nakashima, N. Kamiya, M. Goto, Recent advances of enzymatic reactions in ionic liquids, Biochem. Eng. J. 48 (2010) 295-314. doi:10.1016/j.bej.2009.10.002. 
[57] H. Zhao, Effect of ions and other compatible solutes on enzyme activity, and its implication for biocatalysis using ionic liquids, J. Mol. Catal. B Enzym. 37 (2005) 16-25. doi:10.1016/j.molcatb.2005.08.007.

[58] F.J. Deive, A. Rodríguez, L.P.N. Rebelo, I.M. Marrucho, Extraction of Candida antarctica lipase A from aqueous solutions using imidazoliumbased ionic liquids, Sep. Purif. Technol. 97 (2012) 205-210. doi:10.1016/j.seppur.2011.12.013.

[59] J.R. Collett, R.W. Heck, A.J. Zwoster, Dissolved carbonic anhydrase for enhancing post-combustion carbon dioxide hydration in aqueous ammonia, Energy Procedia. 4 (2011) 240-244. doi:10.1016/j.egypro.2011.01.047.

[60] W.C. Floyd, S.E. Baker, C.A. Valdez, J.K. Stolaroff, J.P. Bearinger, J.H. Satcher, R.D. Aines, Evaluation of a carbonic anhydrase mimic for industrial carbon capture, Environ. Sci. Technol. 47 (2013) 10049-10055. doi:10.1021/es401336f.

[61] N.J.M.C. Penders-van Elk, S. Fradette, G.F. Versteeg, Effect of pKa on the kinetics of carbon dioxide absorption in aqueous alkanolamine solutions containing carbonic anhydrase at 298K, Chem. Eng. J. 259 (2015) 682-691. doi:10.1016/j.cej.2014.08.001.

[62] N.J.M.C. Penders-van Elk, E.S. Hamborg, P.J.G. Huttenhuis, S. Fradette, J.A. Carley, G.F. Versteeg, Kinetics of absorption of carbon dioxide in aqueous amine and carbonate solutions with carbonic anhydrase, Int. J. Greenh. Gas Control. 12 (2013) 259-268. doi:10.1016/j.ijggc.2012.10.016.

[63] M.E. Russo, G. Olivieri, A. Marzocchella, P. Salatino, P. Caramuscio, C. Cavaleiro, Post-combustion carbon capture mediated by carbonic anhydrase, Sep. Purif. Technol. $107 \quad$ (2013) 331-339. doi:10.1016/j.seppur.2012.06.022.

[64] M.E. Russo, G. Olivieri, P. Salatino, A. Marzocchella, $\mathrm{CO}_{2}$ capture by biomimetic adsorption: Enzyme mediated $\mathrm{CO}_{2}$ absorption for postcombustion Carbon sequestration and storage process, Environ. Eng. Manag. J. 12 (2013) 1595-1603. doi:10.30638/eemj.2013.194.

[65] M. Vinoba, M. Bhagiyalakshmi, A.N. Grace, D.H. Kim, Y. Yoon, S.C. Nam, I.H. Baek, S.K. Jeong, Carbonic anhydrase promotes the absorption rate of $\mathrm{CO}_{2}$ in post-combustion processes, J. Phys. Chem. B. 117 (2013) 5683-5690. doi:10.1021/jp401622c.

[66] D. Camper, C. Becker, C. Koval, R. Noble, Diffusion and solubility measurements in room temperature ionic liquids, Ind. Eng. Chem. Res. 45 (2006) 445-450. doi:10.1021/ie0506668. 
[67] R. Condemarin, P. Scovazzo, Gas permeabilities, solubilities, diffusivities, and diffusivity correlations for ammonium-based room temperature ionic liquids with comparison to imidazolium and phosphonium RTIL data, Chem. Eng. J. 147 (2009) 51-57. doi:10.1016/j.cej.2008.11.015.

[68] H. Ying, R.E. Baltus, Experimental measurement of the solubility and $\mathrm{CO}_{2}$ in room-temperature ionic liquids using a transient thin-liquid-film method, Ind. Eng. Chem. Res. 46 (2007) 8166-8175. doi:10.1021/ie070501u.

[69] S.S. Moganty, R.E. Baltus, Diffusivity of carbon dioxide in roomtemperature ionic liquids, Ind. Eng. Chem. Res. 49 (2010) 9370-9376. doi:10.1021/ie101260j.

[70] D. Morgan, L. Ferguson, P. Scovazzo, Diffusivities of gases in roomtemperature ionic Liquids: Data and correlations obtained using a lag-time technique, Ind. Eng. Chem. Res. 44 (2005) 4815-4823. doi:10.1021/ie048825v.

[71] S.S. Moganty, P.S. Chinthamanipeta, V.K. Vendra, S. Krishnan, R.E. Baltus, Structure-property relationships in transport and thermodynamic properties of imidazolium bistriflamide ionic liquids for $\mathrm{CO}_{2}$ capture, Chem. Eng. J. 250 (2014) 377-389. doi:10.1016/j.cej.2014.04.010.

[72] L. Ferguson, P. Scovazzo, Solubility, diffusivity, and permeability of gases in phosphonium-based room temperature ionic liquids: Data and correlations, Ind. Eng. Chem. Res. 46 (2007) 1369-1374. doi:10.1021/ie0610905.

[73] A. Ortiz, L.M. Galán, D. Gorri, A.B. De Haan, I. Ortiz, Kinetics of reactive absorption of propylene in RTIL-Ag+ media, Sep. Purif. Technol. 73 (2010) 106-113. doi:10.1016/j.seppur.2010.03.008.

[74] L. Greenspan, Humidity Fixed Points of Binary Saturated Aqueous Solutions, J. Res. Natl. Bur. Stand. - A. Phys. Chem. 81A (1976) 53-66.

[75] J.W. Westwater, H.G. Drickamer, The Mathematics of Diffusion, J. Am. Chem. Soc. 79 (1957) 1267-1268. doi:10.1021/ja01562a072.

[76] D.J.S. Patinha, L.C. Tomé, H. Garcia, R. Ferreira, C.S. Pereira, L.P.N. Rebelo, I.M. Marrucho, The role of water in cholinium carboxylate ionic liquid's aqueous solutions, J. Chem. Thermodyn. 84 (2015) 93-100. doi:10.1016/j.jct.2014.12.020.

[77] G.S. Kell, Precise Representation of Volume Properties of Water at One Atmosphere, J. Chem. Eng. Data. 12 (1967) 66-69. doi:10.1021/je60032a018.

[78] Q. Gan, Y. Zou, D. Rooney, P. Nancarrow, J. Thompson, L. Liang, M. Lewis, Theoretical and experimental correlations of gas dissolution, diffusion, and thermodynamic properties in determination of gas permeability and 
selectivity in supported ionic liquid membranes, Adv. Colloid Interface Sci. 164 (2011) 45-55. doi:10.1016/j.cis.2011.01.005.

[79] M. Gonzalez-Miquel, J. Bedia, C. Abrusci, J. Palomar, F. Rodriguez, Anion effects on kinetics and thermodynamics of $\mathrm{CO}_{2}$ absorption in ionic liquids, J. Phys. Chem. B. 117 (2013) 3398-3406. doi:10.1021/jp4007679.

[80] M. Tariq, P.A.S. Forte, M.F.C. Gomes, J.N.C. Lopes, L.P.N. Rebelo, Densities and refractive indices of imidazolium- and phosphonium-based ionic liquids: Effect of temperature, alkyl chain length, and anion, J. Chem. Thermodyn. 41 (2009) 790-798. doi:10.1016/j.jct.2009.01.012.

[81] S.S. Moganty, R.E. Baltus, Regular solution theory for low pressure carbon dioxide solubility in room temperature ionic liquids: Ionic liquid solubility parameter from activation energy of viscosity, Ind. Eng. Chem. Res. 49 (2010) 5846-5853. doi:10.1021/ie901837k.

[82] D. Camper, J. Bara, C. Koval, R. Noble, Bulk-fluid solubility and membrane feasibility of Rmim-based room-temperature ionic liquids, Ind. Eng. Chem. Res. 45 (2006) 6279-6283. doi:10.1021/ie060177n.

[83] P. Sebastião, Fitteia, (2009). https://lince.ist.utl.pt/cgi-bin/login (accessed July 31, 2015).

[84] K. Hecker, J. Baumert, N. Horn, R. Rossaint, Xenon, a modern anaesthesia gas, Minerva Anestesiol. 70 (2004) 255-260.

[85] S.D. Faulkner, N.A. Downie, C.J. Mercer, S.A. Kerr, R.D. Sanders, N.J. Robertson, A xenon recirculating ventilator for the newborn piglet: Developing clinical applications of xenon for neonates, Eur. J. Anaesthesiol. 29 (2012) 577-585. doi:10.1097/EJA.0b013e3283583c4b.

[86] T. Goto, Is there a future for xenon anesthesia?, Can. J. Anesth. 49 (2002) 335-338. doi:10.1007/BF03017319.

[87] A. JA, Compound A concentrations during sevoflurane anesthesia in children depend on fresh gas flow, Anesthesiology. 85 (1986) 684. doi:10.1097/00000542-199609000-00031.

[88] A. Mendes, Development of an adsorption/membrane based system for carbon dioxide, nitrogen and spur gases removal from a nitrous oxide and xenon anaesthetic closed loop itle, 5th Annu. Symp. Assoc. (ALFA 2000). 9 (2000).

[89] J.K.J. Yong, G.W. Stevens, F. Caruso, S.E. Kentish, In situ layer-by-layer assembled carbonic anhydrase-coated hollow fiber membrane contactor for rapid $\mathrm{CO}_{2}$ absorption, J. Memb. Sci. 514 (2016) 556-565. doi:10.1016/j.memsci.2016.05.020. 
[90] C.F. Martins, L.A. Neves, M. Estevão, A. Rosatella, V.D. Alves, C.A.M. Afonso, J.G. Crespo, I.M. Coelhoso, Effect of water activity on carbon dioxide transport in cholinium-based ionic liquids with carbonic anhydrase, Sep. Purif. Technol. 168 (2016) 74-82.

[91] J. Hou, M.Y. Zulkifli, M. Mohammad, Y. Zhang, A. Razmjou, V. Chen, Biocatalytic gas-liquid membrane contactors for $\mathrm{CO}_{2}$ hydration with immobilized carbonic anhydrase, J. Memb. Sci. 520 (2016) 303-313. doi:10.1016/j.memsci.2016.07.003.

[92] E. Torralba-Calleja, J. Skinner, D. Gutiérrez-Tauste, $\mathrm{CO}_{2}$ capture in ionic liquids: A review of solubilities and experimental methods, J. Chem. 2013 (2013). doi:10.1155/2013/473584.

[93] T. Kniazeva, A.A. Epshteyn, J.C. Hsiao, E.S. Kim, V.B. Kolachalama, J.L. Charest, J.T. Borenstein, Performance and scaling effects in a multilayer microfluidic extracorporeal lung oxygenation device, Lab Chip. 12 (2012) 1686-1695. doi:10.1039/c2lc21156d.

[94] J.T. Borenstein, H. Terai, K.R. King, E.J. Weinberg, M.R. KaazempurMofrad, J.P. Vacanti, Microfabrication technology for vascularized tissue engineering, Biomed. Microdevices. 4 (2002) 167-175. doi:10.1023/A:1016040212127.

[95] B.G. Subramani, P.R. Selvaganapathy, Surface micromachined PDMS microfluidic devices fabricated using a sacrificial photoresist, J. Micromechanics Microengineering. 19 (2009). doi:10.1088/09601317/19/1/015013.

[96] D.M. Hoganson, H.I. Pryor, E.K. Bassett, I.D. Spool, J.P. Vacanti, Lung assist device technology with physiologic blood flow developed on a tissue engineered scaffold platform, Lab Chip. 11 (2011) 700-707. doi:10.1039/c01c00158a.

[97] N. Rochow, E.C. Chan, W.I. Wu, P.R. Selvaganapathy, G. Fusch, L. Berry, J. Brash, A.K. Chan, C. Fusch, Artificial placenta - Lung assist devices for term and preterm newborns with respiratory failure, Int. J. Artif. Organs. 36 (2013) 377-391. doi:10.5301/ijao.5000195.

[98] S. Bhattacharya, A. Datta, J.M. Berg, S. Gangopadhyay, Studies on surface wettability of poly(dimethyl) siloxane (PDMS) and glass under oxygenplasma treatment and correlation with bond strength, J. Microelectromechanical Syst. $14 \quad$ (2005) 590-597. doi:10.1109/JMEMS.2005.844746.

[99] E.L. Cussler, Diffusion - Mass transfer in fluid systems, 3rd ed., Cambridge Series in Chemical Engineering. Cambridge University Press., 2009. 
[100] T.C. Merkel, V.I. Bondar, K. Nagai, B.D. Freeman, I. Pinnau, Gas sorption, diffusion, and permeation in poly(dimethylsiloxane), J. Polym. Sci. B Polym. Phys. $38 \quad$ (2000) 415-434. doi:10.1002/(SICI)10990488(20000201)38:3<415::AID-POLB8>3.0.CO;2-Z.

[101] A. Lamberti, S.L. Marasso, M. Cocuzza, PDMS membranes with tunable gas permeability for microfluidic applications, RSC Adv. 4 (2014) 6141561419. doi:10.1039/c4ra12934b.

[102] A. Singh, B.D. Freeman, I. Pinnau, Pure and mixed gas acetone/nitrogen permeation properties of polydimethylsiloxane [PDMS], J. Polym. Sci. Part B Polym. Phys. 36 (1998) 289-301. doi:10.1002/(SICI)10990488(19980130)36:2<289::AID-POLB8>3.0.CO;2-M.

[103] K. Khanafer, A. Duprey, M. Schlicht, R. Berguer, Effects of strain rate, mixing ratio, and stress-strain definition on the mechanical behavior of the polydimethylsiloxane (PDMS) material as related to its biological applications, Biomed. Microdevices. 11 (2009) 503-508. doi:10.1007/s10544008-9256-6.

[104] M. Liu, J. Sun, Q. Chen, Influences of heating temperature on mechanical properties of polydimethylsiloxane, Sensors Actuators, A Phys. 151 (2009) 42-45. doi:10.1016/j.sna.2009.02.016.

[105] B.E. Poling, J.M. Prausnitz, J.P. O'Connell, The Properties of Gases and Liquids, 5th ed., McGraw-Hill, New York, 2001.

[106] W. Funk, M. Gruber, K. Wild, J. Hobbhahn, Dry soda lime markedly degrades sevoflurane during simulated inhalation induction, Br. J. Anaesth. 82 (1999) 193-198. doi:10.1093/bja/82.2.193.

[107] I. Lund, L.L. Andersen, H. Erikson, Efficiency of carbon dioxide absorption by soda lime in a closed system, Br. J. Anaesth. 28 (1956) 13-19. doi:10.1093/bja/28.1.13.

[108] A.F. Portugal, F.D. Magalhães, A. Mendes, Carbon dioxide removal from anaesthetic gas circuits using hollow fiber membrane contactors with amino acid salt solutions, J. Memb. Sci. 339 (2009) 275-286. doi:10.1016/j.memsci.2009.04.055.

[109] D.K. Spracklin, E.D. Kharasch, Evidence for metabolism of fluoromethyl 2,2-difluoro-1-(trifluoromethyl)vinyl ether (compound A), a sevoflurane degradation product, by cysteine conjugate $\beta$-lyase, Chem. Res. Toxicol. 9 (1996) 696-702. doi:10.1021/tx9502103.

[110] H. Wissing, D. Ph, I. Kuhn, U. Warnken, D. Ph, R. Dudziak, D. Ph, Carbon monoxide production from Desflurane, Enflurane, Halothane, Isoflurane , and Sevoflurane with dry soda lime, Anesthesiology. 95 (2001) 1205-1212. 
doi:10.1097/00000542-200111000-00026.

[111] H. Bito, Y. Ikeuchi, K. Ikeda, Effects of the water content of soda lime on Compound A concentration in the anesthesia circuit in sevoflurane anesthesia, Anesthesiology. 88 (1998) 66-71. doi:10.1097/00000542199801000-00012.

[112] N.M. Simon, M. Zanatta, F.P. Santos, M.C. Corvo, J. Eurico, N.M. Simon, M. Zanatta, P. Santos, M.C. Corvo, J. Eurico, J. Dupont, Carbon dioxide capture by aqueous ionic liquid solutions, ChemSusChem. 10 (2017) 49274933. doi:10.1021/es201808e.

[113] J. Ma, Z. Zhou, F. Zhang, C. Fang, Y. Wu, Z. Zhang, A. Li, Ditetraalkylammonium Amino Acid Ionic Liquids as $\mathrm{CO}_{2}$ Absorbents of High Capacity, Environ. Sci. Technol. 45 (2011) 10627-10633. doi:10.1021/es201808e.

[114] Z. Zhijun, D. Haifeng, Z. Xiangping, The Research Progress of $\mathrm{CO}_{2}$ Capture with Ionic Liquids, Chinese J. Chem. Eng. 20 (2012) 120-129. doi:10.1016/S1004-9541(12)60371-1.

[115] B. Li, Y. Chen, Z. Yang, X. Ji, X. Lu, Thermodynamic study on carbon dioxide absorption in aqueous solutions of choline-based amino acid ionic liquids, Sep. Purif. Technol. $341 \quad$ (2019) 128-138. doi:10.1016/j.seppur.2018.01.058.

[116] Q. Yang, Z. Wang, Z. Bao, Z. Zhang, Y. Yang, Q. Ren, New Insights into $\mathrm{CO}_{2}$ Absorption Mechanisms with Amino-Acid Ionic Liquids, ChemSusChem. 9 (2016) 806-812. doi:10.1002/cssc.201501691.

[117] S. Bhattacharyya, F.U. Shah, Ether functionalized choline tethered amino acid ionic liquids for enhanced $\mathrm{CO}_{2}$ capture, ACS Sustain. Chem. Eng. 4 (2016) 5441-5449. doi:10.1021/acssuschemeng.6b00824.

[118] S. Saravanamurugan, A.J. Kunov-kruse, R. Fehrmann, A. Riisager, Aminefunctionalized amino acid-based ionic liquids as efficient and highcapacity absorbents for $\mathrm{CO}_{2}$, ChemSusChem. 7 (2014) 897-902. doi:10.1002/cssc.201300691.

[119] P.S. Kumar, J.A. Hogendoorn, P.H.M. Feron, G.F. Versteeg, New absorption liquids for the removal of $\mathrm{CO}_{2}$ from dilute gas streams using membrane contactors, Chem. Eng. Sci. 57 (2002) 1639-1651. doi:10.1016/S0009-2509(02)00041-6.

[120] B. Chen, J. Li, B. Chen, Review of $\mathrm{CO}_{2}$ absorption using chemical solvents in hollow fiber membrane contactors, Sep. Purif. Technol. 41 (2005) 109122. doi:10.1016/j.seppur.2004.09.008.

[121] J. Albo, P. Luis, A. Irabien, Absorption of coal combustion flue gases in 
ionic liquids using different membrane contactors, Desalin. Water Treat. 27 (2011) 54-59. doi:10.1021/acs.iecr.6b01247.

[122] Z. Dai, L. Ansaloni, L. Deng, Precombustion $\mathrm{CO}_{2}$ capture in polymeric hollow fiber membrane contactors using ionic liquids : porous membrane versus nonporous composite membrane, Ind. Eng. Chem. Res. 55 (2016) 5983-5992. doi:10.1021/acs.iecr.6b01247.

[123] R. Wang, H.Y. Zhang, P.H.M. Feron, D.T. Liang, Influence of membrane wetting on $\mathrm{CO}_{2}$ capture in microporous hollow fiber membrane contactors, Sep. Purif. Technol. 46 (2005) 33-40. doi:10.1016/j.seppur.2005.04.007.

[124] M. Malankowska, C.F. Martins, H.S. Rho, L.A. Neves, R.M. Tiggelaar, J.G. Crespo, M.P. Pina, R. Mallada, H. Gardeniers, I.M. Coelhoso, Microfluidic devices as gas - Ionic liquid membrane contactors for $\mathrm{CO}_{2}$ removal from anaesthesia gases, J. Memb. Sci. $545 \quad$ (2018) 107-115. doi:10.1016/j.memsci.2017.09.065.

[125] E. Chabanon, E. Kimball, E. Favre, O. Lorain, E. Goetheer, D. Ferre, A. Gomez, P. Broutin, Hollow Fiber Membrane Contactors for PostCombustion $\mathrm{CO}_{2}$ Capture: A Scale-Up Study from Laboratory to Pilot Plant, 69 (2014) 1035-1045. doi:10.2516/ogst/2012046.

[126] J. Sun, N.V.S.N.M. Konda, J. Shi, R. Parthasarathi, T. Dutta, F. Xu, C.D. Scown, A. Simmons, S. Singh, $\mathrm{CO}_{2}$ enabled process integration for the production of cellulosic ethanol using bionic liquids, Energy Environ. Sci. 9 (2016) 2822-2834. doi:10.1039/C6EE00913A.

[127] I. V. Hertel, M. Faubel, D. Nolting, E.F. Aziz, B. Winter, N. Ottosson, pHInduced Protonation of Lysine in Aqueous Solution Causes Chemical Shifts in X-ray Photoelectron Spectroscopy, J. Am. Chem. Soc. 129 (2007) 14068-14073. doi:10.1021/ja0729711.

[128] B.W. Reed, M.J. Semmens, E.L. Cussler, Chapter 10 - Membrane contactors, Volume 2, Elsevier, 1995.

[129] G. Mychaskiw, Low and minimal flow anesthesia: Angels dancing on the point of a needle, J. Anaesthesiol. Clin. Pharmacol. 28 (2012) 423. doi:10.4103/0970-9185.101883.

[130] P.H. Langowski, A.K. Seth, T. Cohen, D.E. Shaughnessy, G.A. Freeman, M.P. Sheerin, R.J. Weber, G.L. Hendrickson, M.R. Keen, M.E. Woolsey, H.F. Crowther, J.A. Kohler, C.E. Marriott, R.M. Martin, S.T. Bushby, F. Myers, K.W. Cooper, ANSI/ASHRAE/ASHE standard 170-2013 - Ventilation of health care facilities., in: American Society of Heating, Refrigerating and Air-Conditioning Engineers, Inc., Atlanta, 2008.

[131] Y. Yuan, T.R. Lee, Chapter 1 - Contact Angle and Wetting Properties, in: 
Surf. Sci. Tech., Springer, 2013.

[132] B.S. Freeman, Chapter 17 - Absorption of Carbon Dioxide, in: Anesthesiol. Core Rev. Part One Basic Exam, McGraw-Hill Education, 2014.

[133] Y. Sistla, A. Khanna, CO2 absorption studies in amino acid-anion based ionic liquids, Chem. Eng. J. $273 \quad$ (2015) 268-276. doi:10.1016/j.cej.2014.09.043.

[134] K. Robinson, A. Mccluskey, M.I. Attalla, An FTIR Spectroscopic Study on the Effect of Molecular Structural Variations on the $\mathrm{CO}_{2}$ Absorption Characteristics of Heterocyclic Amines, ChemPhysChem. 12 (2011) 10881099. doi:10.1002/cphc.201001056.

[135] B. Smith, Infrared Spectral Interpretation: A systematic approach, CRC press, New York, 1999.

[136] J. Wang, J. Luo, S. Feng, H. Li, Y. Wan, X. Zhang, Recent development of ionic liquid membranes, Green Energy Environ. 1 (2016) 43-61. http://dx.doi.org/10.1016/j.gee.2016.05.002.

[137] A.F. Ismail, K.C. Khulbe, T. Matsuura, Gas separation membranes: Polymeric and inorganic, Springer, 2015. doi:10.1007/978-3-319-01095-3.

[138] S. Matteucci, Y. Yampolskii, B.D. Freeman, I. Pinnau, Transport of Gases and Vapors in Glassy and Rubbery Polymers, 2006. doi:10.1002/047002903X.ch1.

[139] D.M. Muñoz, A.F. Portugal, A.E. Lozano, J.G. De La Campa, J. De Abajo, New liquid absorbents for the removal of $\mathrm{CO}_{2}$ from gas mixtures, Energy Environ. Sci. 2 (2009) 883-891. doi:10.1016/j.jct.2013.10.023.

[140] J. Wilcox, Carbon Capture, 1st ed., Springer-Verlag, New York, 2012.

[141] A.M. Pinto, H. Rodríguez, A. Arce, A. Soto, Combined physical and chemical absorption of carbon dioxide in a mixture of ionic liquids, J. Chem. Thermodyn. 77 (2013) 197-205. doi:10.1039/C9CS00016J.

[142] P. Styring, E. Quadrelli, K. Armstrong, Carbon dioxide utilisation: closing the carbon cycle., Elsevier, 2015.

[143] J.M. Gomes, S.S. Silva, R.L. Reis, Biocompatible ionic liquids: Fundamental behaviours and applications, Chem. Soc. Rev. 48 (2019) 4317-4335. doi:10.1039/c9cs00016j.

[144] S. Yuan, Y. Chen, X. Ji, Z. Yang, X. Lu, Experimental study of $\mathrm{CO}_{2}$ absorption in aqueous cholinium-based ionic liquids, Fluid Phase Equilib. 445 (2017) 14-24. doi:10.1016/j.fluid.2017.04.001.

[145] S. Yuan, Z. Yang, X. Ji, Y. Chen, Y. Sun, X. Lu, CO2 Absorption in Mixed 
Aqueous Solution of MDEA and Cholinium Glycinate, Energy and Fuels. 31 (2017) 7325-7333. doi:10.1021/acs.energyfuels.7b00927.

[146] X.D. Hou, Q.P. Liu, T.J. Smith, N. Li, M.H. Zong, Evaluation of Toxicity and Biodegradability of Cholinium Amino Acids Ionic Liquids, PLoS One. 8 (2013). doi:10.1371/journal.pone.0059145.

[147] K. Simons, W.D.W.F. Brilman, H. Mengers, K. Nijmeijer, M. Wessling, Kinetics of $\mathrm{CO}_{2}$ Absorption in Aqueous Sarcosine Salt Solutions : Influence of Concentration, Temperature, and CO2 Loading, Ind. Eng. Chem. Res. 49 (2010) 9693-9702. doi:10.1021/ie100241y.

[148] A.F. Portugal, P.W.J. Derks, G.F. Versteeg, F.D. Magalhães, A. Mendes, Characterization of potassium glycinate for carbon dioxide absorption purposes, Chem. Eng. Sci. $62 \quad$ (2007) 6534-6547. doi:10.1016/j.ces.2007.07.068.

[149] X. Zhou, G. Jing, F. Liu, B. Lv, Z. Zhou, Mechanism and Kinetics of $\mathrm{CO}_{2}$ Absorption into an Aqueous Solution of a Triamino-Functionalized Ionic Liquid, Energy and Fuels. 31 (2017) 1793-1802. doi:10.1021/acs.energyfuels.6b02963.

[150] H. Guo, Z. Zhou, G. Jing, Kinetics of carbon dioxide absorption into aqueous [Hmim][Gly] solution, Int. J. Greenh. Gas Control. 16 (2013) 197205. doi:10.1016/j.ijggc.2013.03.024.

[151] B. Lv, G. Jing, Y. Qian, Z. Zhou, An efficient absorbent of amine-based amino acid-functionalized ionic liquids for $\mathrm{CO}_{2}$ capture: High capacity and regeneration ability, Chem. Eng. J. $289 \quad$ (2016) 212-218. doi:10.1016/j.cej.2015.12.096.

[152] H. Suleman, A.S. Maulud, A. Syalsabila, M.Z. Shahid, The contribution of aqueous L-arginine salts to equilibrium carbon dioxide absorption in a copromoter role at high pressure, Fluid Phase Equilib. 524 (2020) 112743. doi:10.1016/j.fluid.2020.112743.

[153] B.H. Stuart, Infrared Spectroscopy: Fundamentals and Applications B, John Wiley \& Sons, Ltd, 2004.

[154] G. Richner, G. Puxty, Assessing the chemical speciation during $\mathrm{CO}_{2}$ absorption by aqueous amines using in situ FTIR, Ind. Eng. Chem. Res. 51 (2012) 14317-14324. doi:10.1021/ie302056f.

[155] J.L. McDonald, R.E. Sykora, P. Hixon, A. Mirjafari, J.H. Davis, Impact of water on $\mathrm{CO}_{2}$ capture by amino acid ionic liquids, Environ. Chem. Lett. 12 (2014) 201-208. doi:10.1007/s10311-013-0435-1.

[156] P. Prakash, A. Venkatnathan, Site-Specific Interactions in $\mathrm{CO}_{2}$ Capture by Lysinate Anion and Role of Water Using Density Functional Theory, J. 
Phys. Chem. C. 122 (2018) 12647-12656. doi:10.1021/acs.jpcc.8b03882.

[157] David R Lide, CRC Handbook of Chemistry and Physics, 84th Edition, 2003-2004, Handb. Chem. Phys. (2003).

[158] C.-C. Chen, H.I. Britt, J.F. Boston, L.B. Evans, Local Composition Model for Excess Gibbs Energy of Electrolyte Systems, AlChe J. 28 (1982) 588-596. doi:10.1002/aic.690280410.

[159] C. -C Chen, L.B. Evans, A local composition model for the excess Gibbs energy of aqueous electrolyte systems, AIChE J. 32 (1986) 444-454. doi:10.1002/aic.690320311.

[160] C.C. Chen, Y. Song, Generalized electrolyte-NRTL model for mixedsolvent electrolyte systems, AIChE J. 50 (2004) 1928-1941. doi:0.1002/aic.10151.

[161] O. Redlich, J.N.S. Kwong, On the Thermodynamics of Solutions., Chem. Rev. 44 (1949) 233-244. doi:10.1021/cr60137a013.

[162] K.S. Pitzer, Electrolytes. From Dilute Solutions to Fused Salts, J. Am. Chem. Soc. 102 (1980) 2902-2906. doi:10.1021/ja00529a006.

[163] R.M. Felder, R.W. Rousseau, L.G. Bullard, Felder's Elementary Principles of Chemical Processes, 4th ed., Wiley, New York, 2016.

[164] C.F. Martins, L.A. Neves, R. Chagas, L.M. Ferreira, C.A.M. Afonso, J.G. Crespo, I.M. Coelhoso, $\mathrm{CO}_{2}$ removal from anaesthesia circuits using gasionic liquid membrane contactors, Sep. Purif. Technol. 250 (2020) 116983. doi:10.1016/j.seppur.2020.116983.

[165] M.M. Villar-Chavero, J.C. Domínguez, M.V. Alonso, V. Rigual, M. Oliet, F. Rodriguez, Viscoelastic properties of physical cellulosic bionogels of cholinium lysinate, Int. J. Biol. Macromol. 133 (2019) 262-269. doi:10.1016/j.ijbiomac.2019.04.057.

[166] A. Archane, W. Fürst, E. Provost, Influence of poly(ethylene oxide) 400 (PEG400) on the absorption of $\mathrm{CO}_{2}$ in diethanolamine (DEA) $/ \mathrm{H}_{2} \mathrm{O}$ systems, J. Chem. Eng. Data. 56 (2011) 1852-1856. doi:10.1021/je100854j.

[167] J.P. Belaud, M. Pons, Open software architecture for process simulation: The current status of CAPE-OPEN standard, Comput. Aided Chem. Eng. 10 (2002) 847-852. doi:10.1016/S1570-7946(02)80169-9.

[168] M. Pons, The CAPE-OPEN interface specification for reactions package, Comput. Aided Chem. Eng. 14 (2003) 863-868. doi:10.1016/S15707946(03)80225-0.

[169] J. van Baten, R. Szczepanski, A thermodynamic equilibrium reactor model as a CAPE-OPEN unit operation, Comput. Chem. Eng. 35 (2011) 1251-1256. 
doi:10.1016/j.compchemeng.2010.07.016.

[170] J. Van Baten, M. Pons, Cape-open: Interoperability in industrial flowsheet simulation software, Chemie-Ingenieur-Technik. 86 (2014) 1052-1064. doi:10.1002/cite.201400009.

[171] G. Tolksdorf, E. Esche, J. van Baten, G. Wozny, Taylor-Made Modeling and Solution of Novel Process Units by Modular CAPE-OPEN-based Flowsheeting, Comput. Aided Chem. Eng. 38 (2016) 787-792. doi:10.1016/B978-0-444-63428-3.50136-3.

[172] gPROMS Physical Properties Guide, Release v3.7. (2013) Process Systems Enterprise Ltd. http://www.psenterprise.com.

[173] CO-LaN Consortium, Thermodynamic and Physical Properties version 1.1, ver. 3.11, CAPE-OPEN Laboratories Network, (2011).

[174] P. Jackson, K. Robinson, G. Puxty, M. Attalla, In situ Fourier TransformInfrared (FT-IR) analysis of carbon dioxide absorption and desorption in amine solutions, Energy Procedia. 1 (2009) 985-994. doi:10.1016/j.egypro.2009.01.131.

[175] P.W.J. Derks, P.J.G. Huttenhuis, C. Van Aken, J.H. Marsman, G.F. Versteeg, Determination of the liquid-phase speciation in the $\mathrm{MDEA}-\mathrm{H}_{2} \mathrm{O}-\mathrm{CO}_{2}$ system, Energy Procedia. 4 (2011) 599-605. doi:10.1016/j.egypro.2011.01.094.

[176] Z. Feng, G. Yuan, W. Xian-Kun, M. Jing-Wen, W. You-Ting, Z. Zhi-Bing, Regeneration performance of amino acid ionic liquid (AAIL) activated MDEA solutions for $\mathrm{CO}_{2}$ capture, Chem. Eng. J. 223 (2013) 371-378. doi:10.1016/j.cej.2013.03.005.

[177] A.B. Lumb, Nunn's Applied Respiratory Physiology, 8th ed., Elsevier, 2017.

[178] G.J. Tortora, B.H. Derrickson, Principles of Anatomy and Physiology - With A Brief Atlas of the Skeleton, Surface Anatomy, John Wiley \& Sons, Ltd, 2008.

[179] A. Ridgwell, R.E. Zeebe, The role of the global carbonate cycle in the regulation and evolution of the Earth system, Earth Planet. Sci. Lett. 234 (2005) 299-315. doi:10.1016/j.epsl.2005.03.006. 


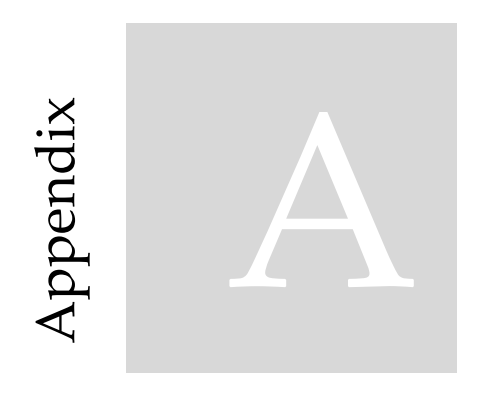

\section{Appendix A: List of Publications}

\section{A.1 Articles in scientific journals with review and transfer of copyright}

C. F. Martins, L. A. Neves, M. Estevão, A. Rosatella, V. D. Alves, C. A. M. Afonso, J. G. Crespo, I. M. Coelhoso, Effect of water activity on carbon dioxide transport in cholinium-based ionic liquids with carbonic anhydrase, Separation and Purification Technology, 168 (2016), pp. 74-82.

M. Malankowska, C. F. Martins, H. S. Rho, L. A. Neves, R. M. Tiggelaar, J. G. Crespo, M. P. Pina, R. Mallada, H. Gardeniers, I. M. Coelhoso, Microfluidic devices as gas - Ionic liquid membrane contactors for $\mathrm{CO}_{2}$ removal from anaesthesia gases, Journal of Membrane Science, 545 (2018), pp. 107-115.

C. F. Martins, L. A. Neves, R. Chagas, L. M. Ferreira, C. A. M. Afonso, J. G. Crespo, I. M. Coelhoso, $\mathrm{CO}_{2}$ removal from anaesthesia circuits using gas-ionic liquid membrane contactors, Separation and Purification Technology, 250 (2020), 116983. 
C. F. Martins, L. A. Neves, R. Chagas, L. M. Ferreira, C. A. M. Afonso, I. M. Coelhoso, J. G. Crespo, J. P. B. Mota, Modelling $\mathrm{CO}_{2}$ absorption in aqueous solutions of cholinium lysinate ionic liquid, Chemical Engineering Journal, 2020, 127875.

C. F. Martins, L. A. Neves, R. Chagas, L. M. Ferreira, I. M. Coelhoso, J. G. Crespo, Removal of $\mathrm{CO}_{2}$ from Xenon anaesthesia circuits using an amino acid ionic liquid solution in a membrane contactor, to be submitted for publication in Separation and Purification Technology.

\section{A.2 Related articles in scientific journals with review and transfer of copyright}

A. A. Akhmetshina, I. M. Davletbaeva, E. S. Grebenschikova, T. S. Sazanova, A. N. Petukhov, A. A. Atlaskin, E. N. Razov, I. I. Zaripov, C. F. Martins, L. A. Neves, I. V. Vorotyntsev, The Effect of Microporous Polymeric Support Modification on Surface and Gas Transport Properties of Supported Ionic Liquid Membranes, Membranes, 2016, 6(1), 4 .

M. Y. M. Abdelrahima, C. F. Martins, L. A. Neves, C. Capasso, C. T. Supuran, I. M. Coelhoso, J. G. Crespo, M. Barboiu, Supported ionic liquid membranes immobilized with carbonic anhydrases for $\mathrm{CO}_{2}$ transport at high temperatures, Journal of Membrane Science, 528 (2017), pp. 225-230.

\section{A.3 Oral communications}

C. F. Martins, L. A. Neves, C.A.M. Afonso, I. M. Coelhoso, J. G. Crespo, $\mathrm{CO}_{2}$ removal using gas - ionic liquid membrane contactor: A new perspective for anaesthesia, Engineering with Membranes 2019, Bastad, Sweden, April 8 - 10, 2019. 
C. F. Martins, L. A. Neves, I. M. Coelhoso, J. G. Crespo, Inhale, exhale and remove $\mathrm{CO}_{2}$ : A new perspective for anaesthesia, Bridging academia \& industry in chemistry and life sciences Workshop, Almada, Portugal, May 29 - 30, 2018.

C. F. Martins, L. A. Neves, C. A. M. Afonso, I. M. Coelhoso, J. G. Crespo, Carbon dioxide capture in anaesthetic circuits using membrane contactors and biocompatible ionic liquids, ICOM 2017, San Francisco, USA, July 29 - August 4, 2017.

L. A. Neves, C. F. Martins, M. Estevão, C. A. M. Afonso, I. M. Coelhoso, J. G. Crespo, " $\mathrm{CO}_{2}$ Separation from anaesthetic circuits with biocompatible ionic liquids and membrane contactors", PERMEA 2016, Prague, Check Republic, May 15-19, 2016.

C. F. Martins, L. A. Neves, M. Estevão, C. A. M. Afonso, I. M. Coelhoso, J. G. Crespo, "Biocatalytic $\mathrm{CO}_{2}$ separation from anaesthetic gases using membrane contactors and biocompatible ionic liquids", Membranes in Bioprocessing, Bologna, Italy, May 8-10, 2016.

C. F. Martins, L. A. Neves, A. Rosatella, C. A. M. Afonso, I. M. Coelhoso1, J. G. Crespo, Separation of $\mathrm{CO}_{2}$ from anaesthetic gas circuits using membrane contactors and biocompatible ionic liquids, $2^{\text {nd }}$ EuCheMS Congress on Green and Sustainable Chemistry, Almada, Portugal, October 4-7, 2015.

C. F. Martins, L. A. Neves, A. Rosatella, C. A. M. Afonso, I. M. Coelhoso, J. G. Crespo, " $\mathrm{CO}_{2}$ removal from anaesthetic gas circuits using membrane contactors and biocompatible ionic liquids", Euromembrane 2015, Aachen, Germany, September 6-10, 2015. 
C. F. Martins, L. A. Neves, C. A. M. Afonso, I. M. Coelhoso, J. G. Crespo, “Carbon dioxide removal from anaesthetic gas circuits using carbonic anhydrase and ionic liquid membranes", $12^{\text {th }}$ International Chemical and Biological Engineering Conference (CHEMPOR2014), Porto, Portugal, September 10-12, 2014.

L. A. Neves, C. F. Martins, C. A. M. Afonso, I. M. Coelhoso, J. G. Crespo, "CO 2 removal from anaesthetic gas circuits integrating enzymatic conversion and ionic liquid membrane extraction", 9 ${ }^{\text {th }}$ Ibero-American Conference on Membrane Science and Technology (CITEM), Santander, Spain, May 25-28, 2014.

L. A. Neves, C. Martins, C. A. M. Afonso, I. M. Coelhoso, J. G. Crespo, “CO2 removal from anaesthetic gas circuits by enzymatic bioconversion with ionic liquids", $4^{\text {th }}$ International Conference on Green Process Engineering, Sevilla, Spain, April 7-10, 2014.

\section{A.4 Poster communications}

L. A. Neves, C. F. Martins, C. A. M. Afonso, I. M. Coelhoso, J. G. Crespo, Purification of anaesthetic gases using gas-ionic liquid membrane contactors, Euromembrane 2018, Valencia, Spain, July 9 - 13, 2018.

C. F. Martins, L. A. Neves, C. A. M. Afonso, I. M. Coelhoso, J. G. Crespo “Carbon dioxide separation from anaesthetic gases with membrane contactors and biocompatible ionic liquids", ECI - Separations Technology IX: New Frontiers in Media, Techniques, and Technologies, Albufeira, Portugal, March 5-10, 2017 (awarded with $1^{\text {st }}$ Poster Prize). 
M. Yahia M. Abdelrahim, C. Martins, Luísa. A. Neves, C. Capasso, C. T. Supuran, M. Barboiu, Isabel. M. Coelhoso, Joao. G. Crespo, “Comparison of supported ionic liquid membranes immobilized with two carbonic anhydrase enzymes for CO 2 capture", Euromembrane2015, Aachen, Germany, September 6-10, 2015.

Elisa Esposito, Carla Martins, Luísa Neves, Johannes C. Jansen, Franco Tasselli, Isabel M. Coelhoso, João G. Crespo, “Potential use of membrane contactors for $\mathrm{CO}_{2} / \mathrm{CH}_{4}$ separation by facilitated $\mathrm{CO}_{2}$ transport in ionic liquids", Euromembrane2015, Aachen, Germany, September 6-10, 2015.

C. F. Martins, L. A. Neves, C. A. M. Afonso, I. M. Coelhoso, J. G. Crespo, “CO2 removal from anaesthetic gas circuits using membrane contactors with ionic liquids", 29th European Membrane Summerschool 2013, Essen, Germany, July 2226, 2013. 


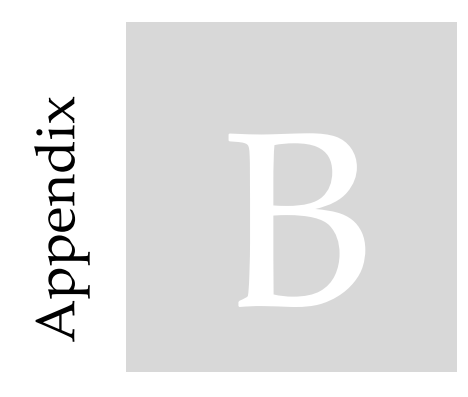

\section{Appendix B: Supplementary material}

A)

B)

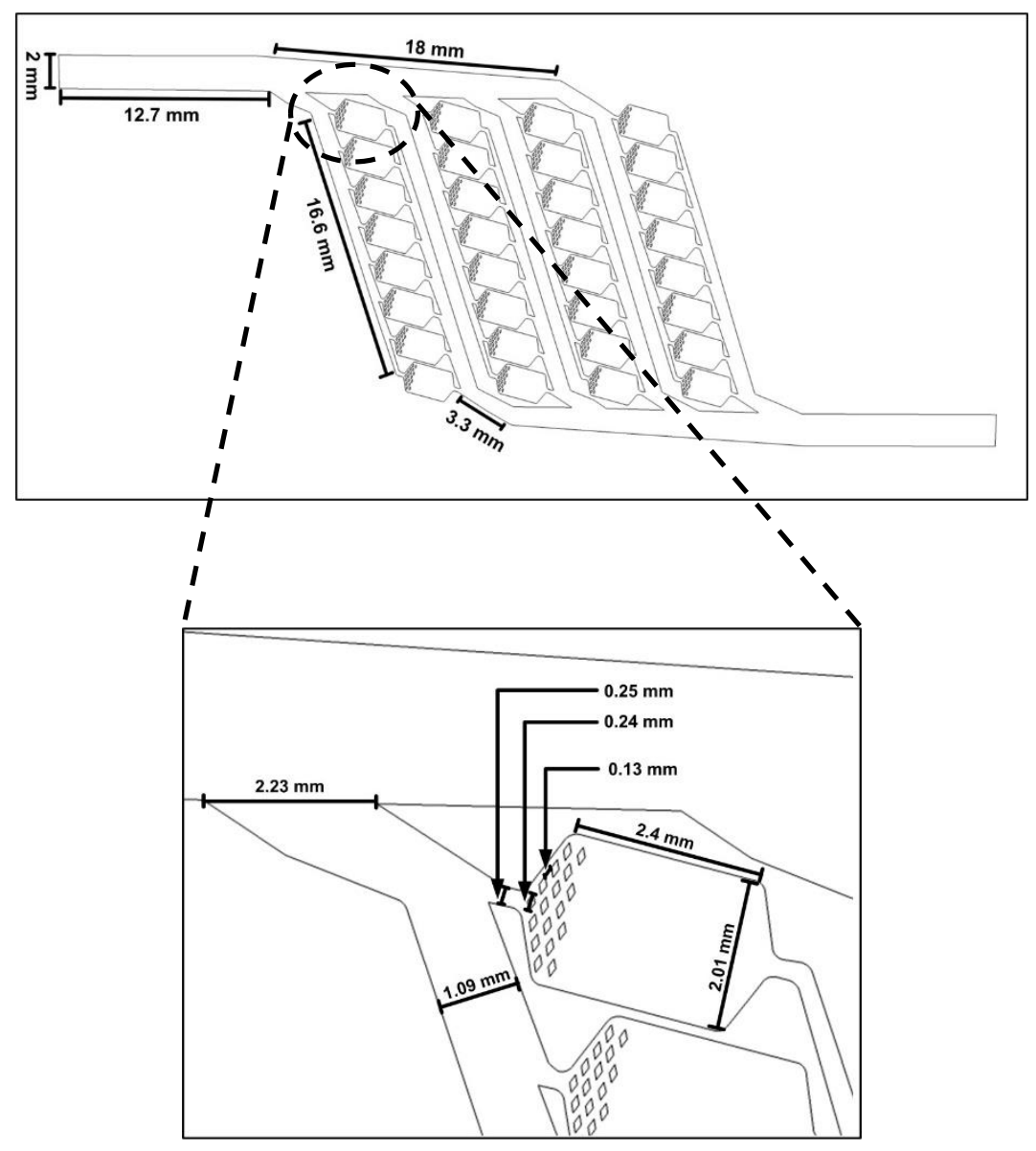

Figure S1 Graphical representation of the liquid chamber design and the dimensions for (A) total structure and (B) a magnification of the small channels with flow distributors 


\section{Lithography with SU-8 photoresist}

SU-8 (Microchem) is a high contrast, epoxy based photoresist which is designed for micromachining and other microelectronic applications. SU-8 is used when a thick chemically and thermally stable image is desired. Depending on the desired thicknesses of the channels there are different types of SU-8 resists. SU850, giving the range of depths from 40 to $250 \mu \mathrm{m}$, was used in this work since the targeted chamber thickness was $100 \mu \mathrm{m}$. Figure S2 shows the SU-8 lithography process flow.

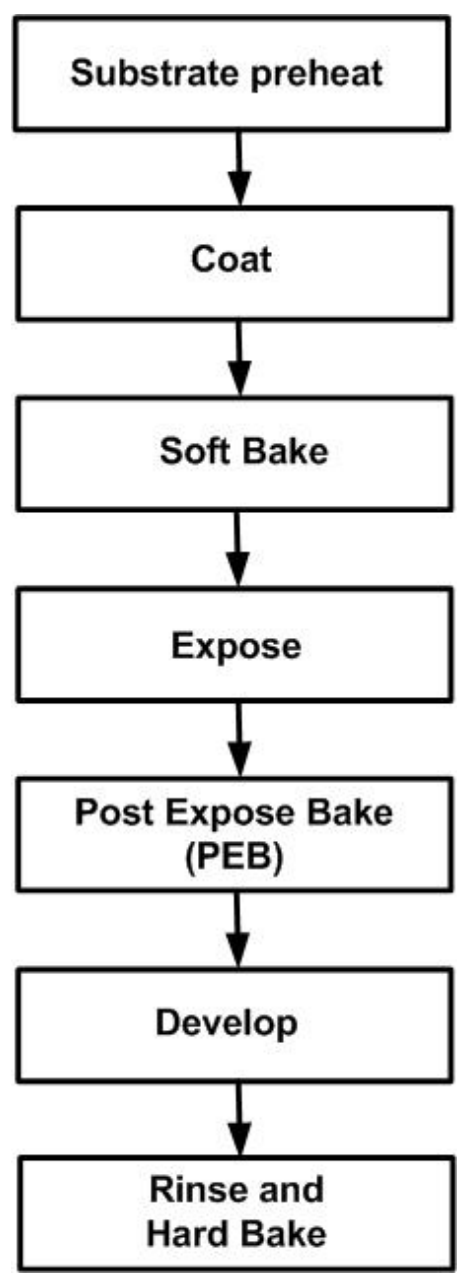

Figure S2 SU-8 lithography process flow
In order to obtain maximum process reliability, the substrate (wafer) had to be clean and dry before applying the SU-8. Next, the wafer was coated with the SU-8 by spin coater. The revolutions per minute and time depend exclusively on the desired channel thickness (1250 rpm for $100 \mu \mathrm{m})$. After the resist has been applied to the substrate, it was soft baked in order to evaporate the solvent and to densify the film. The temperature and time of soft baking also depends on the final anticipated thickness (In this work - Chapter 3: Pre-bake at 65 ${ }^{\circ} \mathrm{C}: 10 \mathrm{~min}$ and Softbake at $\left.95^{\circ} \mathrm{C}: 30 \mathrm{~min}\right) . \mathrm{SU}-8$ is a negative photoresist, thus it has to be taken into account that the designed mask should be likemirror reflection in order to obtain the desired structure. SU-8 is optimized for near UV (350-400 $\mathrm{nm})$ exposure. The optimal dose depends as well on the film thickness (thicker films will require higher dosage) and process parameters (i. e. exposure energy). After exposure, a post expose bake (PEB) have to be performed in order to crosslink the exposed film.

To obtain optimum cross-link density the temperature and time should be adjusted to the type of SU-8 and the desired thickness (PEB 1 at $65{ }^{\circ} \mathrm{C}: 1 \mathrm{~min}$ and PEB 2 at $95{ }^{\circ} \mathrm{C}$ : $\left.10 \mathrm{~min}\right)$. PEB can be performed either on the hot plate or in a 
convection oven. Next, the structure is developed in a SU-8 developer by immersing a structured wafer. The time of immersion depends on the thickness, temperature, agitation rate etc. (for $100 \mu \mathrm{m}$ the time of immersion is approximately $10 \mathrm{~min}$ ). Following development, the substrate is rinsed with isopropyl alcohol. Finally, the resist is hard baked at $150-200{ }^{\circ} \mathrm{C}$ on a hot plate.

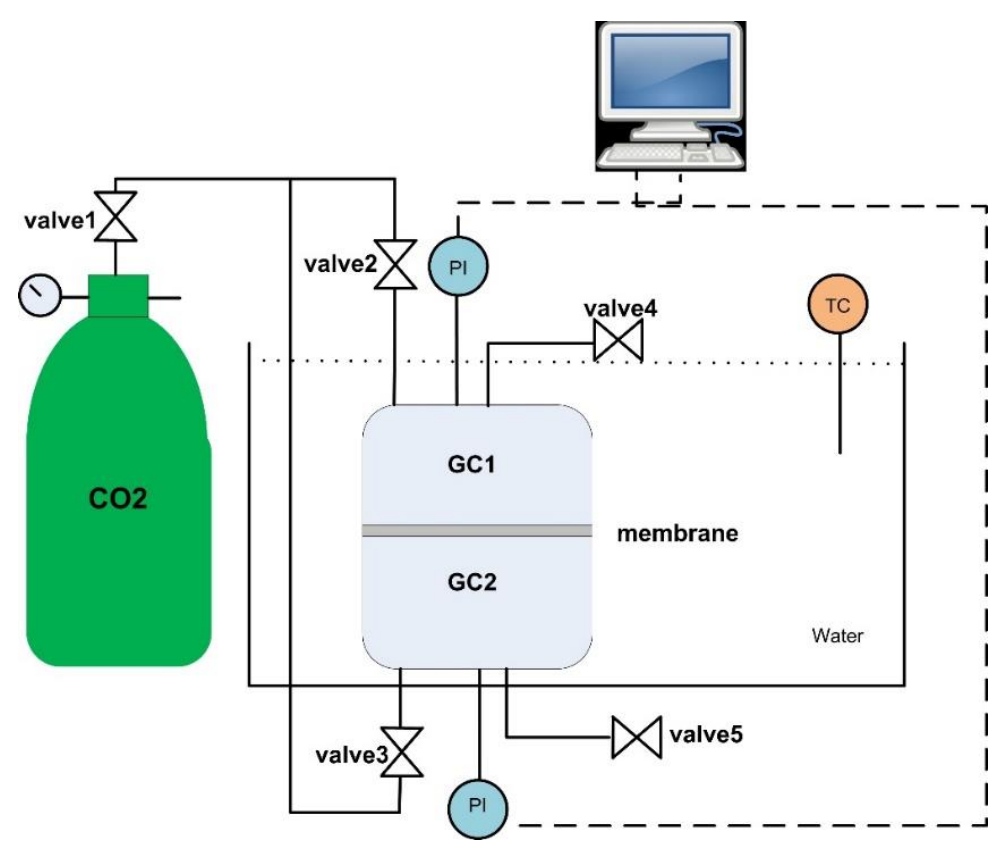

Figure S3 Experimental system for measuring the gas permeation of freestanding membrane mounted on the stainless-steel cell.

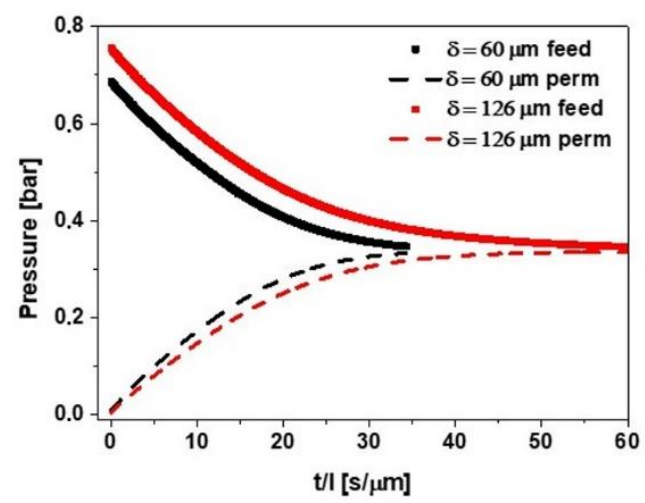

Figure S4 Two distinctive free-standing membranes $(60 \mu \mathrm{m}$ and $126 \mu \mathrm{m}$ thickness) and their feed pressure decay and permeate pressure increase of $\mathrm{CO}_{2}$ 


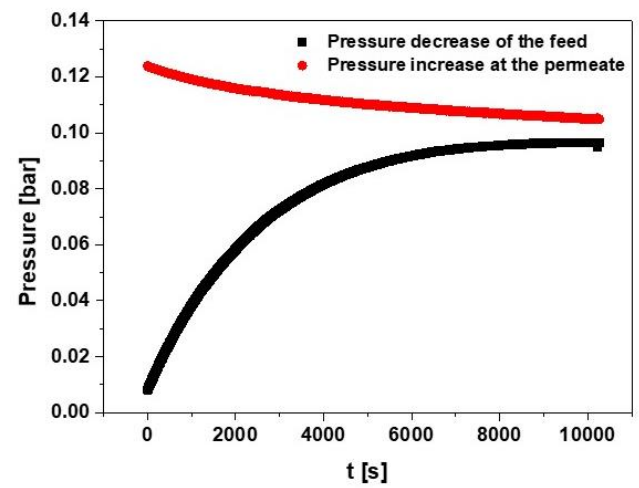

Figure $\mathrm{S} 5 \mathrm{CO}_{2}$ pressure evolution on both compartments of the microfluidic device-chip 1

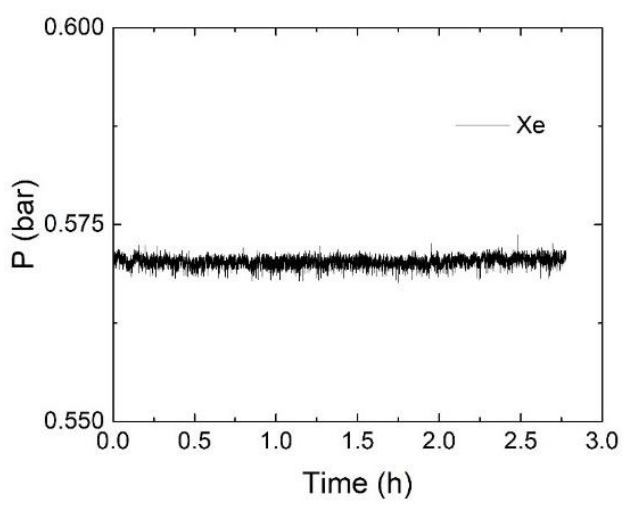

Figure S6 Xe solubility experiment in cholinium propionate ionic liquid. The experiment was carried out by monitoring the evolution of the pressure decay with time, which was related with the absorption of the gas by the ionic liquids' thin film (see Chapter 2 for more details about the set-up). It can be noticed that the Xe pressure remains constant with an average value of $0.570 \pm 0.006$ bar during the entire period of the experiment, $3 \mathrm{~h}$. This experiment shows that the solubility of Xe in the ionic liquid selected is negligible. 


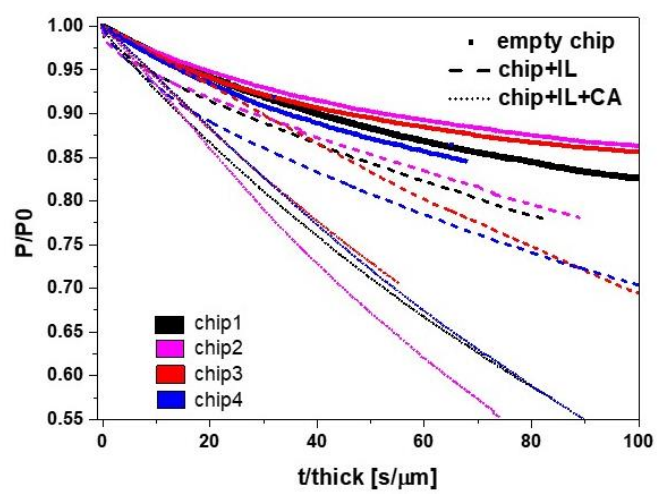

Figure S7 Normalized $\mathrm{CO}_{2}$ pressure decay of four chips in three different experimental configurations: 1) with the liquid chamber being empty, 2) with ionic liquid and 3) with ionic liquid combined with the CA enzyme

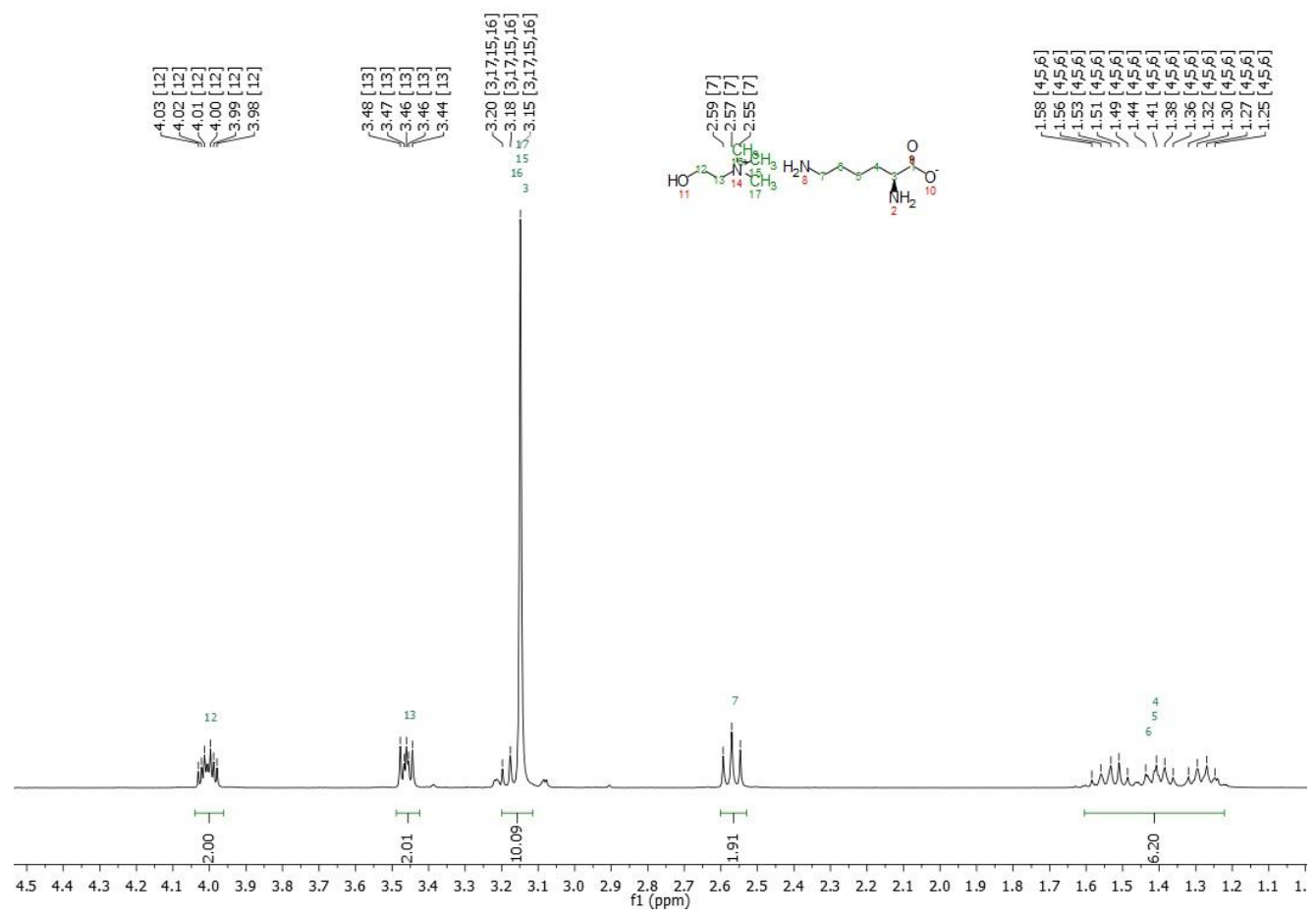

Figure S8 Proton nuclear magnetic resonance $\left({ }^{1} \mathrm{H}-\mathrm{NMR}\right)$ spectrum of $\left[\mathrm{Cho}^{+}\right]\left[\mathrm{Lys}^{-}\right]$ionic liquid. 


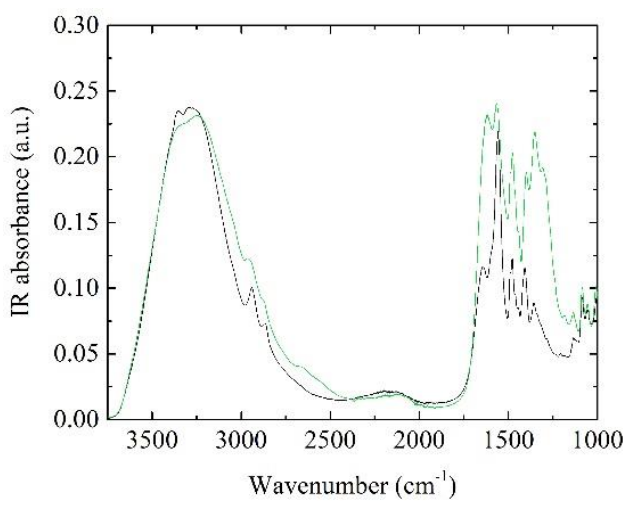

Figure S9 ATR-FTIR spectrum of [Cho $\left.{ }^{+}\right]\left[\mathrm{Lys}^{-}\right]$ionic liquid solution before and after $\mathrm{CO}_{2}$ absorption. 